\title{
Innervation, control and electromyography of the urinary bladder
}

Citation for published version (APA):

Kinder, M. V. (2001). Innervation, control and electromyography of the urinary bladder. [Doctoral Thesis, Maastricht University]. Universiteit Maastricht. https://doi.org/10.26481/dis.20011130mk

Document status and date:

Published: 01/01/2001

DOI:

10.26481/dis.20011130mk

Document Version:

Publisher's PDF, also known as Version of record

\section{Please check the document version of this publication:}

- A submitted manuscript is the version of the article upon submission and before peer-review. There can be important differences between the submitted version and the official published version of record.

People interested in the research are advised to contact the author for the final version of the publication, or visit the DOI to the publisher's website.

- The final author version and the galley proof are versions of the publication after peer review.

- The final published version features the final layout of the paper including the volume, issue and page numbers.

Link to publication

\footnotetext{
General rights rights.

- You may freely distribute the URL identifying the publication in the public portal. please follow below link for the End User Agreement:

www.umlib.nl/taverne-license

Take down policy

If you believe that this document breaches copyright please contact us at:

repository@maastrichtuniversity.nl

providing details and we will investigate your claim.
}

Copyright and moral rights for the publications made accessible in the public portal are retained by the authors and/or other copyright owners and it is a condition of accessing publications that users recognise and abide by the legal requirements associated with these

- Users may download and print one copy of any publication from the public portal for the purpose of private study or research.

- You may not further distribute the material or use it for any profit-making activity or commercial gain

If the publication is distributed under the terms of Article $25 \mathrm{fa}$ of the Dutch Copyright Act, indicated by the "Taverne" license above, 
Innervation, Control and Electromyography of the Urinary Bladder 
All rights reserved. No part of this book may be reproduced, stored in a retrieval system or transmitted, in any form or by any means, electronic, mechanical, photocopying or otherwise, without the prior written permission of the author.

Niets uit deze uitgave mag worden verveelvoudigd en/of vermenigvuldigd door middel van druk, fotocopie, microfilm, internet of op welke andere wijze dan ook zonder voorafgaande schriftelijke toestemming van de auteur.

(C) Matti V. Kinder, Maastricht 2001

ISBN 90-9015245-8

Cover: Mechanical bladder activity induced by electrical stimulation of sacral nerve roots in the rabbit. Cover design: Paul Verspaget.

Printing: Eindhoven University Press. 


\title{
Innervation, Control and Electromyography of the Urinary Bladder
}

\author{
PROEFSCHRIFT
}

ter verkrijging van de graad van doctor

aan de Universiteit Maastricht,

op gezag van de Rector Magnificus

Prof.dr. A.C. Nieuwenhuijzen Kruseman

volgens het besluit van het College van Decanen

in het openbaar te verdedigen op vrijdag

30 november 2001 om 10.00 uur

door

Mathias Vincent Kinder

geboren te Geleen op 17 januari 1970 


\section{Promotores}

Prof.dr. R.A. Janknegt

Prof.dr. E. Marani (Universiteit Twente)

\section{Beoordelingscommissie}

Prof.dr. C.G.M.J. Baeten (voorzitter)

Prof.dr. J. Drukker

Prof.dr.ir. J.D. Janssen (Technische Universiteit Eindhoven)

Drs. G. Kramer (Unfallklinik Murnau, Duitsland)

Dr.ir. R. van Mastrigt (Erasmus Universiteit Rotterdam)

Prof.dr. R.S. Reneman

The experimental studies in this thesis were financially supported by the Instituut Wetenschappelijke Activiteiten Maastrichtse Urologie.

Operational costs were covered by private funding from several scientific enthusiastics and by funding from the Maastricht University. 
Für meine Eltern 



\section{Contents}

Introduction, aim and outline of this thesis

Includes: Introduction to this special issue on Neurourology.

Arch Physiol Biochem (1999) 107:195-202.

\section{Chapter 1}

Neuronal circuitry of the lower urinary tract;

central and peripheral neuronal control of the micturition cycle.

Anat \& Embryol (1995) 192:195-209.

\section{Chapter 2}

The neuronal control of the lower urinary tract:

A model of architecture and control mechanisms.

Arch Physiol Biochem (1999) 107:203-222.

\section{Chapter 3}

A method for the electromyographic mapping of the detrusor smooth muscle.

Arch Physiol Biochem (1997) 105:673-690.

\section{Chapter 4}

Three dimensional registration of mechanical bladder activity using polystyrene fluorescent spheres: a technical note.

Arch Physiol Biochem (1999) 107:236-241.

\section{Chapter 5}

Demonstration of spontaneous and stretch induced urinary bladder EMG in the living rabbit.

Accepted in Arch Physiol Biochem on October 12, 2001.

Addendum to chapter 5

Recording the detrusor electromyogram is still a difficult and controversial enterprise.

Neurourol Urodyn (1998) 17:571-573. 
A non-invasive method for bladder electromyography in humans.

Arch Physiol Biochem (1998) 106:2-11.

Discussion

Sense and nonsense about urinary bladder EMG.

Summary

Samenvatting

Acknowledgements

List of publications

Curriculum Vitae 



\section{Introduction, aim and outline of this thesis}

The introduction has been accepted on September 10, 1999 as 'Introduction to this Special Issue on Neurourology' in:

Archives of Physiology and Biochemistry 107:195-202. 


\section{Introduction, aim and outline of this thesis}

\section{Introduction}

Millions of people world wide suffer from chronic impairment of continence and voiding activities (Rekers et al., 1992; Toba et al., 1996; Hampel et al., 1997; Samuelsson, 1997; Schulman et al., 1997, Busby-Whitehead \& Johnson, 1998; Payne, 1998; Roberts et al., 1998; Day, 2000; Groutz et al., 2001; Milsom et al., 2001). Examples of such impairment are urge incontinence, i.e., the involuntary loss of urine associated with a strong desire to void; obstruction due to urethral overactivity, this occurs when the urethral closure mechanism contracts against a detrusor contraction or fails to open at attempted micturition; the acontractile detrusor, defined as a detrusor that cannot be demonstrated to contract during urodynamic studies (Abrams et al., ICS 1988). The etiology of urge incontinence, obstruction due to urethral overactivity or the acontractile detrusor is unclear in many patients. In these cases, general terms such as urgency/ frequency syndrome and lower urinary tract symptoms (LUTS) are used to describe the idiopatic disorders which are thought to be of untraced neurological origin. More research on the process of efficient urine storage and evacuation, the micturition process, is needed to reveal the underlying causes for these dysfunctions. New insights would ultimately enable better diagnostics and treatment for these patients.

The micturition process is executed by the muscular system of bladder, urethra and pelvic floor. Process control is organised in the central and peripheral nervous system. Peripheral pathways connect the nerve fibers and ganglia that innervate the muscular system of bladder, urethra, and pelvic floor to the spinal cord. Cell groups involved in micturition control are located at a sacral and thoracolumbar spinal cord level. Ascending and descending tracts connect the cell groups in the spinal cord to the brain and vice versa. All together these neuronal cell groups, ganglia and connections constitute the peripheral and central innervation of the lower urinary tract and the pelvic floor. This innervation can be interpreted as the 'hardware' necessary to implement the neuronal controller of the micturition process. The neuronal controller holds the blueprint for the micturition cycle, it represents the logic, or 'software', necessary to control the micturition process. Information about the process status reaches the neuronal controller continuously. The controller processes this informa- tion and, when necessary, executes control actions that result in muscle contraction or relaxation (Fig. 1). Defects or dysbalances in the muscular or neuronal system may cause serious loss of performance, resulting in incontinence and voiding disorders.

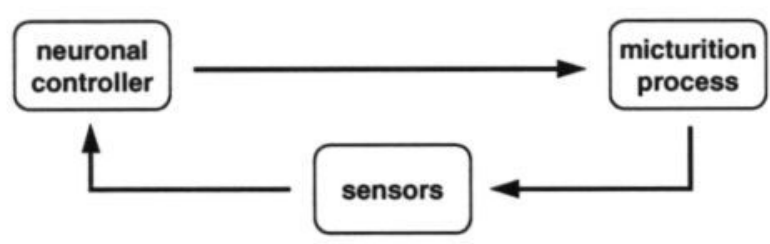

Figure 1: Simple model that describes the neuronal control of the micturition process. Note that a closed loop model is defined.

The micturition process in humans is complicated. Despite significant research efforts, reports in literature disagree about muscle morphology (Dröes, 1972; Van Ulden, 1975; Dixon \& Gosling, 1987; Elbadawi, 1987a, b; Van Arsdalen \& Wein, 1991), the architecture of peripheral and central innervation (Bradley et al., 1974; Blaivas, 1982; Morrison, 1987a; De Groat \& Steers, 1990; Holstege \& Griffiths, 1990; Marani et al., 1993), and the control strategies involved (Bradley et al., 1974; Blaivas, 1982; Morrison, 1987b, 1987c; De Groat \& Steers, 1990; Holstege \& Griffiths, 1990). How the micturition process is organised in detail is not clear (for a review see Kinder et al., 1995, Chapter one of this thesis).

The complex biological situation, the limitations of the research tools available and the prevailing equivocal anatomical nomenclature have contributed to the present dissension in literature (Kinder et al., 1999, Chapter two of this thesis). To give some examples of the problems encountered:

Within the peripheral connections in human an obstacle for the study is the broad variability of the pathways present, e.g., the constitution of a peripheral nerve in the cauda equina has been shown to contain a greater variability than expected (Mersdorf et al., 1993). This also holds for the sacral ventral rami (Marani et al., 1993).

The possibilities for (neuro-)anatomical and (neuro-) physiological research are limited. The traditional work horses of anatomical research, tract tracing and their staining techniques, can hardly be applied in human. Functional studies using PET-scans in humans show promising results, but at present PET-scans 
have a rather limited spatial and temporal resolution (Blok et al., 1997). In animals, the relay stations in the pathways between the spinal cord and the target organs are difficult to study. Acetylcholinesterase in total stainings (Baljet \& Drukker, 1979; Baljet, 1981) only demonstrates the overall nerve paths, but can not discern the relay stations very well. Tract tracing in the peripheral nervous system is seldom reported in literature, with the consequence that convergency and divergency are badly understood in the peripheral innervation of the lower urinary tract.

In the clinic, current diagnostic techniques fail to indicate selectively the origins of lower urinary tract dysfunction. The 'gold standard' to investigate lower urinary tract function objectively is urodynamic investigation (Rowan et al., 1987; Abrams et al., 1988; both ICS). A physiological micturition cycle is simulated by artificial bladder filling and subsequent emptying with continuous recording of intravesical, rectal and urethral pressure and the registration of the produced urine flow. Urodynamics is, in fact, restricted to the monitoring of a set of micturition process parameters. Although an urodynamic investigation is very useful to demonstrate the overall behaviour of the bladder and the urethral closure mechanisms, it does not reveal the underlying causes for dysfunction.

The meaning of electrical stimulation tests to check the integrity of neuronal pathways involved in micturition control is limited. Several neurophysiological tests are available, such as the bulbocavernosus reflex, which shows the functional status of afferent and efferent fibers in the pudendal nerve (Vignoli, 1978; Vereecken et al., 1981; Vodusek et al., 1983); the vesicoanal reflex, of which it is claimed to check the anatomical integrity of bladder and urethral afferents in the pelvic nerve and somatic efferents in the pudendal nerve (Bradley, 1972; Rockswold \& Bradley, 1977; Vereecken et al., 1981); and somatosensory evoked potentials, with which bladder afferents in the pelvic, hypogastric and pudendal nerve and the subsequent ascending tracts to the cortex are thought to be tested (Badr et al., 1982, 1984). However, these tests show a poor correlation with urodynamic findings in diabetic patients and seem, therefore, not reliable to determine causes for lower urinary tract dysfunction (Anten, 1989). Moreover, the integrity of descending tracts from the pons to the sacral spinal cord, that are part of the micturition reflex (Kinder et al., 1995; 1999, Chapters one and two of this thesis), can not yet be investigated selectively. No neurophysiological test is available to selectively check the functionality of the efferent parasympathetic nerve fibers that mediate the micturition reflex towards the bladder and, thus, bring on a bladder contraction.
The discussions in the literature show that each scientific discipline approaches the object of study from its own point of view. Besides biological and technical problems as mentioned above, the dissension is based, in part, on interdisciplinary communication problems. Abstraction and generalisation defines the essence of the micturition process and makes it accessible for discussion in a wider and multidisciplinary field. System theory has proven to be a useful tool for abstraction and generalisation of complex problems. The principles of system theory are notably utilised in technical disciplines as predecessor of control theory and cybernetics, but are increasingly applied in sociology, psychology, economy and biology as well. In system theory an arbitrary defined system is seen and analysed as entity, while its subsystems are considered and analysed in their function to this system entity. This way large and complex problems can be subdivided into smaller, more easy to handle subproblems without losing their interrelation.

System theory to describe the organisation of the complex micturition process seems very promising and its application is described in the first part of this thesis, Chapters one and two. The desired result is the abstract description of a system in which the neuronal elements and their interconnections, that are involved in the control of the micturition process, are emphasized. This 'description of a system' will be referred to as qualitative control model. The deliverables of such a model should include that white spots in present knowledge not only get recognized, but also are defined as accurately as possible. Detailed modelling of the muscular system or the pharmacology of the micturition process will not be considered in this thesis.

Approaching the micturition process with system theory provides thus a qualitative model and therefore the foundation for the design of mathematical models for process simulation. Mathematical models are a tool to investigate how structures or processes function and how they are controlled. They offer the possibility to simulate functionality beyond the borders that are desirable in the real world. Variations in system characteristics can be implemented and their effect be tested rather quickly. Focusing on biological systems, it is often difficult or simply impossible to obtain specific knowledge from structures or processes in the human body by direct measurement or observation. An indirect approach using mathematical and physical models of subsystems in the human body can then be helpful. System theory guarantees the integration of these subsystems and thus tries to tackle the primary problem. An important contribution of mathematical models may, for example, be the well-considered extrapolation of data 
that have been obtained by in vitro or animal experiments to the human in vivo situation.

The basic principles of mathematical modelling are easy to explain, often though difficult to carry out. An arbitrary system can be described by the relationship between its input signal and its output signal, i.e., the input/output relation (see Example 1). Interpreting a system as a relation between variables enables, in many cases, abstract reasoning using mathematical models, which offers afore mentioned advantages. Two approaches that can be followed to obtain an input/output relation are experimental and theoretical modelling.

In experimental modelling the system input and output are being measured to determine the input/output relation that is translated to a model (see Example 1A). This is known as system identification and can be a very elaborate endeavour. It can be applied on different scales, for example, on a bladder strip in vitro or a bladder in vivo; on a single neuron, a set of neurons like Onuf's nucleus or even the central nervous system as a whole. (An alternative mathematical approach is not to determine the input/output relation directly, but to train a neural network with the observed system input and output (Bastiaanssen, 1996). However, the problems associated with getting information on system input and output, as discussed in the following text, also exist for this approach.) For theoretical modelling the existing knowledge of phenomena that occur inside the system are used to describe the system behaviour (see Example 1B).

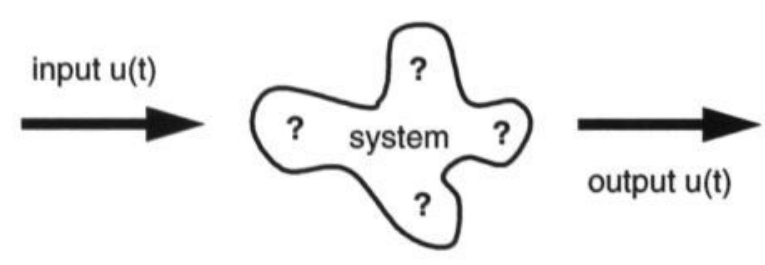

Example 1A: The principle of experimental modelling or system identification: measurement and observation of system input and output leads to an assumed input/output relation, in which the output is a function of the input and possibly other signals.
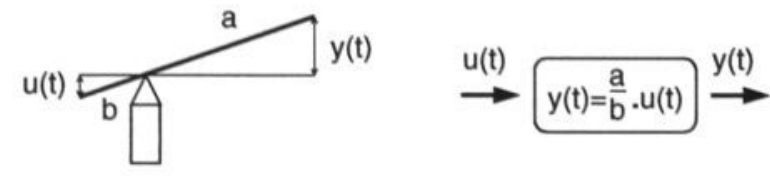

Example 1B: An example of theoretical modelling: the behaviour of a cantilever system is known and thus the input/output relation can be defined.
Both methods, experimental and theoretical modelling, are used in tandem as experimental data are needed to develop theories and theories are indispensable for the design of useful experiments. However, methods for system identification of neuronal structures involved in micturition control are hard to find, especially for structures inside the central nervous system (Araki, 1994; Araki \& De Groat, 1996), and sound theories on their system behaviour are lacking. As a result, mathematical modelling of the micturition process is yet of limited value. Therefore, it is not chosen as subject of study in this thesis.

The significance mathematical models will attain in the future largely depends on the development of methods that will provide new experimental data on micturition control, muscle behaviour and its interaction vice versa. The second part of this thesis focuses on one such method, detrusor electromyography (detrusor EMG), that might deliver new information on the functioning of the lower urinary tract and the bladder muscle in specific. This technique aims to record electrical detrusor smooth muscle activity using extracellular needle-like or surface electrodes. Detrusor EMG might be utilized for fundamental investigations on bladder muscle (patho-)physiology, for testing neuronal circuitries and control mechanisms and for the clinical evaluation of lower urinary tract function.

Electrophysiological studies of the heart muscle using surface electrodes, for example, are common in both clinical practice and fundamental research (e.g., Allessie et al., 1986; Hoeks et al., 1988). They have contributed an enormous amount of knowledge on the (patho-)physiology of the heart and electrocardiography (ECG) has become an important diagnostic technique (e.g., Golshayan et al., 1998; Wijffels et al., 1997; Wilterdink et al., 1998). Detrusor EMG has potential applications that are similar and is therefore worthwhile to be explored. Not much is known, for example, about the existence and nature of electrical activation patterns across the bladder surface, local muscle activity or possible uncoordinated bladder activity during the filling phase. The same holds for the relationships between electrical detrusor smooth muscle activity and, respectively, mechanical detrusor smooth muscle activity, neurotransmitter release or neuronal activity of innervating nerve fibers.

Using latencies of detrusor EMG-changes evoked by neuronal stimulation to test neuronal circuitries and control mechanisms is expected to be superior to existing techniques. Recording latencies on nerve fibers in close proximity of the bladder or urethra, for example, is extremely difficult, because here the peripheral innervation diverges into a web-like structure of very small nerve fibers and ganglia (Elbadawi, 1984, 1987a, b, 1991). It is here that the 
neuronal controller has the final opportunity to modulate the nerve output to the bladder and urethra what makes a more proximal recording site less attractive from a methodological point of view as well (Bradley \& Teague, 1968; Elbadawi, 1984).

Recording latencies of detrusor pressure changes crosses the border between neuronal activity of small innervating nerve fibers and mechanical activity of detrusor muscle fibers on the other side of the excitation-contraction coupling. Pressure changes are rather slow when compared to the velocity of nerve traffic and are the result of the mechanical behaviour of the complete detrusor muscle and its outlet; uncoordinated local contractions may not cause a pressure rise and remain undetected. Changes in local detrusor EMG after nerve stimulation are expected to appear quicker and be more accurate than detrusor pressure changes.

Detrusor EMG changes are expected to show a more integrative result than recordings on one or few innervating nerve fibres and are probably easier to obtain, while they offer higher spatial resolution and better dynamic behaviour than pressure changes.

Unfortunately, detrusor EMG techniques are far from being established, although they have been studied for about 50 years now. The interpretation of recordings is controversial and reports in literature show considerable variation on signal amplitude, frequency and shape (Corey et al., 1951; Boyce, 1952; Franksson \& Petersen, 1953; Brunsting, 1958; Fredericks et al., 1969; Stanton et al., 1973, 1974; Cosgrove et al., 1974, 1977; Jones et al., 1974; Doyle et al., 1975; La Joie et al., 1975; Craggs \& Stephenson, 1976, 1982, 1985; Kaplan et al., 1976; Kaplan \& Nanninga, 1978; Nanninga \& Kaplan, 1978; AbdelRahman et al., 1982; Takaiwa et al., 1983a, b, 1992; Takaiwa \& Shiraiwa, 1984; Jünemann et al., 1994; Shafik, 1994).

Objective comparison of these results is complicated by the limited information provided on the exact experimental set-ups and the wide variety of techniques applied. Nevertheless, it seems unrealistic to attribute the variation of results merely to the differences in electrode material, electrode geometry, registration site, filter and gain settings, sample frequency, data processing and species studied.

Instead of focusing on the differences, a general methodology seems to be present in the blueprint of these studies. Detrusor electromyography is performed: i) in living mammals; ii) during active bladder emptying; iii) using electrodes that are in contact with the bladder wall (surface electrodes) or the detrusor muscle (needle or wire electrodes); iv) using either one single bipolar electrode, several bipolar electrodes on distant recording sites or two separate electrodes that function as one bipolar electrode.
Moreover, reviewing their own recordings, most investigators unconditionally interprete signal changes as electrical detrusor activity when they occur simultaneously with bladder contractions. This interpretation is based on the idea that the mechanical activity will be accompanied by (increased) electrical activity. Movement of the bladder relative to the recording electrodes as a possible signal source during bladder contraction and emptying is not seriously considered by most investigators.

Detrusor EMG carried out according to this general blueprint, in which the electrodes contact the bladder wall or detrusor muscle directly and bladder emptying is provoked (e.g., by peripheral nerve stimulation, chemical stimulation and filling cystometry), seems very liable to the recording of such movement artefact. It was Brunsting who, as a student, published an article as early as 1958 in which he described the effects of slow electrode movement in various set-ups on electrical recordings made and their resemblance to bladder EMG's published by Corey and Boyce earlier (Corey et al., 1951; Boyce, 1952). These findings were refined in experimental set-ups in vivo, where it was stated that disturbing movement could be evoked by respiration, bowel activity or striated muscle activity (Abdel-Rahman et al., 1982). In some detrusor EMG studies, the authors themselves, after several publications, finally concluded (Doyle et al., 1975; Takaiwa et al., 1992) that movement is difficult to exclude, while other investigators (Brunsting, 1958; Abdel-Rahman et al., 1982) have suggested that movement is most likely to have caused the recorded signals. The general problem is the separation of very small extracellular signals, reflecting actual membrane potential changes of detrusor muscle cells, from the large electromechanical artefact caused by electrode movement as the tissue contracts. Reliable control experiments to exclude or identify various signal components from sources other than the detrusor muscle are rare whenever a detrusor EMG technique is presented. Although the signals recorded in each of these studies might show a real detrusor electromyogram, its unequivocal identification is, in my opinion, impossible without relevant control experiments (see Chapter three of this thesis).

This even enticed some investigators to the statement that it was not important whether the recordings were caused by an electrical signal source or mere bladder wall and electrode movement. Since in the latter case the recordings would still represent activity of the bladder muscle and might therefore be useful.

The current problems can be postulated and summarized as follows:

1. the signal characteristics of electrical detrusor muscle activity recorded with extracellular 
electrodes are yet unknown;

2. the separation of electrical and mechanically induced signal components in so called detrusor EMG can not be carried out yet;

3. the functional relation between electrical and mechanical detrusor muscle activity is yet unknown;

4. the characteristics of mechanical detrusor muscle activity during storage and micturition, the overall and local strain distribution, are yet unknown;

5. to the best of our knowledge, no suitable experimental set-up has been described in literature to succesfully record detrusor EMG.

Since the signal properties of electrical detrusor activity are not clear, the discrimination between true electrical activity from the detrusor muscle and signal components from other, interfering, signal sources becomes difficult, even when using appropriate recording equipment and sophisticated data-analysis techniques.

Not much is known about the relation between electrical and mechanical bladder wall activity either. In EMG studies (Kinder et al., 1997, 1998a, b, Chapter three, Addendum to Chapter five, and Chapter six of this thesis; Scheepe et al., 1998, 1999) the local relation between electrical and mechanical activity of the bladder muscle normally is not determined: overall bladder muscle mechanical activity remains to be estimated indirectly by vesical pressure. Information on properties of local mechanical activity, however, could be crucial for the interpretation of bladder EMG in its relation to the physiology and pathophysiology of the muscle and its innervation, something that has proven to be very difficult to date. Moreover, it would enable the design of reliable control experiments to describe the effects of electrode movement on the electromyographic recordings as the tissue contracts.

Unfortunately, studies on the overall or local strain distribution of bladder tissue during storage and micturition are absent from literature to the best of our knowledge. Information on local strain distribution across the bladder surface could elucidate where contractions and relaxations originate in the bladder, how they propagate over the bladder wall, and how several wavelike contractions and relaxations interfere. Reliable methods to study mechanical activity have been applied succesfully in recent years on heart tissue (Delhaas et al., 1993), skin (Van Ratingen et al., 1993) and striated muscles (Van Bavel et al., 1996, 1998; Van Donkelaar et al., 1999). A similar approach might be feasible for the detrusor muscle in vivo (Kinder et al., 1999, 2001, Chapters four and five of this thesis).

The current situation on detrusor EMG techniques demands fundamentally different approaches rather than repetition of the previously described blueprint using ever more sophisticated signal analysis methods and high tech recording equipment.

The challenge is clear: design a blueprint that incorperates the possibilities i) to get a hold of the isolated electrical detrusor muscle activity to determine its signal characteristics; ii) to integrate the recording of local mechanical activity into the detrusor EMG recordings to determine their relation; and iii) to eliminate or at least identify signal components not originating from electrical detrusor muscle activity as early as during the detrusor-EMG recordings.

\section{Aim}

The investigations described in this thesis are restricted to innervation and control of the urinary bladder, the urethra and the pelvic floor and to electromyography of the urinary bladder.

The objectives are:

- to inventory data and concepts that have been presented in the literature on neuronal innervation and control of the bladder, the urethra and the pelvic floor, using abstraction and generalisation methods that are derived from system and control theory. White spots in present knowledge are clearly to be indicated as such, which means that a line between reliable data and hypotheses has to be drawn.

- to design a working hypothesis (a general neuronal innervation and control concept for the bladder, the urethra and the pelvic floor) to support future research efforts. This is to be achieved by a multidisciplinary approach, using (neuro-)anatomy, (neuro-)physiology, clinical urology and system and control theory as available design tools.

- to propose, develop and validate alternative methodologies for detrusor electromyography as a tool for physiological research of detrusor muscle function.

- to identify, in several recording situations, signal properties such as amplitude, frequency and shape of electrical activity generated by the detrusor smooth muscle.

\section{Outline}

This thesis is composed of two major parts. Chapters one and two focus on innervation and control of bladder, urethra and pelvic floor, while Chapters three 
to six deal with electromyography of the detrusor smooth muscle. A more detailed outline is given below.

The first Chapter is a review on the neuronal innervation of the lower urinary tract and mechanisms that control the micturition cycle. The concepts of four research groups are selected for detailed analysis as they describe most completely the neuro-anatomical architecture in relation to micturition control.

Each concept is translated to a higher level of abstraction. Using flow charts as universal representation technique, neuro-anatomical architecture and elementary control mechanisms are visualized, compared and discussed. These flow charts integrate neuronal innervation and control in three different stages of the micturition cycle: storage, voiding and end of micturition.

In Chapter two, again the neuronal innervation of the lower urinary tract and mechanisms that control the micturition cycle are discussed. Unlike in Chapter one, where the essence of each concept was derived from a different research perspective, now an integrative approach using (neuro-)anatomy, (neuro-) physiology, clinical urology, system and control theory is chosen to design a qualitative controller of the lower urinary tract. State-of-the-art neuro-anatomy of peripheral pathways, central connections and interconnecting cell groups is applied. The function of the peripheral and central neuro-anatomical organisation in micturition control is described. White spots and controversial items in present knowledge are clearly indicated. Applications of this qualitative control model for mathematical modelling, e.g., neural network simulations, are described.

With Chapter three, the second part of this thesis on electromyography of the detrusor smooth muscle is introduced. Bladder electromyography over the past 50 years shows difficulties in discerning artefacts, generated by movement between recording electrodes and bladder tissue during evoked voiding contractions, from electrical bladder smooth muscle activity. However, abundant reports on spontaneous mechanical and electrical activity in bladder smooth muscle cells and strips are available in the literature. Assuming that spontaneous electrical activity is present in vivo as well, there seems no initial need to provoke major contractions or bladder emptying for succesful bladder electromyography in living animals or humans. In a first attempt to validate this hypothesis, a new strategy on detrusor electromyography is formulated to study occurence, amplitude, frequency, shape and spread of electrical detrusor activity. Bladder EMG is studied qualitatively and quantitatively in the mortalised rabbit. In a postmortem study with six rabbits, a large area $(37 \mathrm{~mm} \mathrm{x}$ $37 \mathrm{~mm}$ ) of the detrusor muscle is mapped with 240 electrodes that are placed against the serosal bladder surface. Control experiments are executed to validate the technique and to interprete the results correctly.

In Chapter four, the feasibility of video monitoring fluorescent spheres placed on top of the outer urinary bladder wall to assess three dimensional strain fields in the living rabbit is investigated. Optical marker tracing methods have been applied succesfully in recent years to quantify local material deformation of heart tissue, skin and striated muscles. In this study, polystyrene fluorescent spheres $(\mathrm{d}=0.6 \mathrm{~mm})$ are glued to the ventral serosal bladder wall in the rabbit. Three dimensional video registration of the polystyrene spheres is used to calculate two directions of principal strain $\left(\varepsilon_{1}, \varepsilon_{2}\right)$ on the bladder surface in vivo. The aim is to investigate the feasibility of the technique for this new application in two experimental circumstances: during spontaneous bladder wall activity and after electrical stimulation of bladder innervating nerve fibers.

Chapter five describes the study of spontaneous bladder EMG from an isovolumetric bladder without chemical or electrical stimulation in the living rabbit. Moreover, mechanical intervention, either by lifting the bladder out of the abdomen or by rapid filling, results in stretch induced bladder EMG. On four occasions, Hypnorm ${ }^{\star}$ was administered during the recordings. A self made epoxy resin electrode device that embeds 32 EMG recording electrodes in a matrix like pattern, each electrode $\mathrm{Ag} / \mathrm{AgCl}, \mathrm{d}=0.6 \mathrm{~mm}$ with an interdistance of $2.3 \mathrm{~mm}$, is used for registration. The new recording equipment uses a common average reference technique and a sample frequency of $400 \mathrm{~Hz}$. A signal bandwidth of 0.05 to $108 \mathrm{~Hz}$ is available for analysis.

The addendum to chapter five discusses topics related to the unchanged experimental approach several research groups nowadays choose for urinary bladder EMG despite of the problems that are known for over the past $\mathbf{5 0}$ years. It underlines that not only technical, but mainly methodological shortcomings hamper the successful recording of urinary bladder EMG.

In Chapter six, a new method for human bladder electromyography is proposed. Non-invasive surface electrodes are placed on the abdominal skin of human volunteers for bladder electromyography. Electromyography is performed simultaneously with urodynamic free flow and pressure flow studies. Recordings are 
made with both a full and empty bladder at rest and during micturition itself. Control experiments are conducted with a full bladder at rest and comprise coughing, abdominal straining, contraction of the pelvic floor and the subsequent lifting of each leg. The results of the standard urodynamic investigation and the control experiments are used to interprete the abdominal electrode signals and to validate the technique.

The Discussion of this thesis does not recapitulate the discussions that have already been carried out in each Chapter. Instead, it is focused on four attention points related to sense and nonsense about urinary bladder EMG in the past, present and the future. Firstly, bladder EMG evoked by electrical sacral nerve root stimulation has the reputation to deliver real bladder electromyograms (Craggs \& Stephenson, 1976; Scheepe et al., 1999). Arguments are presented that question this reputation and the consequences are discussed. Secondly, we will show the frequency band of the signals we found more in detail using power spectral density analysis. Thirdly, a concept is put forward that links the electrical activity presented in Chapters three and six to the neuronal control of Chapters one and two. Finally, the effect of aneasthetics on electrical bladder smooth muscle activity is pointed out using power spectral density analysis.

\section{References}

Abdel-Rahman M, Coulombe A, Abdel-Hakim A, Galeano C, Elhilali M (1982) Vesicourethral electromyography: facts or artefacts. Br J Urol 54:381-386

Abrams P, Blaivas JG, Stanton SL, Andersen JT (1988) Standardization of terminology of lower urinary tract function. The international continence society committee on standardization of terminology. Neurourol Urodyn 7 , 403-427 / Scand J Urol Nephrol 114 (suppl):5-19

Allessie MA, Hoeks APG, Schmitz GML, Reneman RS (1986) On-line mapping system for the visualization of the electrical activation of the heart. Int J Card Im 2:59-63

Anten HWM (1989) De neurologie van het urogenitaalstelsel. Thesis, Maastricht University, Maastricht, The Netherlands

Araki I (1994) Inhibitory postsynaptic currents and the effects of GABA on visually identified sacral parasympathetic preganglionic neurons in neonatal rats. $\mathrm{J}$ Neurophysiol 72:2903-2910

Araki I, De Groat WC (1996) Unitary excitatory synaptic currents in preganglionic neurons mediated by two distinct groups of interneurons in neonatal rat parasympathetic nucleus. J Neurophysiol 76:215-226

Badr G, Carlsson CA, Fall M, Friberg S, Lindstrőm L, Ohlsson B (1982) Cortical evoked potentials following stimulation of the urinary bladder in man. Electro- encephalogr Clin Neurophysiol 54:494-498

Badr G, Fall M, Carlsson CA, Lindström L, Friberg S, Ohlsson B (1984) Cortical evoked potentials obtained after stimulation of the lower urinary tract. $\mathrm{J}$ Urol 131:306-309

Baljet B (1981) The innervation of the abdominal, pelvic and adjoining viscera in the female. Thesis, Amsterdam, The Netherlands

Baljet B, Drukker J (1979) The extrinsic innervation of the pelvic organs in the female rat. Acta Anat 107:241-267

Bastiaanssen EHC (1996) The neural control of the lower urinary tract: modelling and simulation. Thesis, Leiden University, Leiden, The Netherlands

Blaivas JG (1982) The neurophysiology of micturition: a clinical study of 550 patients. J Urol 127:958-963

Blok BFM, Willemsen ATM, Holstege G (1997) A PET study on brain control of micturition in humans. Brain 120:111. 121

Boyce WH (1952) Bladder electromyography: a new approach to the diagnosis of urinary bladder dysfunction. J Urol 67:650-658

Bradley WE (1972) Urethral electromyography. J Urol 108, 563-564

Bradley WE, Teague CT (1968) The pelvic ganglia. J Urol 100:649-652

Bradley WE, Timm GW, Scott FB (1974) Innervation of the detrusor muscle and urethra. Urol Clin North Am 1:3-27

Brunsting, CD (1958) An interpretation of the urinary bladder "electrocystogram" as artefact. J Urol 79:165-170

Busby-Whitehead JM, Johnson TM (1998) Urinary incontinence. Clin Geriatr Med 14:285-296

Corey EL, Boyce WH, Vest A, French CR (1951) Electropotential changes in human urinary bladder: a method of measurement. J Appl Physiol 3:631-636

Cosgrove MD, Jones WG, La Joie WJ, Kaplan PE, Morrow JW (1974) Electromyographic studies of human urinary bladder. Urology 3:239-242

Cosgrove MD, La Joie WJ, Jones WG (1977) Further observations of the detrusor electromyogram. Urol Int 32:123-126

Craggs MD, Stephenson JD (1976) The real bladder electromyogram. Br J Urol 48:443-451

Craggs MD, Stephenson JD (1982) The effects of parasympathetic blocking agents on bladder electromyograms and function in conscious and anaesthetized cats. Neuropharmacology 21:695-703

Craggs MD, Stephenson JD (1985) Bladder electromyograms and function in monkeys after atropine. $\mathrm{Br} \mathrm{J}$ Urol 57:341-345

Day PL (2000) Findings of a three-year retrospective study to investigate prevalence and incidence of urinary incontinence and overactive badder in a typical managed care setting Pharm Pract Manag Q 20:1-11

De Groat WC, Steers WD (1990) Autonomic regulation of the urinary bladder and sexual organs. In: Central Regulation of Autonomic Functions. Loewy AD, Spyer KM eds. pp 310-323. Oxford University Press, New York, USA

Delhaas T, Arts T, Prinzen FW, Reneman RS (1993) Relation between regional electrical activation time and subepicardial fiber strain in the canine left ventricle. Pfluegers Arch 423:78-87

Dixon J, Gosling J (1987) Structure and innervation in the 
human. In: The Physiology of the Lower Urinary Tract. Torrens MJ, Morrison JFB eds. pp. 3-22. Springer Verlag, New York, USA

Doyle PT, Hill DW, Stanton SL (1975) Electromyography of the detrusor muscle. J Urol 114:208-212

Drōes JTPM (1972) De musculatuur van blaas en urethra in de menselijke foetus. Thesis, Leiden University, Leiden, The Netherlands

Elbadawi A (1984) Ultrastructure of vesicourethral innervation. II. Postganglionic axoaxonal synapses in intrinsic innervation of the vesicourethral lissosphincter: a new structural and functional concept in micturition. $\mathrm{J}$ Urol 131:781-790

Elbadawi A (1987a) Comparative neuromorphology in animals. In: The Physiology of the Lower Urinary Tract. Torrens MJ, Morrison JFB eds. pp. 23-52. Springer Verlag, New York, USA

Elbadawi A (1987b) Neuromuscular Mechanisms of Micturition. In: The Principles and Practice of Neurourology and Urodynamics. Yalla SV, McGuire EJ, Elbadawi A, Blaivas JG eds. pp 3-35. Macmillan Publishing Company, New York, USA.

Elbadawi A (1991) Anatomy and innervation of the vesicourethral muscular unit of micturition. In: Clinical Neuro-Urology. Krane, RJ, Siroky, MB eds. 2nd Ed. pp 5-23. Little, Brown \& Company, Boston, USA

Franksson C, Petersen I (1953) Electromyographic recording from the normal human urinary bladder, internal urethral sphincter and ureter. Acta Physiol Scand 29:150-156

Fredericks CM, Anderson GF, Rasmussen EA, Pierce JM (1969) Electrophysiology of the canine urinary bladder. Invest Urol 7:33-40

Golshayan D, Seydoux C, Berguer DG, Stumpe F, Hurni M, Ruchat $\mathrm{P}$, Fischer A, Mueller $\mathrm{X}$, Sadeghi $\mathrm{H}$, Von Segesser L, Goy JJ (1998) Incidence and prognostic value of electrocardiographic abnormalities after heart transplantation. Clin Cardiol 21:680-684

Groutz A, Blaivas JG, Pies C, Sassone AM (2001) Learned voiding dysfunction (non-neurogenic, neurogenic bladder) among adults. Neurourol Urodyn 20:259-268

Hampel C, Wienhold D, Benken N, Eggersman C, Thuroff JW (1997) Definition of overactive bladder and epidemiology of urinary incontinence. Urology 50 (Suppl $6 \mathrm{~A}): 4-14$

Hoeks APG, Schmitz GML, Allessie MA, Jas H, Hollen SJ, Reneman RS (1988) Multichannel storage and display system to record the electrical activity of the heart. Med Biol Eng Comput 26:434-438

Holstege G, Griffiths D (1990) Neuronal organization of micturition. In: The Human Nervous System. Paxinos G ed. pp 297-306. Academic Press, Inc, San Diego, USA

Jones WG, La Joie WJ, Cosgrove MD (1974) Electromyography in pathologic bladder. Urology 2:186189

Jünemann KP, Scheepe J, Persson-Jüneman C, Schmidt P, Abel K, Zwick A, Tschada R, Alken P (1994) Basic experimental studies on corpus cavernosum electromyography and smooth-muscle electromyography of the urinary bladder. World J Urol 12:266-273

Kaplan PE, Nanninga JB (1978) Electromyography of the human urinary bladder. Electromyogr Clin Neurophysiol 18:63-68
Kaplan PE, Nanninga JB, Lai S (1976) Electromyography and cystometry of the neurogenic bladder. A preliminary report. Electromyogr Clin Neurophysio 16:463

Kinder MV, Bastiaanssen EHC, Janknegt RA, Marani E (1995) Neuronal circuitry of the lower urinary tract; central and peripheral neuronal control of the micturition cycle. Anat Embryol 192:195-209

Kinder MV, Bastiaanssen EHC, Janknegt RA, Marani E (1999) The neuronal control of the lower urinary tract: A model of architecture and control mechanisms. Arch Physiol Biochem 107:203-222

Kinder MV, Gommer ED, Janknegt RA, Van Waalwijk van Doorn ESC (1997) A method for the electromyographic mapping of the detrusor smooth muscle. Arch Physiol Biochem 105:673-690

Kinder MV, Gommer ED, Janknegt RA, Van Waalwijk van Doorn ESC (1998a) Recording the detrusor electromyogram is still a difficult and controversial enterprise. Neurourol Urodyn 17:571-573

Kinder MV, Van Waalwijk van Doorn ESC, Gommer ED Janknegt RA (1998b) A non-invasive method for bladder electromyography in humans. Arch Physiol Biochem 106:2-11

La Joie WJ, Cosgrove MD, Jones WG, Kaplan PE (1975) Electromyography of the human bladder: a preliminary report. Electromyogr Clin Neurophysiol 15:191-206

Le Feber J, Van Asselt E, Van Mastrigt R (1997) Neurophysiological modelling of voiding in rats: Bladder pressure and postganglionic nerve activity. Am J Physiol 272:413-421

Marani E, Pijl MEJ, Kraan MC, Lyckama à Nijeholt GAB, Videleer AC (1993) Interconnections of the upper ventral rami of the human sacral plexus: a reappraisal for dorsal rhizotomy in neurostimulation operations. Neurourol Urodyn 12:585-598

Mersdorf A, Schmidt RA, Tanagho EA (1993) Topographic-anatomical basis of sacral neurostimulation: neuroanatomical variations. J Urol 149:345-346

Milsom I, Abrams P, Cardozo L, Roberts RG, Thuroff J, Wein AJ (2001) How widespread are the symptons of an overactive bladder and how are they managed? A population-based prevalence study $\mathrm{Br} \mathrm{J}$ Urol Int 87:760766

Morrison JFB (1987a) Neural connections between the lower urinary tract and the spinal cord. In: The Physiology of the Lower Urinary Tract. Torrens MJ, Morrison JFB, eds., pp. 53-85. Springer Verlag, New York, USA

Morrison JFB (1987b) Reflex control of the lower urinary tract. In: The Physiology of the Lower Urinary Tract. Torrens MJ, Morrison JFB, eds., pp. 193-235. Springer Verlag, New York, USA

Morrison JFB (1987c) Bladder control: role of higher levels of the central nervous system. In: The Physiology of the Lower Urinary Tract. Torrens MJ, Morrison JFB, eds., pp. 237-274. Springer Verlag, New York, USA

Nanninga JB, Kaplan PE (1978) Experience with measurement of bladder electrical activity. J Urol 120:8285

Payne CK (1998) Epidemiology, pathophysiology, and evaluation of urinary incontinence and overative bladder. Urology 1 (Suppl 2A):3-10

Rekers H, Drogendijk AC, Valkenburg H, Riphagen F (1992) Urinary incontinence in women from 35 to 79 years of 
age: prevalence and consequences. Eur J Obstet Gynecol Reprod Biol 43:229-234

Roberts RO, Jacobsen SJ, Rhodes T, Reilly WT, Girman CJ, Talley NJ, Lieber MM (1998) Urinary incontinence in a community-based cohort: prevalence an healthcareseeking. J Am Geriatr Soc 46:467-472

Rockswold GL, Bradley WE (1977) The use of evoked electromyographic responses in diagnosing lesions of the cauda equina. J Urol 118:629-631

Rowan D, James ED, Kramer AEJL, Sterling AM, Suhel PF (1987) Urodynamic equipment: technical aspects. J Med Eng Techn 11:57-64

Samuelsson E, Victor A, Tibblin G (1997) A population study of urinary incontinence and nocturia among women aged 20-59 years. Prevalence, well-being and wish for treatment. Acta Obstet Gynecol Scand 76:74-80

Scheepe JR, Wipfler G, Schumacher S, Bross S, Zendler S, Juenneman KP, Alken P (1998) Smooth muscle electromyography of the urinary bladder. Neurourol Urodynam 17:71-83

Scheepe J, Bross S, Schumacher S, Braun P, Weiss J, Alken P, Juennemann K (1999) Recording the evoked canine detrusor electromyogram. Neurourol Urodyn 18:687-695

Schulman C, Claes H, Mathijs J (1997) Urinary incontinence in Belgium: a population epidemiological survey. Eur Urol 32:315-320

Shafik A (1994) Study of the electromechanical activity of the urinary bladder. World J Urol 12:316-318

Stanton SL, Hill DW, Williams JP (1973) Electromyography of the detrusor muscle. Br J Urol 45:289-298

Stanton SL, Hill DW, Williams JP (1974) Electromyography of the detrusor muscle Preliminary communication. Urol Int 29:182-184

Takaiwa M, Shiraiwa $Y$ (1984) A new technique of vesical electromyogram with cystometrogram and urethral electromyogram. Urol Int 39:217-221

Takaiwa M, Ishiwata H, Kobayashi M, Shiraiwa Y (1983a) Electromyography of urinary bladder using carbon fiber electrodes. Fukushima Med J 33:33-47

Takaiwa M, Shiraiwa Y, Katahira K, Tsukahara S (1983b) A new urinary bladder electromyogram technique. Urol Int 38:1-4

Takaiwa M, Yamaguchi O, Yoshimura Y, Fukaya Y, Shiraiwa $Y$ (1992) Recording the bladder electromyogram for bladder activity evaluation during post-operative urinary urgency. Fukushima J Med Sci 38:91-97

Toba K, Ouchi Y, Orimo H, limura O, Sasaki H, Nakamura Y, Takasaki M, Kuzuya F, Sekimoto H, Yoshioka H, Ogiwara T, Kimura I, Ozawa T, Fujishima M (1996) Urinary incontinence in elderly inpatients in Japan: a comparison between general and geriatric hospitals. Aging 8:47-54

Van Arsdalen K, Wein AJ (1991) Physiology of micturition and continence. In: Clinical Neuro-Urology. Krane RJ, Siroky MB, eds., 2nd edn., pp. 25-82. Little Brown and Company, Boston, USA

Van Bavel H, Drost MR, Wielders JDL, Huyghe JM, Huson A, Janssen JD (1996) Strain distribution on rat medial gastrocnemius (MG) during passive stretch. J Biomechanics 29:1069-1074

Van Bavel H, Holtzer CAJ, Van Leeuwen JL, Muijtjens AMM, Willems PJB, Drost MR (1998) Quantification of local surface strains of cat gastrocnemius medialis muscle during contraction. Netherlands J Zoology 48:323-334

Van Donkelaar CC, Willems PJB, Muijtjens AMM, Drost MR (1999) Skeletal muscle transverse strain during isovolumetric contraction at different lengths. J Biomechanics. In press.

Van Ratingen MR, Petterson R, Drost MR, Oomens CWJ, Janssen JD (1993) A mixed numerical/experimental method to find Langer's lines of skin. Proc. W AM ASME Applied Mechanics, Bioengineering, and Fluids Engineering Conf., New Orleans, Louisiana.

Van Ulden BM (1975) De musculatuur van de blaashals en de urethra posterior bij de man. Thesis, Leiden University, Leiden, The Netherlands

Vereecken RL, De Meirsman J, Puers B, Van Mulders J (1981) Electrophysiological exploration of the sacral conus. Phys Med Electromyogr 12:1-11

Vignoli GCMD (1978) Premature ejaculation: New electrophysiologic approach. Urology 11:81-82

Vodusek DB, Janko M, Lokar J (1983) Direct and reflex responses in perineal muscles on electrical stimulation. $\mathrm{J}$ Neurol Neurosurg Psychiatry 46:67-71

Wijffels MC, Jirchhof CJ, Dorland R, Power J, Allessie MA (1997) Electrical remodelling due to atrial fibrillation in chronically instrumented conscious goats: roles of neurohumoral changes, ischemia, atrial stretch, and high rate of electrical activation. Circulation 96:3710-3720

Wilterdink JL, Furie KL, Easton JD (1998) Cardiac evaluation of stroke patients. Neurology 51:S23-26 


\section{Neuronal circuitry of the lower urinary tract; central and peripheral neuronal control of the micturition cycle}


Matti V. Kinder - Erica H.C. Bastiaanssen

Ruud A. Janknegt - Enrico Marani

\title{
Neuronal circuitry of the lower urinary tract; central and peripheral neuronal control of the micturition cycle
}

\begin{abstract}
A new presentation technique is introduced to describe the neuronal circuitry involved in the control of the uropoetic system and its control mechanisms during the micturition cycle. This method is based on the preparation of flow charts and is applied to the discussion of four qualitative models which are derived from the literature. Opinions concerning the reflex arcs and supraspinal connections said to be involved in micturition and continence are different and sometimes contradictory. Little is known about how autonomic information from the lower urinary tract is relayed to supraspinal structures. Information about supraspinal (inter)connections and their function in micturition control is still fragmentary. The control mechanisms which terminate voiding are not totally clear. Moreover, the role of the pelvic floor musculature in the control of the lower urinary tract is probably underestimated. The flow charts presented in this paper contribute to the future design of a single complete qualitative model representing the general central and peripheral nervous connections and control mechanisms. Such a model would provide an approach for future research in neuromodulation and neurostimulation of the uropoetic system and a reduced version could be used for quantitative modelling, e.g., in neural network simulations.
\end{abstract}

Key words Uropoetic System · Innervation - Bladder · Urethra · Pelvic Floor

M.V. Kinder

Faculty of Mechanical Engineering, Eindhoven University of Technology, Eindhoven, The Netherlands

M.V. Kinder - R.A. Janknegt

Department of Urology, Maastricht University Hospital, Maastricht, The Netherlands

E.H.C. Bastiaanssen - E. Marani

Neuroregulation Group, Department of Physiology, Leiden University, Leiden, The Netherlands

E.H.C. Bastiaanssen

Medical Informatics, Medical Faculty, Leiden University, Leiden, The Netherlands. 


\section{Introduction}

The human system of bladder, urethra and pelvic floor has to satisfy two contradictory needs: its function is to store urine, thereby offering complete continence, while it is also responsible for the controlled evacuation of urine. This paper reviews the literature on the neuronal pathways controlling the lower urinary tract. It does not concern conflicting data on the structure of the bladder and its neck, nor does it discuss differences between the female and male urethrae.

A structured or complete qualitative model of the central and peripheral nervous connections involved in the control of the lower urinary tract is difficult to provide (Baljet, 1981; Blaivas, 1982, 1985, 1990; Bradley, 1978; Bradley et al., 1974; De Groat, 1975; De Groat et al., 1979b; De Groat \& Steers, 1990; Dixon \& Gosling, 1987; Donker et al., 1982; Elbadawi, 1987a, b, 1991; Fletcher \& Bradley, 1978; Fowler \& Fowler, 1987; Gosling, 1985; Hald \& Bradley, 1982a, b; Holstege, 1989; Holstege \& Griffiths, 1990; Morrison, 1987a-e; Sato et al., 1979; Van Arsdalen \& Wein, 1991). Other studies are restricted to a specific connection or function of the neuronal circuitry (e.g., Andersson, 1986; Awad et al., 1974; Baljet \& Drukker, 1979; Bradley, 1969a, b; Bradley \& Conway, 1966; Bradley \& Teague, 1968a, b, 1969a-d; Coote et al., 1982; De Groat \& Saum, 1971; Donker, 1986; Droës, 1972; Elbadawi, 1984; Gosling et al., 1983; Griffiths et al., 1990; Hickey et al., 1982; Marani et al., 1993; Raz, 1978; Tanagho et al., 1982; Van Ulden, 1975; Venema, 1988).

However, overviews of both central and peripheral connections have been published: De Groat (1975), De Groat et al. (1979b), De Groat \& Steers (1990), Bradley et al. (1974), Bradley (1978), Blaivas (1982, 1985, 1990), Holstege (1989), Holstege \& Griffiths (1990) and Griffiths et al. (1990). The theories of these authors have been chosen for discussion in this paper because they seem to be most complete. The authors integrate central and peripheral connections and describe the function of these connections in the control of the lower urinary tract.

De Groat includes data from animal experiments to support parts of his description of pathways and their function in human (De Groat \& Lalley, 1972; De Groat, 1975; De Groat et al., 1979a, b; De Groat \& Steers, 1990). Bradley uses a "loop concept" to describe the central and peripheral circuitry of the lower urinary tract (Bradley et al., 1974; Bradley, 1978; Fletcher \& Bradley, 1978). Blaivas' main article is based on a clinical study, the results of which he compared to models of De Groat and Bradley, leading to his own representation (Blaivas, 1982). His descrip- tion of pathways has been updated in 1990. The most extensive study on connections related to the micturition center in the brain stem has been published by Holstege (1989), Holstege \& Griffiths (1990) and Griffiths et al. (1990).

\section{Materials and Methods}

Four qualitative models are presented in the same way: (1) by a description of the neuronal circuitry itself; (2) by a description of the functional interpretation of this circuitry. The models are presented as flow charts (Figs. 1 to 4 ) and in each case the lay-out is in principle the same. Only structures known to have a function in the control of the uropoetic system are considered. Some putative anatomical connections still have to be demonstrated and as a result the functional design of the flow charts does not necessarily coincide with neuroanatomical data.

The flow charts should be read from top to bottom (Figs. 1-4). The blue printed upper part of the flow chart consists of the afferent or sensory system. The afferent system connects receptors present in effector structures to spinal and/or supraspinal structures. Spinal structures that process sensory information are thought to be part of the afferent system and are also coloured blue. The supraspinal structures are located in the black coloured mid-portion of the flow chart. The green coloured lower part shows the efferent or motor system, which includes spinal motor structures. The flow charts can also be interpreted from left to right, showing structures belonging to the somatic, parasympathetic and sympathetic nervous system in that order.

A block represents a nervous structure or a muscle effector. A nervous structure can be located in the peripheral nervous system or in the spinal part of the central nervous system. Sensors and receptors are thought to be integrated in the muscle effector blocks. Supraspinal nervous structures in the central nervous system are represented by a circle.

The arrows in the flow chart denote the connections between the different structures and their direction. Peripheral structures are connected to each other by nerves, indicated in the descriptions by their anatomical names. Central connections are named as tracts. Each connection is described in the "Circuitry" sections, and in these sections the appropriate text is linked to its flow chart by a reference in brackets.

Sometimes plus and minus signs are included in the flow charts to indicate the effect of a control mechanism (Figs. 2-4). The plus sign denotes an excitatory effect and the minus sign indicates an inhibitory effect. These signs are placed in the 
efferent pathways only. Flow charts that represent control mechanisms show thick red lines for the activated pathways and structures; pathways and structures that are not activated are shown by thin black lines.

The coloured bars placed on the left side of the flow charts enable the reader to compare the emphasis placed on specific structures by the original authors. The three basic colours are as follows: blue for the afferent part, black for the supraspinal part and green for the efferent part. The circles within the coloured bars indicate muscular or nervous structures in the following way: red for muscular tissue, orange for nervous structures of the peripheral nervous system and yellow for nervous structures inside the spinal cord. The coloured circles refer to the structures in the flow chart at the same vertical level.

The signal flow within the flow charts is as follows:

1. In the case of a supraspinal reflex, the afferent pathway originates in a muscle effector at the top of the flow chart and terminates in a supraspinal nervous structure. Along this afferent pathway several other synapses may occur, which for various reasons will not always be depicted, e.g., because the author does not specify them by name. The efferent pathway originates in the supraspinal nervous structure(s) and serves two functions: a muscle effector can be affected, or another nervous structure - supraspinal, spinal or peripheral - can be modulated.

2. In the case of a spinal reflex, supraspinal structures in the mid-portion of the flow chart are not involved. The afferent pathway terminates in a spinal nervous structure in the upper half of the flow chart. The efferent pathway originates in the same spinal nervous structure located in the bottom half of the flow chart; a muscle effector can be affected or another nervous structure can be modulated.

For all structures, the nomenclature used by the author in his cited papers is adopted. However, even in the papers by the same author, the nomenclature sometimes varies; in such a case a consistent nomenclature is used here, and when necessary the nomenclature used in the paper referred to is also mentioned. The division of sympathetic, parasympathetic or somatic pathways is arbitrarily based on the (vesico-)motoneurons inside the spinal cord to which the pathways connect.

\section{Results}

\section{The De Groat model}

\section{Circuitry (Fig. 1)}

Musculature of the lower urinary tract. Within the lower urinary tract the following muscular structures are described: striated urethral musculature, referred to as the external urethral sphincter [EXTERNAL URETHRAL SPHINCTER]; the bladder, consisting of the smooth detrusor muscle [BLADDER] and the trigone and its connected smooth urethral muscles [TRIGONE \& SMOOTH URET. MUSC.].

Sympathetic connections. Tension receptors inside the bladder wall are connected to afferent fibres, which are conveyed by the pelvic nerve. These fibres enter the sacral spinal cord to terminate on sympathetic neurons inside the thoracolumbar cord (De Groat \& Lalley, 1972; De Groat et al., 1979b; De Groat \& Steers, 1990) [BLADDER $\rightarrow$ TH-L].

A descending spinal tract originates in the pontine micturition centre and projects to the thoracolumbar spinal cord segments (De Groat et al., 1979b; De Groat \& Steers, 1990) [PONTINE MICTUR. CENTRE $\rightarrow$ TH-L]. Sympathetic efferent fibres are presented from a functional point of view (Fig. 1) as originating in the thoracolumbar spinal cord, synapsing in pelvic ganglia [TH-L $\rightarrow$ PELVIC PLEXUS], on the detrusor muscle [TH-L $\rightarrow$ BLADDER] and on the bladder base and the smooth musculature of the urethra (De Groat \& Steers, 1990; De Groat et al., 1979b) [TH-L $\rightarrow$ TRIGONE \& SMOOTH URET. MUSC.].

Somatic connections. Afferent input from tension receptors inside the bladder wall in De Groat's model travels in the pelvic nerve to Onuf's nucleus, a circumscribed somatic motor region in the ventral horn of the sacral spinal cord [BLADDER $\rightarrow$ ONUF's NUCLEUS]. Afferent nerve fibres from the external urethral sphincter and other urethral areas reach, through the pudendal nerve, the sacral spinal cord, where they terminate in several layers of the sacral dorsal horn (De Groat \& Steers, 1990) [EXTERNAL URETHRAL SPHINCTER $\rightarrow$ SACRAL DORSAL HORN AND TRIGONE \& SMOOTH URET. MUSC. $\rightarrow$ SACRAL DORSAL HORN]. The sensory endings of these pudendal nerve afferents transmit, among other information, the sensation of urine flow in the urethra. The pontine micturition centre is connected to Onuf's nucleus by a direct descending spinal tract [PONTINE MICTUR. CENTRE $\rightarrow$ ONUF'S NUCLEUS]. In the cat, fibres coming from higher supraspinal structures 

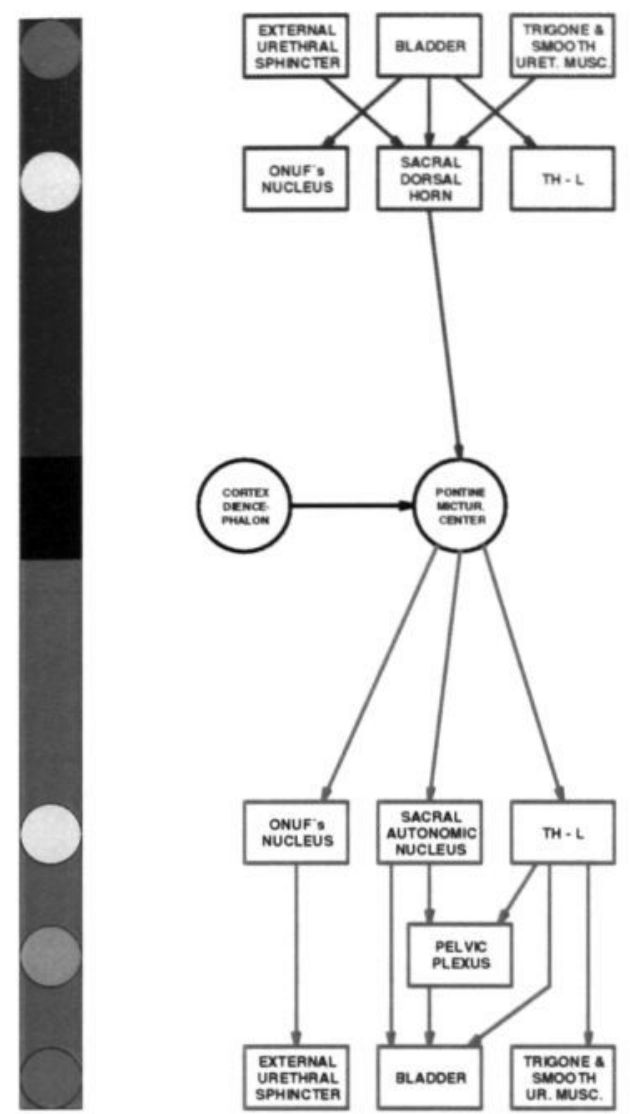

Circuitry as described by De Groat et al.
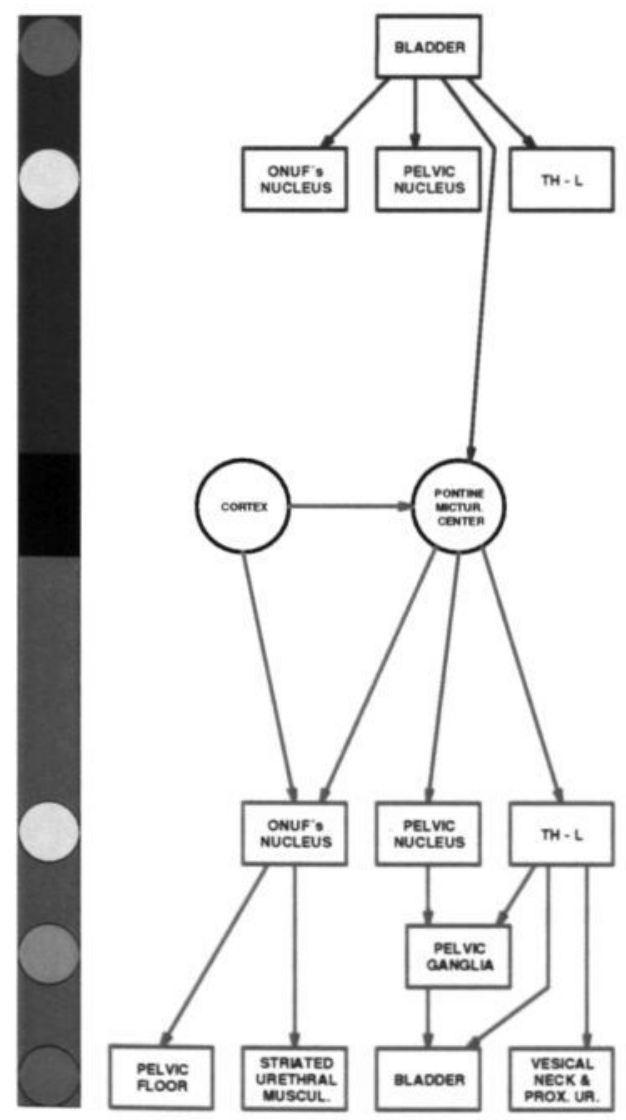

Circuitry as described by Blaivas.

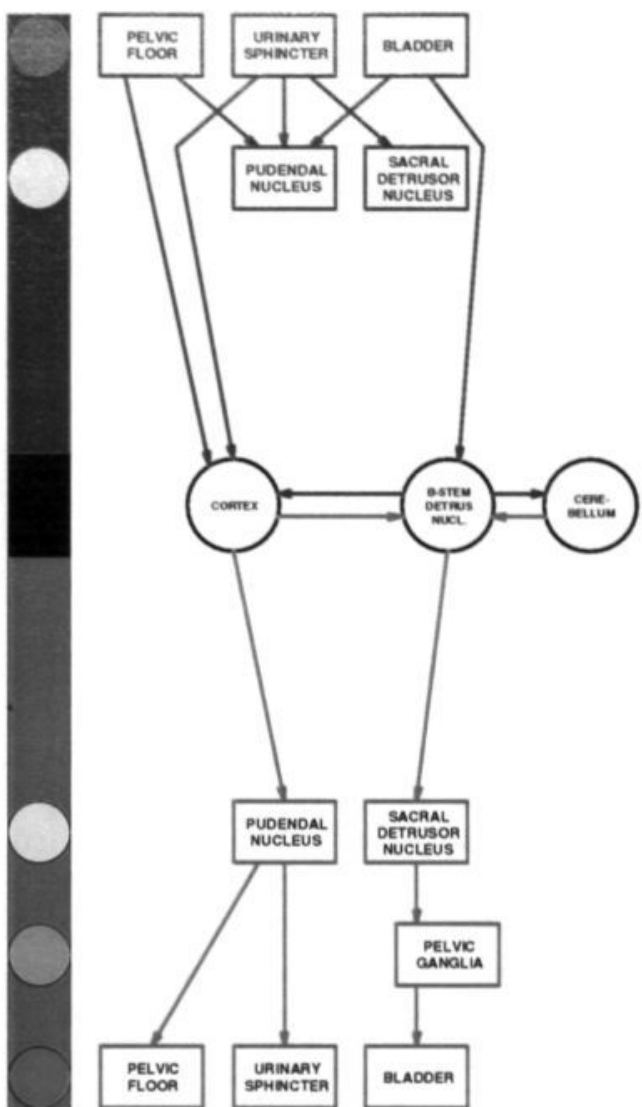

Circuitry as described by Bradley et al.
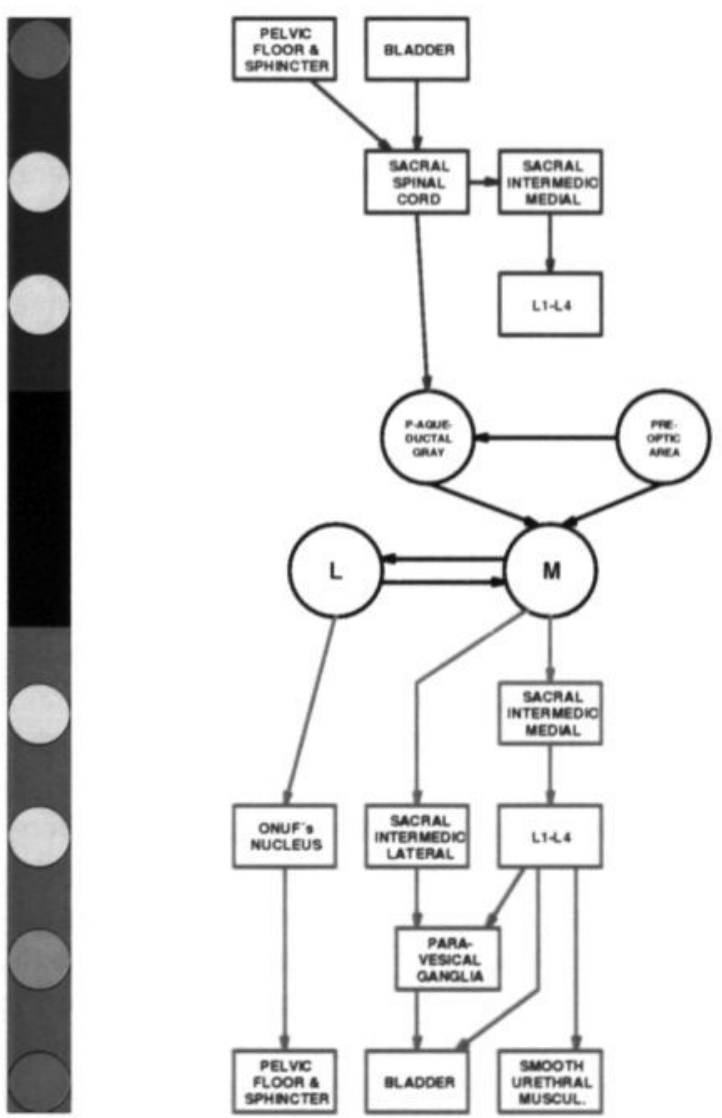

Circuitry as described by Holstege et al.

Figure 1: circuitries as described by De Groat, Bradley, Blaivas, Holstege and associates. 
synapse in the pontine micturition centre before they terminate on Onuf's nucleus (De Groat \& Steers, 1990) [CORTEX DIENCEPHALON $\rightarrow$ PONTINE MICTUR. CENTRE $\rightarrow$ ONUF'S NUCLEUS]. Efferent nerve fibres originating in Onuf's nucleus are conveyed to the external urethral sphincter by the pudendal nerve [ONUF's NUCLEUS $\rightarrow$ EXTERNAL URETHRAL SPHINCTER].

Parasympathetic connections. Tension receptors inside the bladder wall project to neurons in laminae I, V, VII and $X$ of the sacral spinal cord via the pelvic nerve [BLADDER $\rightarrow$ SACRAL DORSAL HORN]. From here, ascending neurons terminate in the pontine micturition centre (De Groat \& Steers, 1990) [SACRAL DORSAL HORN $\rightarrow$ PONTINE MICTUR. CENTRE].

An efferent tract, originating in the pontine micturition centre, projects to the sacral autonomic nucleus, an intermediolateral cell group at sacral spinal cord segments $\mathrm{S}_{2}-\mathrm{S}_{4}$ [PONTINE MICTUR. CENTRE $\rightarrow$ SACRAL AUTONOMIC NUCLEUS]. From the sacral autonomic nucleus, preganglionic neurons send axons in the pelvic nerve to ganglion cells situated inside the pelvic plexus [SACRAL AUTONOMIC NUCLEUS $\rightarrow$ PELVIC PLEXUS] and bladder wall (De Groat \& Steers, 1990) [SACRAL AUTONOMIC NUCLEUS $\rightarrow$ BLADDER]. The pelvic ganglia send parasympathetic nerve fibres to innervate the urinary bladder [PELVIC PLEXUS $\rightarrow$ BLADDER].

Efferent fibres leaving the sacral detrusor nucleus to innervate the bladder presumably give off collaterals, which probably return to interneurons near the sacral autonomic nucleus (De Groat et al., 1979b; De Groat \& Lalley, 1972). In Figs. 1 to 4 this recurrent connection is thought to be integrated in the block [SACRAL AUTONOMIC NUCLEUS].

\section{Control mechanisms}

Storage (Fig. 2). During the filling phase of the urinary bladder, tension receptors inside the bladder wall note the distension of the bladder and produce low-level firing in pelvic nerve afferents. This information is conveyed to the sacral spinal cord, where the pelvic nerve afferents connect to Onuf's nucleus or ascend to the thoracolumbar segmental levels. The afferent firing excites Onuf's nucleus, which stimulates the striated urethral musculature to contract (De Groat \& Steers, 1990). A complex vesicosympathetic mechanism that is relayed over a sacrolumbar intersegmental spinal tract is activated. An effect of the sympathetic activity during storage is the inhibition of bladder activity by stimulation of B-adrenoceptors that are situated in the bladder wall. Another effect is the inhibition, at the pelvic ganglionic level, of parasym- pathetic neurons that mediate the micturition reflex. Finally, closure of the bladder neck is realized: the trigone and the smooth urethral muscular fibres are brought to contraction via their a-adrenoceptors. These sympathetic reflexes are generally accepted as occuring in animals (e.g., De Groat et al., 1979a, b; De Groat \& Saum, 1971), but in humans their existence is still debated (De Groat \& Steers, 1990). These two spinal segmental reflexes, involving stimulation of the somatic and sympathetic nerve outflow during bladder filling by low-level afferent activity, are referred to as "guarding reflexes" that promote continence.

It is possible that recurrent inhibition of the sacral parasympathetic outflow occurs (De Groat et al., 1979b; De Groat \& Lalley, 1972), but no control mechanism or detailed pathway has been suggested (De Groat et al., 1979b). Recurrent inhibition is presumed to be present during storage and absent during micturition (De Groat, 1975).

Micturition (Fig. 3). At the initiation of micturition, intense activity of tension receptors inside the bladder wall is transmitted by pelvic nerve afferents to the sacral dorsal horn and is projected to the pontine micturition centre. From here, the two "guarding reflexes" are overruled.

1. The sympathetic vesicomotoneurons inside the thoracolumbar spinal cord are inhibited by the pontine micturition centre. Sympathetic influence on the trigone, the smooth urethral musculature, the bladder wall and the pelvic ganglia is eliminated. The bladder neck opens.

2. The somatic motoneurons inside the sacral spinal cord are inhibited by the pontine micturition centre and probably indirectly by the cerebral cortex and diencephalon as well. The excitatory activity of Onuf's nucleus on the striated urethral muscles is inhibited, which results in relaxation of these muscles.

The pontine micturition centre generates excitatory outflow to the sacral autonomic nucleus, which is sent through the pelvic ganglia to the detrusor muscle. The signal flow through this supraspinal circuit establishes and maintains the detrusor contraction.

During micturition detrusor contraction is reinforced by urine flow in the urethra, which results in activity of pudendal afferents. Excitatory signals are conveyed to the dorsal sacral spinal cord and reach the bladder, but the spinal relay station is not known.

End of micturition. Higher centres in the cerebral cortex and diencephalon are involved in voluntary control of micturition; the external urethral sphincter can be contracted or inhibited voluntarily by cortical control, but no specific control mechanism is 

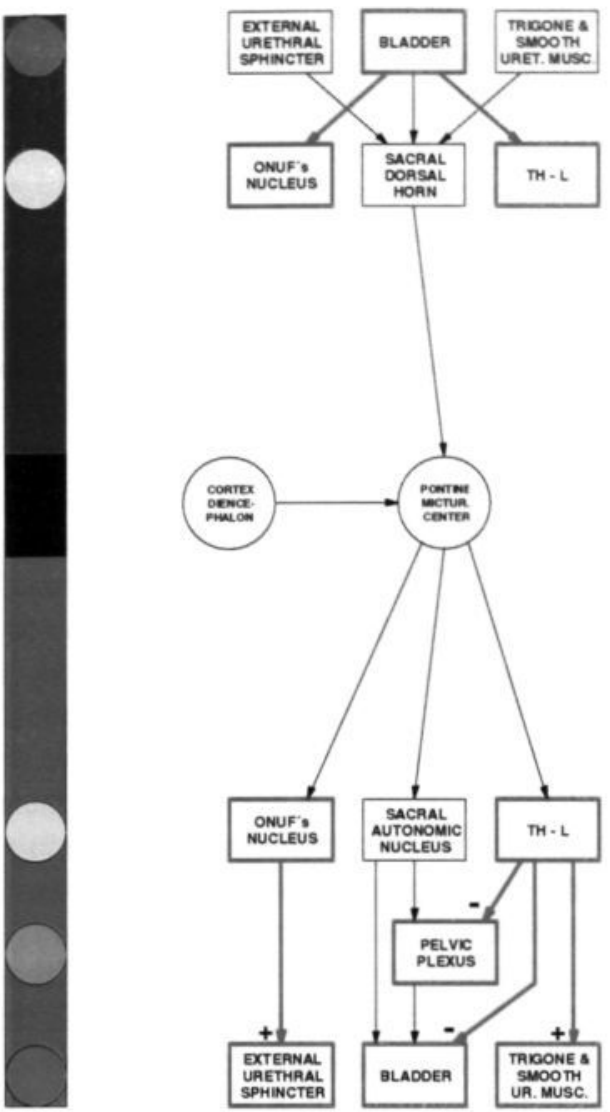

Storage as described by De Groat et al.
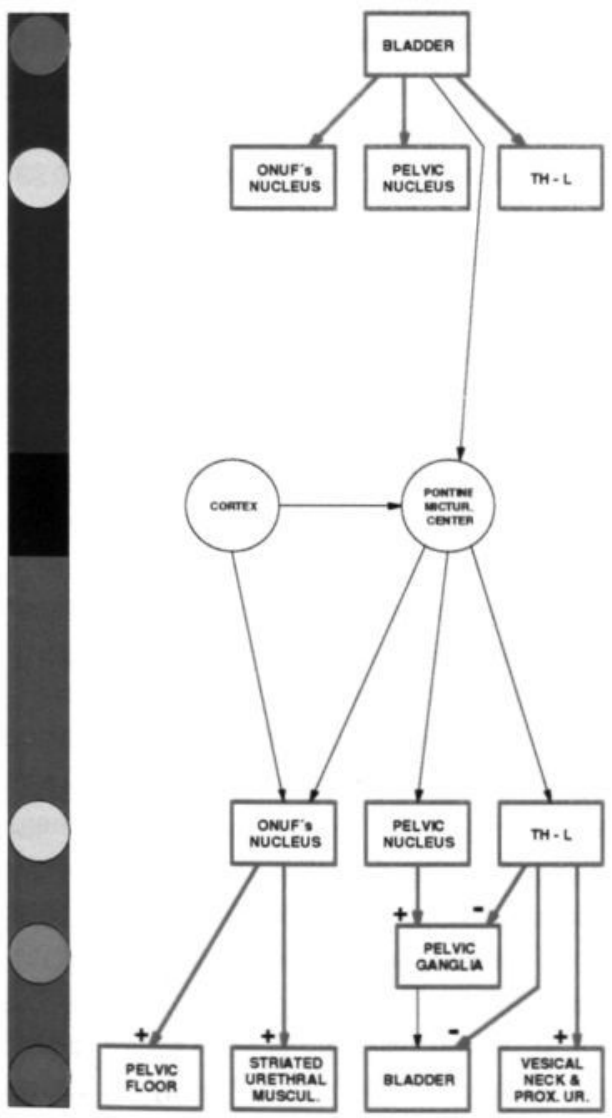

Storage as described by Blaivas.

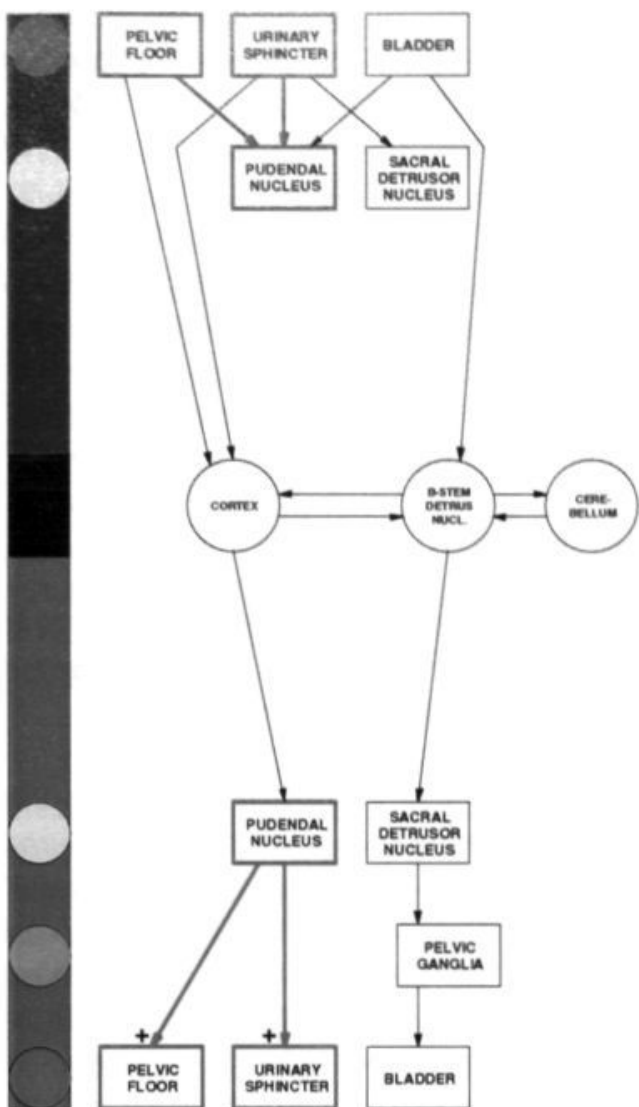

Storage as described by Bradley et al.
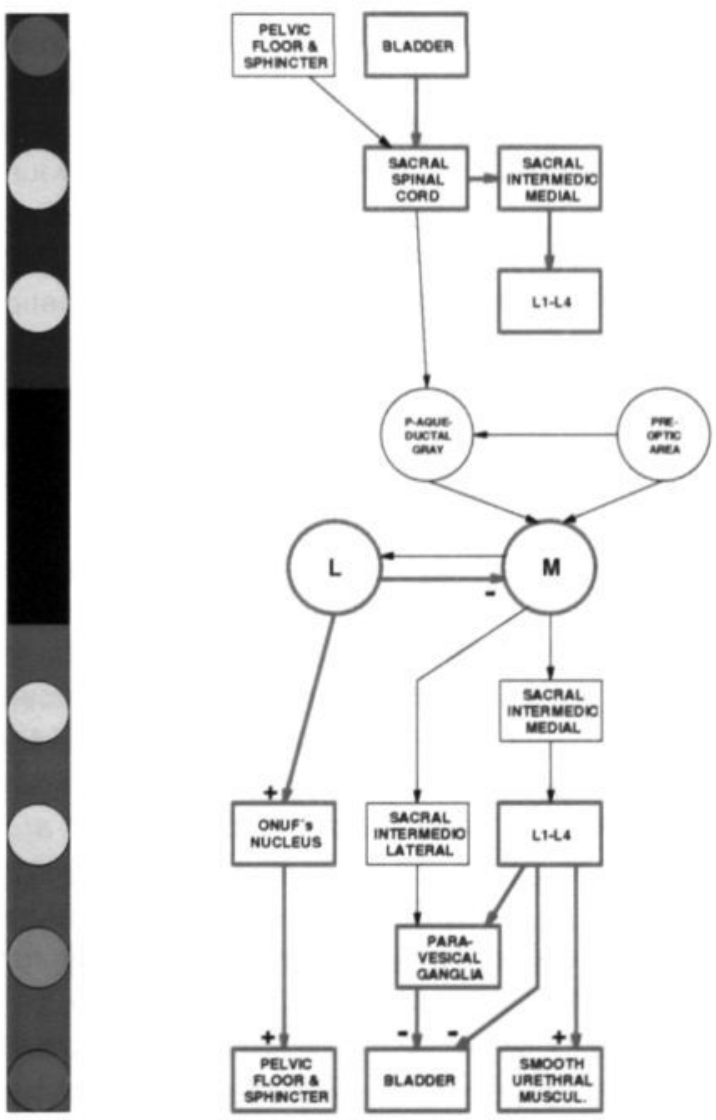

Storage as described by Holstege et al.

Figure 2: functional mechanisms during storage as described by De Groat, Bradley, Blaivas, Holstege and associates. 
described. Contraction of the striated urethral musculature results in bladder relaxation, but which pathways are active is not known (De Groat \& Steers, 1990). It has been suggested that a part of the circuit responsible is formed by a descending tract from the cortex to the pontine micturition centre, which terminates in Onuf's nucleus (De Groat \& Steers, 1990).

\section{Bradley's "Ioop concept"}

Circuitry (Fig. 1)

Bradley's "loop concept" (Bradley et al., 1974; Bradley, 1978), consisting of several interconnected sub-loops, has been integrated into one circuit.

Musculature of the lower urinary tract. Within the lower urinary tract the following muscular structures are described: a urinary sphincter [URINARY SPHINCTER], the pelvic floor [PELVIC FLOOR] and the smooth detrusor muscle [BLADDER]. The urinary sphincter is defined as the striated muscle portion of the urethra, located at a mid-urethral segment, in combination with a striated external circular urethral muscle (Bradley et al., 1974).

Sympathetic connections. Bradley does describe sympathetic nerve fibres that innervate the lower urinary tract, but no sympathetic connections or any functional influence of the sympathetic nervous system are integrated into his "loop concept" (Bradley et al., 1974, Bradley, 1978, Fletcher \& Bradley, 1978). According to Bradley et al. (1974), sympathetic bladder afferents are carried in the pelvic nerve, enter the sacral spinal cord and pass rostrally to synapse on sympathetic vesicomotoneurons in the first two segments of the lumbar spinal cord. Efferent fibres originating in the lumbar spinal cord travel via the hypogastric nerve and are organized in three ways: they innervate the pelvic ganglia, individual smooth muscle cells of the proximal urethra, and the vascular cushion situated in the submucosa of the bladder epithelium at the bladder neck (Bradley et al., 1974). Ablation of the sympathetic system, however, has no effect on detrusor reflex function (Bradley et al., 1974)

Somatic connections. Proprioceptive sensory axons originating in the detrusor muscle are carried in the pelvic nerve and connect to the pudendal nucleus [BLADDER $\rightarrow$ PUDENDAL NUCLEUS]. The pudendal nucleus consists of somatic motoneurons situated in the anterior grey horn of the spinal cord segments $S_{2}$ $\mathrm{S}_{4}$.
Sensory axons emanating from the periurethral striated muscle (seen as a part of the urinary sphincter) and the pelvic floor musculature travel in the pudendal nerve to terminate on the pudendal nucleus [URINARY SPHINCTER $\rightarrow$ PUDENDAL NUCLEUS AND PELVIC FLOOR $\rightarrow$ PUDENDAL NUCLEUS]. Some of the sensory endings are muscle spindles, but it is still unclear whether there are muscle spindles present in the striated external urethral musculature, the periurethral striated muscle or the pelvic floor musculature (Bradley et al., 1974; Bradley, 1978; Fletcher \& Bradley, 1978).

A supraspinal circuit is described: "The supraspinal innervation consists of sensory impulses from the muscle spindles passing cranially in the posterior columns. These axons send collaterals to the cerebellum and thalamus to terminate in the sensorimotor cortex of the frontal lobes. The motor neurons in layer $\mathrm{V}$ of the sensorimotor cortex send impulses down the corticospinal tract that end by synapsing on motor neurons in the pudendal nucleus in the ventral horn of the sacral spinal cord" (Bradley, 1978) [URINARY SPHINCTER $\rightarrow$ CORTEX; PELVIC FLOOR $\rightarrow$ CORTEX AND CORTEX $\rightarrow$ PUDENDAL NUCLEUS]. Although the thalamus is specifically named, neither a clear function in micturition control is given, nor is the structure integrated into the functional "loop concept" (Bradley, 1978; Bradley et al., 1974); consequently it is not integrated in Figs. 1 to 4. The pudendal nucleus innervates the urinary sphincter and the pelvic floor musculature by pudendal nerve efferents [PUDENDAL NUCLEUS $\rightarrow$ URINARY SPHINCTER AND PUDENDAL NUCLEUS $\rightarrow$ PELVIC FLOOR]

Parasympathetic connections. Urine flow in the urethra is registered by stretch receptors in the periurethral striated muscle, which are probably connected to the detrusor nucleus in the sacral spinal cord (Bradley, 1978) [URINARY SPHINCTER $\rightarrow$ SACRAL DETRUSOR NUCLEUS]. The sacral detrusor nucleus consists of parasympathetic neurons that are located in the intermediolateral cell column of the sacral grey matter.

Proprioceptive sensory axons originating in the detrusor muscle are carried in the pelvic nerve to the sacral spinal cord. From here the afferent fibres ascend in the posterior columns to the brain stem detrusor nucleus [BLADDER $\rightarrow$ B-STEM DETRUS NUCL.]. In this context it is noted that "These axons do not synapse but rather 'long route' to the brain stem." (Bradley, 1978); similar remarks can also be found in Bradley et al. (1974) and Bradley \& Conway (1966). Descending spinal tracts from the brain stem detrusor nucleus synapse on the sacral detrusor nucleus [B-STEM DETRUS NUCL. $\rightarrow$ SACRAL 
DETRUSOR NUCLEUS]. Axons of vesicomotoneurons are carried in the pelvic nerve and connect to the pelvic ganglia [SACRAL DETRUSOR NUCLEUS $\rightarrow$ PELVIC GANGLIA], from which pelvic nerve efferents innervate the detrusor muscle [PELVIC GANGLIA $\rightarrow$ BLADDER].

Efferent fibres leaving the sacral detrusor nucleus to innervate the bladder probably give off collaterals, which constitute a recurrent connection. This connection might even be formed by vesical afferent fibres, entering the anterior roots of the sacral spinal cord, instead of recurrent collaterals of efferent fibres (Fletcher \& Bradley, 1978). In Figs. 1-4 this "recurrent" connection is thought to be integrated in the block [SACRAL DETRUSOR NUCLEUS].

Supraspinal connections. A lot of attention is being paid to supraspinal structures, such as the grey matter of the cerebral cortex, the thalamus, the basal ganglia, the cerebellum, and the locus coeruleus. "The brain stem detrusor nucleus is located on the border between the pons and midbrain in a dorsal position. It is called the nucleus locus coeruleus." (Bradley, 1978). Three interconnected supraspinal structures, the supraspinal cooperation of which is not totally clear, are integrated into the "loop concept" for the coordination of the micturition cycle: the cortex, the cerebellum and the brain stem detrusor nucleus [CORTEX $\leftrightarrow$ B-STEM DETRUS NUCL. $\leftrightarrow$ CEREBELLUM].

\section{Control mechanisms}

Storage (Fig. 2). Muscle spindles, located in the striated musculature, continuously send signals to the pudendal nucleus during the filling phase of the bladder. This afferent activity results in a state of tonic contraction of the urinary sphincter and pelvic floor musculature, thereby promoting continence (Bradley et al., 1974; Bradley, 1978).

Micturition (Fig. 3). Intense vesical activity and the consequent bladder contraction stimulates proprioceptive nerve endings inside the bladder wall. The information about the condition of the bladder is conveyed to the sacral spinal cord by pelvic nerve afferents.

An inhibitory signal, which is proportional to the intensity of stimulation of the pelvic nerve afferents, impinges upon the pudendal nucleus (Bradley et al., 1974; Bradley, 1978). As a consequence, the urinary sphincter and the pelvic floor musculature relax (Bradley, 1978).

Micturition is established and maintained by a supraspinal pathway. The pelvic nerve afferents enter the sacral spinal cord and are "long routed" to the brain stem detrusor nucleus and higher structures (Bradley et al., 1974; Bradley, 1978; Bradley \& Conway, 1966). The sensory information is processed and excitatory signals are sent to the detrusor nucleus in the sacral spinal cord. The sacral detrusor nucleus sends excitatory signals to the pelvic ganglia, which leads to bladder contraction (Bradley, 1978).

During voiding, the detrusor contraction is sustained by positive feedback of urethrovesical reflexes. Urine passing the urethra stimulates stretch receptors inside the urethral wall and inside the periurethral striated muscle that probably pass their signals to the detrusor nucleus in the sacral spinal cord. The sacral detrusor nucleus stimulates the bladder to sustain the contraction until the bladder is completely emptied (Bradley, 1978).

End of micturition (Fig. 4). A negative feedback mechanism probably employs recurrent collaterals of parasympathetic preganglionic neurons to regulate the output of the sacral detrusor nucleus and supports the termination of the detrusor reflex (Bradley et al., 1974).

Pudendal nerve afferents send information about the condition of the urinary sphincter and pelvic floor not only to the cortex but also, as a spinal reflex, to the pudendal nucleus in the sacral spinal cord. The pudendal nucleus receives an additional excitatory influence from the cortex. The urinary sphincter and pelvic floor musculature are stimulated by the pudendal nucleus to contract (Bradley, 1978).

\section{The Blaivas model}

Circuitry (Fig. 1)

Musculature of the lower urinary tract. Within the lower urinary tract the following muscular structures are described: striated urethral and pelvic floor muscles (Blaivas, 1985) [STRIATED URETHRAL MUSCUL. AND PELVIC FLOOR], the smooth detrusor muscle of the bladder (BLADDER), and the vesical neck and proximal urethra (constituting an internal sphincter mechanism (Blaivas, 1985)) [VESICAL NECK \& PROX. UR.].

Sympathetic connections. Sympathetic bladder afferents are conveyed in the hypogastric nerve to synapse inside the thoracolumbar spinal cord (Blaivas, 1982) [BLADDER $\rightarrow \mathrm{TH}-\mathrm{L}$ ].

The pontine micturition centre connects with the sympathetic vesicomotoneurons inside thoracolumbar spinal cord segments by a descending spinal tract (Blaivas, 1982) [PONTINE MICTUR. CENTRE $\rightarrow$ THL]. Efferent sympathetic axons emanating from 

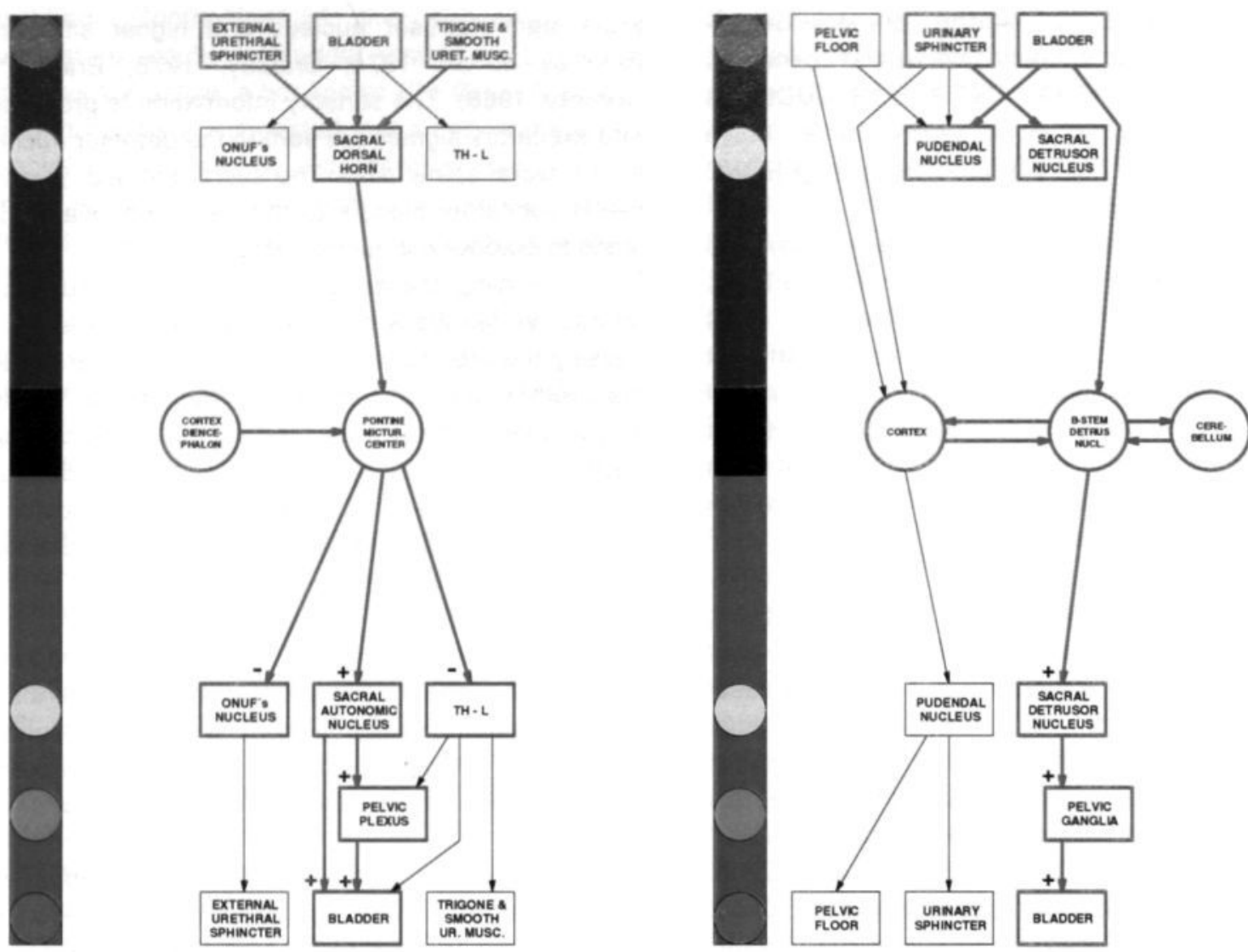

Micturition as described by De Groat et al.

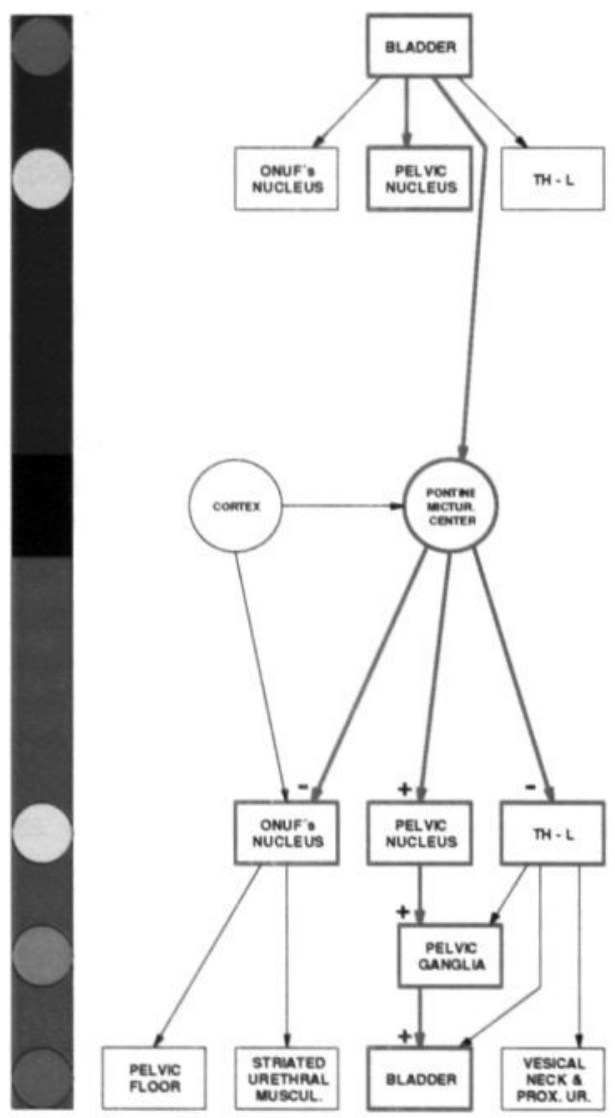

Micturition as described by Blaivas.
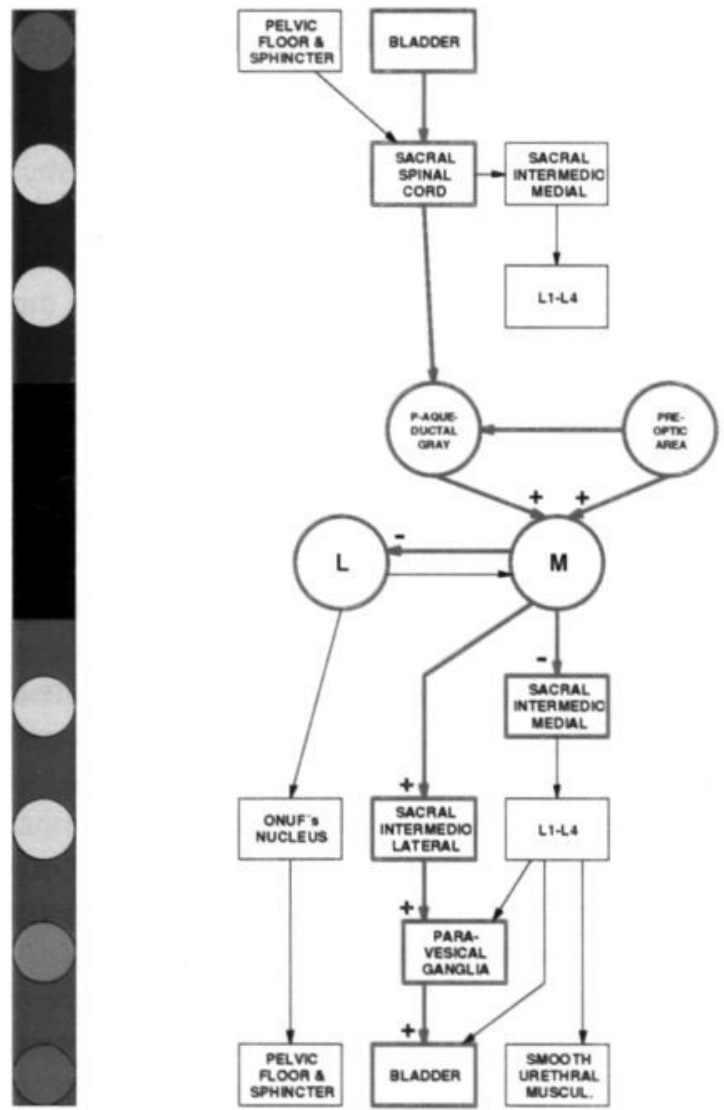

Micturition as described by Holstege et al.

Figure 3: functional mechanisms during micturition as described by De Groat, Bradley, Blaivas, Holstege and associates. 
vesicomotoneurons inside the thoracolumbar spinal cord travel in the hypogastric nerve to innervate the smooth musculature of the proximal urethra and vesical neck [TH-L $\rightarrow$ VESICAL NECK \& PROX. UR.]. The detrusor body and the pelvic ganglia are similarly innervated (Blaivas, 1982, 1985, 1990) [TH-L $\rightarrow$ BLADDER AND TH-L $\rightarrow$ PELVIC GANGLIA]. (Note the lower part of Blaivas' circuitry in Fig. 1).

Somatic connections. Pudendal nerve afferents travel from the pelvic floor and striated urethral musculature to Onuf's nucleus in the anterior horn of the sacral spinal cord, but no function in micturition control is mentioned (Blaivas, 1985, 1990).

Pelvic nerve afferents from the bladder wall connect to Onuf's nucleus (Blaivas, 1982, 1990) [BLADDER $\rightarrow$ ONUF's NUCLEUS].

A corticospinal tract connects the frontal cortex to Onuf's nucleus, which sends efferent pudendal nerve fibres to innervate the external urethral sphincter and the pelvic floor (Blaivas, 1982, 1985) [CORTEX $\rightarrow$ ONUF'S NUCLEUS; ONUF'S NUCLEUS $\rightarrow$ PELVIC FLOOR AND ONUF'S NUCLEUS $\rightarrow$ STRIATED URETHRAL MUSCUL.]. The pontine micturition centre projects to Onuf's nucleus by a descending spinal tract (Blaivas, 1982) [PONTINE MICTUR. CENTRE $\rightarrow$ ONUF's NUCLEUS].

Parasympathetic connections. Tension receptors inside the bladder wall send signals in pelvic nerve afferents that synapse on the pelvic nucleus inside the spinal cord [BLADDER $\rightarrow$ PELVIC NUCLEUS], while other afferents "long route" to the pontine micturition centre (Blaivas, 1982, 1985, 1990) [BLADDER $\rightarrow$ PONTINE MICTUR. CENTRE]. The pelvic nucleus is located in an intermediolateral cell column of spinal cord segments $\mathrm{S}_{2}-\mathrm{S}_{4}$ (Blaivas, 1982 , 1985). Blaivas (1985) notes: "The 'micturition reflex' is integrated in the rostral brain stem in an area designated as the 'pontine micturition centre' which is connected to the 'sacral micturition centre' via spinal pathways in the posterior and lateral columns." We assume (although it is not specifically noted in the cited text), that the pons projects to the pelvic nucleus in the sacral spinal cord [PONTINE MICTUR. CENTRE $\rightarrow$ PELVIC NUCLEUS]. The pelvic nucleus sends preganglionic parasympathetic nerve fibres via the pelvic nerve to the pelvic ganglia [PELVIC NUCLEUS $\rightarrow$ PELVIC GANGLIA]. The postganglionic nerve fibres innervate the bladder (Blaivas, 1982, 1985, 1990) [PELVIC GANGLIA $\rightarrow$ BLADDER].

Supraspinal connections. Blaivas (1982, 1990) notes facilitatory and inhibitory influences of suprapontine brain structures on the pontine micturition centre during the micturition cycle. The influence of higher brain structures is symbolically illustrated by the connection between the cortex and the pontine micturition centre in Fig. 1, because no control mechanisms have been suggested for this purpose [CORTEX $\rightarrow$ PONTINE MICTUR. CENTRE].

\section{Control mechanisms}

Storage (Fig. 2). During the filling phase of the bladder, sympathetic afferents convey signals from the bladder body to neurons inside the thoracolumbar spinal cord. The resulting efferent sympathetic influence on the lower urinary tract is threefold:

1. Closure of the vesical neck and proximal urethra is realized by direct stimulation of a-adrenoceptors present in this region.

2. The transmission of signals from the pre- to postganglionic parasympathetic nerve fibres, which mediate the micturition reflex, is inhibited at a ganglionic level.

3. Stimulation of $B$-adrenoceptors inside the bladder wall results in inhibition of detrusor activity.

Bladder distension produces activity in pelvic nerve afferents, which stimulate, probably via an interneuron, Onuf's nucleus. Stimulation of Onuf's nucleus is responsible for the contraction of the striated urethral and periurethral musculature, the latter being a part of the pelvic floor (Blaivas, 1982, 1985, 1990). Activity in pelvic nerve afferents stimulates the pelvic nucleus inside the sacral spinal cord as well. From here, parasympathetic outflow is mediated through the pelvic nerve and is blocked at a ganglionic level by sympathetic influences (Blaivas, 1990).

Micturition (Fig. 3). Two major reflex pathways are discerned, both of which have an excitatory influence on the detrusor muscle: a brain stem reflex (Blaivas, 1982,1985 ) and a reflex pathway organized on a sacral spinal level (Blaivas, 1985).

The brain stem reflex is responsible for a coordinated micturition and results in normal voiding. Pelvic nerve afferents originating in the bladder send signals to the pontine micturition centre. Descending spinal tracts fulfil two functions, one of which is the inhibition of reflexes underlying the storage function:

1. Inhibition of the sympathetic vesicomotoneurons in thoracolumbar spinal cord segments opens the bladder neck, stops the direct inhibition of the detrusor body and ends the inhibition of parasympathetic efferent activity at a pelvic ganglionic level.

2. Inhibition of Onuf's nucleus activity results in relaxation of the external urethral sphincter. Micturition is initiated by a sudden and complete relaxation of striated urethral and pelvic floor musculature. 
The second function of the descending spinal tracts is the stimulation of the pelvic nucleus, resulting in bladder contraction.

The sacral reflex arc mediates a parasympathetic reflex. Pelvic nerve afferents originating in the bladder synapse in the pelvic nucleus. The signals sent through pelvic nerve efferents are no longer blocked at ganglionic level by a sympathetic influence (Blaivas, 1990).

End of micturition (Fig. 4). To end the micturition phase the cortex stimulates the pudendal nucleus via a direct corticospinal pathway. This results in efferent pudendal nerve activity and consequently in contraction of the striated muscles. The end of micturition is probably a complex neurological event, of which the above reflex is a part. Other control mechanisms have not yet been elucidated (Blaivas, 1982).

\section{The Holstege model}

\section{Circuitry (Fig. 1)}

Musculature of the lower urinary tract. Within the lower urinary tract the following muscular structures are described: the pelvic floor, including the intrinsic external urethral sphincter [PELVIC FLOOR \& SPHINCTER], the bladder, consisting of the smooth detrusor muscle [BLADDER], and smooth musculature of the bladder base and the urethra [SMOOTH URETHRAL MUSCUL.],

Sympathetic connections. A spinal vesicosympathetic reflex is suggested. After entering the sacral spinal cord through the dorsal roots, bladder afferents are thought to synapse on a sacral intermediomedial cell group [BLADDER $\rightarrow$ SACRAL SPINAL CORD $\rightarrow$ SACRAL INTERMEDIOMEDIAL], which in its turn connects with a lumbar mediolateral (sympathetic) cell group (Holstege \& Griffiths, 1990) [SACRAL INTERMEDIOMEDIAL $\rightarrow$ L1-L4]. This suggestion is based on the following considerations: the pontine micturition centre, referred to as the dorsolateral pontine tegmentum (Holstege, 1989; Holstege \& Griffiths, 1990), does not project directly to the lumbar intermediolateral (sympathetic) cell group. Neurons in the dorsolateral pontine tegmentum, medial to the locus coeruleus (M-region), project to the sacral intermediomedial cell group [M $\rightarrow$ SACRAL INTERMEDIOMEDIAL]. The M-region is thought to inhibit the vesicosympathetic reflex during micturition. The sacral intermediomedial cell group is innervated by dorsal root afferents. Therefore, the sacral intermediomedial cell group could be the missing link in the vesicosympathetic reflex pathway (Holstege \& Griffiths, 1990).

Axons of sympathetic vesicomotoneurons, located in the intermediolateral cell group inside the lumbar cord, are carried in the pelvic and the hypogastric nerve. These sympathetic fibres innervate the smooth musculature of the urethra and the bladder base [L1. L4 $\rightarrow$ SMOOTH URETHRAL MUSCUL.], terminate inside the bladder wall [L1-L4 $\rightarrow$ BLADDER] and connect to the paravesical ganglia (Holstege \& Griffiths, 1990) [L1-L4 $\rightarrow$ PARAVESICAL GANGLIA].

Somatic connections. Afferent nerve fibres from the pelvic floor, including the intrinsic external urethral sphincter, enter the sacral spinal cord through the dorsal roots [PELVIC FLOOR \& SPHINCTER $\rightarrow$ SACRAL SPINAL CORD]. The sacral intermediomedial cell group receives dorsal root afferents (Holstege \& Griffiths, 1990), but it is not clear whether afferent fibres from the pelvic floor project to the sacral intermediomedial cell group.

The efferent somatic circuitry origins in a more lateral part of the dorsolateral pontine tegmentum, which is therefore named the L-region (Holstege \& Griffiths, 1990; Griffiths et al., 1990). From the L-region, there is a descending spinal tract to the nucleus of Onuf in the sacral spinal cord (Griffiths et al., 1990) [ $\mathrm{L} \rightarrow$ ONUF's NUCLEUS]. Onuf's nucleus relays to the intrinsic external urethral sphincter and the pelvic floor [ONUF'S NUCLEUS $\rightarrow$ PELVIC FLOOR \& SPHINCTER].

Parasympathetic connections. Bladder afferents enter the sacral spinal cord through the dorsal roots (Holstege \& Griffiths, 1990; Holstege, 1989) [BLADDER $\rightarrow$ SACRAL SPINAL CORD]. A supraspinal bladder to bladder reflex pathway is mentioned, but no complete circuitry has been described (Holstege \& Griffiths, 1990). Information about the degree of bladder filling is conveyed to supraspinal structures, "...but specific sacral projections to the pontine micturition centre have not been demonstrated. On the other hand, neurons in the sacral cord project very strongly to specific portions of the caudal half of the periaqueductal grey (PAG)." (Holstege, 1989) [SACRAL SPINAL CORD $\rightarrow$ P. AQUEDUCTAL GREY]. The periaqueductal grey is a subcortical structure.

The M-region projects to the sacral intermediolateral cell group and to the sacral intermediomedial cell group (Holstege \& Griffiths, 1990) [M $\rightarrow$ SACRAL INTERMEDIOLATERAL AND $M \rightarrow$ SACRAL INTERMEDIOMEDIAL]. Preganglionic parasympathetic neurons, located in the sacral intermediolateral cell group, use the pelvic nerve to innervate the bladder via paravesical ganglia [SACRAL INTERMEDIOLATE- 


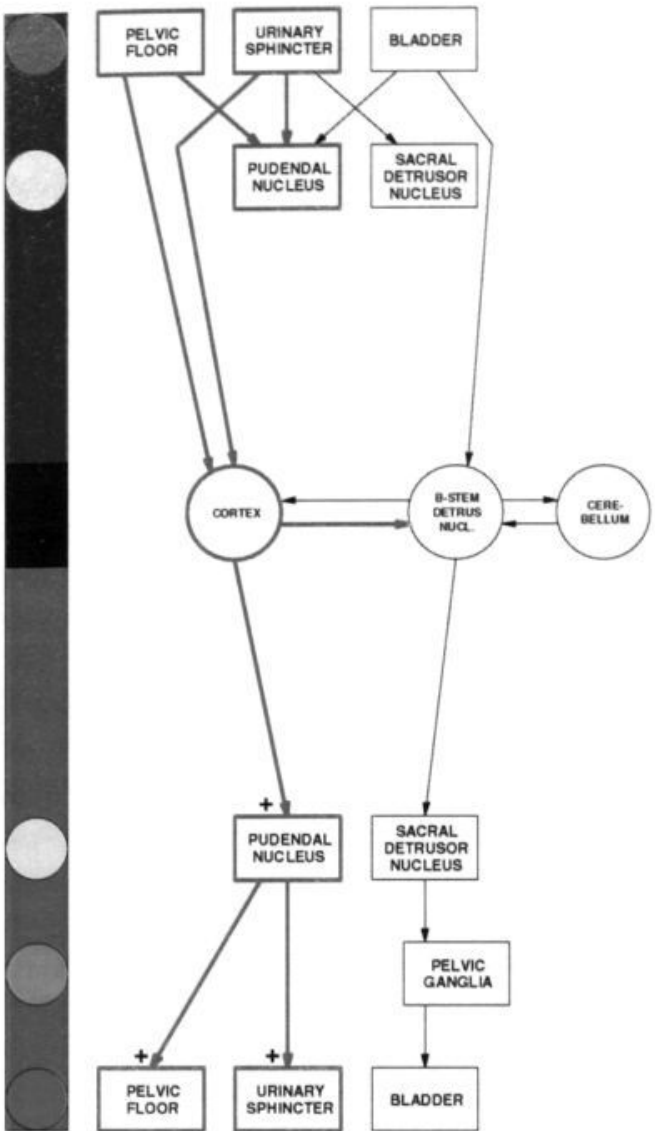

End of micturition as described by Bradley et al.

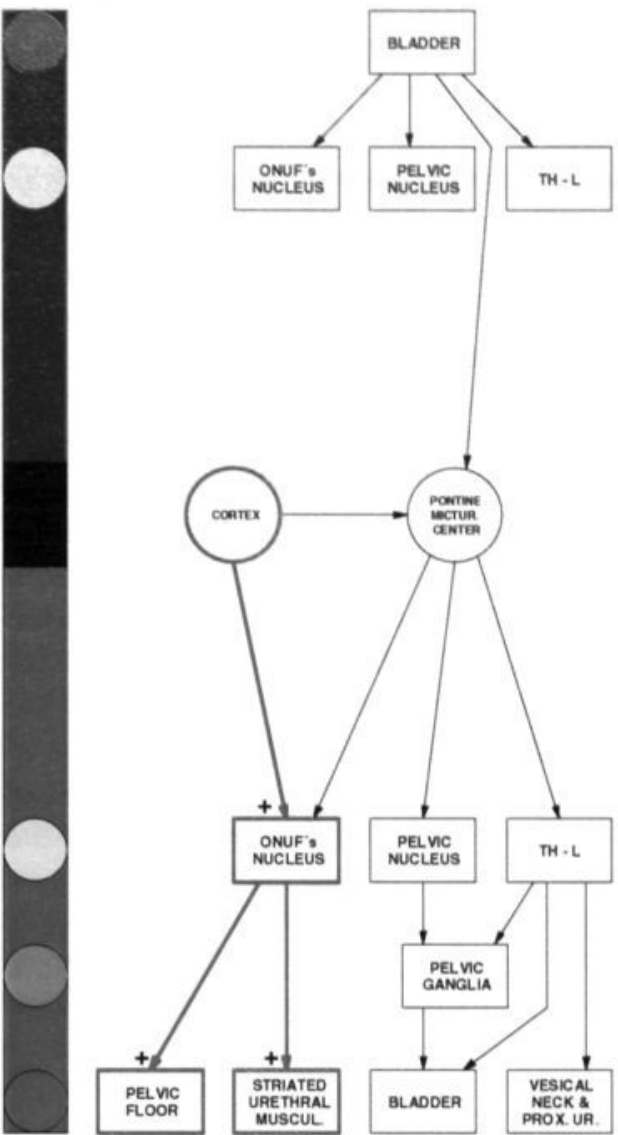

End of micturition as described by Blaivas.

Figure 4: functional mechanisms during the end of micturition as described by Bradley, Blaivas and associates.

RAL $\rightarrow$ PARAVESICAL GANGLIA $\rightarrow$ BLADDER].

Supraspinal connections. In the cat, the preoptic area lying just rostral to the hypothalamus seems to receive no afferent input. Although it is suggested that structures rostral to the pons receive information from the sacral spinal cord, no spinal tract is mentioned (Holstege \& Griffiths, 1990). The output of the preoptic area is aimed towards the periaqueductal grey, a structure inside the mesencephalon, and the $\mathrm{M}$-region of the pons [PREOPTIC AREA $\rightarrow \mathrm{P}$. AQUEDUCTAL GREY AND PREOPTIC AREA $\rightarrow \mathrm{M}$ ]. The periaqueductal grey projects only to the $\mathrm{M}$-region of the pons [P-AQUEDUCTAL GREY $\rightarrow \mathrm{M}$ ]. The Mand L-region of the pons are reciprocally connected (Holstege, 1989) [L $\leftrightarrow M]$.

\section{Control mechanisms}

A mechanism of major importance during the micturition cycle is the reciproke inhibitory effect of the M-region and the L-region on each other, both being regions of the pontine micturition centre (Holstege, 1989). This mutual inhibitory effect awaits further confirmation by physiological and anatomical data.

Storage (Fig. 2). Bladder filling activates the complex spinal vesicosympathetic pathway. Bladder afferents pass their signals through the sacral dorsal roots and synapse on the sacral intermediomedial cell group, which connects to a lumbar intermediolateral (sympathetic) cell group. Efferent sympathetic nerve activity originating in the lumbar cord inhibits bladder activity and stimulates the contraction of the smooth musculature of the urethra and the bladder base, thereby promoting continence. An increase in bladder pressure results in an increase of the sympathetic inhibitory activity, allowing the bladder to collect more fluid. Continuous activity of the L-region excites Onuf's nucleus; urethral closure is supported by contraction of the pelvic floor and intrinsic external urethral sphincter (Holstege \& Griffiths, 1990; Holstege, 1989). Detrusor inhibition might be supported by the presumed inhibitory influence of the L-region on the M-region, although it has not been specifically noted (Holstege, 1989).

Micturition (Fig. 3). Specific projections from neurons 
in the sacral cord to the caudal half of the periaqueductal grey are reported (Holstege, 1989; Holstege \& Griffiths, 1990). It is suggested that information about the condition of the bladder is conveyed to the periaqueductal grey and also to other structures rostral to the pontine micturition centre. The preoptic area and a portion of the periaqueductal grey project to the M-region in the cat. Stimulation of these two structures results in micturition or micturitionlike contractions of the bladder. These areas possibly determine the onset of micturition (Holstege, 1989).

The onset of micturition takes place when the $M$ region increasingly excites the sacral parasympathetic motoneurons, causing bladder contraction. Simultaneously, the L-region, which is partly responsible for the closure of the urethra, is inhibited by the increased activity of the M-region. This results in relaxation of the intrinsic external urethral sphincter and the pelvic floor. The inhibitory influence of the vesicosympathetic reflex is eliminated by the M-region activity. The M-region sends signals to the sacral intermediomedial cell group that forms a part of the vesicosympathetic reflex arc. This opens the bladder neck and stops the inhibition of the detrusor body.

End of Micturition. No circuitry or control mechanisms are mentioned that could be responsible for the termination of voiding.

\section{Discussion}

The differences between the presented theories are discussed, using the same schematic representation as before. The discussion is supported by using the flow charts (Figs. 1-4).

\section{Circuitry (Fig. 1)}

Musculature of the lower urinary tract. All authors discern a smooth detrusor muscle and striated urethral musculature. The smooth muscle sphincter constitutes one functional unit rather than an anatomical one and consists of smooth musculature from the proximal urethra, the trigone and/or the vesical neck. Bradley doubts the function of such a smooth muscle sphincter in promoting continence (Fletcher \& Bradley, 1978).

All authors, except De Groat, discern a role for the pelvic floor musculature in the functioning of the lower urinary tract, but the anatomical interpretation of the pelvic floor musculature varies and remains vague. De Groat mentions periurethral striated musculature in a recent paper briefly (De Groat \& Steers, 1990), but this structure is thought complementary to the external urethral sphincter.

Sympathetic Connections. Two views are presented for the most important sympathetic afferent connections.

1. According to De Groat (De Groat \& Lalley, 1972; De Groat et al., 1979b; De Groat \& Steers, 1990), Bradley (Bradley et al., 1974) and Holstege (Holstege \& Griffiths, 1990), bladder afferents enter the sacral spinal cord and ascend to thoracic and/or lumbar segments. This is the afferent part of an intersegmental spinal vesicosympathetic reflex arc. De Groat (De Groat \& Lalley, 1972; De Groat et al., 1979b; De Groat \& Steers, 1990) and Bradley (Bradley et al., 1974) suggest that the bladder afferents are carried in the pelvic nerve. Holstege suggests that the bladder afferents, which enter in the sacral dorsal horn, connect to a sacral intermediomedial cell group, before they ascend to higher spinal levels (Holstege, 1989; Holstege \& Griffiths, 1990).

2. According to Blaivas, no intersegmental spinal reflex occurs. Bladder afferents directly connect to thoracolumbar spinal cord segments by only the hypogastric nerve.

Afferents from the vesical neck and proximal urethra (Blaivas, 1985, 1990) and from the bladder and urethra (De Groat \& Steers, 1990) are also directly connected to thoracolumbar spinal cord segments by the hypogastric nerve, but no function in micturition control is demonstrated. These connections are therefore not integrated in figs. 1 to 4 .

In De Groat's and Blaivas' opinion, the pons projects to sympathetic vesicomotoneurons, which are located inside the thoracolumbar spinal cord. Holstege denies the existence of a connection between the pons and sympathetic vesicomotoneurons on a (thoraco-) lumbar spinal level. Holstege suggests that pontine structures (the M-region) project to a sacral intermediomedial cell group instead, which takes part in the intersegmental vesicosympathetic circuitry. According to De Groat and Blaivas lower thoracic and higher lumbar spinal cord segments contain vesicosympathetic vesicomotoneurons, whereas Bradley and Holstege suggest lumbar segments only. The sympathetic efferent fibres are conveyed by only the hypogastric nerve, according to Bradley and Blaivas. De Groat and Holstege also include the pelvic nerve in conveying sympathetic fibres to the lower urinary tract. Blaivas and De Groat describe the anatomical course of the hypogastric nerve to the lower urinary tract extensively, but in the description of micturition control, a pure functional design of pathways is applied by them. Sympathetic nerve fibres in all four theories synapse in the 
parasympathetic ganglia. Blaivas specificly notes a (urogenital) short neuron system (Blaivas, 1990). The smooth urethral musculature, bladder base and/or the trigone are innervated by sympathetic nerve fibres. De Groat, Blaivas and Holstege mention sympathetic fibres that innervate $B$-adrenoceptors located inside the bladder wall. Bradley summarizes some sympathetic connections, but does not integrate them in his "loop concept".

Somatic connections. De Groat, Bradley and Blaivas report bladder afferents, which are conveyed by the pelvic nerve to terminate on Onuf's nucleus inside the sacral spinal cord. This connection is based on functional considerations (De Groat \& Steers, 1990) and electrical stimulation experiments with cats (Bradley \& Teague, 1969d).

The pelvic floor musculature (except for De Groat as remarked before) and striated urethral musculature are connected to the sacral spinal cord by pudendal nerve afferents. Once the fibres enter the sacral spinal cord, two different views are present. According to De Groat and Holstege, the afferents synapse somewhere in the dorsal horn. Blaivas and Bradley describe that the afferent fibres terminate on Onuf's nucleus (pudendal nucleus), indicating a myotatic reflex arc. Blaivas notes that this connection has no function in micturition control and it is therefore not integrated in figs. 1 to 4 . Bradley also discerns afferent (somatic) fibres from the urethra, which probably travel to the sacral detrusor nucleus.

The connection between the cortex and Onuf's nucleus inside the sacral spinal cord is a point of discussion. Only Bradley mentions an ascending tract: sensory information from the pelvic floor and urinary sphincter passes cranially in the posterior columns of the spinal cord to finally terminate in the cortex. Bradley and Blaivas discern a direct corticospinal tract involved in guiding Onuf's nucleus, whereas De Groat formulates an indirect corticospinal tract, which synapses in the pontine micturition centre. Blaivas notes, besides a direct corticospinal tract, an additional connection between the pons and Onuf's nucleus. Holstege mentions a similar tract from the Lregion in the pons to Onuf's nucleus. Holstege notes that a direct cortical projection to Onuf's nucleus has not been demonstrated convincingly yet, but he mentions no alternative circuit that could be responsible for the voluntary control of the striated urethral musculature (Holstege, 1989; Holstege \& Griffiths, 1990).

All four authors agree that the peripheral innervation of the striated urethral musculature and, where appropriate, the pelvic floor musculature originates in Onuf's nucleus inside the sacral spinal cord. The striated urethral and pelvic floor musculature is innervated in their view by only the pudendal nerve and not by the pelvic nerve.

Parasympathetic connections. The most essential afferent pathway in micturition control gives rise to discussion. Bladder afferents are noticed which are conveyed by the pelvic nerve to the sacral spinal cord, entering through the dorsal roots. From this point, different opinions are present.

Bradley and Blaivas mark "long-routed" afferents, i.e. afferents which enter the spinal cord, do not synapse, but rather ascend in the spinal cord to terminate in the pontine micturition centre. Blaivas also notes a spinal circuit: a part of the afferent fibres do synapse on the sacral pelvic nucleus, i.e., the sacral intermediolateral cell group. De Groat does not share the view that the afferents are "long-routed" to the pons. In his opinion, the afferents first synapse in the sacral dorsal horn, before they ascend to the pons. Holstege mentions bladder afferents entering the sacral spinal cord in the dorsal horn, but describes no synapses. Holstege remarks that no specific projection from the sacral spinal cord to the pontine micturition centre has been demonstrated yet. Instead, he mentions a connection between the sacral spinal cord and the periaqueductal grey of the cat. Both the periaqueductal grey and the preoptic area project to the pontine micturition centre (M-region).

The efferent parasympathetic circuitry is the same for all four theories. From the pons, a projection is found to the sacral parasympathetic nucleus. This cell group sends parasympathetic preganglionic fibres through the pelvic nerve to synapse on neurons, constituting postganglionic fibres, inside ganglia of the pelvic plexus or inside ganglia, that are located closer to the bladder. In this context, De Groat mentions efferent fibres that originate from the sacral parasympathetic nucleus and terminate in the bladder without synapses in ganglia of the pelvic plexus.

Supraspinal connections. According to De Groat's theory, the cerebral cortex and diencephalon fulfil a function in the voluntary control of micturition. A short review is given in a recent paper, focusing on Holstege's ideas about supraspinal control of the micturition cycle (De Groat \& Steers, 1990). These ideas are not integrated in De Groat's circuitry, but are in this paper dealt with in the description of Holstege's theory. Bradley not only pays attention to cortical structures, but also to the cerebellum. Although cerebellar organization of the micturition reflex is proposed (Bradley et al., 1974; Bradley \& Teague, $1969 \mathrm{a}, \mathrm{c})$, the connections and the functional role of this area during the micturition cycle remain unclear. Blaivas only discerns the cortex as an important supraspinal structure in micturition control, 
besides the pontine micturition centre. Holstege divides the pontine micturition centre in a lateral region (L-region) and medial region (M-region), both with different connections and functions. Holstege also discerns the preoptic area and the periaqueductal grey as supraspinal structures involved in the control of the lower urinary tract in the cat.

In three theories supraspinal structures without incoming connections can be discerned, e.g., the cortex according to De Groat and Blaivas and the preoptic area according to Holstege. Control theory does not allow this isolation: such a system would not work properly. Every muscular structure on the efferent side that is under indirect or direct supraspinal control has to send sensory information on the afferent side to supraspinal structures in order to close the circuit. Although the afferent somatic pathway as proposed by Bradley may be quite exotic from an anatomical point of view, the requirement that somehow information has to be passed to supraspinal structures is met.

\section{Control mechanisms}

Storage (see fig. 2). A high degree of bladder filling is possible due to the existence of several mechanisms which prevent urine to pass the urethra and thus realise continence. De Groat, Blaivas and Holstege report that the sympathetic nervous system has considerable influence during bladder filling. The sympathetic nervous system now employs only spinally organized control mechanisms. The smooth musculature of the proximal urethra, bladder neck and/or trigone is contracted. Inhibition of the parasympathetic neurons, which mediate the micturition reflex, by the sympathetic nervous system at a pelvic ganglionic level is mentioned by $\mathrm{De}$ Groat and Blaivas. Holstege, De Groat and Blaivas note direct inhibitory influence on bladder activity by the stimulation of B-adrenoceptors inside the bladder wall. Holstege also suggests an inhibition of the detrusor muscle by fibres that synapse in the paravesical ganglia of the parasympathetic system. The functional consequences of this synapse are not described.

Bradley describes only the role of the somatic nervous system for promoting continence. There is no internal sphincter (smooth muscle sphincter), trigone or bladder neck mechanism mentioned that could contribute in maintaining continence during the filling phase (Bradley, 1978), although a circular layer of urethral smooth musculature is partly responsible for regulating urethral resistance (Bradley et al., 1974). The proximal urethra is mainly occluded by the inherent tonicity of collagen and elastic fibres (Bradley et al., 1974).

The somatic control mechanisms employed during storage differ. De Groat and Blaivas discern bladder afferents being carried to Onuf's nucleus in the pelvic nerve and being activated during storage. This results in contraction of striated urethral and, where appropriate, pelvic floor musculature on the efferent side (see fig. 2). To fulfil the same motor function Bradley employs pudendal nerve afferents instead, which originate in the urinary sphincter and pelvic floor and project to the pudendal nucleus. Holstege suggests more influence of the pontine micturition centre. Here, the L-region is the most rostral integrative structure during the filling phase. It inhibits the supraspinal M-region and also activates the striated pelvic floor and sphincter muscles.

Termination of guarding reflexes (see fig. 3). Before micturition can fully develop, the sympathetic and somatic guarding reflexes that promote continence during the filling phase of the bladder have to be eliminated in order to realise relaxation of all striated and relevant smooth urethral muscles. According to De Groat, Bradley and Blaivas, bladder afferents send information about the degree of bladder filling to the pontine micturition centre. Holstege describes that this information is being send to the periaqueductal grey first, before it is transferred to the M-region of the pontine micturition centre.

In De Groat's and Blaivas' theories, just before micturition the pontine micturition centre develops an inhibitory influence on vesicomotoneurons inside the thoracolumbar spinal cord and on Onuf's nucleus. De Groat mentions an additional inhibitory influence of the cortical/diencephalic structures on Onuf's nucleus. Holstege claims that the M-region of the pontine micturition centre eliminates the effect of the sympathetic nervous system by inhibition of the sacral intermediomedial cell group. Inhibition of the somatic nervous system happens on a supraspinal level only. The M-region of the pontine micturition centre inhibits the L-region, which controls the pelvic floor musculature and the striated urethral musculature.

Bradley needs to explain the inhibition of only the somatic nervous system. He claims a sacral spinal reflex mechanism, where high-level activity of bladder afferents results in inhibition of the pudendal nucleus and therefore relaxation of the urinary sphincter and pelvic floor shortly before and during micturition (see fig. 3). Note that Bradley uses for this mechanism the same pathways as described by De Groat and Blaivas to explain the contraction of the striated musculature during storage.

Micturition (see fig. 3). Once the pelvic floor and striated urethral musculatures are relaxed and the 
urethra has opened, micturition can fully develop. The pontine micturition centre plays a central role in the development of micturition. The mechanisms presented are principally the same for all theories (see fig. 3). The pontine micturition centre stimulates the parasympathetic motoneurons, located in the sacral spinal cord. The resulting parasympathetic efferent activity stimulates the detrusor to contract.

De Groat and Holstege discern a sacral spinal micturition reflex system, that is functionally nonexistent in humans and animals with an intact neuraxis (De Groat, 1975; De Groat et al., 1979b; De Groat \& Steers, 1990; Holstege, 1989; Holstege \& Griffiths, 1990). Blaivas notes a sacral spinal parasympathetic pathway, of which the activity during the filling phase is inhibited by sympathetic discharges at a ganglionic level. De Groat and Bradley discern a "second reflex wave" initiated by urine flow in the urethra, which reinforces micturition.

End of micturition (see fig. 4). The pathways and the control mechanisms underlying the termination of voiding remain unclear. De Groat and Bradley propose recurrent inhibition of sacral parasympathetic preganglionic neurons as a mechanism, which takes part in the termination of the micturition reflex. However, no anatomical evidence for the existence of recurrent collaterals from sacral parasympathetic fibres, which mediate the micturition reflex, has been found yet.

Bradley and Blaivas formulate a direct corticospinal tract, which makes voluntary control of the pelvic floor and striated urethral musculature possible. By contracting the pelvic floor and striated urethral musculature, an unknown reflex pathway is activated, which results in relaxation of the detrusor muscle. Bradley also notes that the connection between the cortex and the pontine micturition centre is part of a control mechanism to terminate voiding, but no detailed explanation is given.

\section{Conclusion}

The review given in this paper on the anatomy and function of the uropoetic system demonstrates:

1. The proposed reflex arches and supraspinal connections in literature involved in micturition and continence are different and sometimes contradictory.

2. The significance of the sympathetic nervous system during bladder filling in human is a point of discussion.

3. Little is known about how autonomic information of the lower urinary tract is relayed to supraspinal

\section{structures.}

4. Information about supraspinal (inter)connections and their function in micturition control is still fragmentary, e.g., the existence of a direct corticospinal tract to the nucleus of Onuf.

5. Control mechanisms active to terminate voiding are not totally clear.

6. The role of the pelvic floor musculature during the micturition cycle remains vague, but is probably underestimated.

7. A mismatch seems to be present between the neuroanatomical knowledge and the functional description of the micturition cycle.

Future research on the mentioned subjects will be necessary to gain more insight in the micturition cycle and to develop a complete qualitative model, in which present neuro-anatomical knowledge is integrated.

\section{References}

Andersson KE (1986) Clinical relevance of some findings in neuroanatomy and neurophysiology of the lower urinary tract. Clin Sci Suppl 14, vol 70:21-32

Awad SA, Bruce AW, Carro-Ciampi G, Downie JW, Lin M (1974) Distribution of alpha and beta adrenoceptors in human urinary bladder. Br J Pharmacol 50:525-529

Baljet B (1981) The innervation of the abdominal, pelvic and adjoining viscera in the female. Thesis, Amsterdam.

Baljet B, Drukker J (1979) The extrinsic innervation of the pelvic organs in the female rat. Acta Anat 107:241-267

Blaivas JG (1982) The neurophysiology of micturition: a clinical study of 550 patients. J Urol 127:958-963

Blaivas JG (1985) Pathophysiology of lower urinary tract dysfunction. Clin Obstet Gynaecol 12:295-309

Blaivas JG (1990) Mechanisms of micturition. In: Chisholm GD, Fair WR (eds) Scientific Foundations of Urology. 3th Ed. Heinemann Medical Books, Oxford, pp 273-286

Bradley WE (1969a) Micturition reflex amplification. J Urol 101:403-407

Bradley WE (1969b) Regulation of the micturition reflex by negative feedback. J Urol 101:400-407

Bradley WE (1978) Innervation of the male urinary bladder. Urol Clin North Am 5:279-293

Bradley WE, Conway CJ (1966) Bladder representation in the pontine-mesencephalic reticular formation. Exp Neurol 16:237-244

Bradley WE, Teague CT (1968a) The pelvic ganglia. J Urol 100:649-652

Bradley WE, Teague CT (1968b) Spinal cord organization of micturition reflex afferents. Exp Neurol 22:504-516

Bradley WE, Teague CT (1969a) Cerebellar influence on the micturition reflex. ExpNeurol 23:399-411

Bradley WE, Teague CT (1969b) Hypogastric and pelvic nerve activity during the micturition reflex. J Urol 102:438-440

Bradley WE, Teague CT (1969c) Cerebellar regulation of the micturition reflex. J Urol 101:396-399 
Bradley WE, Teague CT (1969d) Spinal cord representation of the peripheral neural pathways of the micturition reflex. $J$ Urol 101:220-223

Bradley WE, Timm GW, Scott FB (1974) Innervation of the detrusor muscle and urethra. Urol Clin North Am 1:3-27

Coote JH, Fleetwood-Walker SM, Gilbey MP, Peterson DF (1982) Possible role of oxytocin, vassopression and the paraventriculospinal pathway in the regulation of sympathetic preganglionic neurons. J Physiol 324:81P

De Groat WC (1975) Nervous control of the urinary bladder of the cat. Brain Res 87:201-211

De Groat WC, Booth AM, Krier J (1979a) Interaction between sacral parasympathetic and lumbar sympathetic inputs to pelvic ganglia. In: McC Brooks $\mathrm{C}$, Koizumi $\mathrm{K}$, Sato A (eds) Integrative Functions of the Autonomic Nervous System, ch 15. Tokyo University Press, Tokyo, pp 234-247

De Groat WC, Booth AM, Krier J, Milne RJ, Morgan C, Nadelhaft I (1979b) Neural control of the urinary bladder and large intestine. In: McC Brooks C, Koizumi K, Sato A (eds) Integrative Functions of the Autonomic Nervous System, ch 4. Tokyo University Press, Tokyo, pp 50-67

De Groat WC, Lalley PM (1972) Reflex firing in the lumbar sympathetic outflow to activation of vesical afferent fibres. J Physiol 226:289-309

De Groat WC, Saum WR (1971) Adrenergic inhibition in mammalian para-sympathetic ganglia. Nature 231:188189

De Groat WC, Steers WD (1990) Autonomic regulation of the urinary bladder and sexual organs. In: Loewy AD \& Spyer KM (eds) Central Regulation of Autonomic Functions. Oxford University Press, New York, pp 310323

Dixon J, Gosling J (1987) Structure and innervation in the human. In: Torrens MJ, Morrison JFB (eds) The Physiology of the Lower Urinary Tract, ch 1. Springer Verlag, London, pp 3-22

Donker PJ (1986) A study of myelinated fibres in the branches of the pelvic plexus. Neurourol Urodynam 5:185-202

Donker PJ, Drőes JTPM, Van Ulder BM (1982) Anatomy of the musculature and innervation of the bladder and urethra. In: Chisholm GD and Williams DI (eds) Scientific Foundations of Urology. Yearbook, Chicago, pp 404-411

Drőes JTPM (1972) De musculatuur van blaas en urethra in de menselijke foetus. Thesis, Leiden University, Leiden

Elbadawi A (1991) Anatomy and innervation of the vesicourethral muscular unit of micturition. In: Krane RJ, Siroky MB (eds) Clinical Neuro-Urology, ch 2. 2nd Ed. Little, Brown \& Company, Boston, pp 5-23

Elbadawi A (1984) Ultrastructure of vesicourethral innervation. II. Postganglionicaxoaxonal synapses in intrinsic innervation of the vesicourethral lissosphincter: a new structural and functional concept in micturition. $J$ Urol 131:781-790

Elbadawi A (1987a) Comparative neuromorphology in animals. In: Torrens MJ, Morrison JFB (eds) The Physiology of the Lower Urinary Tract, ch 2. Springer Verlag, London, pp 23-52

Elbadawi A (1987b) Neuromuscular Mechanisms of Micturition. In: Yalla SV, McGuire EJ, Elbadawi A, Blaivas JG (eds) The Principles and Practice of Neurourology and Urodynamics, ch 1. Macmillan, New York, pp 3-35
Fletcher TF, Bradley WE (1978) Neuroanatomy of the bladder-urethra. J Urol 119:153-160

Fowler CJ, Fowler C (1987) Clinical neurophysiology. In: Torrens MJ, Morrison JFB (eds) The Physiology of the Lower Urinary Tract, ch 4. Springer Verlag, London, pp 89-131

Gosling JA (1985) Structure of the lower urinary tract and pelvic floor. Clin Obstet Gynaecol 12:285-301

Gosling JA, Dixon JS, Humpherson JR (1983) Gross and microscopic anatomy of the urethra, I and II. In: Gosling JA, Dixon JS, Humpherson JR (eds) Functional Anatomy of the Urinary Tract, chs 4 and 5 . Churchill Livingstone, Edingburgh

Griffiths D, Holstege G, Dalm E, De Wall H (1990) Control and coordination of bladder and urethral function in the brain stem of the cat. Neurourol Urodynam 9:63-82

Hald T, Bradley WE (1982a) Neuroanatomy. In Hald T, Bradley WE (eds) "The Urinary Bladder, Neurology and Dynamics." Baltimore/London: William \& Wilkins, ch 2, pp 5-21

Hald T, Bradley WE (1982b) Neurophysiology of the urinary bladder. In Hald T, Bradley WE (eds) "The Urinary Bladder, Neurology and Dynamics." Baltimore/London: William \& Wilkins, ch 3, pp 22-36

Hickey DS, Phillips JI, Hukins DWL (1982) Arrangements of collagen fibrils and muscle fibres in the female urethra and their implications for the control of micturition. $\mathrm{Br} \mathrm{J}$ Urol 54:556-561

Holstege G (1989) Neuronal organization of micturition. In: Lower Urinary Tract Dysfunction: from Cell to Clinical Approach. Micro-symposium. Erasmus University Rotterdam, Rotterdam

Holstege G, Griffiths D (1990) Neuronal organization of micturition. In: Paxinos G (ed) The Human Nervous System. Academic Press, Inc, San Diego e.0., pp 297. 306

Marani E, Pijl MEJ, Kraan MC, Lyckama à Nijeholt GAB, Videleer AC (1993) Interconnections of the upper ventral rami of the human sacral plexus: a reappraisal for dorsal rhizotomy in neurostimulation operations. Neurourol Urodynam 12:585-598

Morrison JFB (1987a) Neural connections between the lower urinary tract and the spinal cord. In: Torrens MJ, Morrison JFB (eds) The Physiology of the Lower Urinary Tract, ch 3. Springer Verlag, London, pp 53-85

Morrison JFB (1987b) Sensations arising from the lower urinary tract. In: Torrens MJ, Morrison JFB (eds) The Physiology of the Lower Urinary Tract, ch 4. Springer Verlag, London, pp 89-131

Morrison JFB (1987c) The functions of efferent nerves to the lower urinary tract. In: Torrens MJ, Morrison JFB (eds) The Physiology of the Lower Urinary Tract, ch 5. Springer Verlag, London, pp 133-159

Morrison JFB (1987d) Reflex control of the lower urinary tract. In: Torrens MJ, Morrison JFB (eds) The Physiology of the Lower Urinary Tract, ch 7. Springer Verlag, London, pp 193-235

Morrison JFB (1987e) Bladder control: role of higher levels of the central nervous system. In: Torrens MJ, Morrison JFB (eds) The Physiology of the Lower Urinary Tract, ch 8. Springer Verlag, London, pp 237-274

Raz S (1978) Pathophysiology of male incontinence. Urol Clin North Am 5:295-304 
Sato A, Sato Y, Schmidt RF (1979) Somatic afferents and their effect on bladder function. In Brooks $\mathrm{CMcC}$, Koizumi $\mathrm{K}$, Sato A (eds) "Integrative Functions of the Autonomic Nervous System." Tokyo: Tokyo University Press, ch 22, pp 309-318

Tanagho EA, Schmidt RA, de Araujo GG (1982) Urinary striated sphincter: What is its nerve supply? Urology 20:415-417

Van Arsdalen K, Wein AJ (1991) Physiology of micturition and continence. In: Krane RJ, Siroky MB (eds) Clinical Neuro-Urology, ch 3. 2nd Ed., Little, Brown and Company, Boston, pp 25-82

Van Ulden BM (1975) De musculatuur van de blaashals an de urethra posterior bij de man. Thesis Leiden University, Leiden

Venema (1988) De klinische betekenis van de instabiele urethra van de vrouw. Thesis, Leiden University, Leiden 


\section{The neuronal control of the lower urinary tract:}

A model of architecture and control mechanisms

CHAPTER 2

Chapter 2 has been accepted on September 17, 1999 as regular article in:

Archives of Physiology and Biochemistry (1999) 107:203-222. 
Matti V. Kinder - Erica H.C. Bastiaanssen

Ruud A. Janknegt - Enrico Marani

\title{
The neuronal control of the lower urinary tract:
}

\section{A model of architecture and control mechanisms}

\begin{abstract}
The human micturition cycle is controlled by central and peripheral nervous structures and connections. In literature, no complete or generally accepted model describes the principles of micturition control. In this paper, the integration of (neuro-)anatomy, (neuro-)physiology and control theory is used to describe and model the neuronal control of the lower urinary tract.

Neuroanatomy supplies the most basic information necessary for the modellation of the peripheral pathways and central connections involved in the control of the uropoetic system. It is found that not all the nervous structures and connections have been identified as such yet. The linking up between several nervous structures (e.g., the presence of central and peripheral relay stations) is not completely clear. As a consequence, each model to describe the micturition cycle from the perspective of control theory is yet of limited physiological value as it can not exceed a rather general level of modellation. Adding functional considerations (neurophysiology and control theory) to the neuroanatomical skeleton completes the model.

Crucial questions on the neuronal innervation of the human uropoetic system and the control mechanisms active during the micturition cycle remain, like how the supraspinal trigger mechanisms for micturition are organised, or how the voluntary cessation of voiding is realised. A simplified version of the model discussed in this paper can already be used for mathematical modelling, e.g., neural network simulations.
\end{abstract}

Key words: Uropoetic System · Innervation · Bladder · Urethra · Pelvic Floor

\author{
M.V. Kinder \\ Faculty of Mechanical Engineering, Eindhoven University of Technology, Eindhoven, The Netherlands \\ M.V. Kinder - R.A. Janknegt \\ Department of Urology, Maastricht University Hospital, Maastricht, The Netherlands \\ E.H.C. Bastiaanssen - E. Marani \\ Neuroregulation Group, Department of Physiology, Leiden University, Leiden, The Netherlands \\ E.H.C. Bastiaanssen \\ Medical Informatics, Medical Faculty, Leiden University, Leiden, The Netherlands.
}




\section{Introduction}

The human system of bladder, urethra and pelvic floor has to satisfy two contradictory needs: its function is to store urine, thereby offering complete continence, while it is also responsible for the controlled evacuation of urine. The co-ordination of these two functions is achieved by the combined action of central and peripheral nervous structures. These nervous structures function as relay stations or controllers and are connected to each other by a network of (supra-) spinal tracts and peripheral pathways.

A complete and detailed review of the central and peripheral nervous structures and connections involved in the control of the lower urinary tract is difficult to provide due to the complex biological situation, the limitations of the research tools available and equivoque anatomical nomenclature used in literature (Kinder et al., 1995).

Within the peripheral connections an obstacle for the study is the broad variability of the pathways present, e.g., the constitution of a peripheral nerve in the cauda equina has recently been shown to contain a greater variability than expected (Mersdorf et al., 1993). This also holds for the sacral ventral rami. After passing the sacral foramina the ventral rami constitute the sacral plexus. Within the sacral plexus the interconnections of the upper ventral rami fluctuate as to interconnections between $\mathrm{S} 1$ and $\mathrm{S} 2$ and between S2 and S3, both for male and female (Marani et al., 1993). Another distorting factor is that the branches of the ventral rami contributing to the pelvic plexus differ greatly, both individually and intersexually (Marani et al., 1993). It is, of course, important to be aware of the wide range of branches, including interconnections between the ventral rami of the sacral nerves, which are involved in the formation of the pelvic plexus, when decisions have to be made concerning the strategy of neuromodulation, neurostimulation and the extent of a dorsal rhizotomy to be performed on bladder stimulation patients.

In human, the possibilities for (neuro-)anatomical and (neuro-)physiological research are limited. The traditional work horses of anatomical research, tract tracing and its staining techniques, can not be applied. The extrapolation of animal data to the human situation is difficult, since in man a voluntary action to uphold micturition is present, which presumably is indicative for a fundamentally different organisation of micturition control.

The relay stations in the pathways between the spinal cord and the target organs are difficult to study. Using acetylcholinesterase in total stainings as used by the former Amsterdam Baljet group (Baljet \& Drukker,
1979; Baljet, 1981) only demonstrates the overall nerve paths, but can not discern the relay stations for micturition. Tract tracing in the peripheral nervous system is seldom reported in literature, with the consequence that convergence and divergence are badly understood in the peripheral innervation of the lower urinary tract.

Tract tracing in the central nervous system may result in very few fibres projecting to specific structures or an abundant and diffuse projection throughout several levels of the spinal cord. Sensory information of the autonomic nervous system for example is known to ascend in the spinal cord via a diffuse neuronal system. This makes the identification of specific connections between two nervous structures difficult. Furthermore, the interconnected cellgroups may each be dense and concentrated in a small and specific area as a so-called nucleus or be diffuse themselves and scattered over a larger area. It is not known how many cells in such a nucleus or how many interconnecting fibres are minimally needed to fulfil a specific task. Moreover, the specificity of various tract tracing techniques is different.

The tools available for the functional evaluation of the nervous system, such as the electrical and chemical stimulation of nervous structures in combination with selective lesions in the central nervous system and the (partly) de-innervation of target organs, are rough when compared to the microscopic complexity of neuro-anatomical architecture. When the functional experiments are limited to a small and simple part of the circuitry, the neuroanatomical pathways and structures involved can be determined more in detail and the match of functional with neuroanatomical data will be more reliable. Nevertheless, it remains difficult in functional evaluations to identify or exclude interference of other connected nervous structures, which do not belong to the specific aim of study.

The pudendal nerve complex causes in its definition confusion. "Two definitions are used: a functional and an anatomical one. The functional one describes the pudendal nerve as the somatic axons of the sacral plexus and includes subsequently the autonomic axons belonging to the pelvic plexus (Jünemann et al., 1988; Tanagho et al., 1982). The anatomical definition, found in classical literature (Cunningham, 1972; Gray 1985; Morris, 1942; Paturet, 1964; Pernkopf, 1941; Piersol, 1930) defines the pudendal nerve as a major trunk originating from the sacral plexus, which leaves the pelvis by the infrapiriformic foramen and enters laterally, via the lesser sciatic foramen, into the ischiorectal fossa."; see Marani et al. (1993).

A first orientation in literature focused on four research groups who integrated central and peripheral 
connections and described the function of these connections in the control of the lower urinary tract. The concepts published by these four research groups were chosen for closer study because they seemed to be most complete. The results of this literature review were rather disappointing: the central and peripheral nervous structures and connections said to be involved in micturition control are different and sometimes contradictory. This also is true for the control mechanisms which are thought responsible for a co-ordinated and successful micturition cycle. On some occasions the control mechanisms proposed were in conflict with neuro-anatomical knowledge or with the principles of control theory (see Kinder et al., 1995).

An explanation for the differences in the concepts of the four research groups, which are named here by their most prominent worker, might be found in the different perspectives used by each of them to approach the subject. De Groat (De Groat, 1975; De Groat et al., 1979b; De Groat \& Steers, 1990) included data from animal experiments to support parts of his description of pathways and their function in human; Bradley (Bradley et al., 1974; Bradley, 1978) employed a functional approach with his "loopconcept"; Blaivas' main article (Blaivas, 1982) is based on a clinical study and Holstege (Holstege, 1989; Holstege \& Griffiths, 1990; Griffiths et al,. 1990) focused on supraspinal nervous structures and connections.

In this paper, an integrative approach using (neuro-) anatomy, (neuro-)physiology and control theory is chosen. The discussion will focus on:

1. the pathways used in the peripheral nervous system to reach the target organs and the linking up of the central nervous system to the peripheral connections;

2. the sacral and thoracolumbar cell groups, their connections to supraspinal nervous structures and the supraspinal interconnections;

3. the function of the peripheral and the central neuroanatomical organisation in micturition control;

4. possible applications of the present results for mathematical modelling, e.g., neural network simulations (Bastiaanssen et al., 1993).

This paper does not concern conflicting data on the structure of the bladder and its neck, nor does it discuss differences between the male and female urethrae.

\section{Methods}

Control theory offers a general approach to describe the control of a process such as the micturition cycle; for an introduction see Kok (1985). The physical situation is examined and a system, which forms a simplification of the real situation, is defined.

The human micturition cycle can be simplified in a first step by a closed loop system as shown in Fig. 1. The process is confined to the storage and the expulsion of urine, which is realised by the co-ordinated contraction and relaxation of several muscle groups, together comprising the lower urinary tract, and the pelvic floor. Sensors, which are mainly stretch receptors, produce information about the condition of the process and send it to the controller. The physical neuronal controller consists of central and peripheral nervous structures, which belong to the sympathetic, parasympathetic and somatic nervous system. The sensory information is processed by these central and peripheral nervous structures, which generate control signals for the musculature of the lower urinary tract. Based on this system definition, the process, musculature, sensors and controller of the lower urinary tract are described more in detail by a qualitative model in the Results section. The major part of this model focuses on the modelling of the neuronal controller. It comprises the architecture and function of the central and peripheral nervous structures and connections known to be involved in the control of the uropoetic system (Kinder et al., 1995).

Finally, the last step implies a simplification of the qualitative model to make it a working concept for mathematical models, e.g., neural network simulations.

\section{Results}

\section{The process}

The process to be modelled is the micturition cycle in healthy adults. The micturition cycle can be divided in three different functional stages: bladder filling voiding and the cessation of voiding. The stage of bladder filling starts when voiding has terminated and ends at the onset of voiding. Voiding is defined as the onset of voiding followed by urine flow out of the urethra that continues, when it is not terminated voluntarily or prematurely, until the bladder has emptied. Termination of voiding brings the micturition cycle from the voiding to the filling stage again. Termination of voiding happens either voluntarily, while the bladder has not emptied completely yet, or involuntarily once the bladder is empty. 


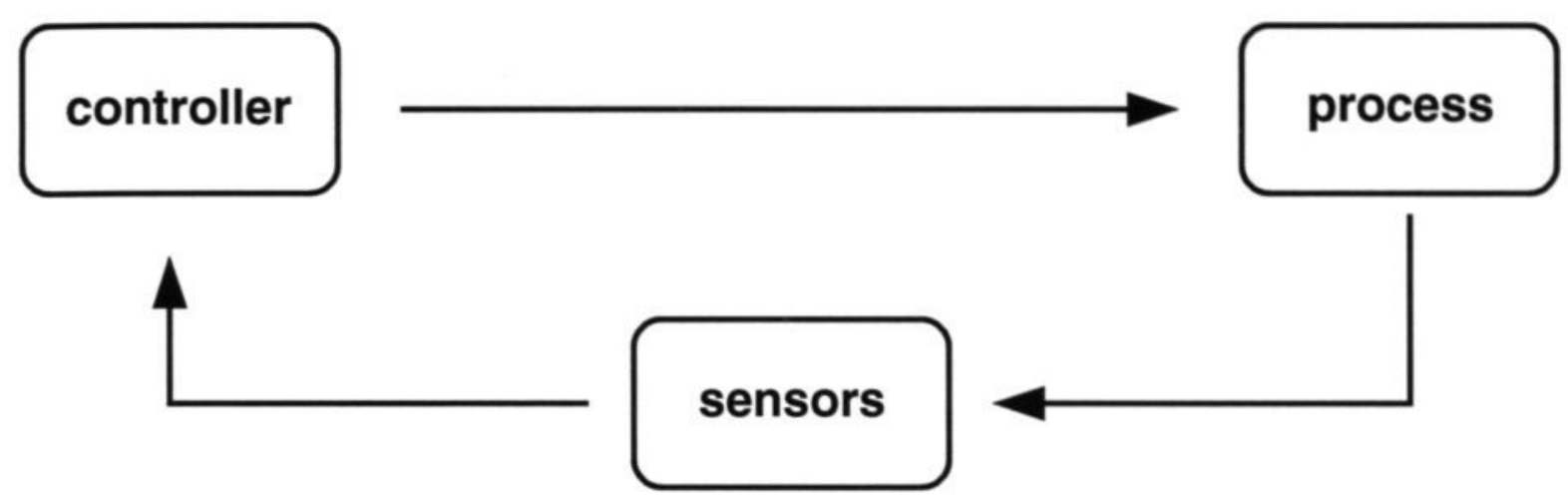

Figure 1: The control of the micturition process is modelled according to the closed loop principle.

\section{The musculature and the sensors of the lower urinary tract}

Functionally, the following muscular structures are discerned: the smooth musculature of the detrusor (including the deep trigonal muscle) [BLADDER]; the smooth musculature of the vesical neck, the superficial trigonal muscle and the smooth musculature of the urethra, which can be seen as one functional unit [SMOOTH URETHRAL MUSCULATURE]; all to the urethra connected striated musculature, i.e., all striated urethral musculature and that part of the pelvic diaphragm, which lies adjacent to the urethra [STRIATED URETHRAL MUSCULATURE]; and the pelvic floor musculature, seen as a from the urethra independent muscular structure [PELVIC FLOOR].

The trigone consists of two muscles: the deep trigonal muscle and the superficial trigonal muscle. The muscle cells of the deep trigonal muscle are indiscernible from those of the detrusor and receive the same autonomic innervation (Dixon \& Gosling, 1987; Gosling, 1985). Therefore, they are functionally integrated with the smooth detrusor muscle.

The sensors located in the organs will not be discussed in this article.

\section{Modelling the controller from a neuro- anatomical perspective}

\section{Introduction to the periphery}

Detailed information about the peripheral connections and relay stations are hard to find in literature. A general scheme for the relay stations for the somatic, parasympathetic and sympathetic systems is given in Fig. 2. From gross anatomy we know that three nerves are available to connect the lower urinary tract to the spinal cord, i.e., the hypogastric, the pelvic and the pudendal nerve. The hypogastric nerve connects the bladder and the smooth urethral musculature to the thoracolumbar spinal cord. The pelvic nerve connects the bladder, the smooth urethral muscula- ture and the striated urethral musculature to the sacral spinal cord. The pelvic nerve as a carrier for nerve fibres between the striated urethral musculature and the spinal cord is a point of discussion in literature. The pudendal nerve carries nerve fibres between the pelvic floor and the sacral spinal cord.

Most publications focus on the efferent fibres that these nerves contain. Not much is known about the afferent nerve fibres coming from the lower urinary tract; they are difficult to study. Lately, the traditional view that afferent nerve fibres coming from the bladder and smooth urethral musculature route without synapse in any peripheral relay station to the spinal cord has been doubted (Morrison, 1987c). The same holds for the traditional two stage organisation of the efferent sympathetic and parasympathetic nerve fibres (Fig. 2) innervating the lower urinary tract. Elbadawi $(1984,1987$ a, b, 1991) postulated the existence and function of a short neuron system. This system consists of juxta- and intramural ganglia, which lie in or on the outer surface of the bladder wall, together with the ganglia of the pelvic plexus. The ganglia of the short neuron system are innervated by either sympathetic nerve fibres, parasympathetic nerve fibres or both (Bradley \& Teague, 1968a). Besides synapses of efferent axons from one autonomic nervous system on dendrites and cell bodies inside ganglia of the other autonomic nervous system, also direct axoaxonal contacts between both autonomic nervous systems have been discerned on the bladder base and proximal urethra (Elbadawi, 1984). The actual autonomic innervation of the lower urinary tract is derived predominantly from the peripheral ganglia adjacent to or within the bladder and urethra.

\section{Afferent view - general nerve routing}

N. hypogastricus is a concentration of lumbar splanchnic nerves and axons derived from the gang- 

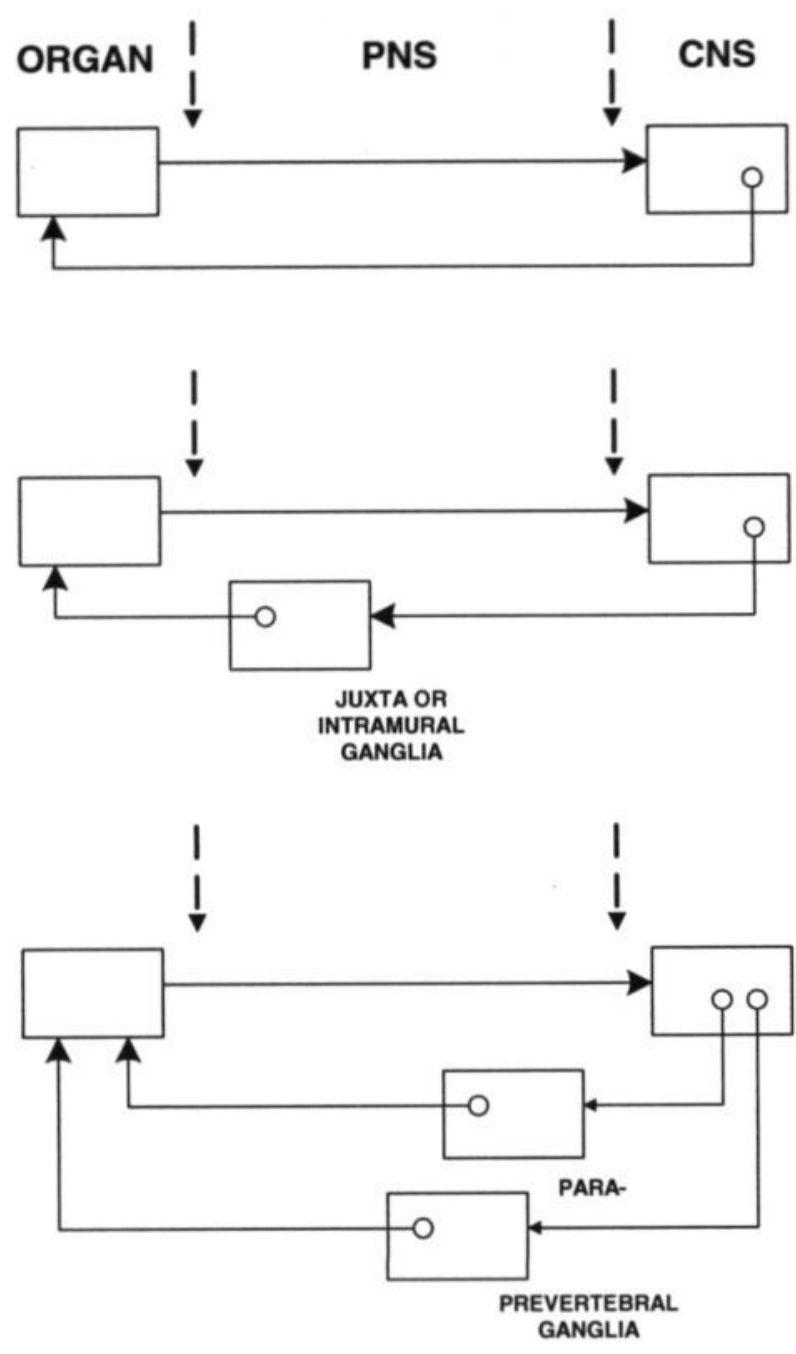

Figure 2: Closed loop control principles applied on the human nervous system. In upper figure panel: Somatic system; middle panel: Parasympathetic system, lower panel: Sympathetic system.

lion hypogastricus superior.

Afferent nerve fibres originating in the bladder and smooth urethral musculature are conveyed by the hypogastric nerve and course through the periphery to the thoracolumbar spinal cord segments. These afferents pass or connect to the juxta- and intramural ganglia, which lie in or on the outer surface of the bladder wall. On this muscular level chemical effects of sensor activity not only produces afferent signal outflow, but also influences the local efferent activity (Elbadawi, 1984, 1987a, b, 1991). Functionally this can be seen as a collection of recurrent (chemically induced) pathways. The afferents continue and synapse in or traverse the pelvic plexus, which is also known as the inferior hypogastric plexus or plexus of Frankenhäuser. Afferent fibres that synapse in the pelvic plexus give rise to extraspinal loops, i.e., some afferent fibres possibly connect to efferent fibres in peripheral structures, do not reach the spinal cord and influence in that way the neuronal control of the lower urinary tract (Bradley \& Teague, 1968a; Elbadawi, 1987b; Morrison, 1987a). The afferents leave the mesh-like area of the pelvic plexus in the left and right hypogastric nerve. Reaching the lumbosacral area anterior to the aorta, both constitute a plexiform nerve arrangement, which is in fact a caudal extension of the superior hypogastric plexus and the sympathetic chain. The afferent fibres course to the hypogastric plexus and synapse or traverse it. Leaving the hypogastric plexus, fibres enter via the grey rami communicantes the sympathetic chain, which consists of interconnected paravertebral ganglia. Now each fiber follows one out of three common pathways before entering the spinal cord:

1. Fibres synapse on the thoracolumbar level of entry in a paravertebral ganglion.

2. Fibres ascend or descend in the sympathetic chain before they synapse in a paravertebral ganglion.

3. Fibres traverse the sympathetic chain without synapsing.

Inside the sympathetic chain fibres may synapse more than once (Pick, 1970). Fibres synapsing in ganglia of the hypogastric plexus or paravertebral ganglia of the sympathetic chain, might give rise to extraspinal circuits (Morrison, 1987c). Leaving the sympathetic chain by the white rami communicantes, the spinal nerves are thought to enter the upper lumbar and lower thoracic spinal cord, presumably being concentrated on levels $\mathrm{Th}_{11}-\mathrm{L}_{2}$ (Van Arsdalen \& Wein, 1991) and might synapse on dorsal column nuclei. Collaterals enter the dorsal horn and connect directly or via interneurons on sympathic vesicomotoneurons (Morrison, 1987a).

N. pelvicus Pelvic afferents from the bladder and urethral musculature pass or connect to the juxta- and intramural ganglia and synapse in or traverse the pelvic plexus. Synapses in the short neuron system give rise to extraspinal loops. Reaching the sacral spinal cord the pelvic nerve fans out in visceral branches of the sacral dorsal roots, which enter the sacral spinal cord and might synapse on dorsal column nuclei. Collaterals enter the dorsal horn and connect directly or via interneurons on motoneurons, see 'spinal connections'.

N. pudendus The pudendal afferents coming from the pelvic floor musculature, the anal sphincter, the transverse perinei and cavernosus muscles, and the urogenital diafragm merge to one single trunk and pass Alcock's canal. The fibres originating from the pelvic floor musculature enter the spinal cord on levels $S_{1}-S_{3}$, but use predominantly $S_{2}$. Using inter- 
neurons or projecting directly they reach the motoneurons on sacral levels, see 'spinal connections'. Collaterals are entering the posterior columns to ascend to the posterior column nuclei.

\section{Afferent routes from the bladder and smooth urethral musculature to the thoracolumbar spinal cord. \\ Afferent nerve fibres emanating from the bladder and the urethra take three routings to reach thoracolumbar cell group in the spinal cord.}

Route I. The first route connecting the bladder and smooth urethral musculature to the thoracolumbar spinal cord is formed by the $n$. hypogastricus (Morrison, 1987b) [BLADDER $\rightarrow$ THORACIC $11-$ LUMBAR 2 and SMOOTH URETHRAL MUSCULATURE $\rightarrow$ THORACIC 11 - LUMBAR 2].

Route II. In the second route, afferent nerve fibres, which are connected to receptors inside the bladder wall and urethra, are conveyed to the sacral spinal cord by the pelvic nerve. The afferents enter the sacral spinal cord and synapse on the sacral intermediomedial cell group (Holstege \& Griffiths, 1990) [BLADDER $\rightarrow$ SACRAL INTERMEDIOMEDIAL CELL GROUP and SMOOTH URETHRAL MUSCULATURE $\rightarrow$ SACRAL INTERMEDIOMEDIAL CELL GROUP]. The intermediomedial cell group is part of a spinal intersegmental tract, which is discerned in cats (De Groat \& Lalley, 1972) and for which a control mechanism is proposed by Holstege \& Griffiths (1990) and by De Groat \& Steers (1990). The sacral intermediomedial cell group presumably projects to the sympathetic vesicomotoneurons inside the thoracolumbar spinal cord (Holstege \& Griffiths, 1990; De Groat \& Lalley, 1972) [SACRAL INTERMEDIOMEDIAL CELL GROUP $\rightarrow$ THORACIC 11 - LUMBAR 2].

Route III. The third route is partly realised by the pelvic nerve and partly by the sympathetic chain (Morisson, 1987a). Afferent nerve fibres are conveyed by the pelvic nerve towards the sacral spinal cord, until the sympathetic chain is approached. Once the pelvic nerve trunks come near the sympathetic chain, some afferent nerve fibres exit, enter the sympathetic chain and ascend to a thoracolumbar level, synapsing once or more on paravertebral ganglia along the way. From here, the connection to thoracolumbar spinal cord segments is made [BLADDER $\rightarrow$ THORACIC 11 - LUMBAR 2; SMOOTH URETHRAL MUSCULATURE $\rightarrow$ THORACIC 11 - LUMBAR 2].

Afferent routes from the bladder and smooth urethral musculature to the sacral spinal cord.

Route IV. The nerve fibres, which connect the bladder and the smooth urethral musculature to the sacral spinal cord, are conveyed in the pelvic nerve. Once the afferents enter the sacral spinal cord, they synapse on the dorsal horn, directly or via interneurons on parasympathetic vesicomotoneurons, which are located in a lateral band of the grey matter (intermediolateral cell group) (Morrison, 1987a; Fletcher \& Bradley, 1978) [BLADDER $\rightarrow$ SACRAL INTERMEDIOLATERAL CELL GROUP].

Route V. Afferent fibres in the pelvic nerve of cats, probably being fibres from tension receptors within the bladder wall, enter the sacral dorsal horn and travel via a medial collateral pathway to the dorsal grey commissure (Morrison, 1987a). At this site in cats contact with specialised somatic motoneurons that innervate the striated urethral musculature is possible (Morrison, 1987c) [BLADDER $\rightarrow$ ONUF's NUCLEUS].

Afferent route from the striated urethral musculature to the sacral spinal cord.

Route VI and Route VII. The nerve supply of striated urethral musculature by afferent and somatic efferent fibres is a point of discussion in literature. Some authors suggest an innervation by the pelvic plexus (Donker, 1986; Gil Vernet, 1964, Gosling et al., 1983, Marani et al., 1993), others favour an innervation by the pudendal nerve (Gray, 1985; Jünemann et al., 1988; Morris, 1942; Tanagho et al., 1982). In our opinion, afferents from the striated urethral musculature and urethral mucosa are carried to the sacral spinal cord in the pelvic nerve. The afferents traverse the ganglia of the short neuron system, but it is not known if they also synapse. The afferents continue their course to the spinal cord and enter on sacral levels $S_{1}-S_{3}$. Directly, or via interneurons, they synapse on Onuf's nucleus, Route VI [STRIATED URETHRAL MUSCULATURE $\rightarrow$ ONUF'S NUCLEUS] and probably on the parasympathetic motoneurons as well (Bradley, 1969a, 1978), Route VII, see 'spinal connections' [STRIATED URETHRAL MUSCULATURE $\rightarrow$ INTERMEDIOLATERAL CELL GROUP]. Onuf's nucleus is believed to be divided in an upper part for the specialised motoneurons of the striated urethral musculature and a lower part for the anal external sphincter.

\section{Afferent route from the pelvic floor to the sacral spinal cord.}

Route VIII. Afferents from the pelvic floor musculature are conveyed by the pudendal nerve to the sacral spinal cord. Near the spinal cord the pudendal nerve splits; the fibres originating from the pelvic floor musculature enter the spinal cord on levels $S_{1}-S_{3}$, but use predominantly $S_{2}$. They connect to sacral spinal cord motoneurons that innervate the pelvic floor [PELVIC FLOOR $\rightarrow$ SACRAL SPINAL CORD MOTONEURONS]. 


\section{Efferent periphery}

\section{Sympathetic connections - from the thoraco- lumbar spinal cord to the bladder and smooth urethral musculature.}

From spinal cord segments $T_{11}-L_{2}$ efferent fibres arise, leave the spinal cord through the ventral roots, split from the spinal nerve via the white rami communicantes and travel to the sympathetic chain (Pick, 1970). Once fibres enter the sympathetic chain, one of three common paths is followed:

1. Fibres synapse on the level of entry in a paravertebral ganglion and leave the sympathetic chain by the grey rami communicantes, which connects to the spinal nerve again.

2. Fibres ascend or descend in the sympathetic chain before they synapse in a paravertebral ganglion. Fibres are able to descend to a sacral level this way (Pick, 1970).

3. Inside the sympathetic chain fibres may synapse more than once. Sympathetic efferent fibres, innervating the lower urinary tract, emanate from the paravertebral ganglia on levels $\mathrm{L}_{3}-\mathrm{S}_{3}$. Fibres coming from the rostral part of the sympathetic chain traverse or synapse once or more in the superior hypogastric plexus, the pelvic plexus, and the juxta- and intramural ganglia, before they terminate on the detrusor muscle and urethra. Fibres originating in a more caudal part of the sympathetic chain are not conveyed to the superior hypogastric plexus, but to the pelvic plexus instead, where they continue their way to the lower urinary tract as described above. Part of these sympathetic fibres are carried in the pelvic nerve.

4. Fibres traverse the sympathetic chain ganglia and synapse within the superior hypogastric plexus (a prevertebral ganglion), the pelvic plexus, both plexi or neither one. They course to innervate the bladder and the urethra as described above.

\section{Route description}

Route 1. Sympathetic outflow can reach bladder and urethra by the hypogastric nerve. Within its course the amount of relay stations in the sympathetic trunk and perhaps via prevertebral sympathetic ganglia is unknown. The hypogastric nerve is considered to innervate bladder, bladder neck and urethra [THORACIC 11 - LUMBAR $2 \rightarrow$ BLADDER; THORACIC 11 - LUMBAR $2 \rightarrow$ SMOOTH URETHRAL MUSCULATURE]. In all the literature, see Pick (1970) for review of older literature, the hypogastric nerve is considered the main contributor for the lower urinary tract.

Route 2. A second route of sympathetic outflow is organised along the pelvic nerve (Morisson, 1987a), innervating both bladder, bladder neck and urethra [THORACIC 11 - LUMBAR $2 \rightarrow$ BLADDER; THORACIC 11 - LUMBAR $2 \rightarrow$ SMOOTH URETHRAL MUSCULATURE]. In man, formally, the nervi erigentes were considered as strict parasympathetic outflow to the pelvic plexus. Whether contributions from the extending lower part of the sympathetic trunk to the pelvic plexus is involved in man is unknown.

Once the sympathetic efferent fibres have reached the bladder and urethra, the following view is generally accepted (Dixon \& Gosling, 1987; Gosling, 1985) sympathetic efferent fibres innervate the smooth musculature of the bladder neck, the urethra and the superficial trigonal muscle. In male this superficial trigonal region receives rich sympathetic innervation (Raz, 1978), which is sparse in female (see '5. Control Mechanisms, Storage'). The detrusor muscle and deep trigonal muscle have the same autonomic innervation, being rich in parasympathetic supply and less abundant in sympathetic supply. Sympathetic efferent fibres could play an inhibitory role in the muscular control of the bladder in humans (Andersson, 1986) and cats (De Groat, 1975).

\section{Parasympathetic connections - from the sacral spinal cord to the bladder and smooth urethral musculature}

Efferent parasympathetic fibres originate in the intermediolateral cell group of spinal cord segments $\mathrm{S}_{2}-\mathrm{S}_{4}$, being concentrated in $\mathrm{S}_{3}$, and are carried in the pelvic nerve. The pelvic nerve conveys mainly parasympathetic fibres. It arises by linking up visceral branches of sacral ventral roots and consists of two to three trunks in the human (Marani et al., 1993). All parasympathetic fibres of the pelvic nerve synapse very near their target organ in the short neuron system for the first time. The fibres synapse in or traverse the pelvic plexus and synapse and/or terminate in the juxta- and intramural ganglia. The smooth detrusor muscle, including the vesical neck and deep trigonal muscle, and the smooth urethral musculature receive rich parasympathetic supply (Dixon \& Gosling, 1987; Gosling, 1985).

A recurrent inhibitory pathway on parasympathetic preganglionic neurons has been suggested, based on electrical stimulation experiments (Bradley, 1969b; De Groat, 1975), but no anatomical evidence seems to be available (Morrison, 1987b).

These parasympathetic connections are summarised as route 3 and are exclusively retained in man to the nervi erigentes or in animals to the nervus pelvicus (Pick, 1970) [SACRAL INTERMEDIOLATERAL CELL GROUP $\rightarrow$ BLADDER]. The amount of relay stations is unknown. 


\section{Somatic connections}

Efferent somatic fibres originate in Onuf's nucleus, which is predominantly located in spinal cord segment $S_{2}$, with extensions to levels $S_{1}$ and $S_{3}$, and another group of sacral spinal cord motoneurons that innervate the pelvic floor. The efferent somatic fibres leave the spinal cord through the corresponding ventral roots and are conveyed to the pelvic floor musculature by the pudendal nerve (Elbadawi, 1987b; Blaivas, 1985; Holstege, 1989) and to the striated urethral musculature by the pelvic nerve (Donker, 1986, Gil Vernet, 1964; Gosling et al., 1983; Marani et al., 1993). The efferent somatic fibres carried in the pudendal nerve converge to one single trunk after they have left the spinal cord. Several branches arise from the pudendal nerve not earlier than after it has passed Alcock's canal. The pudendal nerve with its branches innervates, among other structures, the pelvic floor musculature.

For these connections, two functional routes can be described. Route $\mathbf{4}$ from sacral spinal cord motoneurons to the pelvic floor musculature by the pudendal nerve [SACRAL SPINAL CORD MOTONEURONS $\rightarrow$ PELVIC FLOOR]. Route 5 from Onuf's nucleus to the striated urethral musculature by the pelvic nerve [ONUF's NUCLEUS $\rightarrow$ STRIATED URETHRAL MUSCULATURE].

\section{Spinal connections}

Thoracolumbar spinal connections. The thoracolumbar afferent input from the lower urinary tract to the spinal cord uses two nerves, the $n$. pelvicus and the $n$. hypogastricus, to reach the sympathetic chain. Entering the thoracolumbar spinal cord through the spinal nerves (Route I and III), the afferents reach the dorsal horn to connect on vesicosympathetic motoneurons, an intermediolateral cell group. The afferent input connects, via the dorsal column nuclei, to supraspinal structures as well, see 'supraspinal connections'.

Afferent input that enters the sacral spinal cord connects to the sacral intermediomedial cell group, which presumably projects to the sympathetic vesicomotoneurons inside the thoracolumbar spinal cord (Route II).

Sacral spinal connections - smooth musculature. The sacral input from the bladder, bladder neck and smooth urethral musculature (Route IV and V) will synapse on the sacral dorsal horn using the pelvic nerve. They synapse directly and indirectly on the parasympathetic vesicomotoneurons, an intermediolateral cellgroup, and possibly, in cats, on Onuf's nucleus (Morrison, 1987a, 1987d).

An alternative route is a direct sensory connection from the tension and stretch receptors of bladder wall and urethra over the spinal nerves to the sacral intermediomedial cellgroup (Route II) (Holstege \& Griffiths, 1990). Eventually, this input reaches thoracolumbar sympathetic vesicomotoneurons by an interneuron pathway (Holstege \& Griffiths, 1990; De Groat \& Lalley, 1972). Whether this interneuron system will reach higher spinal or supraspinal levels is unknown.

Thoracolumbar and sacral intermediate grey interneurons are interconnected by the cornumarginal fibres. Interconnections between different spinal cord levels of sensory and motor nuclei involved in the spinal urinary tract coordination are found in most of these nuclei.

Sacral spinal connections - striated musculature. When the afferent fibres coming from the striated urethral musculature (via the pelvic nerve) reach the sacral spinal cord via the dorsal roots, they enter the dorsal horn and terminate mainly near the intermediolateral cell group, where parasympathetic vesicomotoneurons and dendrites of somatic motoneurons are located. The afferents probably synapse directly or via interneurons on both the somatic motoneurons (Fletcher \& Bradley, 1978; Morrison 1987b) (route $\mathrm{VI}$ and VIII) and the parasympathetic motoneurons (Bradley, 1969a, 1978) (Route VII). Evidence for synapses of afferents, arising from the striated urethral musculature, on pelvic vesicomotoneurons has been found in animals, e.g., by HRP-tracing (Morrison, 1987a). In cats, these afferents synapse in the sacral parasympathetic nucleus after they have entered the spinal cord (Bradley \& Teague, 1968b, 1969d). In monkeys pudendal nerve afferents enter the sacral spinal cord and synapse just dorsal to the sacral parasympathetic nucleus, which would be an ideal site to contact interneurons of the micturition reflex pathway (Morrison, 1987a).

The afferent fibres from the pelvic floor enter the dorsal horn and connect to ventral motor anterior horn cells at different sacral levels. These motoneurons innervate the pelvic floor musculature.

\section{Supraspinal connections}

It is beyond doubt that the main neuronal control strategy of the natural alteration of storage and expulsion of urine is organised on the supraspinal level as exemplified by high spinal and suprapontine lesions (Krongrad \& Sotolongo Jr., 1994). However, the comparison of the four leading theories on neuronal control (Kinder et al., 1995) shows them to be different, contradictory and fragmentary. This part on the supraspinal connections regroups evidence on the supraspinal systems. 
Thoracolumbar supraspinal connections (thoracolumbar-bulbar-thoracolumbar). The spinal nerves are thought to enter the upper lumbar and lower thoracic spinal cord, presumably being concentrated on levels $T h_{11}-L_{2}$ (Van Arsdalen \& Wein, 1991). Now two ways are followed:

1. Collaterals enter the dorsal horn and connect, possibly via interneurons, on sympathetic vesicomotoneurons (see before).

2. Ascending fibres connect presumably via the dorsal column nuclei, to the thalamus, which on its turn projects to the cortex (preoptic area), to terminate in the nucleus paraventricularis hypothalami. The by Lakke \& Hinderink (1989) and Lakke (1997) demonstrated existence of a connection between the sympathetic vesicomotoneurons, located at the thoracolumbar intermediolateral cell group, and the paraventricularis nucleus in the hypothalamus in the rat, makes this suggested afferent pathway assured.

The existence of a descending spinal tract, which modulates sympathetic spinal outflow, has been elucidated in functional experiments with cats by cutting the spinal cord on a thoracic level (De Groat \& Lalley, 1972). However, neither the exact starting point in the brain nor the termination site in the spinal cord are known. Lakke \& Hinderink (1989) and Lakke (1997) demonstrated the development and the presence of projections from the hypothalamus (paraventricular hypothalamic nucleus) to thoracic spinal cord segments in rats. Holstege demonstrated, by autoradiography, a descending tract from the medial region of the pontine micturition center (Mregion) to the sacral intermediomedial cell group, which in turn connects to thoracolumbar vesicomotoneurons in a spinal intersegmental tract (Route II) (Holstege \& Griffiths, 1990). Holstege claims the tract from the M-region to the sacral intermediomedial cell group to be identical with the undefined tract found in De Groat's functional experiments. Activity of this tract, from the M-region to the sacral intermediomedial cell group, inhibits sympathetic influence and strongly correlates with activity of the descending micturition tract, which starts in the M-region and ends in the sacral intermediolateral cell group. This is one argument for Holstege to present the intermediomedial cell group as the missing sacral link of an intersegmental vesicosympathetic circuit, which is active during bladder filling. Whether the functional tract found by De Groat coincides with the tract found by Lakke or by Holstege remains to be established.

Efferent sympathetic fibres, innervating the lower urinary tract, presumably originate in the thoracolumbar intermediolateral cell group of spinal cord segments $\mathrm{Th}_{11}-\mathrm{L}_{2}$.
Sacral supraspinal connections (sacral-bulbarsacral). The discussion how information about the degree of bladder filling is conveyed to supraspinal structures is delicate. The "long-routing" of bladder afferents as described by Bradley (Bradley, 1978; Bradley \& Teague, 1969d; Bradley et al., 1974) and Blaivas $(1982,1985,1990)$ seems very unlikely. Holstege denies the existence of an ascending tract between the sacral spinal cord and the pontine micturition center and suggests an indirect projection to higher brain structures (Holstege, 1989; Holstege \& Griffiths 1990).

A descending tract origins in the pontine tegmental field, medial to the locus coeruleus (M-region). The tract connects the $\mathrm{M}$-region to the parasympathetic vesicomotoneurons in the sacral cord (Holstege, 1989; Holstege \& Griffiths 1990) [M $\rightarrow$ SACRAL INTERMEDIOLATERAL]). Lakke et al. (1990) and Oudega et al. (1993) have demonstrated a descending projection of the nucleus tegmentalis laterodorsalis (TLD), located adjacent to the locus coeruleus, to target cells in the $L_{6}-S_{2}$ intermediolateral grey matter in the rat. The pontine nucleus TLD might coincide with Holstege's M-region: it mediates bladder contraction upon electrical stimulation. Holstege and Lakke both demonstrate that not the locus coeruleus constitutes the pontine micturition center, but structures located close to it.

Cortico supraspinal connections (sacral-corticalsacral). The afferent fibres, which are carried in the pelvic and pudendal nerve (routes VI-VIII), enter the sacral spinal cord via the dorsal roots and synapse in the posterior column nuclei, ascend as a spinal tract on the ipsilateral side, cross the mid-line on a higher spinal level and continue to terminate in the thalamus. The thalamus projects to cortical and subcortical structures. Sensations from the urethra and pelvic floor are transmitted (Morrison, 1987b).

The pelvic floor and other striated musculature of the lower urinary tract are under voluntary control, which points out the involvement of a corticospinal tract. A descending tract has been identified, for example by magnetic stimulation of the motor cortex (Ingram, 1982). It is a point of discussion whether this connection consists of a direct projection between the cortex and Onuf's nucleus and the sacral motoneurons, that innervate the pelvic floor, respectively, or an indirect projection with synapses in thalamus, brain stem and probably other structures. However, the corticospinal tract in humans reaches the S2 level (Schoen, 1969). Morrison (1987d) suggests that both, a direct and indirect connection, are present. Research by Iwatsubo et al. (1990) suggests however, that the human nucleus of Onuf has predominantly indirect and virtually no direct corticospinal connections. This 
would indicate a more prominent role for the lateral cell group in the dorsolateral pons (L-region), which projects to Onuf's nucleus, in voluntary control of striated urethral musculature (Holstege, 1989; Holstege \& Griffiths, 1990).

Pontine supraspinal connections. The $\mathrm{M}$ - and Lregion of the pontine reticular formation are supposed to reciprocally inhibit each other (Holstege, 1989; Holstege \& Griffiths, 1990). In a later publication, however, this hypothesis has been abandoned (Blok \& Holstege, 1999). In the cat the M-region is innervated by the preoptic area and the periaqueductal grey (PAG) (Holstege \& Griffiths, 1990).

\section{Model design}

The results obtained in the previous parts show that several anatomical structures, pathways and connections are uncertain and only partially described. As a consequence, each model to describe the micturition cycle in perspective of control theory is yet of limited value as it can not exceed a rather general level of modellation. Anatomical connections and relay stations have to be joined together from the perspective of control theory, while doubted connections should be left out or clearly be indicated as such.

The main two subsystems that can be discerned in the anatomical architecture are the central nervous system and the short neuron system. Wherever present, short neuron systems are thought to be inherent to blocks in the diagrams. Connections between blocks can be relayed via several nerves, i.e., different pathways fulfilling the same functionality are being grouped together. Therefore, arrows in the block diagrams cannot be read as anatomical connections. The underlying basic pattern is given in Figs. 1-2, which is extended in the added scheme Figs. 3-7. Since the model cannot be grouped in one figure, parts are split up.

In Fig. 3A the model is given for the striated urethral musculature and the pelvic floor in its peripheral connections to the sacral spinal cord. Afferents pass directly from the pelvic floor and striated urethral musculature to the sacral spinal cord. The interrelations of interconnections between sensory and motor parts in the sacral spinal cord are extended in Fig. 3B. At this level, the connection to the parasympathetic system is organised.

The somatic efferent connections are direct to the striated urethral musculature and originate exclusively from the nucleus of Onuf as motorcenter. Pelvic floor muscles are innervated by ventral motor anterior horn cells at different sacral levels. The anal sphincter,
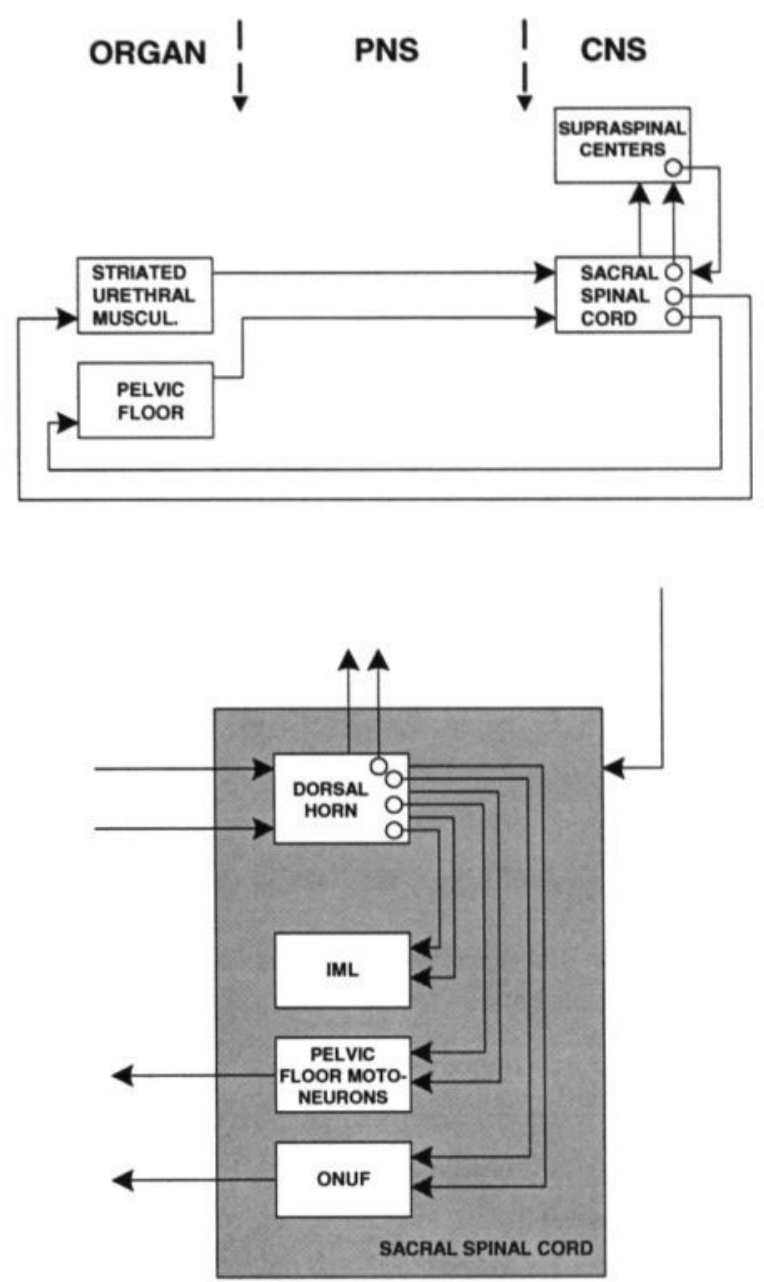

Figure 3:

A) The peripheral connections for the striated urethral musculature and the pelvic floor.

B) Detail of the block 'sacral spinal cord' in (A). It shows the spinal integration of afferent and efferent connections from and to the striated urethral musculature and the pelvic floor. The 'pelvic floor motoneurons' represent the sacral spinal cord motoneurons that innervate the pelvic floor musculature.

which is not included in the model, is innervated by Onuf's nucleus.

Fig. 4 represents the sensibility pathways of the autonomic part. Smooth muscle of the urethra, neck and bladder dome project via the intramural ganglia and the pelvic plexus. A short loop system exists between the intramural ganglia and the smooth muscle of urethra, neck and dome of the bladder. Although doubted in literature, seemingly a series of publications stresses this short loop connection. A somewhat longer short loop system is stressed for the plexus pelvicus output back to the output of the smooth muscles of urethra, bladder neck and dome. By installing the block of the plexus pelvicus in the block of the intramural ganglia, a close relation is 


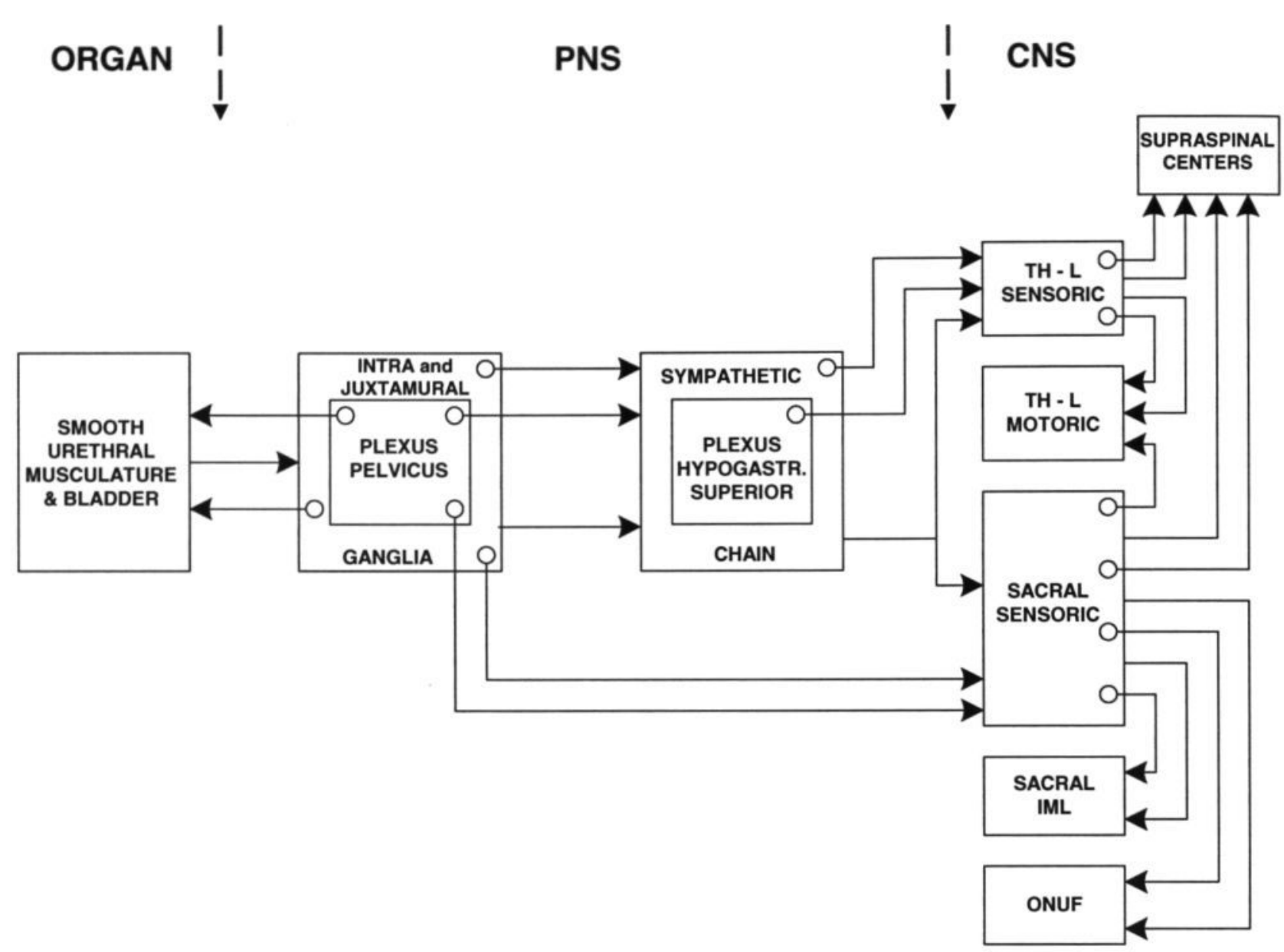

Figure 4: The autonomic peripheral connections from the bladder and smooth urethral musculature to the sacral and thoracolumbar spinal cord. For description, see text.

established between the two short loops. Splitting of the sensibility for sympathetic and parasympathetic occurs after the plexus pelvicus. Parasympathetic routing is directly to the sacral spinal cord, while sympathetic information reaches the plexus hypogastricus and the sympathetic chain before ending in the thoracolumbar spinal cord. Some connections seemingly can be relayed directly from plexus pelvicus to the thoracolumbar spinal cord. In the central nervous system, the sensory thoracolumbar sympathetic areas, see Fig. 4, connect to the motorthoracolumbar areas and connect to higher spinal cord and brain stem centers. The sensory sacral parasympathetic area projects to the motorsacral parasympathetic area (IML) and to Onuf's nuclei. From this sensory center information also reaches higher spinal cord and brain stem centers.

Fig. 5 describes the autonomic motor connections. Starting at the motoneurons in the spinal cord, the thoracolumbar sympathetic vesicomotoneurons connect directly the smooth muscle of urethra and bladder neck or via an integrated connection system between sympathetic chain, plexus hypogastricus superior, plexus pelvicus and intramural ganglia. The motor sacral parasympathetic parts reach the smooth muscle dome via the intramural ganglia and/or pelvic plexus.

Fig. 6. Sacral sensoric and thoracolumbar sensoric information reach a system that is postulated as urocontrol and which is responsible for influencing directly the thoracolumbar area, steering the $\mathrm{M}$ region, and relaying information to cortical structures. The urocontrol, the L-region and the sacral motoneurons that innervate the pelvic floor receive cortical input. There is no reciproque relation between $\mathrm{M}$ - and L-region modelled.

The anatomical substrate that urocontrol represents is a point of discussion in literature. This discussion does not provide adequate control strategies yet. For the time being, urocontrol contributes the minimal control strategy to the model that is needed to realise a succesfull micturition cycle. 


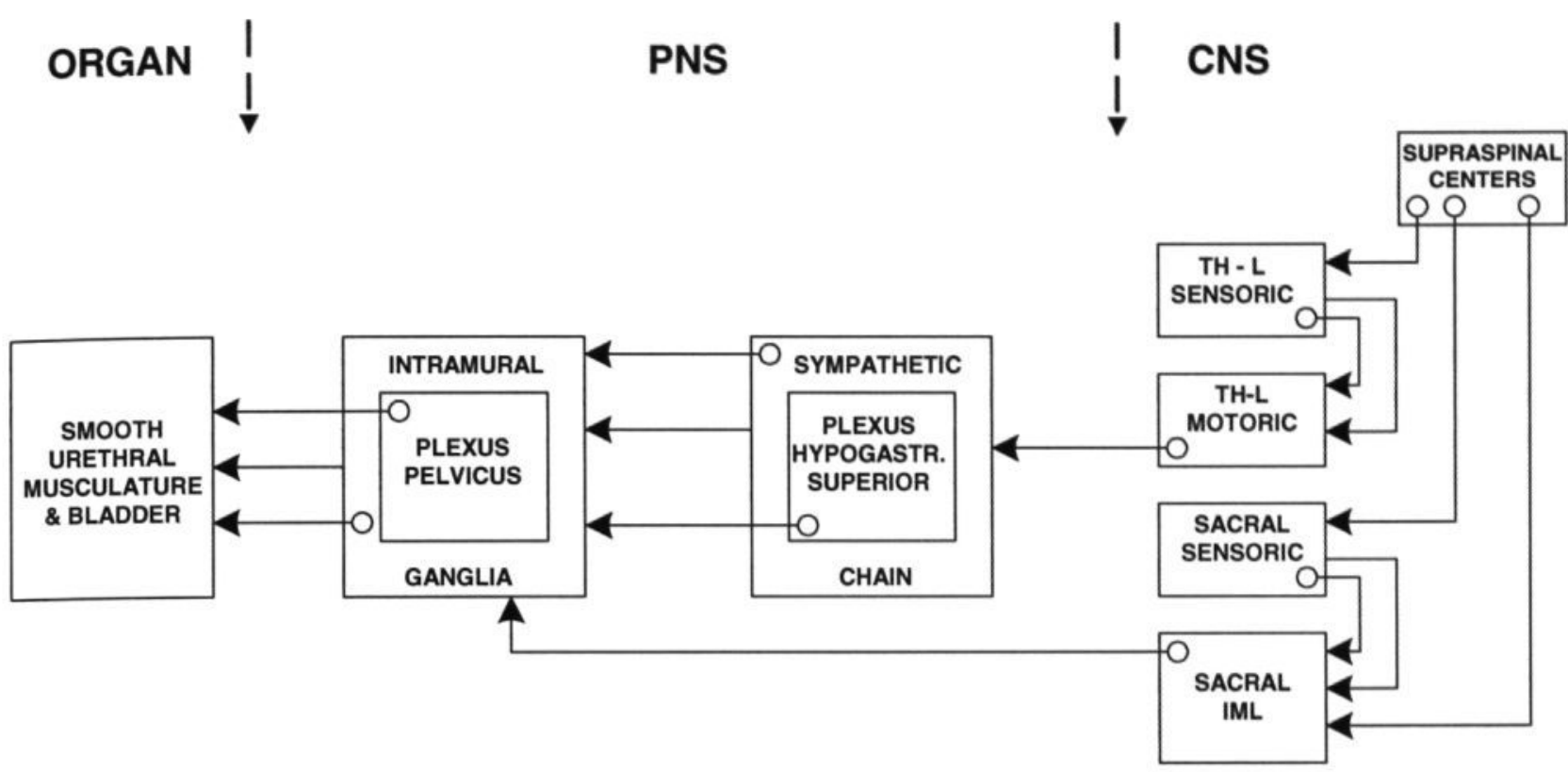

Figure 5: The autonomic peripheral connections from the sacral and thoracolumbar spinal cord to the bladder and smooth urethral musculature. For description, see text.

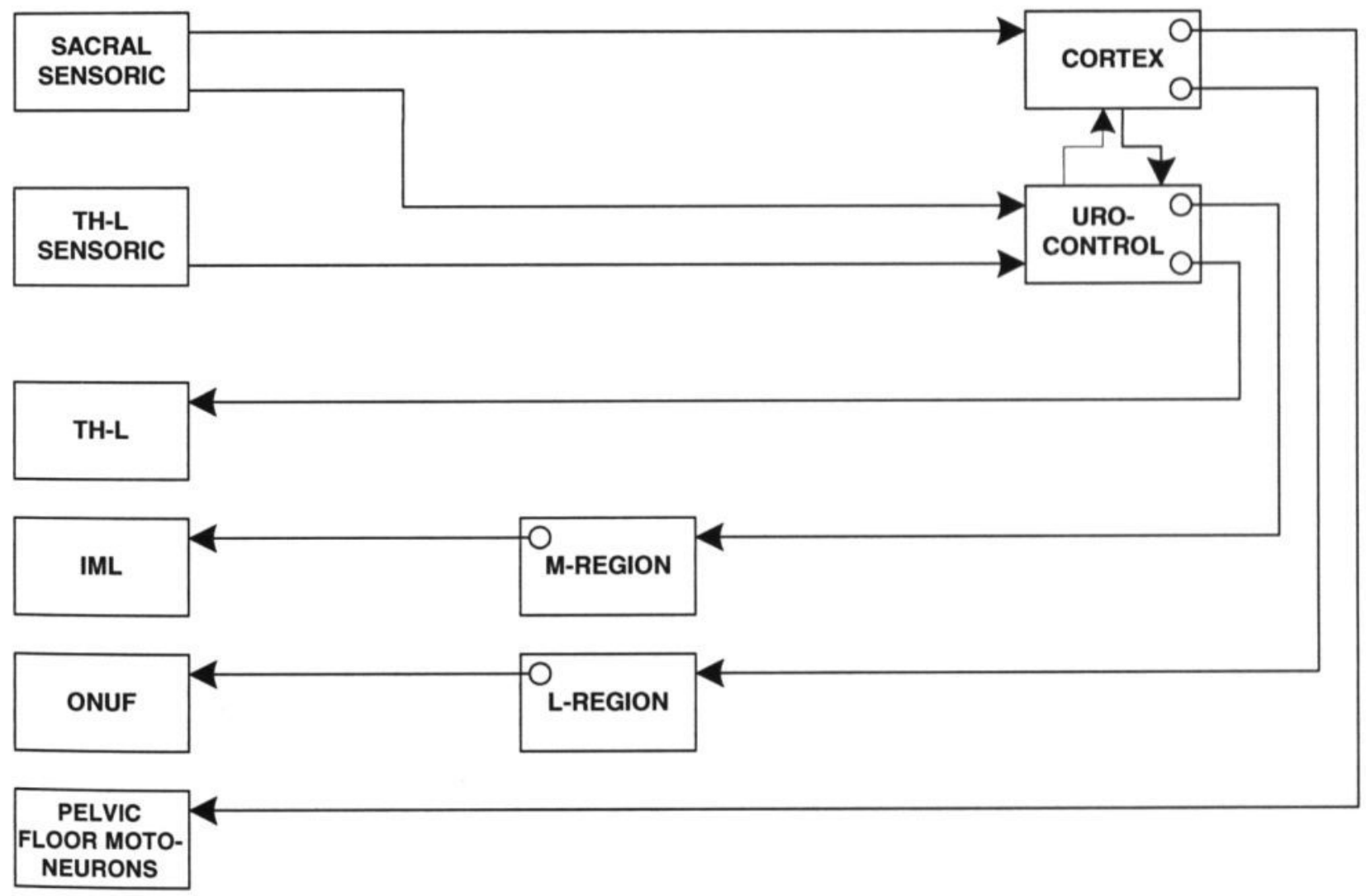

Figure 6: Spinal and supraspinal integration, and supraspinal control. The block 'urocontrol' is postulated to serve the control of the micturition cycle. It's anatomical substrate is a point of discussion in literature. This discussion does not provide adequate control strategies yet. The urocontrol contributes the minimal control strategy needed to realise a successful micturition cycle. 


\section{Control mechanisms}

The best known reflex is the guarding reflex (Park et al., 1997). During filling of the bladder a spinal mechanism is at work, which will be transferred to a supraspinal mechanism at high filling levels. At low levels of bladder filling humans are not aware of this reflex. At higher levels awareness of the filled bladder and voiding desire is present. In humans, therefore, unaware spinal reflexes can be changed to awareness by a still unknown mechanism of direct supraspinal control.

In paraplegia the supraspinal control is absent, which means that bladder filling is purely organised by the spinal reflex.

To describe the various stages of spinal reflexes, such as the guarding reflex, during storage, micturition and the ending of the micturition, subsequently, for each stage the sympathetic, parasympathetic and somatic steering is considered.

\section{Storage}

During the filling phase of the bladder a vesicosympathetic reflex and a somatic reflex act as guarding reflexes, thus promoting continence (Bradley et al., 1974; Bradley, 1978; De Groat \& Steers, 1990; Holstege \& Griffiths, 1990).

In case of the vesicosympathetic reflex, bladder and urethral afferents of both the pelvic and hypogastric nerve send signals to the thoracolumbar (sympathetic) intermediolateral cell group. Pelvic nerve afferents use a spinal intersegmental tract, where fibres synapse in the dorsal horn of the sacral spinal cord and connect to ascending fibres that project to the thoracolumbar intermediolateral cell group (De Groat \& Lalley, 1972; De Groat \& Steers, 1990; Holstege \& Griffiths, 1990).

Hypogastric nerve afferents synapse in thoracolumbar spinal cord segments (Fletcher \& Bradley, 1978; Morrison, 1987a). Here they probably project to the intermediolateral cell group. According to four authors reviewed (Kinder et al., 1995) these sympathetic afferent fibres do not contribute to micturition control. With the rather complex and badly understood afferent sympathetic circuitry, the possible extraspinal pathways and the spinal tract from thoracolumbar spinal cord segments to the paraventricularis nucleus in the hypothalamus in mind (Lakke \& Hinderink, 1989; Lakke, 1997), it seems very unlikely though that these fibres have no function in micturition control. The exact role of these hypogastric afferents in the control of the lower urinary tract remains to be established, but they appear to transmit information about the degree of bladder filling (Morrison, 1987b). Efferent sympathetic neurons inside the thoracolumbar cord are excited by the described two active afferent pathways. The effects are fourfold:

1. In all ganglia where the sympathetic nervous system meets the parasympathetic nervous system, the latter is inhibited (De Groat et al., 1979a, b; De Groat, 1975). The short neuron system is under sympathetic control and transmission of parasympathetic excitatory signals is inhibited at a ganglionic level (De Groat et al., 1979a, b; De Groat, 1975; De Groat \& Saum, 1971) and probably also by direct axoaxonal contacts (Elbadawi, 1984).

2. The detrusor activity is inhibited by receptors inside the bladder wall (De Groat, 1975, cats).

3. A smooth muscle sphincter mechanism is activated. Smooth urethral musculature, the trigone and the vesical neck are brought under tension (De Groat et al., 1979b; Elbadawi, 1984; Mattiasson et al., 1984). Elbadawi introduced for this purpose the functional concept of a lissosphincter, constituting of smooth musculature from the bladder base, proximal urethra and a periureteral sheath component (1987a, b, 1991).

4. The vascular bed of the mucosa is affected (Fletcher \& Bradley, 1978).

These effects are present in animals under unphysiological conditions. The importance of either these elements under more physiological conditions in the human remains unclear.

In case of the somatic reflex, afferents from the striated urethral musculature and from the pelvic floor musculature send signals to Onuf's nucleus and sacral motoneurons respectively. Collateral somatic afferents relay information to the cortex. Possibly by both a spinal and a supraspinal circuit the sacral motoneurons bring the striated urethral musculature and the pelvic floor musculature under strain. The supraspinal influence on the striated urethral musculature comes from the L-region that is thought to continuously excite Onuf's nucleus. The pelvic floor, being innervated by ventral motoneurons, is modelled under direct cortical control.

Bladder afferents enter the sacral spinal cord and connect to Onuf's nucleus (Morrison, 1987a). This circuitry might be active during storage to excite the striated sphincters or it might be active when micturition is about to happen to inhibit Onuf's nucleus, resulting in relaxation of the striated sphincters. Until either function has been demonstrated convincingly, in our opinion it might be functionally non-existent in human.

The pelvic floor contributes to urethral closure by contraction of striated muscle fibres adjacent to the urethra, especially when a sudden rise in abdominal pressure as during coughing or sneezing appears (Fowler \& Fowler, 1987). The importance of the pelvic 
floor as a from the urethra separated muscular structure in the micturition cycle however, is often underestimated or not recognised. Clinical evidence in the treatment of refractory detrusor instability and stress urinary incontinence by neurostimulation and neuromodulation suggests that the pelvic floor as a whole has considerable effect on micturition control (Dijkema et al., 1992; Fall, 1984, Schmidt \& Tanagho 1990; Siegel, 1992; Tanagho et al., 1989; Thon et al., 1991). Both contraction and relaxation of the pelvic floor probably activate several unknown control mechanisms, which affects the bladder stability during storage (Mayo, 1978) and both the initiation and termination phase of voiding. Besides neuronal effects of the pelvic floor, structural influence is present too. The pelvic floor contributes to a correct bladder-to-urethra position during the filling phase, thereby facilitating the closure of the proximal urethra. The anatomical differences in male and female urethra (Awad \& Downie, 1976; Dixon \& Gosling, 1987; Droes, 1972) have their effect on functioning. In contrast with the rich sympathetic innervation of the bladder neck, superficial trigonal muscle and proximal urethra in male human subjects, in female subjects this sympathetic innervation is less abundant (Dixon \& Gosling, 1987; Venema, 1988). Moreover a smooth muscle sphincter can be difficult discerned in female subjects: smooth urethral muscle fibres have a predominant longitudinal orientation throughout the whole urethra and circular or helical orientated fibres are sparse (Gosling, 1985; Hickey et al., 1982). This seems contradictory with the control mechanisms that promote continence during bladder filling by contraction of smooth musculature from the vesical neck, superficial trigone, proximal urethra and more caudal parts of the urethra. However the same control mechanisms contribute to the closure of the urethra and vesical neck in male and female, but the impact of the occurring mechanisms vary intersexually (Awad \& Downie, 1976; Venema 1988).

The material characteristics of the urethral tissue contribute considerably in the closure of the urethra during bladder filling. In this paper only contributions of muscular tissues in the closure of the vesical neck and urethra are discussed.

\section{Micturition}

Critical bladder distension produces high-level firing of bladder (parasympathetic and sympathetic) afferents. The parasympathetic and probably sympathetic bladder afferents that are carried in the pelvic and hypogastric nerve send their signals to the thalamus [UROCONTROL], from where the cortical (possibly the preoptic area in the cat) [CORTEX] and subcortical structures (possibly the nucleus paraventricularis in the hypothalamus and the periaqueductal grey) [UROCONTROL] are stimulated. These suprapontine structures, the cortex, the periaqueductal grey and the nucleus paraventricularis might determine the onset of micturition [CORTEX \& UROCONTROL]. The paraventricular hypothalamic nucleus ([UROCONTROL] probably inhibits the sympathetic vesicomotoneurons inside the spinal cord (Coote et al., 1982), which results in the opening of the bladder neck and urethra, the termination of inhibitory influence on the detrusor muscle and the end of the sympathetic control of the urogenital short neuron system. The cortex indirectly inhibits the nucleus of Onuf and directly the sacral ventral motoneurons that innervate the pelvic floor, resulting in a starting relaxation of the pelvic floor and striated urethral musculature. Both, cortex and periaqueductal grey [CORTEX \& UROCONTROL], stimulate the $M$ region in the pontine tegmental field. The $\mathrm{M}$-region excites the sacral parasympathetic intermediolaterally located motoneurons. This results in parasympathetic control of the urogenital short neuron system, finally leading to detrusor contraction (Holstege, 1989; Holstege \& Griffiths, 1990; Van Arsdalen \& Wein, 1991; Elbadawi, 1984, 1986, 1991). Micturition reflex duration and amplification in cats is realised by central and peripheral control structures. The continual afferent discharge of tension receptors during micturition remains a stimulus for bladder contraction. Centrally, the brain stem reticular formation and the sacral parasympathetic nuclei both endure and amplify the micturition reflex (Bradley, 1969a; De Groat, 1975). Peripherally, the ganglia of the short neuron system, especially the pelvic ganglia inside the pelvic plexus, amplify and elongate the micturition reflex (Bradley, 1969a; Bradley \& Teague, 1968a; De Groat, 1975; De Groat et al., 1979b). In unphysiological conditions, an output of these ganglia can be measured, several minutes after the input has fainted. These ganglia play an essential role in the control of the lower urinary tract, both during storage and micturition. A high pass filter behaviour has been noted, i.e., low-level parasympathetic input does not pass, while repetitive high level input results in a stronger gain (De Groat, 1975; Morrison, 1987b).

The connection between somatic afferent fibres and parasympathetic vesicomoto-neurons (Morrison, 1987a) is supposed to start a second reflex wave as noted by De Groat and Bradley (De Groat et al., 1979b; De Groat \& Steers, 1990; Bradley \& Teague, 1968b; Bradley, 1978). De Groat and Bradley suggest that this reflex reinforces detrusor contraction and is activated by urine flow in the urethra. This reflex is known to be present in animals (Bradley \& Teague, 1968b; Elbadawi, 1991; Morrison, 1987c), but urodynamic measurements in human do not show such a second reflex wave (Griffiths, 1987; Torrens, 
1987a), indicating that if it does exist, the effects are neglectable.

\section{End of micturition}

The end of the micturition reflex remains to be clarified. The striated musculature, that can be contracted voluntary, plays an important role. Corticospinal tracts influence i) Onuf's nucleus via the L-region indirectly, ii) the sacral motoneurons, that innervate the pelvic floor, directly, and, thereby, are able to contract the striated urethral and pelvic floor musculature. This must activate an unidentified reflex arc, which inhibits and terminates further contraction of the detrusor (Blaivas, 1982; De Groat \& Steers, 1990). However, the central organisation remains unclear.

\section{Applications}

Based on the experimental data as described in the paper, a neural network to simulate neuronal control of the urinary bladder has been designed.

\section{Neural network}

To understand the principles underlying information processing in the complex neuronal system for the control of the lower urinary tract, mathematical modelling might be useful. One approach to this problem is the application of techniques from artificial neural networks. Several neural networks have been developed to describe parts of the nervous system of invertebrates (for example Getting, 1989). The neurons in these networks are modelled as electronic circuits like the description by Hodgkin and Huxley (1952). The electrical membrane potential during time can be calculated and compared with electrophysiological measurements. This approach is not applicable to the human nervous system underlying the control of the lower urinary tract: too many neurons are involved and electrophysiological measurements from individual cells is extreme difficult. However, many details of single nerve cells may be unimportant for an understanding of the collective behaviour of a network of cells (Hertz et al., 1991). In physiological nervous systems, features can be recognised (like transmission of signals by threshold units, associative memory, excitatory and inhibitory connections, etc.), which can be modelled in a simplified way in artificial neural networks. Computer simulations of neural networks can be used to predict the behaviour of a neural control system under normal and pathological circumstances (for example the effect of broken connections).

A neural control model for the urinary bladder based on the qualitative model of Holstege, has been developed (Bastiaanssen et al., 1993). The main structures are the nucleus of Onuf, the parasympathetic motoneurons, the sympathetic motoneurons, the intermediomedial cell group in the sacral spinal cord, the micturition centre in the brain stem and the preoptic area in the cortex. It would be too complicated to include all anatomical structures and their connections involved in the control of the lower urinary tract. Therefore, only the most important relay stations in the qualitative model were represented as layers in the neural network, whereas the urethral sphincter and its innervation were initially excluded. The neural pathways are represented as connections between the neurons in the different layers. The fire frequencies of the inhibitory and excitatory motoneurons are the inputs for the mechanical bladder model. The mechanical aspects of the bladder, like the development of tension and pressure, and the flow of urine are described in the bladder model. The output of a sensor in the bladder wall, which is described as the non-linear response to the strain in the wall, feeds back into the neural network.

For the control of the urinary bladder, the fire frequencies of the motoneurons seem to be of more interest than the precise potential fluctuations. The fire frequency of an individual neuron is influenced by its current fire frequency and the incoming excitatory and inhibitory inputs from neurons of previous layers. Dependent on the importance of the connections between different neurons, the weighted sum of all input signals is determined. The response on the weighted sum of inputs can be described by an activation function. For this activation function is a sigmoid (the fire frequency is close to maximal if the sum exceeds a certain threshold, almost zero if the sum is low and somewhere between these values if the sum is near the threshold) is chosen. The neurons can have different time constants, representing slow and fast responding cells. The fire frequency of the neuron will change rapidly as a result of a change in the incoming signals if its time constant is small. In contrast, a slow neuron (with a large time) constant will show a more moderate and lasting response on a change in input. The parameters in the neural network are the time constants and the weights of the connections. The optimal values of these parameters are searched during the learning phase of the neural network. After the learning phase, the trained network shows a behaviour as close as possible to the desired behaviour. In this particularly case, the neural network can control the bladder model to mimic a prescribed filling and emptying behaviour.

In this way, transmission of signals by slow and fast responding threshold units with excitatory and inhibitory connections can be modelled in a quantitative model based on a qualitative description. 
Such a description of neural network simulations can be helpful to understand the collective behaviour of the neural system underlying the control of the lower urinary tract.

\section{Discussion}

This discussion is organised along the lines of the results for the short neuron reflex, spinal cord related reflexes and the steering of the supraspinal controller and a general paragraph on the targeting of future research.

\section{Short neuron reflex systems}

The second motor neuron in the parasympathetic system is localised in or directly at the outside of the organ, having an intra- or juxtamural position.

The second motor neuron in the sympathetic chain is localised aside of the vertebral column or in front of it possessing a paravertebral or a prevertabral position. Other ganglia, localised between the spinal cord and the organ at a further distance from the organ are known, for example, the pelvic plexus.

A short neuron system has been proposed by Elbadawi (1991) in which bladder steering could be performed partially in the periphery. Steering loops are present between parasympathetic juxta or intramural ganglia and sympathetic pre- or paravertebral ganglia. These steering loops can be small, say at the organ level or longer, if ganglia at distance are involved.

The matter is disputed, although sympathetic axon endings are found on the parasympathetic ganglia and vice-versa. It is also unknown, whether this short neuron system has a steering or a stabilisation, say modulation, function. However one thing is clear, if present the system is involuntary and the system should be called a short neuron reflex system.

Although in women a uterocervical reflex as a short neuron reflex system has been described, in which upon slow uterine distention cervical pressure increases and uterine pressure shows small to insignificant changes, rapid distension in this reflex leads to cervical pressure decrease and an increase of uterine pressure, such a functional description lacks for detrusor, trigone and urethra. Anatomical descriptions that support the existence of a short neuron system are present (Elbadawi, 1984, 1987a, b, 1991; Bradley \& Teague, 1968a). Intraganglionar functionality has been studied in the respect of interaction between sympathetic and parasympathetic innervation by Bradley \& Teague (1968a). In general, for the uropoetic system no clear functional arguments are found in literature for its existence yet.

\section{Spinal cord reflexes}

Certainty about spinal cord 'reflexes' only exists for the parasympathetic steering of the detrusor and the sympathetic control of dome and bladder neck, as far as the autonomic spinal control concerns. The somatic reflex control of the striated urethral musculature is beyond any doubt.

Recently, Shafik published a large series of articles concerning the pelvic reflexes. Several new reflexes are described. To sum up:

Ano-urethral reflex: stimulation of the external anal sphincter increases the external urethral sphincter basal activity (Shafik, 1992a)

Recto-urethral reflex: rectal distention evokes external urethral sphincter contraction (Shafik, 1992b)

Vagino-cavernosus reflex: vaginal distention causes contraction of the cavernose muscles (Shafik, 1993a)

Ano-vesical reflex: distention of the anal sphincter results in an increase of vesical pressure (Shafik, 1994a)

Utero-cervical reflex: slow uterine dilatation is followed by cervix contraction, fast uterine dilatation is followed by cervix dilatation (Shafik, 1994b)

Genito-vesical reflex: clitoral and cervical stimulation induces drop of vesical pressure, but an increase of the external urethral sphincter activity (Shafik, 1995a) Clitoro-motor reflex: stimulation of the clitoris produces increase activity of the pelvic floor muscles (Shafik, 1995b)

Vesico-cavernosus reflex: rapid changes in vesical pressure were fastly followed by cavernose muscle contraction in man (Shafik, 1993b)

Peno-motor reflex: stimulation of the glans penis gives a drop in vesical pressure and an increased activity of pelvic floor muscles (puborectalis and levator ani muscles; Shafik, 1995c)

Vagino-levator reflex: distension of the vagina results in contraction of the levator ani (Shafik, 1995d)

Levator-urethral reflex: contraction of the levator ani muscles evokes contraction of the external urethral sphincter (Shafik, 1990)

Vesico-levator reflex: distention of the bladder produces contraction of the levator ani muscles (Shafik, 1993c)

Several other reflexes have been published or studied by Shafik e.g.: Vagino-uterine reflex (Shafik, 1997), deflation reflex (Shafik, 1997) and olfactory micturition reflex in dogs (Shafik, 1994).

Regrouping and study of these reflexes shows that most of the reflexes involved are not real reflexes but results of a controller mechanism in the spinal cord or at supraspinal levels. Distention of rectum, vagina and bladder will be followed by contraction of all striated pelvic floor structures including the striated sphincters. Activation of the pelvic floor or sphincters causes contraction of the same structures. Activation 
of clitoris, penis and cervix has the same effects. In general any change or activation of the state of structures involved in the entrances to the pelvic organs will elicit pelvic floor and sphincter contraction.

\section{Controller mechanisms}

As shown in part five most of the actions performed by the uropoetic system are steered by control mechanisms in the spinal cord or at supraspinal levels. This holds for storage, micturition and the end of micturition. As shown by Kinder et al., (1995), the supraspinal steering as layed down in literature by the groups of Bradley, Blaivas, De Groat and Holstege, is a matter of controversy. The present study does not alter this position, mainly due to the lack of functional research at the brainstem and higher steering levels. Therefore, only the minimal steering connections, based on anatomical results could be given in this study.

A general conclusion is that reflex arches, as they are related to smooth muscles, are partly unknown due to different and sometimes contradictory research results. Most circuitries studied are under supraspinal control, while information about the supraspinal connections and function is still fragmentary. Thus it is unknown whether reflex activity is pure or polluted by supraspinal steering. This is understandable, because several anatomical pathways are used to relay the same information to the smooth muscles. Experimental approach therefore is fragmentary and never shows the overall activity in the autonomous reflex arch. In fact, the short neuron loops, using the pelvic plexus and intramural ganglia can also be involved in this, although nearly no functional arguments in literature are present for this loop.

Reflex activity and its typical modellation can also be measured at the end of the reflex arch, that is, by the reaction of the muscle. For striated muscles, the EMG is highly developed and clinical applicable, which is in contrast to the EMG of smooth muscles. The fact that the role of the pelvic floor musculature is underestimated doesn't originate from the EMG, but is caused by the neglect of its function in upholding voiding.

Further research on the mentioned subjects will profit from the study of the EMG of smooth bladder (Kinder, $1997,1998 \mathrm{ab})$ as it is the end result of the reflex arch, both in continence, micturition and ending of the micturition.

\section{References}

Andersson KE (1986) Clinical relevance of some findings in neuroanatomy and neurophysiology of the lower urinary tract. Clin Sci., Suppl 14, vol 70: 21-32

Awad SA, Downie JW (1976) Relative contributions of smooth and striated muscles to the canine urethral pressure profile. Br J Urol 48:347-354

Baljet B (1981) The innervation of the abdominal, pelvic and adjoining viscera in the female. Thesis, Amsterdam

Baljet B, Drukker J (1979) The extrinsic innervation of the pelvic organs in the female rat. Acta Anat 107:241-267

Bastiaanssen EHC, Vanderschoot J, Van Leeuwen JL (1993) Learning procedure in a neural control model for the urinary bladder. Neurourol Urodynam 12, no 3:285288

Blaivas JG (1982) The neurophysiology of micturition: a clinical study of 550 patients. J Urol 127:958-963

Blaivas JG (1985) Pathophysiology of lower urinary tract dysfunction. Clin Obstet Gynecol 12, no 2:295-309

Blaivas JG (1990) Mechanisms of micturition. In Chisholm GD, Fair WR (eds) "Scientific Foundations of Urology." 3th Ed. Oxford: Heinemann Medical Books, pp 273-286

Blok BFM, Holstege G (1999) The two pontine micturition centers in the cat are not interconnected; implications for the central organisation of micturition. J Comp Neurol 403:209-218

Bradley WE (1969a) Micturition reflex amplification. J Urol 101:403-407

Bradley WE (1969b) Regulation of the micturition reflex by negative feedback. J Urol 101:400-407

Bradley WE (1978) Innervation of the male urinary bladder. Urol Clin North Am 5:279-293

Bradley WE, Teague CT (1968a) The pelvic ganglia. J Urol 100:649-652

Bradley WE, Teague CT (1968b) Spinal cord organization of micturition reflex afferents. Exp Neurol 22:504-516

Bradley WE, Teague CT (1969a) Cerebellar influence on the micturition reflex. Exp Neurol 23:399-411

Bradley WE, Teague CT (1969b) Hypogastric and pelvic nerve activity during the micturition reflex. J Urol 102:438-440

Bradley WE, Teague CT (1969d) Spinal cord representation of the peripheral neural pathways of the micturition reflex. J Urol 101:220-223

Bradley WE, Timm GW, Scott FB (1974) Innervation of the detrusor muscle and urethra. Urol Clin North Am 1:3-27

Coote JH, Fleetwood-Walker SM, Gilbey MP, Peterson DF (1982) Possible role of oxytocin, vassopression and the paraventriculo-spinal pathway in the regulation of sympathetic preganglionic neurons. J Physiol 324:81P

Cunningham DT (1972) In Romanes GJ (ed) "Cunningham's Textbook of Anatomy." 11th Ed. London: Oxford University Press, pp 755-756, 762-764

De Groat WC (1975) Nervous control of the urinary bladder of the cat. Brain Res 87:201-211.

De Groat WC, Booth AM, Krier J (1979a) Interaction between sacral parasympathetic and lumbar sympathetic inputs to pelvic ganglia. In McC Brooks $\mathrm{C}$, Koizumi $\mathrm{K}$, Sato A (eds) "Integrative Functions of the Autonomic Nervous System." Tokyo: Tokyo University Press, ch 15, pp 234-247

De Groat WC, Booth AM, Krier J, Milne RJ, Morgan C, Nadelhaft I (1979b) Neural control of the urinary bladder and large intestine. In McC Brooks C, Koizumi K, Sato A (eds) "Integrative Functions of the Autonomic Nervous System." Tokyo: Tokyo University Press, ch 4, pp 50-67 
De Groat WC, Lalley PM (1972) Reflex firing in the lumbar sympathetic outflow to activation of vesical afferent fibres. J Physiol 226:289-309

De Groat WC, Saum WR (1971) Adrenergic inhibition in mammalian para-sympathetic ganglia. Nature 231:188189

De Groat WC, Steers WD (1990) Autonomic regulation of the urinary bladder and sexual organs. In Loewy AD \& Spyer KM (eds) "Central Regulation of Autonomic Functions." New York: Oxford University Press, pp 310323

Dijkema HE, Weil EHJ, Janknegt RA (1992) Eerste ervaringen met neuromodulatie als behandeling voor incontinentie en mictiestoornissen in Nederland. Ned Tijdschr Geneeskd 136:88-90

Dixon J, Gosling J (1987) Structure and innervation in the human. In Torrens MJ, Morrison JFB (eds) "The Physiology of the Lower Urinary Tract." London: Springer Verlag, ch 1, pp 3-22.

Donker PJ (1986) A study of myelinated fibres in the branches of the pelvic plexus. Neurourol Urodynam 5:185-202

Dröes JTPM (1972) De musculatuur van blaas en urethra in de menselijke foetus. Thesis. Leiden: Leiden University

Elbadawi A (1991) Anatomy and innervation of the vesicourethral muscular unit of micturition. In Krane RJ, Siroky MB (eds) "Clinical Neuro-Urology." 2nd Ed. Boston: Little, Brown \& Company, ch 2, pp 5-23

Elbadawi A (1984) Ultrastructure of vesicourethral innervation. II. Postganglionic axoaxonal synapses in intrinsic innervation of the vesicourethral lissosphincter: a new structural and functional concept in micturition. $J$ Urol 131:781-790

Elbadawi A (1987a) Comparative neuromorphology in animals. In Torrens MJ, Morrison JFB (eds) "The Physiology of the Lower Urinary Tract." London: Springer Verlag, ch 2, pp 23-52

Elbadawi A (1987b) Neuromuscular Mechanisms of Micturition. In Yalla SV, McGuire EJ, Elbadawi A, Blaivas JG (eds) "The Principles and Practice of Neurourology and Urodynamics." New York: Macmillan, ch 1, pp 3-35

Fall M (1984) Does electrostimulation cure urinary incontinence? J Urol 131:664-667

Fletcher TF, Bradley WE (1978) Neuroanatomy of the bladder-urethra. J Urol 119:153-160

Fowler CJ, Fowler C (1987) Clinical neurophysiology. In Torrens MJ, Morrison JFB (eds) "The Physiology of the Lower Urinary Tract." London: Springer Verlag, ch 4, pp 89-131

Getting PA (1989) Reconstruction of small neural networks. In Koch C, Segev I (eds) "Methods in Neuronal Modelling, from Synapses to Networks." Cambridge: Massachusetts Institute of Technology, pp 171-194

Gill Vernet S (1964) Innervation somatique et végétative des organes génito-urinaire. J Urol Nephrol (Paris) 70:45-55

Gosling JA (1985) Structure of the lower urinary tract and pelvic floor. Clin Obstet Gynecol 12. no 2:285-301

Gosling JA, Dixon JS, Humpherson JR (1983) Gross and microscopic anatomy of the urethra, I and II. In Gosling JA, Dixon JS, Humpherson JR (eds) "Functional Anatomy of the Urinary Tract." Edingburgh: Churchill Livingstone, chs 4 and 5

Gray $H$ (1985) In Clement CD (ed) "Anatomy of the Human
Body." 30th Am. Ed. Philadelphia: Lea \& Febiger, pp 509511, 1234-1245, 1539-1545

Griffiths DF (1987) Mechanics of micturition. In Yalla SV, McGuire EJ, Elbadawi A, Blaivas JG (eds) "The Principles and Practice of Neurourology and Urodynamics." New York: Macmillan, ch 5, pp 96-121.

Griffiths D, Holstege G, Dalm E, De Wall H (1990) Control and coordination of bladder and urethral function in the brain stem of the cat. Neurourol Urodynam 9:63-82

Hertz J, Krogh A, Palmer RG (1991) Introduction of the theory of neural computation. Addison-Wesley Publishing Company, USA

Hickey DS, Phillips JI, Hukins DWL (1982) Arrangements of collagen fibrils and muscle fibres in the female urethra and their implications for the control of micturition. $\mathrm{Br} \mathrm{J}$ Urol 54:556-561

Hodgkin AL, Huxley AF (1952) A quantitative description of membrane currence and its application to conduction and excitation in nerve. J Physiol 117:500-544

Holstege G (1989) Neuronal organization of micturition. In "Lower Urinary Tract Dysfunction: from Cell to Clinical Approach." Micro-symposium. Rotterdam: Erasmus University Rotterdam

Holstege G, Griffiths D (1990) Neuronal organization of micturition. In Paxinos G (ed) "The Human Nervous System". San Diego e.o.: Academic Press, Inc, pp 297 306

Ingram DA (1982) Neurophysiological investigation of central motor pathways controlling pelvic floor sphincter muscles. Ch 18

Iwatsubo T, Kuzuhara S, Kanemitsu A, Shimada $H$, Toyokura $Y(1990)$ Corticofugal projections to the motor nuclei of the brainstem and spinal cord in humans. Neurology 40:309-312

Jünemann KP, Lue TF, Schmidt RA, Tanagho EA (1988) Clinical significance of sacral and pudendal nerve anatomy. J Urol 139:74-80

Kinder MV, Bastiaanssen EHC, Janknegt RA, Marani E (1995) Neuronal circuitry of the lower urinary tract; centrl and peripheral neuronal control of the micturition cycle. Anat Embryol 192:195-209

Kinder MV, Gommer ED, Janknegt RA, Van Waalwijk van Doorn ESC (1997) A method for the electromyographic mapping of the detrusor smooth muscle. Arch Physiol Biochem 105:673-690

Kinder MV, Van Waalwijk van Doorn ESC, Gommer ED Janknegt RA (1998a) A non-invasive method for bladder electromyography in humans. Arch Physiol Biochem 106:2-11

Kinder MV, Gommer ED, Janknegt RA, Van Waalwijk van Doorn ESC (1998b) Recording the detrusor electromyogram is still a difficult and controversial enterprise. Neurourol Urodyn 17:571-573

Kok JJ (1985) Systeemkunde en regeltechniek. In Kok (ed) "Handleiding werktuigkundige regeltechniek". Eindhoven, Eindhoven University of Technology

Krongrad A, Sotolongo JR Jr (1996) Bladder neck dysynergia in spinal cord injury. Am J Phys Med Rehabil, 75:204-207

Lakke EAJF (1997) The projections to the spinal cord of the rat durong development; a timetable of descent. Adv Anat Embryol Cell Biol, 135:I-XIV, 1-143

Lakke EAJF, Hinderink JB (1989) Development of the spinal 
projections of the nucleus paraventricularis hypothalami of the rat: an intra-uterine WGA-HRP study. Development Brain Res. 49:115-121

Lakke EAJF, Hinderink JB, Marani E (1990) The development of the descending projection of the nucleus tegmentalis laterodorsalis in the rat. In Kerrebroeck PEV, Debruyne FMJ (eds) "Dysfunction of the Lower Urinary Tract: present achievements and future perspectives." Medicom Europe, Bussum, pp 3-9

Marani E, Pijl MEJ, Kraan MC, Lyckama à Nijeholt GAB, Videleer AC (1993) Interconnections of the upper ventral rami of the human sacral plexus: a reappraisal for dorsal rhizotomy in neurostimulation operations. Neurourol Urodynam 12:585-598

Mattiason A, Andersson K, Sjörgen C (1984) Adrenoceptors and cholinoceptors controlling noradrenaline release from adrenergic nerves in the urethra of rabbit and man. J Urol 131:1190-1195

Mayo ME (1978) Detrusor hyperreflexia: the effect of posture and pelvic floor activity. J Urol 119:635-638

Mersdorf A, Schmidt RA, Tanagho EA (1993) Topographic-anatomical basis of sacral neurostimulation: neuroanatomical variations. J Urol 149:345-346

Morris LR (1942) In Parsons-Schaeffer J (ed) "Morris'Human Anatomy." 10th Ed. Philadelphia: Blakiston, pp 11311144

Morrison JFB (1987a) Neural connections between the lower urinary tract and the spinal cord. In Torrens MJ, Morrison JFB (eds) "The Physiology of the Lower Urinary Tract." London: Springer Verlag, ch 3, pp 53-85

Morrison JFB (1987b) Sensations arising from the lower urinary tract. In Torrens MJ, Morrison JFB (eds) "The Physiology of the Lower Urinary Tract." London: Springer Verlag, ch 4, pp 89-131

Morrison JFB (1987c) Reflex control of the lower urinary tract. In Torrens MJ, Morrison JFB (eds) "The Physiology of the Lower Urinary Tract." London: Springer Verlag, ch 7, pp 193-235

Morrison JFB (1987d) Bladder control: role of higher levels of the central nervous system. In Torrens MJ, Morrison JFB (eds) "The Physiology of the Lower Urinary Tract." London: Springer Verlag, ch 8, pp 237-274

Oudega M, Lakke EAJF, Marani E, Thomeer RTWM (1993) Development of the rat spinal cord: Immuno- and enzymehistochemical approaches. Adv Anat Embryol Cell Biol 129:1-164.

Park JM, Bloom DA, McGuire EJ (1997) The guarding reflex revisited. Br J Urol, 80:940-5

Paturet G (1964) "Traité d'Anatomie Humaine.", Système Nerveux, Tome IV. Paris: Masson et Cie, pp 1021-1040

Pernkopf E (1941) "Topografische Anatomie des Menschen." Bauch, Becken und Beckengliedmaße 2. Bd, Berlin: Urban \& Schwarzenberg, 1. Hälfte pp 102-105, 2. Hälfte pp 470-482

Pick J (1970) The autonomic nervous system Lipincott Company Philidelhia

Piersol GA (1930) In Huber GC (ed) "Piersol's Human Anatomy", 9th Ed. Philadelphia: Lippincott, pp 13311334, 1345-1351

Raz S (1978) Pathophysiology of male incontinence. Urol Clin North Am 5:295-304

Shafik A (1990) Levator-urethral reflex. A new reflex with clinical significance. Urology 36:93-95
Shafik A (1992a) Anaurethral reflex. Description of a reflex and its clinical significance: preliminary study. Paraplegia 30:210-213

Shafik A (1992b) Rectourethral reflex: description of a reflex and its clinical significance. Urol Int 48:302-306

Shafik A (1993a) Vaginocavernosus reflex: clinical significance and role in sexual act. Genaecol Obstet Invest 35:114-117

Shafik A (1993b) The vesicocavernosus reflex: role in the act of micturition. Int Urogynecol J 4:346-349

Shafik A (1993c) Vesicolevator reflex. Description of a new reflex and its clinical significance. Urology 41: 96-100

Shafik A (1994a) Ano-vesical reflex: role in inducing micturition in paraplegic patients. Paraplegia 32:104-107

Shafik A (1994b) Uterocervical reflex: description of the reflex and its clinical significance. Gynecol Obstet Invest 38:241-244

Shafik A (1994c) Olfactory micturition reflex. Experimental study in dogs. Biol Signals, 3:307-11

Shafik A (1995a) Study of the response of the urinary bladder to stimulation of the cervix uteri and clitoris - the "genito vesical reflex": an experimental study. Int Urogynecol J 6:41-46

Shafik A (1995b) The "clitoromotor" reflex. Int Urogynecol J 6:329-336

Shafik A (1995c) The peno-motor reflex: study of the response of the puborectalis and levator ani muscles to glans penis stimulation. Int $\mathrm{J}$ Impotence Res 7:239-246

Shafik A (1995d) Vagino-levator reflex: description of a reflex and its role in sexual performance. Eur $\mathrm{J}$ Obstet Gynecol Reprod Biol 60:161-164

Shafik A (1997a) Study of the uterine response to vaginal distension: the 'vagino-uterine reflex'. Gynecol Obstet Invest, 44:265-9

Shafik A (1997b) Deflation reflex: description and clinical significance. Anat Rec, 249:405-8

Schoen (1969) The corticofugal projection on the brain stem and spinal cord in man. Psychiatr Neurol Neurochir, 72:121-8

Schmidt RA, Tanagho EA (1990) Klinische Anwendung der Elektrostimulation. Urologe A 29:191-195

Siegel SW (1992) Management of voiding dysfunction with an implantable neuroprosthesis. Urol Clin North Am 19 1:163-170

Tanagho EA, Schmidt RA, de Araujo GG (1982) Urinary striated sphincter: What is its nerve supply? Urology 20:415-417

Tanagho EA, Schmidt RA, Orvis BR (1989) Neural stimulation for control of voiding dysfunction: a preliminary report in 22 patients with serious neuropathic voiding disorders. J Urol 142:340-345

Thon WF, Schmidt RA, Jonas U, Tanagho EA (1991) Neurostimulation der sakralen Spinalnerven bei Blasenfunktionsstörungen. Aktive Urologie 22:41-44

Torrens M (1987a) Urodynamics. In Torrens MJ, Morrison JFB (eds) "The Physiology of the Lower Urinary Tract." London: Springer Verlag, ch 9, pp 277-307

Van Arsdalen K, Wein AJ (1991) Physiology of micturition and continence. In Krane RJ, Siroky MB (eds) "Clinical Neuro-Urology." 2nd Ed. Boston: Little, Brown and Company, ch 3, pp 25-82

Van Ulden BM (1975) De musculatuur van de blaashals an de urethra posterior bij de man. Thesis Leiden: Leiden 
University

Venema (1988) De klinische betekenis van de instabiele urethra van de vrouw. Thesis, Leiden University 


\section{A method for the electromyographic mapping of the detrusor smooth muscle}


Matti V. Kinder - Erik D. Gommer

Ruud A. Janknegt - Ernst S.C. van Waalwijk van Doorn

\title{
A method for the electromyographic mapping of the detrusor smooth muscle
}

\begin{abstract}
Various methods for detrusor EMG in the living mammal have been described in the literature. These methods do insufficiently take into account signal components that are caused by movement between the electrodes and the bladder wall. Reliable detrusor EMG has not been achieved yet.

This study investigates the feasibility of a new experimental set-up, in which the electrical activity of the detrusor smooth muscle can be examined. In six rabbits, after cervical dislocation, laparotomy and after excision of the heart, electrical signals of the detrusor muscle are measured with 240 electrodes. The electrodes are positioned on the serosal surface of the filled and isovolumetric bladder. During the recordings, no bladder contractions are deliberately evoked by any stimulus.

Consistent results in all six animals show a repetitive spike pattern on multiple electrodes with a repetition frequency of $1.2 \mathrm{~Hz}$. Spikes are triphasic and have a mean duration of $0.47 \mathrm{~s}(\mathrm{STD}=0.15 \mathrm{~s}, \mathrm{n}=40)$ and a mean amplitude of $0.29 \mathrm{mV}(\mathrm{STD}=0.07 \mathrm{mV}, \mathrm{n}=40)$. On adjacent electrodes a time shift between the spikes is found, suggesting the propagation of electrical activity across the detrusor surface. The maximum conduction velocity of an arbitrary spike front in the direction of propagation is approximately $30 \mathrm{~mm} / \mathrm{s}$. In two animals slow waves are found on the edge of the highpass filter setting.

Extensive control experiments are executed to validate the set-up and to interpret the data obtained by the animal experiments. The bladder is still able to contract thirty minutes post mortem. The heart, as a distant signal source, generates a signal that is present on all electrodes and shows no detectable time shift from one electrode to any other. Motion imposed on the electrodes relative to the bladder wall does not reproduce the slow waves and spikes found in the animal experiments. The control experiments support that the results of the animal experiments show electrical activity originating from the detrusor muscle itself. With the experimental set-up described in this paper, nearly artefact free detrusor EMG can be recorded. An electromyographic map of a considerable detrusor smooth muscle area can be obtained.
\end{abstract}

Key words Bladder - EMG - Lower Urinary Tract - Methods - M. Detrusor - Smooth Muscle

M.V. Kinder - E.D. Gommer - R.A. Janknegt - E.S.C. van Waalwijk van Doorn

Department of Urology, Maastricht University Hospital, Maastricht, The Netherlands

E.D. Gommer

Stan Ackermans Institute, Eindhoven University of Technology, Eindhoven, The Netherlands 


\section{Introduction}

Efficient storage and expulsion of urine is highly dependent on the integrated functioning of the musculature of the lower urinary tract and the relevant neuronal control structures in the peripheral and central nervous system. Defects or dysbalances in any part of the system may cause a loss of performance (Dijkema et al., 1993; Brindley, 1994; Bastiaanssen, 1996).

The diagnostic possibilities to check the integrity of neuronal pathways involved in micturition control are limited. The complexity of the neuronal control of the lower urinary tract was clearly shown in recent studies (Marani et al., 1993; Kinder et al., 1995; Bastiaanssen, 1996). The conventional technique used to evaluate bladder functioning consists of an intravesical and rectal pressure measurement (ICS 1987, 1988). In absence of rectal activity the pressure difference is indicated as detrusor pressure and thought to be generated by the bladder muscle itself. The detrusor pressure is very useful to estimate the overall behaviour of the bladder, but it cannot be used to reveal underlying causes for dysfunction.

The need for more selective tools to evaluate the functioning of the lower urinary tract has become evident. The recording of an electromyogram of the detrusor smooth muscle could partly serve this need. Theoretically, there are several benefits of detrusor electromyography (detrusor EMG) over detrusor pressure determination. Firstly, the spatial resolution of detrusor EMG is higher: local electrical activity of the detrusor muscle can be evaluated, e.g., with multiple small electrodes. Detrusor pressure is the result of the mechanical behaviour of the whole detrusor muscle and its outlet: possible uncoordinated local contractions may not cause a pressure rise and will remain undetected. Secondly, the electrical activity of the detrusor muscle is more closely related to the activity of its neuronal innervation. Changes in neuronal activity will first result in changes of electrical activity, preceding any mechanical effects. Detrusor EMG gives information about the transfer from neuronal to mechanical activity at an early stage. With respect to a rise in detrusor pressure for example, the excitation-contraction coupling of the detrusor muscle fibers has to develop and endure. Thirdly, electrical recordings from the detrusor muscle are likely to comprise both a myogenic signal contribution from the detrusor muscle itself and a neurogenic signal contribution from the innervating nerve fibers. The differentiation between detrusor muscle deficits and disorders of its neuronal innervation might become possible. Based on pressure measurements only, this differentiation can not be made.

Detrusor EMG might become useful in two areas: 1. the fundamental research both on micturition control and on bladder (patho-)physiology (Craggs \& Stephenson, 1982, 1985); 2. the clinical evaluation of lower urinary tract function (Boyce, 1952; La Joie et al., 1975; Takaiwa \& Shiraiwa, 1984). Unfortunately, detrusor EMG has been accompanied by many problems during the last 45 years, leading to contradictory reports in the literature (Corey et al., 1951; Boyce, 1952; Franksson \& Petersen, 1953; Brunsting, 1958; Fredericks et al., 1969; Stanton et al., 1973, 1974; Cosgrove et al., 1974, 1977; Jones et al., 1974; Doyle et al., 1975; La Joie et al., 1975; Craggs \& Stephenson, 1976, 1982, 1985; Kaplan et al., 1976; Kaplan \& Nanninga, 1978; Nanninga \& Kaplan, 1978; Abdel-Rahman et al., 1982; Takaiwa et al., 1983a, b, 1992; Takaiwa \& Shiraiwa, 1984; Jünemann et al., 1994; Shafik, 1994). To review common problems of detrusor EMG to date, five exemplary cases will be discussed (Corey et al., 1951; Boyce, 1952; Brunsting, 1958; Stanton et al., 1973, 1974; Doyle et al., 1975; Craggs \& Stephenson, 1976, 1982, 1985; Takaiwa et al., 1983a, b, 1992; Takaiwa \& Shiraiwa, 1984).

In 1951, Corey et al. placed electrodes transurethrally into the human urinary bladder against the lateral surfaces of the vesical neck. A signal that varied as a "bladder wave" with an amplitude of about $0.6 \mathrm{mV}$ and a frequency of 0.1 to $1.0 \mathrm{~Hz}$ was recorded during voiding (Fig. 1). It was stated that "When the fingers were rested lightly on the electrode-carrier near the urethral orifice, movements [of the electrode carrier] coinciding with the appearance of typical wave forms on the tracing could frequently be detected" (Corey et al., 1951). This was seen as an indication that the signals found did represent contractions of the bladder musculature. Some years later, Brunsting (1958) tested several kinds of electrode materials (Ag, $\mathrm{Ag} / \mathrm{AgCl}$ and stainless steel), electrode geometry's (needle shaped and ball-tipped electrodes) and recording sites (in the outer bladder wall and against the inner bladder wall) on an intact bladder in the anaesthetised cat. In control experiments he also conducted recordings with electrodes placed in or against a formalin-fixed bladder, a wet sponge, saline solution and a rubber bulb. Simple movement of the electrodes in a variety of situations consistently produced wave-like signals that were similar to the "bladder waves" reported earlier by Corey and Boyce (Fig. 2) (Corey et al., 1951; Boyce, 1952). Based on these observations, Brunsting suggested the "bladder wave" to be caused by bladder and electrode movement.

Starting in 1973, Stanton et al. $(1973,1974)$ inserted hook electrodes via the anterior vaginal wall into the 


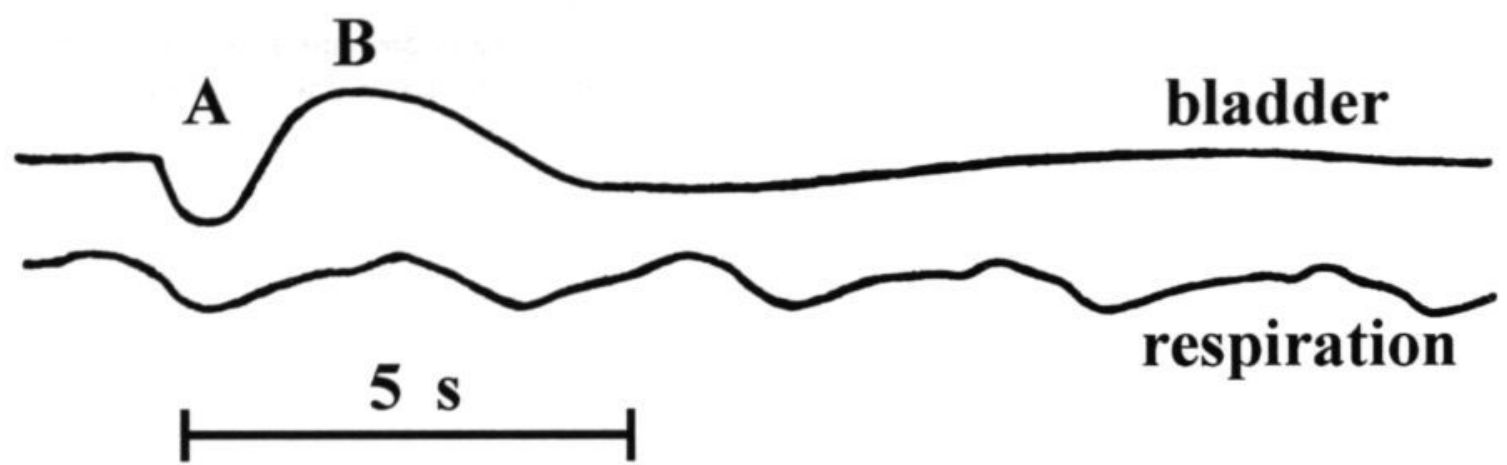

Figure 1: Normal diphasic 'Bladder Wave' with ' $\mathrm{A}$ ' and ' $\mathrm{B}$ ' deflections as described by Corey and colleagues in 1951. Note that no vertical scale is given. (Adapted from: Corey EL, Boyce WH, Vest A, French CR (1951) Electro-potential changes in human urinary bladder: a method of measurement. J Appl Physiol 3:631-636, Fig 2A, reprinted with permission).
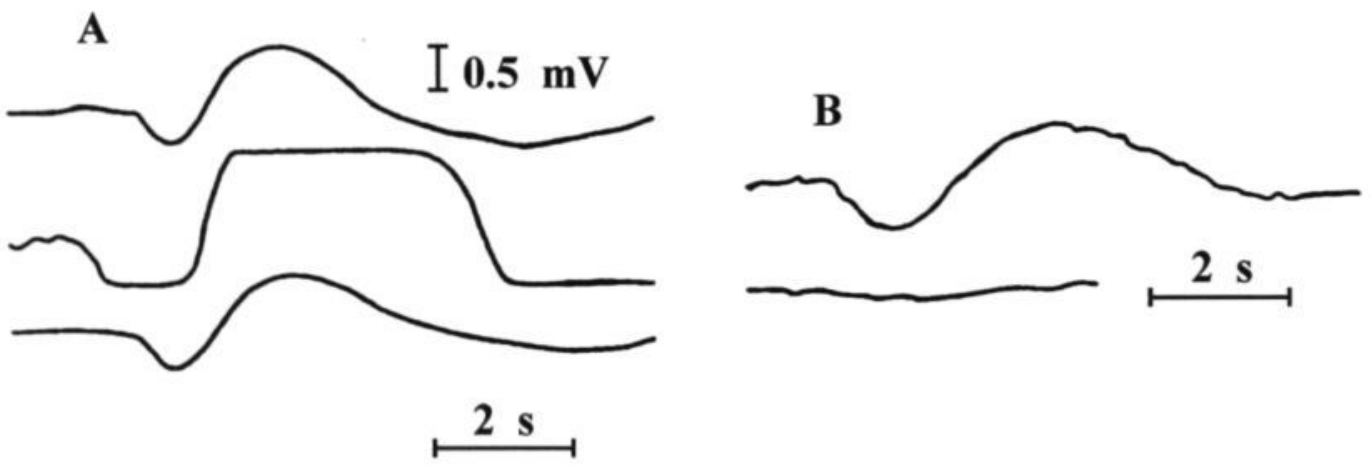

C
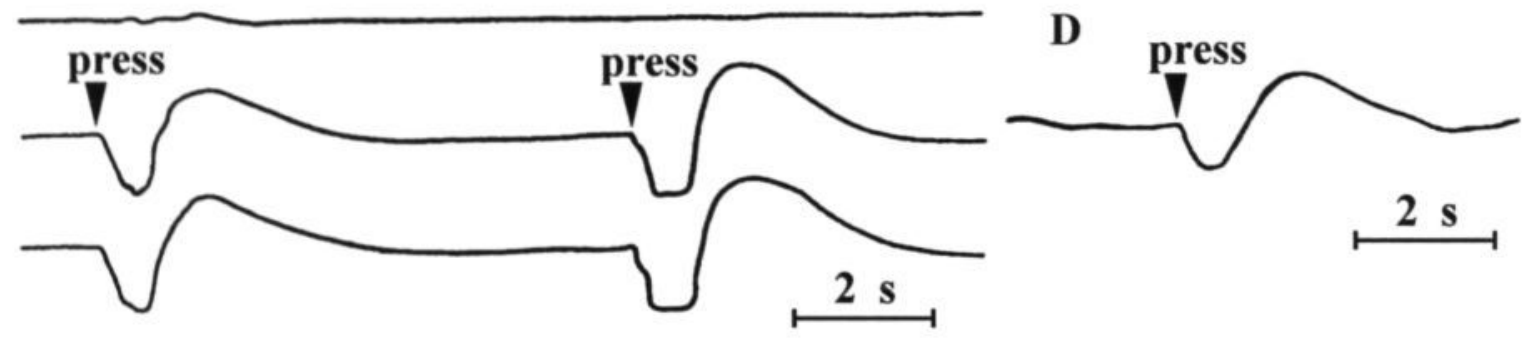

Figure 2: Examples of recordings from the bladder of a cat using externally implanted needle type electrodes.

(A) Typical 'bladder waves' show initial downward phase followed by upward phase;

(B) 'Bladder wave' of type occasionally seen during spontaneous activity. Note that it is not clear what the lower trace represents;

(C) Diphasic waves caused by pressing on one electrode in such a way as to push it deeper into the bladder. Note that it is not clear what the upper trace represents;

(D) Diphasic wave produced by pressing one of two electrodes immersed in saline solution. (Adapted from: Brunsting CD (1958) An interpretation of the urinary bladder 'electrocystogram' as artefact. J Urol 79:165-170, Fig. 2, reprinted with permission).

inner bladder wall of conscious female patients. The investigators recorded low frequent $(0.1-5.0 \mathrm{~Hz})$ signals with an amplitude of 0.1 to $2 \mathrm{mV}$ and referred to similar recordings of Boyce (Corey et al., 1951; Boyce, 1952). The results of Brunsting (1958) were not discussed in their article. A second high frequency (spike) component of the detrusor EMG was identified, having a typical spike amplitude of $0.1 \mathrm{mV}$. In a later publication, Doyle et al. (1975) stated that it had not been possible to correlate changes in 
electrical activity with changes in bladder pressure and that movement artefacts were almost impossible to exclude with this technique.

Craggs and Stephenson $(1976,1982,1985)$ attempted to record "the real bladder electro-myogram". They stimulated the sacral ventral roots of 9 cats and one baboon. Platinum wire electrodes were inserted into the bladder wall from the exposed serosal surface (Craggs \& Stephenson, 1976). They reported profuse random activity in the $0.07-1.0 \mathrm{~Hz}$ frequency band with an amplitude of $1 \mathrm{mV}$, which was also present in an isolated bladder kept in saline for 24 hours. Hence, this activity was interpreted as an artefact, probably resulting from fluid movement around the tip of the electrodes. Activity in the $40-200 \mathrm{~Hz}$ range showed no correlation with the recorded intravesical pressure and increased activity coincided with contractions of adjacent skeletal muscles. Only activity between 10 and $40 \mathrm{~Hz}$ seemed to correlate with contractions of the bladder. However, activity in the $10-40 \mathrm{~Hz}$ band was also present in the absence of voiding (Fig. 3), which was "...attributed to carry-over of the large amplitude activity in the adjacent 1-10 Hz band." (Craggs \& Stephenson, 1976).

Taikawa and Shiraiwa (1984) investigated the electromyographic pattern of the detrusor muscle in 24 humans. They used carbon fiber surface electrodes that were fixed on the tip of a balloon catheter. The catheter was transurethrally inserted into the bladder and kept in position by inflating the balloon. The signals were highpass filtered at $5.3 \mathrm{~Hz}$ and lowpass filtered at $100 \mathrm{~Hz}$. The 24 subjects with various manifestations of lower urinary tract disorders were grouped, based on the approximate amplitude (voltage) of the detrusor EMG signal: normal voltage group (normal, BPH; amplitude 0.05-0.1 mV); low voltage group (e.g., neurogenic bladder due to spina bifida; amplitude $0.01 \mathrm{mV}$ ); and a high-voltage group (e.g., mild spinal cord injury; amplitude 0.3-2 mV). Earlier work showed a correlation between bladder

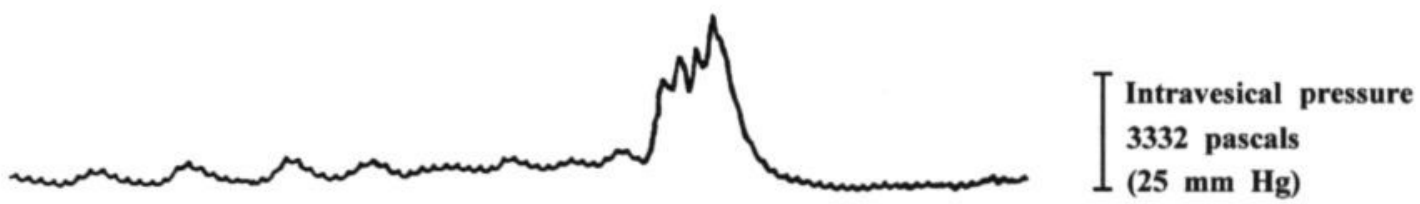

$0.07-1 \mathrm{~Hz}$
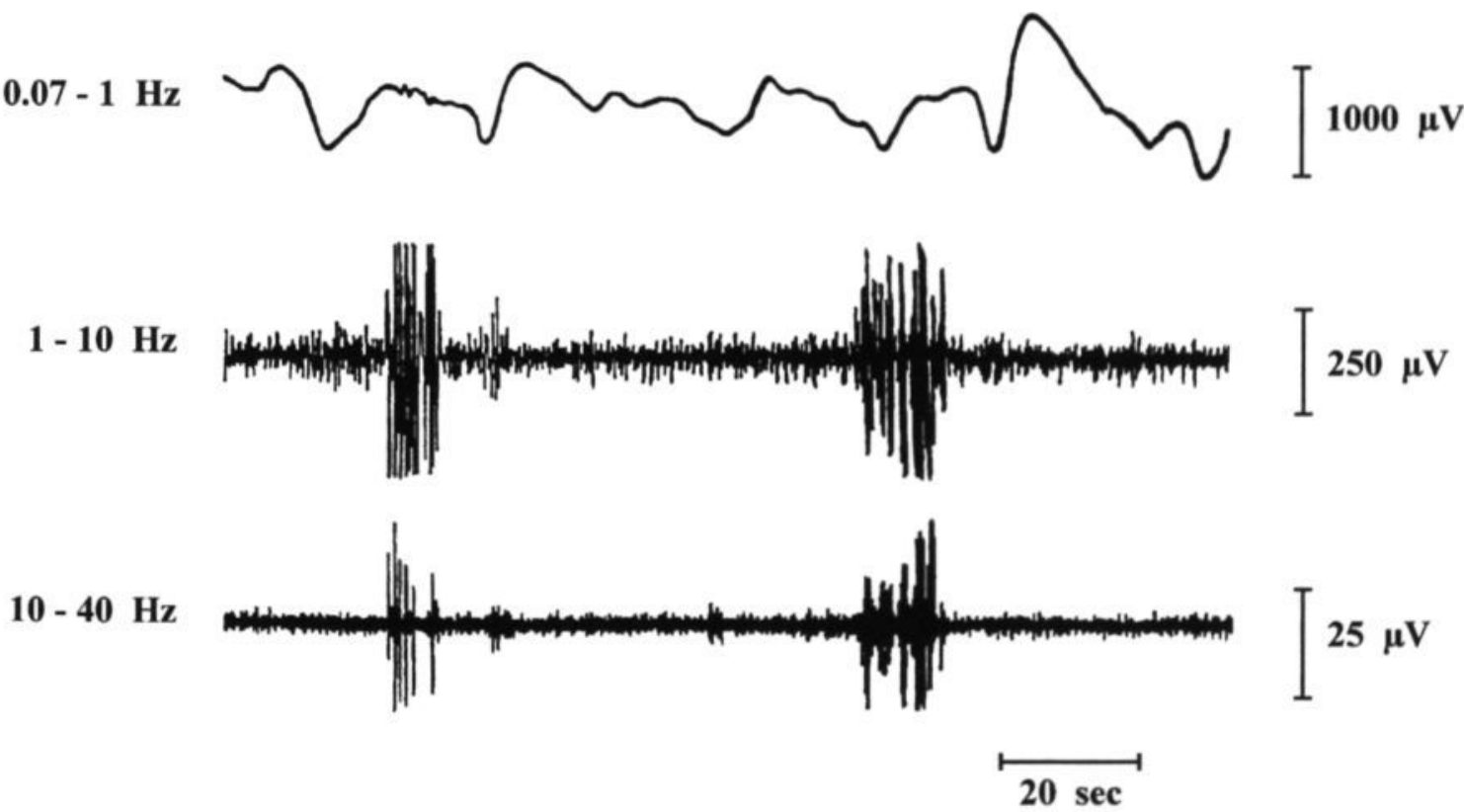

Figure 3: Intravesical pressure changes and electrical bladder activity during reflex voiding in an anaesthetised cat. An example of dissociation between activity in the $1-10 \mathrm{~Hz}$ band and reflex voiding. The small increase in activity in the $10-40 \mathrm{~Hz}$ band in the absence of voiding is attributed to carry over of the large amplitude activity in the 1-10 $\mathrm{Hz}$ band. Note the different vertical scaling. (Adapted from: Craggs MD, Stephenson JD (1976) The real bladder electromyogram. Br J Urol 48:443-451, Fig. 4, reprinted with permission). 
BEMG
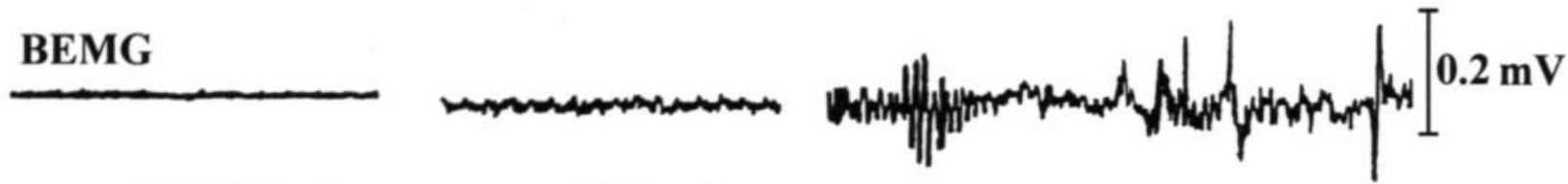

CMG $0 \mathrm{ml}$

$200 \mathrm{ml}$

$300 \mathrm{ml}$

\section{UEMG}
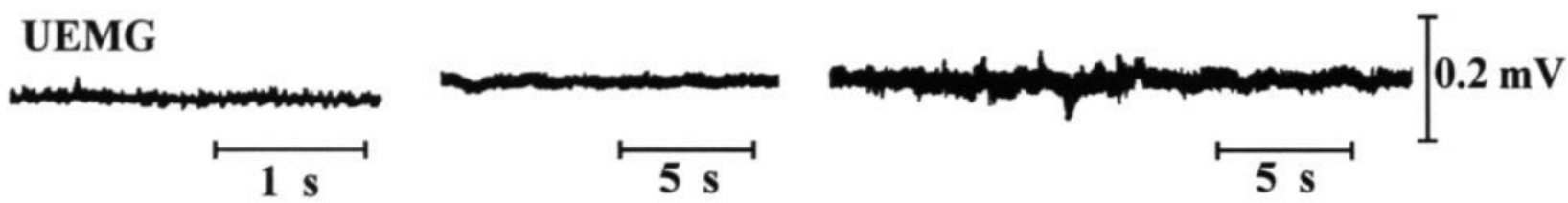

Figure 4: Correlation between intravesical volume (gas infusion) and electrical activity recorded from the bladder. UEMG: Urethral electromyogram; BEMG: Bladder electromyogram; CMG: Cystometrogram. (Adapted from: Takaiwa M, Shiraiwa Y, Katahira K, Tsukahara S (1983) A new urinary bladder electromyogram. Urol Int 38:1-4, Fig. 2A, reprinted with permission of S. Karger A.G.).

volume and electromyographic activity (Fig. 4) (Takaiwa et al., 1983b). No statement was made about possible artefacts, while in 1992 (Takaiwa et al., 1992) they concluded that many problems accompanying this procedure still had to be solved. Movement of the bladder was mentioned as a major difficulty.

The results reported in the literature seem rather limited and the information about signal amplitudes and frequencies is contradictory. In our opinion, different causes have contributed to this unfavourable situation. Firstly, electrical activity of smooth musculature may involve signal components of less than one hertz in frequency. Hence, DC (direct current) recording might be considered. Phenomena near the electrode contact surface become more important when such low frequent signals are recorded (Cooper et al., 1969). A metal electrode immersed in a conducting fluid can generate a voltage between the electrode and the fluid. This voltage depends on the electrode material and the temperature and is called electrode voltage. Applying more than one electrode, differences in electrode voltages give rise to an electrical current between the electrodes. Subsequent impedance changes between these electrodes, e.g., by movement, evoke slow potential changes that can easily result in erroneous interpretation of recordings. Urine is a salty solution (a good electrical conductor) and recordings with intravesical electrodes (Corey et al., 1951; Boyce, 1952) might therefore be bothered by these problems. Secondly, the detrusor muscle is stretched and rather thin when the bladder is full. The bladder is able to change its geometry drastically and has a high degree of freedom in movement. These aspects complicate the reliable fixation of wire or needle electrodes in the muscle. Thirdly, the lack of information given on the exact experimental set-up used and the wide variety of techniques applied complicate the objective comparison of the results obtained by the different research groups. Differences in electrode material, electrode geometry, registration site, filter and gain settings, sample frequency, data processing and species studied are known to have a considerable impact on the results. Finally, most studies focus on detrusor EMG in living mammals and the electrodes are in contact with the bladder wall (surface electrodes) or the detrusor muscle (needle or wire electrodes). This general set-up gives rise to various signal components that do not reflect electrical activity generated by detrusor smooth muscle cells. Electrical activity originating from the heart and striated musculature is sometimes picked up by the electrodes (Craggs \& Stephenson, 1976). Comprising smooth muscles themselves, the bowels are likely to have electrical characteristics resembling those of the detrusor muscle (Weisbrodt, 1991a, b; Guyton \& Hall, 1996) and their electrical activity might be recorded as well. However, the most misleading signal components in the recordings are caused by movement between the electrodes and the bladder (Brunsting, 1958; Abdel-Rahman et al., 1982). Signal changes are unconditionally interpreted to be electrical detrusor activity and used as validation argument for the experimental set-up when they occur simultaneously with bladder contractions. This interpretation is based on the idea that the mechanical activity will be accompanied by (increased) electrical activity. Movement of the bladder to the recording electrodes as a possible signal source is neglected. Movement can for example be evoked by respiration, bowel activity or striated muscle activity (Abdel-Rahman et al., 1982). Stimulating the bladder by various means (e.g., peripheral nerve stimulation, chemical stimulation and filling cystometry), eventually resulting in bladder 
emptying, merely induces more movement between the electrode and the muscle. In some studies, the authors themselves (Doyle et al., 1975; Takaiwa et al., 1992) have finally concluded that movement is difficult to exclude, while other investigators (Brunsting, 1958; Abdel-Rahman et al., 1982) have suggested that movement is most likely to have caused the recorded signals. The problem is the separation of very small extracellular signals, reflecting actual membrane potential changes of detrusor muscle cells, from the large electromechanical artefact caused by electrode movement as the tissue contracts. However, in most studies no control experiments are done to determine to what extent relative movement of the bladder to the electrodes is responsible for the signals recorded.

In general, extensive control experiments to exclude or identify various signal components from sources other than the detrusor muscle are rare whenever a detrusor EMG technique is presented. Although the signals recorded in each of these studies might show a real detrusor electromyogram, its unequivocal identification is, in our opinion, impossible without relevant control experiments. As not much is known about the signal properties of the electrical detrusor activity either, the discrimination between true electrical activity from the detrusor muscle and these summated artefacts becomes difficult even when using appropriate recording equipment and sophisticated data-analysis techniques.

Reviewing the literature with the above mentioned problems in mind, it must be concluded that the amplitude, frequency and shape of the electrical detrusor activity measured with extracellular electrodes are still unknown. Reliable detrusor EMG has not been achieved yet.

This study aims therefore at the identification of electrical activity generated by the detrusor muscle with minimum disturbances in the recordings by any other signal source. The feasibility of an experimental set-up designed for this purpose is investigated.

New strategies are applied for the design and the validation of our experimental set-up and for the interpretation of the results: preliminary exclusion of several unwanted signal sources by working with a post mortem model; reduction of movement between the recording electrodes and the bladder wall by working with an isovolumetric bladder; application of multiple electrodes next to each other.

Animal experiments are conducted to test the performance of the complete experimental set-up and to determine the electrical signal properties of the detrusor muscle under isovolumetric conditions. No pharmacological or electrical bladder stimulation techniques are thought necessary for successful detrusor EMG as several in vitro studies reported that spontaneous electrical and mechanical detrusor activity can be found in various species, especially in rabbits (Creed et al., 1983; van Duyl et al., 1990; Bramich \& Brading, 1996).

Although an experimental set-up with minimum disturbances is chosen, control experiments are necessary to exclude the presence of signal components other than electrical detrusor activity. Part of the control experiments have been described before (Brunsting, 1958) and are performed to demonstrate their effect on our specific set-up.

\section{Materials and Methods}

\section{Animal experiments}

The animal experiments in this study were performed on six rabbits (New Zealand White, male, mean weight: $2.9 \mathrm{~kg})$. A microtip pressure transducer catheter ( $d=2 \mathrm{~mm}$; Gaeltec Ltd, Dunvegan, Scotland) was applied to sense the intravesical pressure. The pressure signal was digitised at $3.4 \mathrm{~Hz}$ by a digital multimeter (M-3850; Metex, U.S.A.) and stored on a personal computer. A filling catheter $(\mathrm{d}=2 \mathrm{~mm})$ and a water bath (WB-7; Memmert GmbH, Schwabach, Germany) were used. The noise level of the pressure measurement was determined with the pressure transducer at a fixed height in the water bath at $\mathrm{T}=35^{\circ} \mathrm{C}$. It was defined as plus and minus three times the standard deviation (STD) of the signal measured. This proved to be $\pm 0.05 \mathrm{kPa}$. The pressure transducer was zeroed just beneath the water surface at $\mathrm{T}=35^{\circ} \mathrm{C}$ before each experiment started.

The electrode device was made of polyester resin. It embedded an octagonal matrix of 256 electrodes $(\mathrm{Ag}$, $\mathrm{d}=0.3 \mathrm{~mm}$; University of Maastricht, Maastricht, The Netherlands) that were positioned $2.3 \mathrm{~mm}$ from each other (Fig. 5). Sixteen electrodes in the two outer left columns were not operational in the present study. The electrodes were made of silver pins, which were soldered to isolated and silvered copper wire. The resistance of the electrodes to the connector was $3 \Omega$. The device had screened cables and could only measure electrical activity at the exposed electrode surfaces, as the rest was highly isolated. A large disk $(\mathrm{Ag}, \mathrm{d}=24 \mathrm{~mm})$ was used both as a grounding and reference electrode. The recording equipment was validated for electrophysiological studies of the heart (Allessie et al., 1986; Hoeks et al., 1988). The signals picked up by the electrode device were amplified by an array of 240 amplifiers with an input impedance of $1 \mathrm{M} \Omega$. As the signal properties were not clear, the widest possible frequency range of the equipment was used. This frequency range was 0.7 to $500 \mathrm{~Hz}$, 


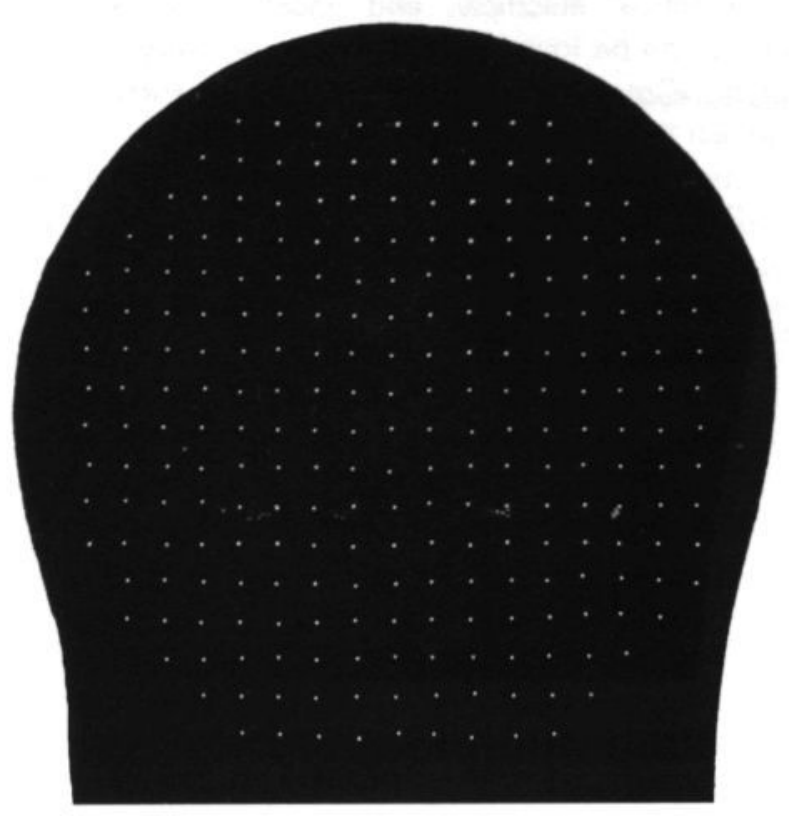

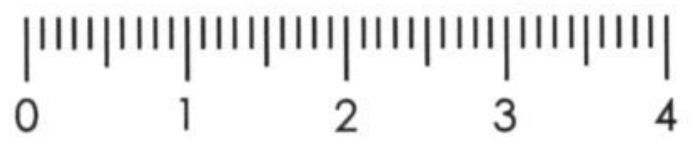

Figure 5: The configuration of the 256 electrodes, embedded in the electrode device. The scale below is in centimeters. Sixteen electrodes in the two outer left columns were not operational in the present study.

which were the $-3 \mathrm{~dB}$ points of the first order hardware filters. All 240 signals were recorded unipolar, individually amplified (gain: 4000), filtered (bandwidth: 0.7 to $500 \mathrm{~Hz}$ ), 8 bits $A D$ converted (sample frequency: $1 \mathrm{Khz}$ ) and digitally stored on videotape. Signals with a maximum amplitude (top-top) of $0.5 \mathrm{mV}$ could be recorded in this setting.

Each rabbit was anaesthetised with $0.5 \mathrm{ml} / \mathrm{kg}$ i.m. Hypnorm $^{\circledast}$ (fentanyl $(0.315 \mathrm{mg} / \mathrm{ml}$ ) and fluanisone (10 $\mathrm{mg} / \mathrm{ml}$ ); Janssen Pharmaceutica, Beerssen, Belgium) and received heparin (1000 IU i.v.; Leo, Weesp, The Netherlands). After cervical dislocation a midsternal thoracotomy was performed to prepare the later excision of the heart. A laparotomy was carried out to expose the bladder. The filling and micro-tip pressure transducer catheter were introduced transurethrally into the bladder. The urethra was ligated to secure the two catheters and to prevent urine loss during the experiment. If necessary, saline solution $\left(T=35{ }^{\circ} \mathrm{C}\right)$ was infused through the filling catheter, until the bladder accommodated approximately $50 \mathrm{ml}$ of fluid.

The electrode device was placed on the serosal surface of the exposed bladder and fixed against the ventral side of the bladder, above the trigone. The large disk, used both as a grounding and reference electrode, was placed in the thoracic region. The bowels were pushed away from the recording area. As soon as all preparations were finished, the heart was excised, followed immediately by the start of the recordings. The time which passed between the cervical dislocation and the removal of the heart was approximately six minutes (the maximum time was 8 $\mathrm{min} .30 \mathrm{~s}$ ). The bladder volume was determined once the recordings were finished.

Final data analysis was carried out digitally. The power spectral density was calculated to determine the bandwidth of the measured signals. Digital filtering of the data was carried out in correspondence with the signal content using a fifth order Butterworth lowpass filter. Cross correlation ratios were calculated to compare the time relation between signals recorded on adjacent electrodes. To calculate a cross correlation ratio, the offset of the signals was removed, the covariance was divided by the product of the two standard deviations of the signals and the degree of overlap was compensated for.

\section{Control experiments}

The control experiments consisted of two parts. The first part was performed on animals as well. Four rabbits (New Zealand White, male, mean weight: 3.1 $\mathrm{kg}$ ) were used. A syringe filled with a mixture of saline solution and carbachol was prepared. For the second part a beaker filled with saline solution and a wet sponge on a dish were available. The remaining materials and the settings of the recording equipment were the same as described for the animal experiments.

The control experiments focused on three aspects. The first aim was to investigate for how long reliable detrusor EMG was possible in one single animal experiment. The second aim was to check the impact of one major disturbing signal with well known signal properties (ECG) on the recordings. The ECG served as a test signal to evaluate the proper functioning of the recording equipment. The third aspect of interest was whether the recordings obtained from the animal experiments could be simulated by movement of the electrodes. The executed test procedure was tuned to the results of the animal experiments.

1. External mechano/chemical stimulation of the bladder combined with intravesical pressure measurements in three rabbits.

The experimental set-up was as described for the animal experiments, with the exception that the electrode device was not positioned. The outer bladder surface was sprinkled with a mixture of saline solution and carbachol $\left(\mathrm{T}=35{ }^{\circ} \mathrm{C}\right)$ from a $10 \mathrm{ml}$ syringe. This first stimulus was given either five or ten minutes post mortem, depending on when the preparation of the experimental set-up was finished. 
The next stimuli followed each in five minutes time intervals until thirty minutes post mortem. In these thirty minutes the syringe was completely emptied. For rabbit no. 1, the concentration of carbachol was $25 \mu \mathrm{g} / \mathrm{ml}$, for rabbit no. 2 and 3 the concentration of carbachol was reduced to $0.25 \mu \mathrm{g} / \mathrm{ml}$.

2. Excision of the heart after the start of the recordings in one rabbit.

The experimental set-up was as described for the animal experiments, with one exception: the heart was still in place when the recordings started. It was quickly removed after two minutes of recording with minimal disturbance of the experimental set-up in one male rabbit.

3a. Movement of the electrode device immersed in a beaker filled with saline solution.

Both the electrode device and the grounding electrode were inserted in a beaker filled with saline solution at room temperature. After an initial phase of rest, the electrode device was pushed gently by hand. A sinusoidal motion with a frequency of approximately 1 $\mathrm{Hz}$ was imposed. Two directions were tested: one direction perpendicular to the electrode surface, as to simulate pressure on the electrodes (normal); and one moving in the direction of the electrode surface, as to simulate slip (tangential). Two amplitudes of the imposed motion were tested: one amplitude (top-top) of approximately $0.4 \mathrm{~cm}$ and the other amplitude (toptop) of approximately $2 \mathrm{~cm}$. The duration of the mechanical stimulus was 30 seconds continuously or 5 seconds on and 5 seconds off during a 30 seconds period (table I).

3b. Movement of the electrode device on a wet sponge that was placed in a dish filled with saline solution.

The electrode device was positioned on top of the sponge and kept in place with an initial force. The grounding electrode was inserted in the sponge. After an initial phase of rest, the electrode device was pushed gently by hand. The test procedure as listed in table I was executed.

3c. Movement of the electrode device underneath a bladder, which had been in situ for nine hours post mortem.

The experimental set-up was as described for the animal experiments, with the exception that no catheters were inserted and the male rabbit was dead for nine hours at room temperature. The test procedure as listed in table I was executed in one animal.

Final data analysis was performed digitally. No additional digital filtering was carried out; the frequency range of the signals shown in Figs. 10-11 is 0.7 to $500 \mathrm{~Hz}$.

\begin{tabular}{lcc}
\hline Direction & $\begin{array}{c}\text { Motion amplitude } \\
\text { top-top (in cm) }\end{array}$ & $\begin{array}{c}\text { Stimulation period } \\
\text { of } 30 \mathrm{~s}\end{array}$ \\
\hline normal & 0.4 & continuous \\
normal & 0.4 & $5 \mathrm{~s}$ intervals \\
normal & 2 & continuous \\
normal & 2 & $5 \mathrm{~s}$ intervals \\
tangential & 0.4 & continuous \\
tangential & 0.4 & $5 \mathrm{~s}$ intervals \\
tangential & 2 & continuous \\
tangential & 2 & $5 \mathrm{~s}$ intervals \\
\hline
\end{tabular}

Table I: Test procedure for the control experiments 3a-c. Frequency of all mechanical stimuli is $1 \mathrm{~Hz}$.

\section{Results}

\section{Animal experiments}

In all six animals, consistent results were found. Frequency analysis of the recorded signals by means of power spectra showed that the significant signal frequencies were well below $25 \mathrm{~Hz}$, except for the 50 $\mathrm{Hz}$ cycle interference (Fig. 6). The limit of $25 \mathrm{~Hz}$ was chosen as it provided a generous margin to the relevant signal frequencies below. Hence the signal to noise ratio could be improved. All signals were lowpass filtered (fifth order Butterworth filter) at $40 \mathrm{~Hz}$ to get rid of the $50 \mathrm{~Hz}$ cycle interference and to guarantee a high quality signal up to $25 \mathrm{~Hz}$.

In all experiments, periods with spikes were seen. Looking at one of the 240 operational electrodes for forty seconds, a signal as shown in Fig. 7A could be recorded; the spikes exhibited a repetition frequency of $1.2 \mathrm{~Hz}$. Reducing the time scale on the $X$ axis to 0.7 seconds revealed more detailed information on the individual spikes (Fig. 7B). The two spikes, taken as a close-up from Fig. 7A, appeared to be triphasic and consisted of a modest first positive wave, followed by a fast, impressive negative deflection and a subsequent rise to conclude with a slow positive wave. The geometry of other recorded spikes varied between the two geometry's shown in Fig. 7B. Quantitative analysis of forty individual triphasic spikes in Fig. 7A yielded a mean duration of $0.47 \mathrm{~s}$ ( $\mathrm{STD}=0.15 \mathrm{~s}$ ); the mean amplitude (top-top) was 0.29 $\mathrm{mV}(\mathrm{STD}=0.07 \mathrm{mV})$.

Analysing an array of adjacent electrodes with a time scale of five seconds, the spikes appeared with a slight time shift (Fig. 8A). To investigate which spikes on two adjacent electrodes related best, the cross correlation ratio was calculated for the signals on two adjacent electrodes (Fig. 8B). The best correlation was found for the spikes with the minimum time shift 


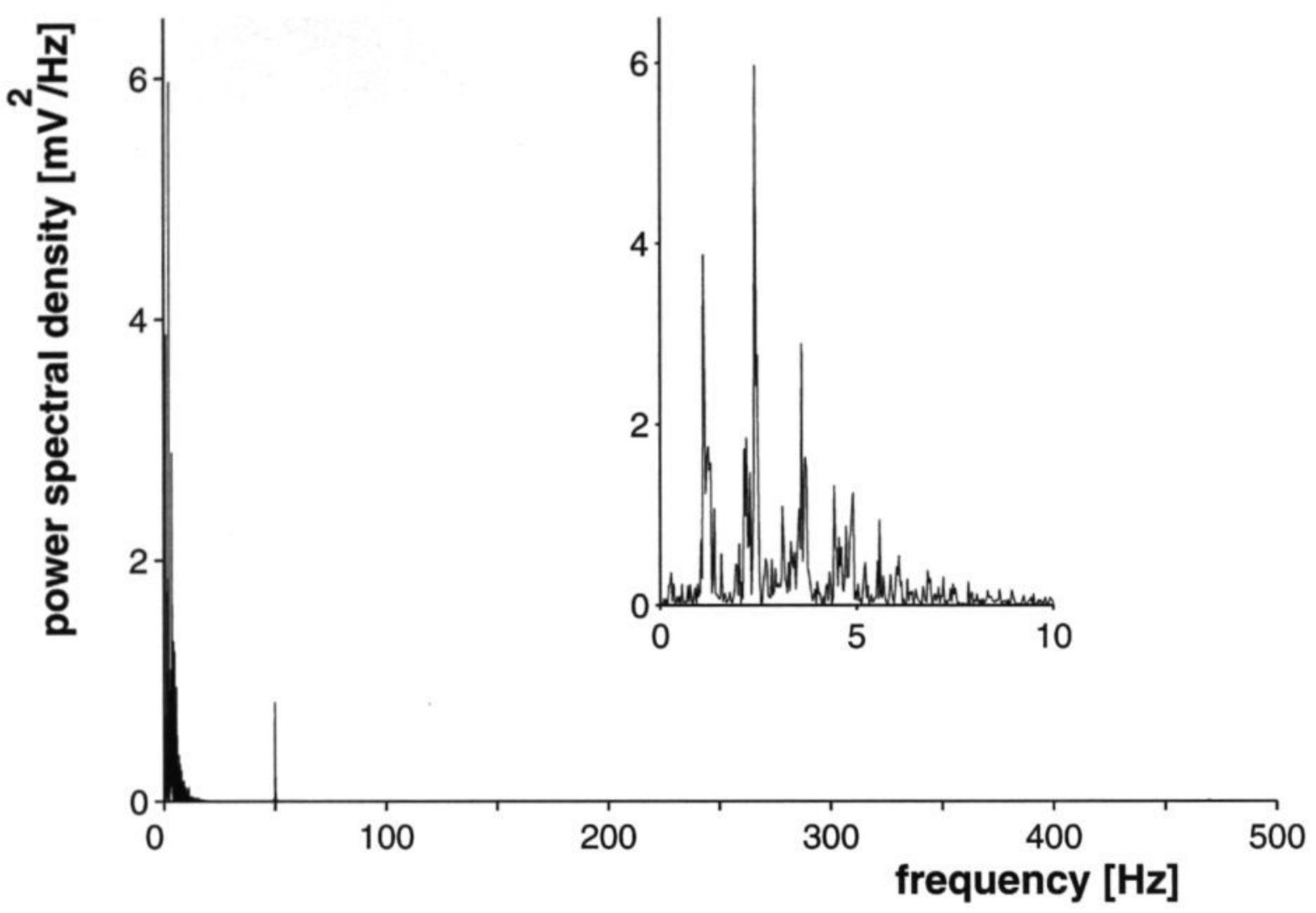

Figure 6: The power spectral density of a raw signal. The filtered version of the raw signal is shown in Fig 7A.

going from one electrode to an adjacent one. This indicated that a unique spike on one electrode could be found on the next electrode as the time nearest spike.

The time shifts on multiple adjacent electrodes suggested a propagation of the electrical activity. To determine the direction and the speed of propagation, time shifts between the time nearest spikes on multiple adjacent electrodes were compared. These time shifts differed. The direction with the maximum time shift between the time nearest spikes on several adjacent electrodes is thought to indicate the direction of propagation. The corresponding conduction velocity, calculated by dividing the distance of the electrodes by this time shift, was up to $30 \mathrm{~mm} / \mathrm{s}$.

In two experiments slow waves were present (Fig. 9). The slow waves also showed a time shift between adjacent electrodes and were present on the edge of the high pass filter of $0.7 \mathrm{~Hz}$.

The electrical activity in each animal was in general located on a limited and varying number of electrodes. The distribution across the 240 electrodes also varied in time. Taking an arbitrary moment in time and analysing a short period, there were regions in the recording area of intense electrical activity and regions of minor or no detectable electrical activity. The spikes could be seen for at least thirty minutes post-mortem; both the repetition frequency of the spikes and their amplitude decreased in time. The slow waves faded away maximally 15 minutes post mortem. After more than an hour all signals became flat and no electrical activity, no spikes or slow waves, could be measured.

The intravesical pressure measurement in one rabbit was excluded from further analysis, because the microtip pressure transducer catheter was placed in the urethra rather than in the bladder. The pressures recorded in the remaining five bladders were rather low, e.g., ten minutes post mortem the mean pressure was $0.51 \mathrm{kPa}(\mathrm{STD}=0.15 \mathrm{kPa} ; \mathrm{n}=5)$ with a mean bladder volume of $51 \mathrm{ml}(\mathrm{STD}=10 \mathrm{ml} ; \mathrm{n}=5)$. The bladder pressures showed no spontaneous contraction-like changes exceeding the noise level ( \pm $0.05 \mathrm{kPa}$ ) of the pressure measurement throughout the electrical recordings.

\section{Control experiments}

1. A massive, clearly visible contraction of the bladder muscle was seen when the outer surface of the bladder in rabbit no. 1 was sprinkled with the 
A

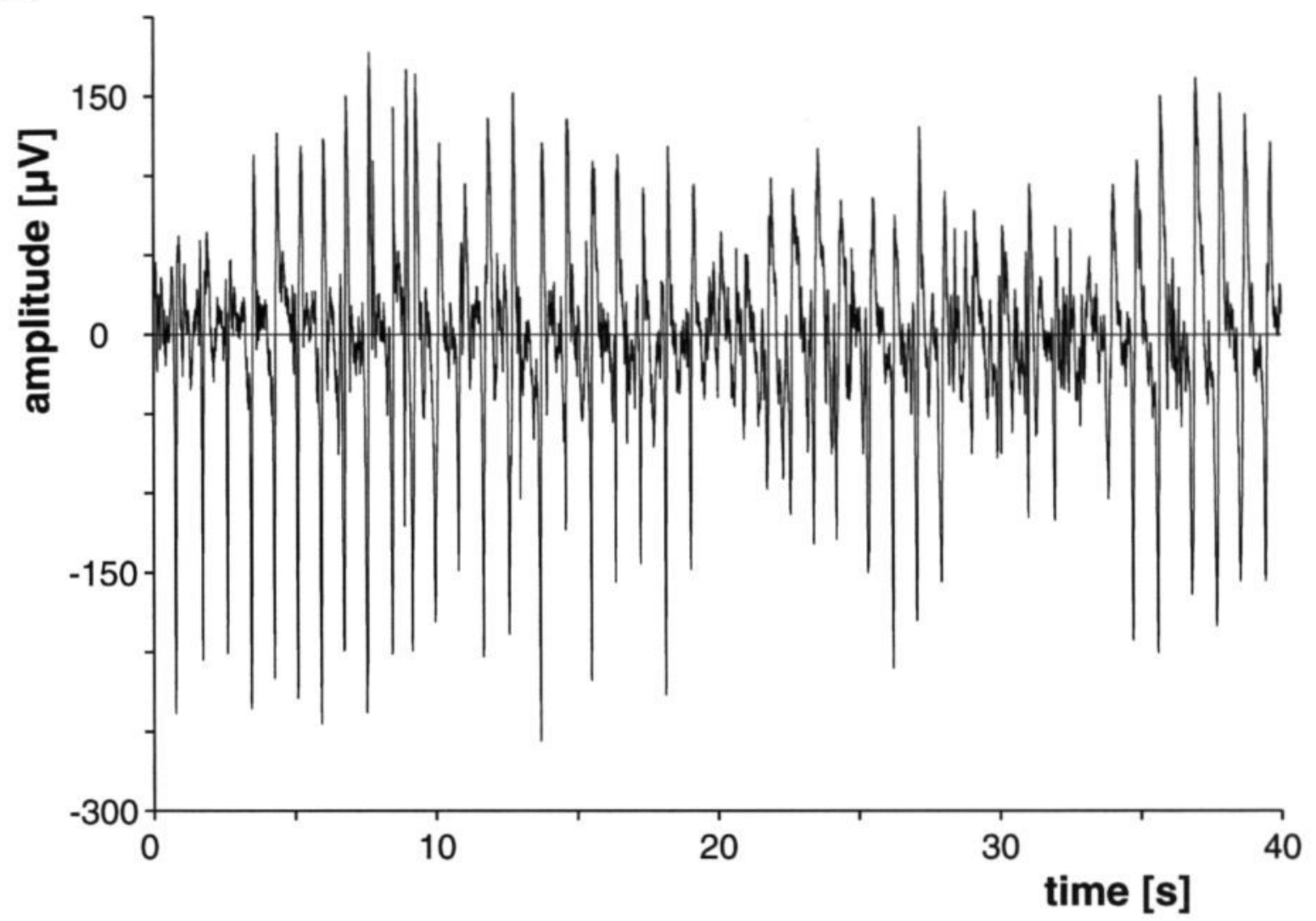

B

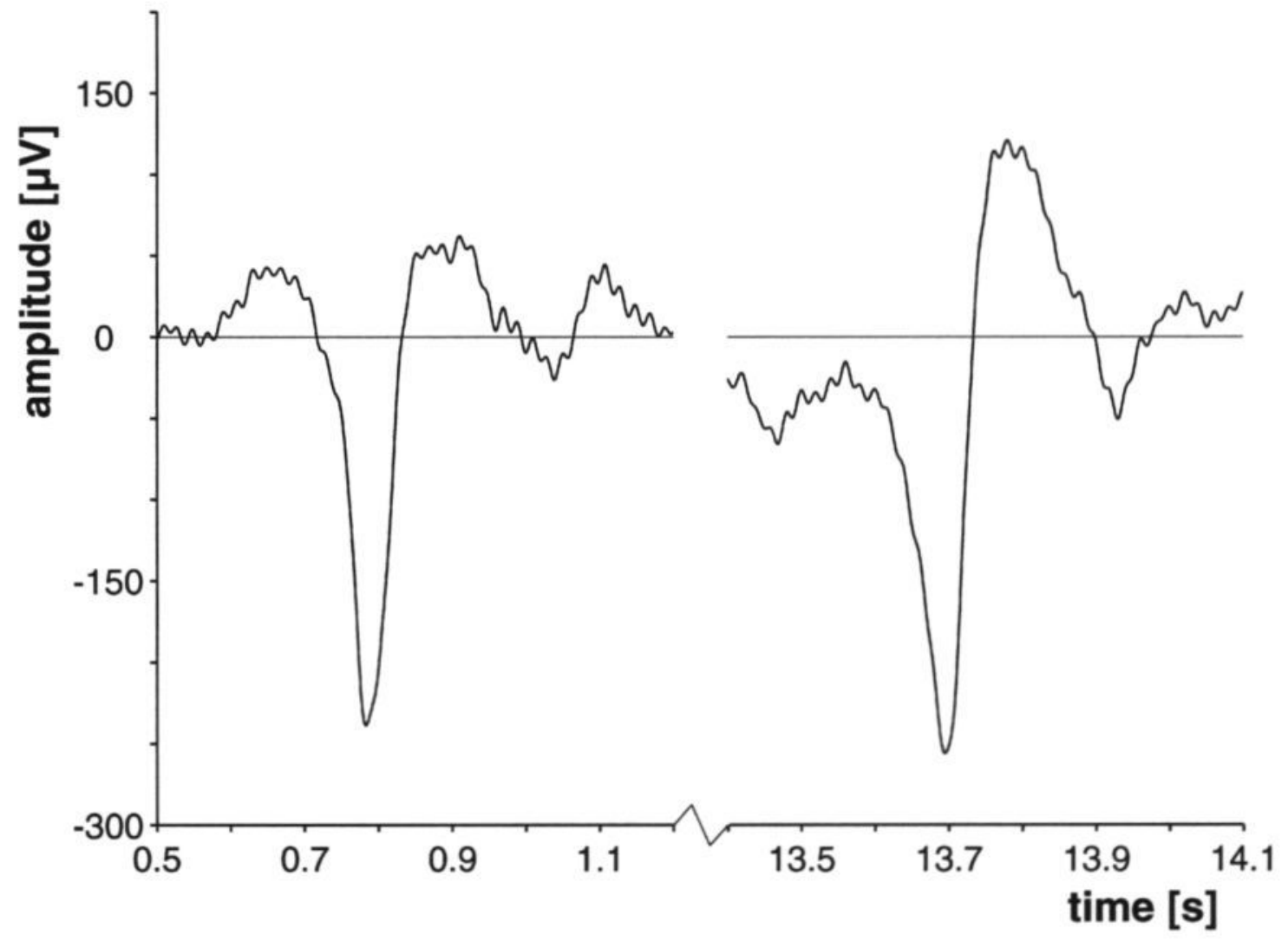

Figure 7:

A) Recording from electrode 120 . The repetitive spike pattern is clearly shown.

B) Focus on two spikes of Fig. 7A. They are triphasic, with some variability in their appearance. 
A

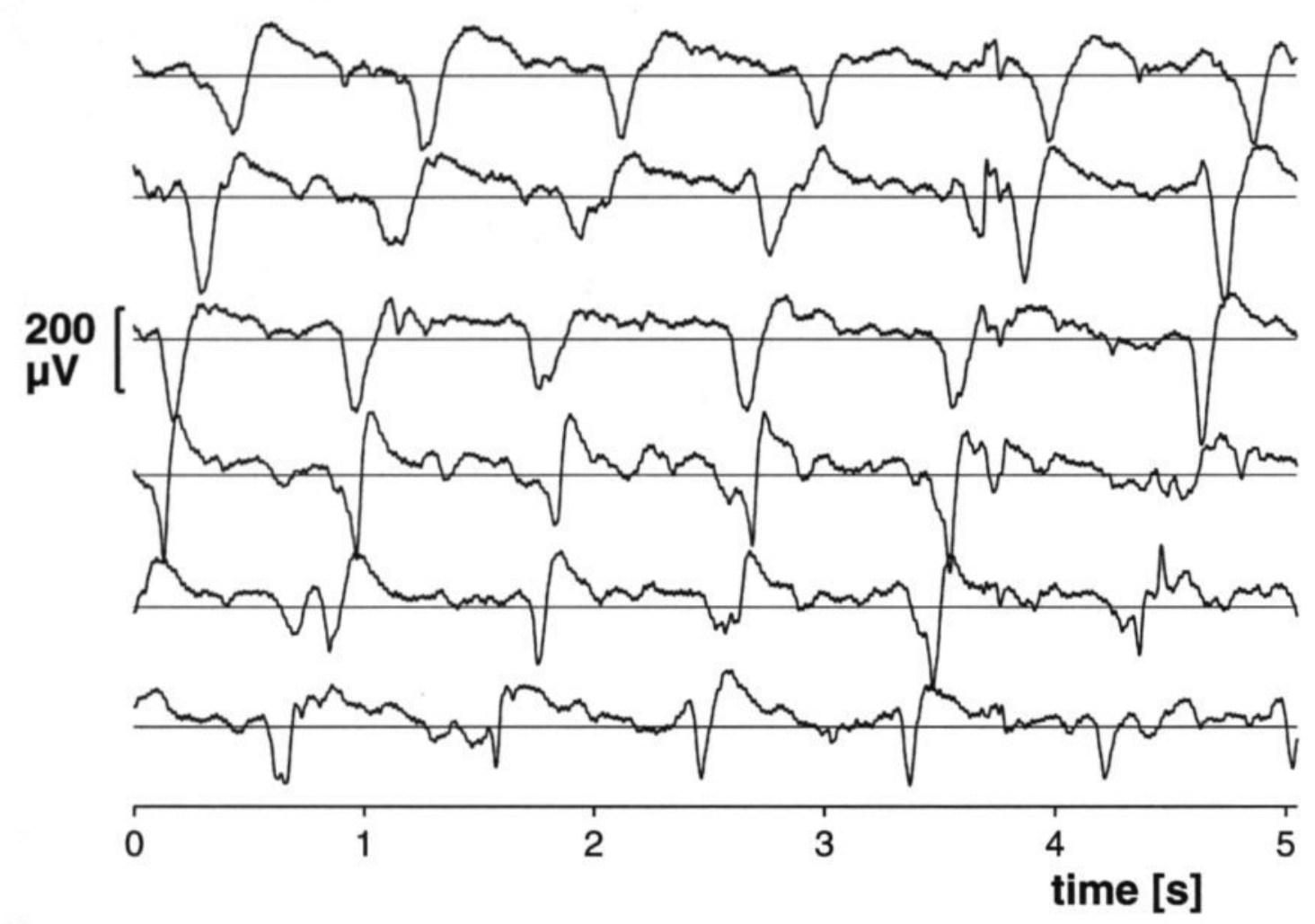

B

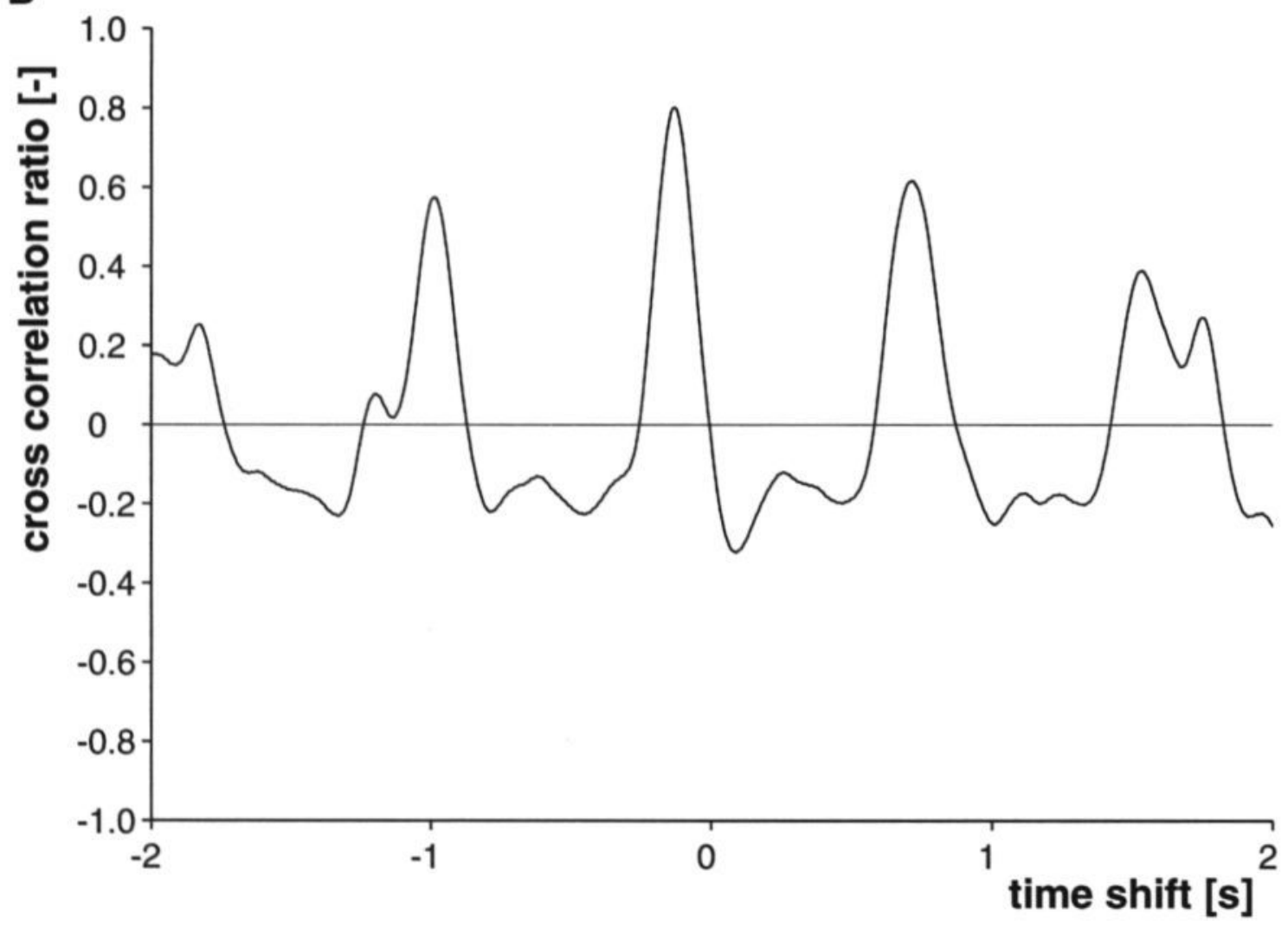

Figure 8:

A) The propagation of spikes across the vertical electrode array 99-104, which is located near the centre of the electrode device.

B) Typical cross correlation ratio, here shown for the two uper traces of Fig. $8 \mathrm{~A}$. The highest correlation ratio of 0.8 occurs at a time shift of $0.13 \mathrm{~s}$, meaning that the time-nearest spikes on these two adjacent electrodes correlate best. 


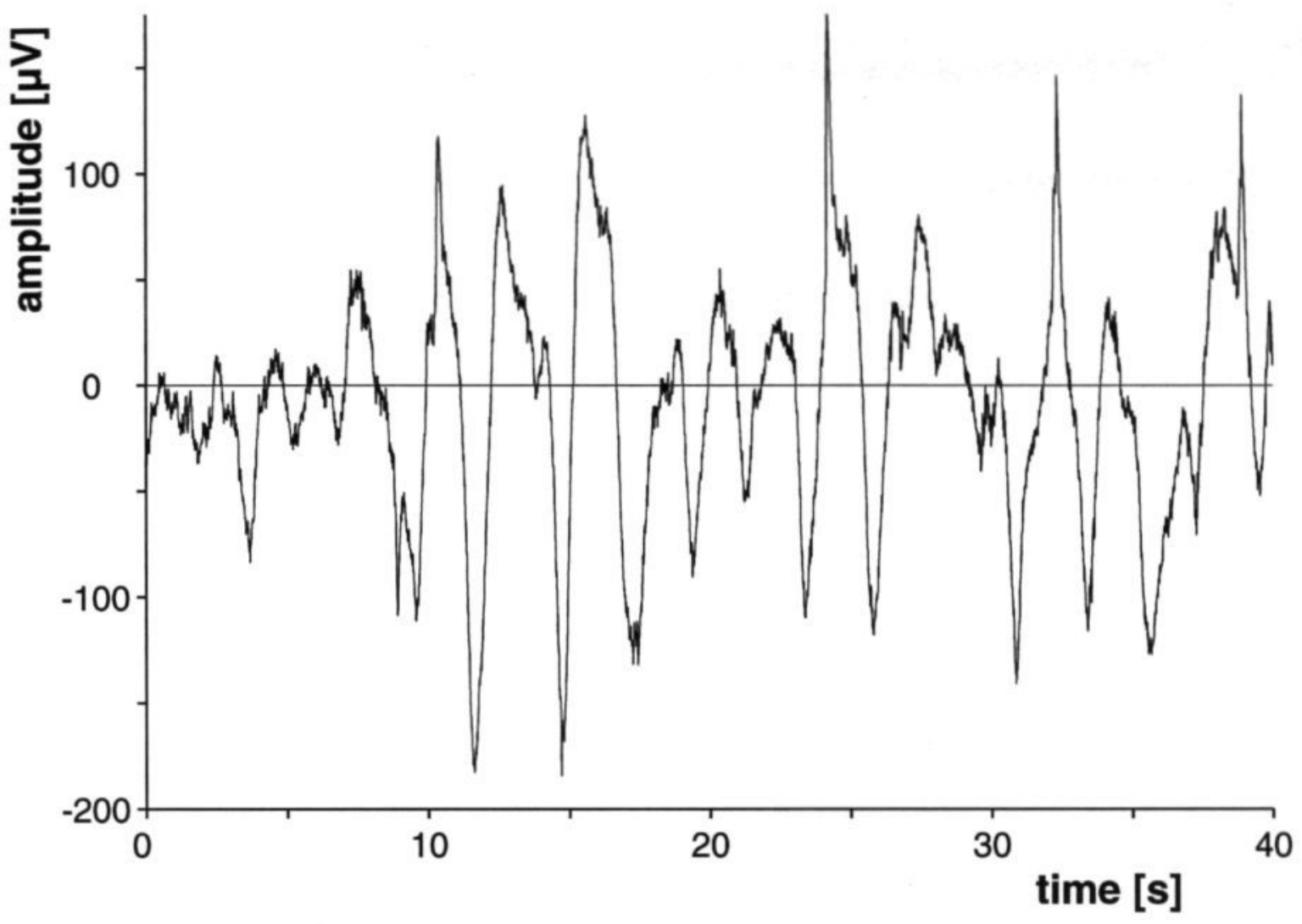

Figure 9: A slow wave on electrode 91.

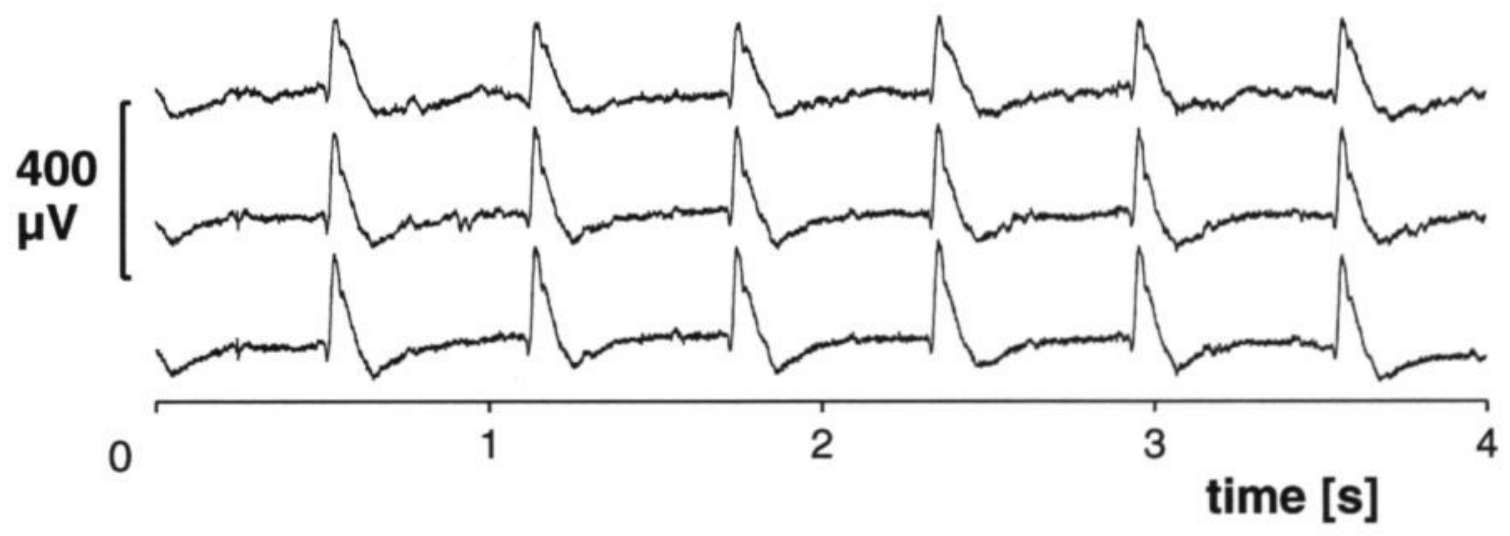

Figure 10: The effect of ECG on the recordings of electrodes 20, 130, and 240. The distance between electrode 20-130 and $130-240$ is $16 \mathrm{~mm}$, between $\mathbf{2 0 - 2 4 0}$ it is $32 \mathrm{~mm}$. The ECG was present at all electrodes and showed no detectable time shift from one electrode to any other. 
A 1.4.

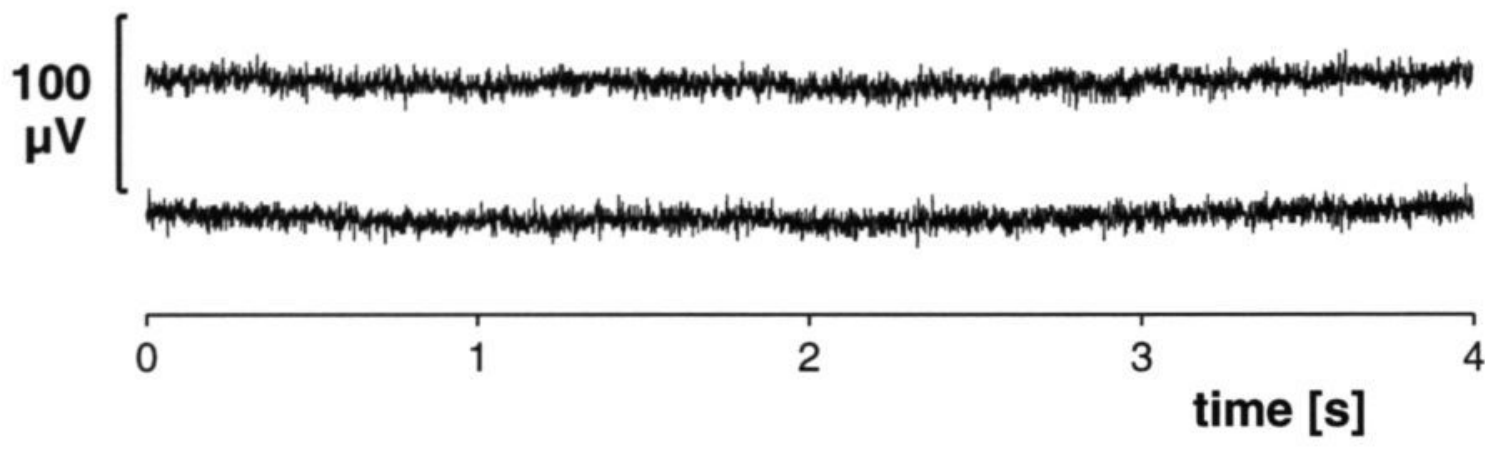

B 100
$\mu V$

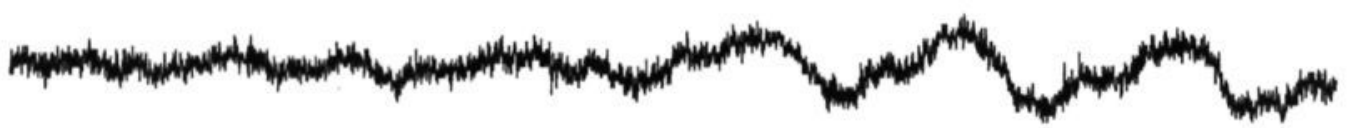

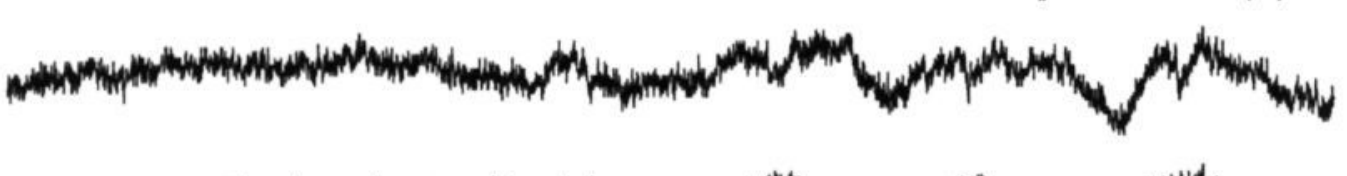
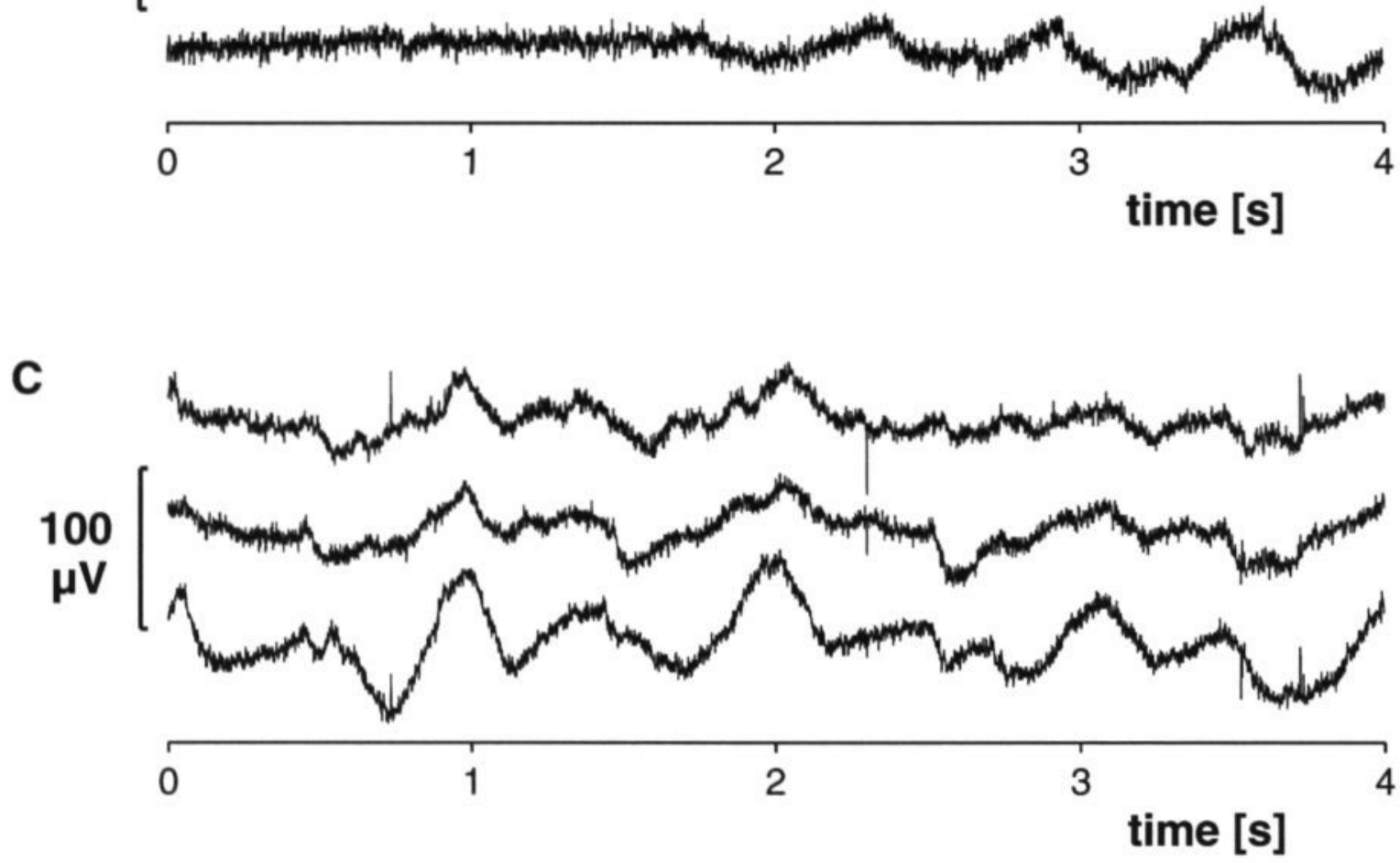

Figure 11:

A) The electrode device was placed underneath a filled rabbit bladder nine hours post mortem. Here it was not moving and the recordings on three adjacent electrodes showed noise only. No spikes or slow waves were present nine hours post mortem.

B) The same set-up as for Fig. 11A. A period of rest (no imposed motion) was followed at second 2 by moving the electrode device with an amplitude of $0.4 \mathrm{~cm}$ in tangential direction. The signals recorded on three adjacent electrodes are shown. The signal amplitudes were about $0.06 \mathrm{mV}$.

C) The same set-up as for Fig. 11A. The imposed motion now had an amplitude of $2 \mathrm{~cm}$ in the normal direction and was applied continuously. Recordings from three adjacent electrodes are shown. The signal amplitudes were about $0.1 \mathrm{mV}$. 
high dose of carbachol $\left(25 \mu \mathrm{g} / \mathrm{ml}, \mathrm{T}=35{ }^{\circ} \mathrm{C}\right)$ ten minutes post mortem. The pressure rise was 0.42 $\mathrm{kPa}$. The bladder wall changed its colour to white and got very stiff upon subjective touch. Once these visible changes had taken place, it was no longer possible to elicit a visible or detectable bladder contraction by sprinkling concentrated carbachol solution at five minutes time intervals. For rabbit no. 2 and 3 , the concentration of carbachol was decreased to $0.25 \mu \mathrm{g} / \mathrm{ml}$. Bladder contractions, verified by intravesical pressure measurements, occurred at every stimulus (applied at five minutes time intervals) and could be evoked at least thirty minutes postmortem. Table II lists the relative pressure, i.e. the pressure just prior to the stimulus $\left(P_{\text {prior }}\right)$ subtracted from the maximum pressure after the stimulus was given $\left(P_{\max }\right)$.

2. Start of the recordings with the heart left in situ resulted in a clear contribution of an ECG in the recordings (Fig. 10). The ECG could be identified as a periodic signal with an amplitude of $0.3 \mathrm{mV}$ and a decreasing frequency in time (start frequency was 1.7 $\mathrm{Hz}$ ). It was present on all electrodes and showed no detectable time shift from one electrode to any other. The ECG disappeared immediately in the recordings after the final excision of the heart.

3. General observations could be made once the electrode device was positioned in the saline solution, on the wet sponge or underneath the bladder nine hours post mortem. No signal components other than background noise were recorded as long as the electrode device was not moving (Fig. 11A). This indicates that signal components possibly caused by spontaneous variation in ion concentrations at the silver electrodes or impedance changes between them are attenuated by the highpass filter settings at $0.7 \mathrm{~Hz}$. Moving the electrode device with a frequency of $1 \mathrm{~Hz}$ resulted in a recorded signal with a frequency of around $1 \mathrm{~Hz}$ as well; a repetitive pattern of disturbances could be generated by imposing a repetitive pattern of motion on the device. The two repetition frequencies were related on a one to one basis. A higher imposed motion amplitude of the electrode device resulted in a higher amplitude of the recorded signals.

3a. Moving the electrode device, which was immersed in a beaker of saline solution, with the motion amplitude of $0.4 \mathrm{~cm}$ had no clearly visible effect on the recordings in either direction of movement. Moving the electrode with the motion amplitude of 2 $\mathrm{cm}$ in either direction resulted in distorted sinusoidallike signals with a maximum amplitude (top-top) of $0.15 \mathrm{mV}$ on some electrodes and minor, less coordinated smooth disturbances on the other electrodes with an amplitude of about $0.05 \mathrm{mV}$.

3b. Moving the electrode device with the motion amplitude of $0.4 \mathrm{~cm}$ on a wet sponge, as to simulate pressure on the electrodes, resulted in sinusoidal-like signals with a frequency of $1 \mathrm{~Hz}$ on almost all electrodes. Very few recorded signals had an amplitude of around $0.25 \mathrm{mV}$; most signals showed an amplitude in the range of $0.07 \mathrm{mV}$. Applying the higher motion amplitude in the same direction resulted in periodic wave-like signals of around $1 \mathrm{~Hz}$ and a signal amplitude of maximally $0.3 \mathrm{mV}$.

Imposing tangential movement with the motion amplitude of $0.4 \mathrm{~cm}$, the limits of the recording equipment were already reached as some signals exceeded $0.5 \mathrm{mV}$. These signals were either periodic and sinusoidal shaped (frequency $=1 \mathrm{~Hz}$ ) or had more random, irregular shapes. Other electrode signals stayed well beneath $0.5 \mathrm{mV}$ and were sinusoidal. The imposed motion amplitude of $2 \mathrm{~cm}$ showed periodic signals with an amplitude of more than $0.5 \mathrm{mV}$ on all electrodes. The sinusoidal-shape was heavily distorted.

3c. Moving the electrode device nine hours post mortem underneath the bladder gave several results. Imposing the motion amplitude of $0.4 \mathrm{~cm}$ in either direction, small sinusoidal-like signals with a frequency of slightly more than $1 \mathrm{~Hz}$ and an amplitude of $0.06 \mathrm{mV}$ were recorded (Fig. 11B). The maximum signal amplitude found on one electrode was $0.1 \mathrm{mV}$. With the $2 \mathrm{~cm}$ motion amplitude applied, the signal amplitudes were a rather stable $0.1 \mathrm{mV}$, regardless of the direction of movement (Fig. 11C).

\begin{tabular}{lcccc}
\hline Rabbit & Mean $\mathrm{P}_{\max }-\mathrm{P}_{\text {prior }}$ (in kPa) & STD $\mathrm{P}_{\max }-\mathrm{P}_{\text {prior }}$ (in kPa) & Max. $\mathrm{P}_{\max }-\mathrm{P}_{\text {prior }}$ (in kPa) & Min. $\mathrm{P}_{\max }-\mathrm{P}_{\text {prior }}$ (in kPa) \\
\hline No. 2 $(n=6)$ & 0.18 & 0.06 & 0.26 & 0.13 \\
No. $3(n=5)$ & 0.25 & 0.04 & 0.28 & 0.20 \\
\hline
\end{tabular}

Table II: Relative intravesical pressure rise after simulation with carbachol solution. The number of stimulations with carbachol is denoted by $\mathrm{n}$. The maximum and minimum pressure value in rabbit no. 2 ocurs at the third and fourth stimulus respectively. In rabbit no.3, this is found at the first and third stimulus respectively 


\section{Discussion}

We want to investigate whether the presented spikes and slow waves are electrical detrusor activity indeed or merely the result of some other phenomena. The impact of signal sources other than eletrical detrusor activity will be evaluated and some results of the control experiments will be discussed. Observations made on the spikes and slow waves will be used for their interpretation, but detailed physiological implications of the present findings are beyond the scope of this paper.

One observation is that the recorded signals fade away in time. This indicates a physiological origin somewhere in the post mortem animal rather than a signal source outside the animal. Possible electrical signal sources inside the animal might be the bowels, the nerve fibers running on the detrusor surface, the striated musculature and the detrusor muscle itself.

Electrical gastrointestinal activity is known to be too slow to measure with the present set-up as it is attenuated by the highpass filter settings at $0.7 \mathrm{~Hz}$ (Weisbrodt, 1991a, b; Guyton \& Hall, 1996). Moreover, picking up electrical bowel activity is unlikely, because the electrodes are in direct contact with the bladder wall, the bowels are pushed at a considerable distance from the recording site and the electrode device itself has a good isolation except for the contact surfaces of the electrodes.

Signals might be recorded from nerve fibers, which are present on the bladder surface, when the electrode device is placed on top of them. The signal components are expected to resemble recordings with wire hook electrodes around nerve fibers meaning that they would contain frequencies clearly exceeding $25 \mathrm{~Hz}$ (Andresen \& Yang, 1989; Le Feber et al., 1997). The electrical activity of striated muscles is known to exceed $25 \mathrm{~Hz}$ as well (Abdel-Rahman et al., 1982; Stöhr \& Bluthardt, 1983). Since the power spectral density of a raw signal shows no relevant signal components above $25 \mathrm{~Hz}$ (except for the $50 \mathrm{~Hz}$ cycle interference) it can be concluded that: either the nerve fibers on the bladder surface were not active or their activity could not be demonstrated with the equipment used; the contribution of striated muscle activity to the present recordings must have been insignificant.

Contractions of the bowels or striated muscles may induce movement of the electrodes or the bladder and result in unwanted signal components. However, the recorded spikes and slow waves show a time shift on adjacent electrodes and a varying distribution in time on the electrodes. This observation indicates that neither a distant (electrical) signal source nor contractions of the bowels or striated muscles cause the recorded signals. Any event that affects the recordings but originates from outside the recording area is expected to result in a similar disturbance on all electrodes at virtually the same moment in time. This is illustrated by the control experiments, especially by the ECG signal. The ECG signal is present on all electrodes and shows no detectable time shift from one electrode to any other. Besides, the ECG signal shows that neither the 240 amplifiers nor other hardware introduce a relevant time shift of the spikes and slow waves on adjacent electrodes.

These considerations point out the detrusor muscle as being the origin of the spikes and slow waves recorded. Since detrusor smooth muscle electrical activity is invariably accompanied by muscle contractions (Creed et al., 1983; Bramich \& Brading, 1996), we wonder to what extent the signals found are caused by each of them. Firstly, contractions of detrusor muscle fibers in our animal experiments do not result in detectable overall intravesical pressure changes. This observation suggests the contractions to be small and/or uncoordinated, which is supported by the local and chaotic appearance of electrical activity in time across the 240 electrodes. Secondly, the control experiments with the bladder nine hours post mortem provide test conditions which are closest to the situation in which the spikes and slow waves were recorded. For contractions of detrusor smooth muscle fibers would predominantly generate motion relative to the fixed electrode device in tangential direction, it seems reasonable to assume that these contractions would produce movement artefacts similar to those generated in the control experiments by moving the electrode device in tangential direction underneath the bladder nine hours post mortem. The signals generated nine hours post mortem do not exceed $0.1 \mathrm{mV}$, regardless of the parameters chosen from the test procedure. In contrast, both the spikes and slow waves show amplitudes of up to $0.3 \mathrm{mV}$, while movement of the electrode device or the isovolumetric bladder is not observed by visual inspection. Thirdly, the triphasic waveform of the spikes corresponds to what is expected with unipolar recording on a muscle by surface electrodes and the grounding and reference electrode on a distant place in the body (Waring, 1974). The typical geometry of the spikes could not be reproduced in the control experiments.

This leads us to the conclusion that signal components in the recordings due to moving muscle fibers of the isovolumetric bladder must be minimal: the recorded spikes and slow waves represent changes in the transmembrane potential of detrusor smooth muscle cells.

The results of our control experiments, in which motion was imposed on the electrodes, confirm earlier 
reports (Brunsting, 1958), keeping in mind the materials and methods used here. It is clear that the slow waves can not be further investigated and validated with the present system settings employed. The slow waves appear on the edge of the present highpass filter setting and their representation may already be attenuated by this first order filter. For more detailed investigation, equipment is needed with highpass filters at a lower cut-off frequency.

\section{Methodological implications}

The electrical activity of the detrusor smooth muscle, as recorded in our post mortem model, contains components actually resembling several artefacts that can occur in a living mammal. The sources of these artefacts were however excluded in our study. This might indicate a major problem for detrusor smooth muscle electromyography in living mammals. The aim of EMG is the study of muscle (patho-)physiology, i.e., the (patho)physiologic basis of (ab)normal mechanical activity. Therefore the relationship between electrical and mechanical activity has to be known. However, the normal functioning of the bladder (collection of urine and bladder emptying) introduces movement of the bladder to the electrodes and hence unwanted signal components which possibly mask the electrical detrusor activity in the recordings completely. Under these circumstances EMG simply would not be a suitable tool to study smooth muscle (patho-)physiology; electromyography would rather produce a detrusor "mechanogram" (Brunsting, 1958). One might argue that a detrusor "mechanogram" is still useful for the study of mechanical muscle activity but then it should not be presented as being detrusor EMG. Instead, one could further explore methods for the study of detrusor smooth muscle physiology which provide more reliable information on mechanical activity (e.g., the application of strain- and force transducers or fluorescent markers (Van Bavel et al., 1996)). The present results on the electrical detrusor activity underline that it will be difficult to obtain reliable information on the functional electromechanical relationship using traditional concepts.

However, the knowledge obtained on signal shape, amplitude and frequency can be used to develop alternative approaches for detrusor EMG in living mammals. For this purpose the experimental set-up and recording equipment described here might be optimized and incorporated or completely different approaches might be chosen. One example of the latter is bladder EMG in humans measured with surface electrodes placed on the abdominal skin as suggested earlier (Kinder et al., 1996). Innovations in data-acquisition techniques can be used to exploit the feasibility of such a new set-up. The advantages of a non-invasive bladder EMG technique, where bladder contractions now indeed seem suitable for validation since the electrodes no longer contact the bladder, are clear.

\section{Conclusion}

A method for detrusor EMG was introduced, in which unwanted signal sources are eliminated or their effect is reduced. The feasibility of the set-up to identify nearly artefact free electrical detrusor activity on a considerable area of the bladder was shown. For detrusor EMG neither the experimental set-up has, to our knowledge, been described before, nor have the propagating spikes and slow waves as presented in this paper. The relationships between mechanical, neuronal and electrical detrusor activity have not been investigated in this study. This remains to be done within the limitations set by detrusor EMG in general.

\section{Acknowledgements}

This study was supported by the Institute Wetenschappelijke Activiteiten Maastrichtse Urologie. The authors would like to thank the Department of Physiology, University of Maastricht, for use of equipment and laboratories.

\section{References}

Abdel-Rahman, M, Coulombe, A, Abdel-Hakim, A, Galeano, C, Elhilali, M (1982) Vesicourethral electromyography: facts or artefacts. Br J Urol 54:381-386

Allessie, MA, Hoeks, APG, Schmitz, GML, Reneman, RS (1986) On-line mapping system for the visualization of the electrical activation of the heart Int J Card Im 2:59-63

Andresen, MC, Yang, M (1989) Interaction among unitary spike trains: implications for whole nerve measurements Am J Physiol 256:R997-R1004

Bastiaanssen, EHC (1996) The neural control of the lower urinary tract: modelling and simulation Dissertation Leiden University, Leiden

Boyce, WH (1952) Bladder electromyography: a new approach to the diagnosis of urinary bladder dysfunction J Urol 67:650-658

Bramich, NJ, Brading, AF (1996) Electrical properties of smooth muscle in the guinea-pig urinary bladder $\mathrm{J}$ Physiol 492:185-198

Brindley, GS (1994) The first 500 patients with sacral anterior root stimulator implants: general description Paraplegia 32:795-805

Brunsting, CD (1958) An interpretation of the urinary bladder "electrocystogram" as artefact J Urol 79:165-170

Cooper, R, Osselton, JW, Shaw, JC (1969): EEG Technology London, Butterworths

Corey, EL, Boyce, WH, Vest, A, French, CR (1951) Electro- 
potential changes in human urinary bladder: a method of measurement J Appl Physiol 3:631-636

Cosgrove, MD, Jones, WG, La Joie, WJ, Kaplan, PE, Morrow, JW (1974) Electromyographic studies of human urinary bladder Urology 3:239-242

Cosgrove, MD, La Joie, WJ, Jones, WG (1977) Further observations of the detrusor electromyogram Urol Int 32:123-126

Craggs, MD, Stephenson, JD (1976) The real bladder electromyogram Br J Urol 48:443-451

Craggs, MD, Stephenson, JD (1982) The effects of parasympathetic blocking agents on bladder electromyograms and function in conscious and anaesthetized cats Neuropharmacology 21:695-703

Craggs, MD, Stephenson, JD (1985) Bladder electromyograms and function in monkeys after atropine $\mathrm{Br} J$ Urol 57:341-345

Creed, KE, Ishikawa, S, Ito, Y (1983) Electrical and mechanical activity recorded from rabbit urinary bladder in response to nerve stimulation J Physiol 338:149-164

Dijkema, HE, Weil, EH, Mijs, PT, Janknegt, RA (1993) Neuromodulation of sacral nerves for incontinence and voiding dysfunction Clinical results and implications Eur Urol 24:72-76

Doyle, PT, Hill, DW, Stanton, SL (1975) Electromyography of the detrusor muscle J Urol 114:208-212

Franksson, C, Petersen, I (1953) Electromyographic recording from the normal human urinary bladder, internal urethral sphincter and ureter Acta Physiol Scand 29:150-156

Fredericks, CM, Anderson, GF, Rasmussen, EA, Pierce, JM (1969) Electrophysiology of the canine urinary bladder Invest Urol 7:33-40

Guyton, AC, Hall, JE (1996): Textbook of medical physiology 9th ed WB Saunders Company, Philadelphia 1148 pages

Hoeks, APG, Schmitz, GML, Allessie, MA, Jas, H, Hollen, SJ, Reneman, RS (1988) Multichannel storage and display system to record the electrical activity of the heart Med Biol Eng Comput 26:434-438

International Continence Society, Abrams, P, Blaivas, JG, Stanton, SL, Andersen, JT (1987) Working party on urodynamic equipment: technical aspects $\mathrm{J}$ Med Eng Tech 11:57-64

International Continence Society, Rowan, D, James, ED, Kramer, AEJL, Sterling, AM, Suhel, PF (1988) The standardisation of terminology of lower urinary tract function Scand J Urol Nephrol 11:5-19

Jones, WG, La Joie, WJ, Cosgrove, MD (1974) Electromyography in pathologic bladder Urology 2:186189

Jünemann, KP, Scheepe, J, Persson-Jüneman, C, Schmidt, P, Abel, K, Zwick, A, Tschada, R, Alken, P (1994) Basic experimental studies on corpus cavernosum electromyography and smooth-muscle electromyography of the urinary bladder World J Urol 12: 266-273

Kaplan, PE, Nanninga, JB (1978) Electromyography of the human urinary bladder Electromyogr Clin Neurophysiol 18:63-68

Kaplan, PE, Nanninga, JB, Lai, S (1976) Electromyography and cystometry of the neurogenic bladder A preliminary report Electromyogr Clin Neurophysio 16:463

Kinder, MV, Bastiaanssen, EHC, Janknegt, RA, Marani, E (1995) Neuronal circuitry of the lower urinary tract; central and peripheral neuronal control of the micturition cycle Anat Embryol 192:195-209

Kinder, MV, Waalwijk van Doorn van, ESC, Gommer, ED, Janknegt, RA (1996) Surface detrusor EMG in healthy volunteers Neurourol Urodyn 15:288-290

La Joie, WJ, Cosgrove, MD, Jones, WG, Kaplan, PE (1975) Electromyography of the human bladder: a preliminary report Electromyogr Clin Neurophysiol 15:191-206

Le Feber, J, van Asselt, E, van Mastrigt, R (1997) Neurophysiological modeling of voiding in rats: bladder pressure and postganglionic bladder nerve activity Am J Physiol 272:R413-R421

Marani, E, Pijl, MEJ, Kraan, MC, Lyckama à Nijeholt, GAB, Videleer, AC (1993) Interconnections of the upper ventral rami of the human sacral plexus: a reappraisal for dorsal rhizotomy in neurostimulation operations Neurourol Urodyn 12:585-598

Nanninga, JB, Kaplan, PE (1978) Experience with measurement of bladder electrical activity J Urol 120:82 85

Shafik, A (1994) Study of the electromechanical activity of the urinary bladder World J Urol 12:316-318

Stanton, SL, Hill, DW, Williams, JP (1973) Electromyography of the detrusor muscle $\mathrm{Br} \mathrm{J}$ Urol 45:289-298

Stanton, SL, Hill, DW, Williams, JP (1974) Electromyography of the detrusor muscle Preliminary communication Urol Int 29:182-184

Stöhr, M, Bluthardt, M (1983): Atlas der klinischen Elektromyographie Verlag Kohlhammer, Stuttgart

Takaiwa, M, Shiraiwa, Y (1984) A new technique of vesical electromyogram with cystometrogram and urethral electromyogram Urol Int 39:217-221

Takaiwa, M, Ishiwata, H, Kobayashi, M, Shiraiwa, Y (1983a) Electromyography of urinary bladder using carbon fiber electrodes Fukushima Med J 33:33-47

Takaiwa, M, Shiraiwa, Y, Katahira, K, Tsukahara, S (1983b) A new urinary bladder electromyogram technique Urol Int 38:1-4

Takaiwa, M, Yamaguchi, O, Yoshimura, Y, Fukaya, Y, Shiraiwa, $Y$ (1992) Recording the bladder electromyogram for bladder activity evaluation during post-operative urinary urgency Fukushima J Med Sci 38: 91-97

Van Bavel, H, Drost, MR, Wielders, JDL, Huyghe, JM, Huson, A, Janssen, JD (1996) Strain distribution on rat medial gastrochnemius (MG) during passive stretch $\mathrm{J}$ Biomechanics 29:1069-1074

Van Duyl, WA, van der Hoeven, AAM, de Bakker, JV (1990) Synchronization of spontaneous contraction activity in smooth muscle of urinary bladder Neurourol Urodyn 9:547-550

Waring, W (1974) Observing signals from nerve and muscle in: Biomedical electrode technology: theory and practice Miller et al Eds Academic Press, Inc, New York pp 215269

Weisbrodt, NW (1991a) Gastric emptying in: Gastrointestinal physiology Johnson Eds Mosby-Year Book, Inc, London pp 32-41

Weisbrodt, NW (1991b) Motility of the small intestine in: Gastrointestinal physiology Johnson Eds Mosby-Year Book, Inc, London pp 42-49 


\section{Three dimensional registration of mechanical bladder}

activity using polystyrene fluorescent spheres: A technical note

CHAPTER 4

Chapter 4 has been accepted on August 31, 1999 as technical note in:

Archives of Physiology and Biochemistry (1999) 107:263-241. 
Matti V. Kinder - Ronald Bos - Paul J.B. Willems - Maarten R. Drost - Carlo A.J. Holtzer ·

Ruud A. Janknegt · Enrico Marani

\title{
Three dimensional registration of mechanical bladder activity using polystyrene fluorescent spheres: A technical note
}

\begin{abstract}
Optical marker tracing methods have been applied succesfully in recent years to quantify local material deformation of heart tissue, skin and striated muscles. In this study, polystyrene fluorescent spheres $(d=0.6 \mathrm{~mm})$ are glued to the ventral serosal bladder wall in the rabbit. Three dimensional video registration of the polystyrene spheres is used to calculate two directions of principal strain $(\varepsilon 1, \varepsilon 2)$ on the bladder surface in vivo. The aim is to investigate the feasibility of the technique for this new application in two experimental circumstances: during spontaneous bladder wall activity and after electrical stimulation of bladder innervating nerve fibers.

During spontaneous activity, random contraction and relaxation occured simultaneously and seperately across the bladder wall for the two principal strains $\varepsilon_{1}$ and $\varepsilon_{2}$. After extradural electrical stimulation of sacral nerve root $\mathrm{S} 2$, the principal strains $\varepsilon_{1}$ and $\varepsilon_{2}$ synchronized in time in such a way that $\varepsilon_{1}$ and $\varepsilon_{2}$ both represented contraction or both represented relaxation. One and the same bladder wall area passed through phases of contraction followed by relaxation and vice versa. After multiple stimulation periods, the coordination between the two principal strains during stimulation was reduced.

This technique allows to identify local areas of contraction and relaxation in the intact bladder wall in vivo. Three dimensional video registration of polystyrene fluorescent spheres to study bladder wall contraction and its relaxation proved to be a feasible technique, with which electrical stimulation effects and spontaneous activity could be measured.
\end{abstract}

Key words: Urinary Bladder - Sacral Nerve Stimulation - Polystyrene Fluorescent Spheres · Strain Field

M.V. Kinder · R. Bos · R.A. Janknegt

Department of Urology, Maastricht University Hospital, Maastricht, The Netherlands

P.J.B. Willems - M.R. Drost

Department of Movement Science, Maastricht University, Maastricht, The Netherlands

C.A.J. Holtzer - E. Marani

Department of Physiology, Neuroregulation Group, Leiden University Medical Center, Leiden, The Netherlands. 


\section{Introduction}

Studies on the overall or local strain distribution of bladder tissue during storage and micturition are absent from literature to the best of our knowledge. Information on local strain distribution across the bladder surface could elucidate where contractions and relaxations originate in the bladder, how they propagate over the bladder wall, and how several wavelike contractions and relaxations interfere.

Not much is known about the relation between electrical and mechanical bladder wall activity either. In EMG studies (Kinder et al., 1997, 1998a, b; Scheepe et al., 1998) the local relation between electrical and mechanical activity of the bladder muscle normally is not determined: overall bladder muscle mechanical activity remains to be estimated indirectly by vesical pressure. Information on properties of local mechanical activity, however, could be crucial for the interpretation of bladder EMG in its relation to the physiology and pathophysiology of the muscle and its innervation, something that has proven to be very difficult to date (Kinder et al., 1997, 1998b; Scheepe et al., 1998). Moreover, it would enable the design of reliable control experiments to describe the effects of electrode movement on the electromyographic recordings as the tissue contracts.

Two dimensional optical marker tracing methods have been applied succesfully in recent years to quantify local material deformation of heart tissue (Delhaas et al., 1993), skin (Van Ratingen et al., 1993) and striated muscles (Van Bavel et al., 1996, 1998), but have been restrained to nearly flat objects. The method described by Van Bavel et al. (1996, 1998) uses polystyrene fluorescent spheres as markers. The coordinates of the marker centroids are obtained by computer processing of digitized video images and relative marker displacements can be calculated as a function of time. Originally, this system was used in a 2dimensional setting, but has been extended to 3 dimensions (Van Donkelaar et al., 1999), which provides the possibility to calculate two principal strains for spherical objects as well. Attachement of polystyrene sphere markers to the serosa of the bladder can give a damped view of the local strain changes of the underlying muscle layers, which can be related to the electrical activity, provided that both are recorded simultaneously.

Alternative approaches to study local mechanical bladder activity are less suitable to be combined with our EMG experimental set-ups. Multidimensional strain gauges are difficult to fix onto the very thin and weak bladder wall without inflicting tissue damage. Each strain gauge requires to be wired what would hamper free movement of the bladder. Moreover, the strain gauge-tissue combination is likely to show mechanical characteristics that differ from those of the unprepared surrounding tissue. Implanting glass fibers through the bladder wall can only be performed in bladder wall strips (Coolsaet et al., 1993). These strain strip results can not be recalculated to the whole bladder and therefore a correlation to the EMG of the bladder is impossible. Using video-urodynamica, in which the bladder is filled with contrast liquid, the overall change in form of the bladder during micturition can be shown in vivo, however, local changes of the bladder surface can not be explored.

These experiments are carried out to estimate whether the use of polystyrene sphere markers to determine strain distribution of the bladder wall is feasible or not. It is investigated whether the polystyrene spheres can be fixed reliably on the bladder serosa and whether the bladder will still perform after attachment of the spheres to the outer bladder wall has been carried out. The regional deformation of the bladder wall is studied under isovolumetric conditions during both spontaneous activity and electrical stimulation of the bladder innervating nerve fibers. Finally, it is determined whether the regional deformation exceeds the resolution of the technique.

\section{Material and Methods}

Two adult male rabbits (Flamisch Giant) were used. Premedication consisted of Hypnorm ${ }^{\odot}(0.5 \mathrm{ml} / \mathrm{kg})$ and was followed by intubation for inhalation anaesthesia: Isoflurane (3-4 \%) and $\mathrm{N}_{2} \mathrm{O} / \mathrm{O}_{2}$. Venal bleeding was decreased by creating a controlled hypotension (Holtzer et al., 1996) and by placing the animal in Trendelenburg position. Arterial blood pressure and heart rate were continously monitored. The pelvic nerve was prepared free by a dorsal approach in advance: the ischiadic nerve was approached and the lower edge of the sacrum was opened. At S1-2 a vertical hemilaminectomy and foraminotomy was performed, by which the split offs of the pelvic nerve from the sacral roots could be reached.

Two stimulation electrodes were placed at a distance of $4 \mathrm{~mm}$ from each other transdurally: first around sacral root 2, and in a second approach around S3. The electrodes were made of flexible teflon coated RFS wire $(\mathrm{d}=0.4 \mathrm{~mm})$ and had a free tip of $3 \mathrm{~mm}$. The proximal electrode served as anode and the distal as kathode. 
A unipolar microtip pressure transducer catheter was placed in the rectum, a quadripolar version (both Gaeltec, Dunvegan, Scotland) was positioned transurethrally with one sensor in the bladder lumen and the three remaining sensors at the level of the striated urethral sphincter and pelvic floor. The urethra was ligated to secure the catheter, thereby creating an isovolumetric bladder. The urethral and detrusor pressure were used to evaluate stimulation effects on bladder and pelvic floor muscles.

The bladder was reached by a ventral laparotomy and kept under luke warm saline. Fluorescent polystyrene spheres (Bangs Laboratories, $d=0.6$ $\mathrm{mm}, \mathrm{n}=36$ ) were fixed on the bladder serosa using histoacryl tissue glue (Histoacryl blau, Braun, Melsungen). The average intermarker distance during the recordings was $2 \mathrm{~mm}$; they were placed over the ventral dome til a few millimeters above the bladder neck in a matrix like pattern, covering an area on an empty bladder of $8 \mathrm{~mm} \times 13 \mathrm{~mm}$.

The video registration unit consisted of two cameras that were fixed on a two dimensional board with an angle of $60.6^{\circ}$ to each other. The cameras were positioned and focussed on the bladder area that was covered with markers. Further data collection and processing was conducted according to Van Donkelaar et al. (1999). In the data interpretation, local macroscopic deformations were described as contraction for negative principal strain and as relaxation for positive principal strain. Underlying physiological mechanisms of individual smooth muscle cells (Glerum et al., 1987; 1990) were not considered.

The stimulus chosen was a blockpulse of $0.2 \mathrm{~ms}$ duration, $20 \mathrm{~Hz}$ frequency and an amplitude range of 0.5-1.5 mA (Nicon Cohen, USA). After stimulation $\mathrm{S} 2$ was chosen for further experiments. Stimuli were given with increasing intervals, ranging from 5 to 40 minutes, until no significant detrusor contraction could be evoked any more.

\section{Results}

Markers were placed in one animal directly on the bladder muscle, after removal of the serosa. Damage of the bladder due to the removal of the serosa interacted with the strain results obtained: extra cooling of the bladder due to prolonged preparation time, damage of the muscles, its innervation and blood vessels. Therefore, only serosal placement of the spheres was subsequently used. Markers adhered well to the serosa using tissue glue. Dripping of luke warm saline did not interfere with the fixation of the spheres. During electrical stimulation the area that was covered with markers reshaped itself into a stronger convex. The marked area remained well within the range the cameras were installed for.

\section{Spontaneous activity of the isovolumetric blad- der wall}

Both contraction and relaxation of the bladder wall could be calculated from the marker displacements. For single fluorescent sphere markers both relative contraction and relative relaxation simultaneously could be distinguished for each principal strain. Only relaxation, only contraction, or relaxation and contraction for the two principal strains were found in separate areas containing more or less markers. The distribution of each of these principal strains was local, showing, however, a concentric wave like appearance travelling over the bladder.

At other localizations the centre of maximum strain stayed at the same local position, ondulating diminishing strain waves over the bladder. The form of these travelling waves were concentric, elliptic or, if two centres were near to each other, cracknel like interfering patterns occurred.

In case that both relaxation and contraction centre of the two principal strains started simultaneously at a similar position, the configuration of each traveling wave could differ.

\section{Activity of the isovolumetric bladder wall after electrical stimulation}

After electrical stimulation of S2 contraction and subsequent relaxation was induced according to the detrusor pressure. Contraction started at the transitional area of bladder neck to dome and propagated with a wave like front. In contrast to spontaneous activity one clear driving centre was present, which lasted throughout the entire contraction phase. It spread towards the dome, for one pricipal strain an active centre split off. A confined area of relaxation was present at the upper part of the dome, finally to be taken up in the contraction wave. After diminuishing of the contraction wave, the relaxation area reappeared and spread towards the bladder neck. For one principal strain the contraction more or less faded away, for the other principal strain a spread of relaxation was shown. In general, for contraction and relaxation both principal strains coincided more than in the case of spontaneous activity.

Activity of the isovolumetric bladder wall after prolonged stimulation

After prolonged electrical stimulation of the sacral root S2 and prolonged exposure of the bladder after laparotomy, both principal strains were clearly 

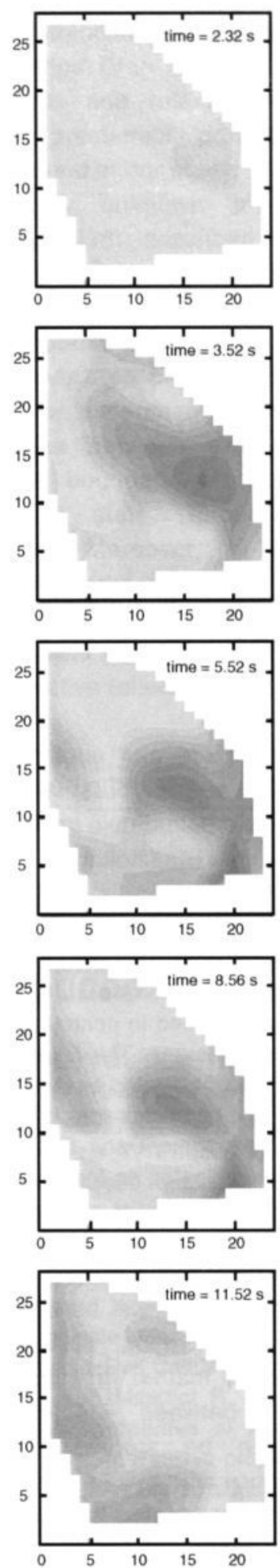
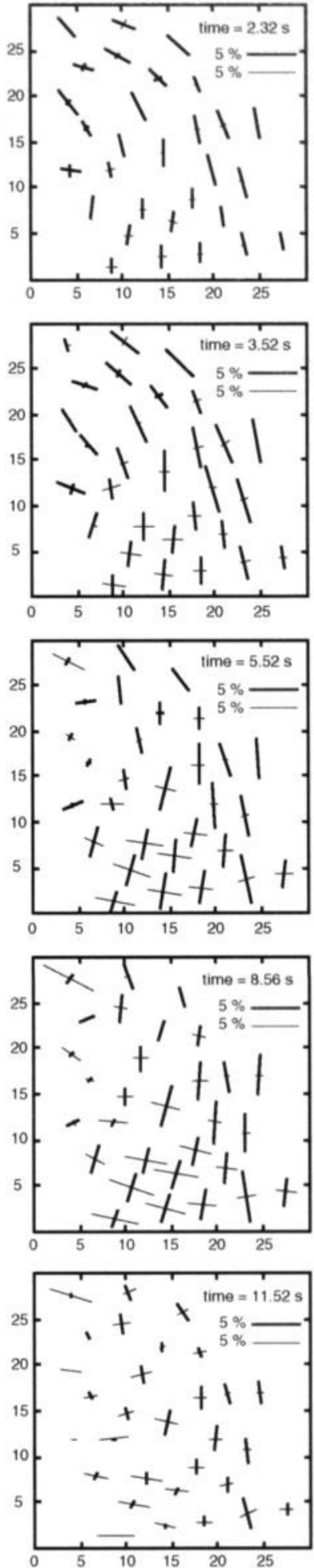
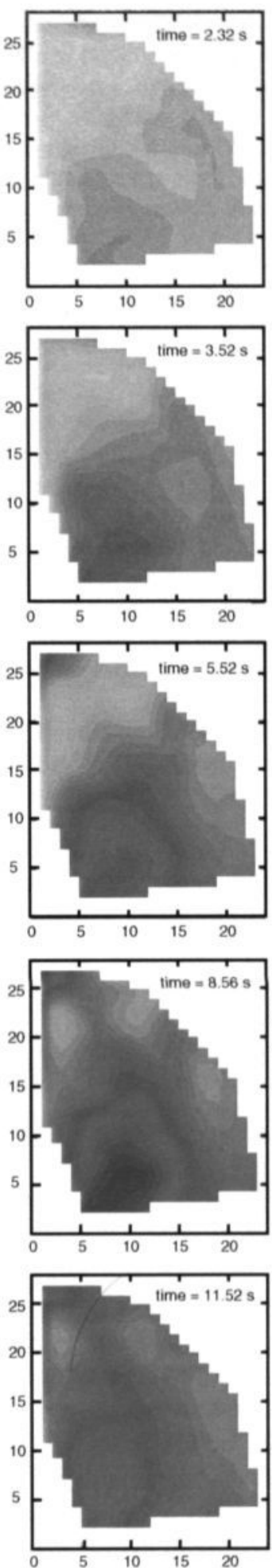

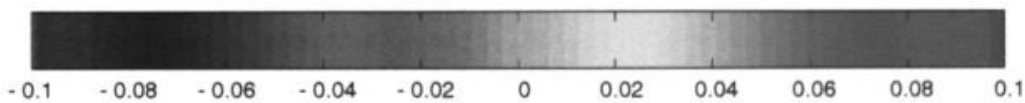

Figure 1: Two principal strains during electrical stimulation after prolonged stimulation earlier in the experiment. The middle column shows a vectorplot of the two principal strains. The left and right column show each a colorplot for one principal strain. Each row of three panels represents the same moment in time. At $\mathrm{t}_{0}=0 \mathrm{~s}$, that is $0.3 \mathrm{~s}$ before stimulation, the strain field analysis started. All strains were calculated relative to $t_{0}$, when all strains were defined being zero \%. The top of each panel is oriented towards the bladder dome, whilst the bottom is located a few millimeters above the bladder neck. The relation in time of the two principal strains to electrical stimulation, intravesical pressure and urethral pressures is displayed in Fig. 2. 

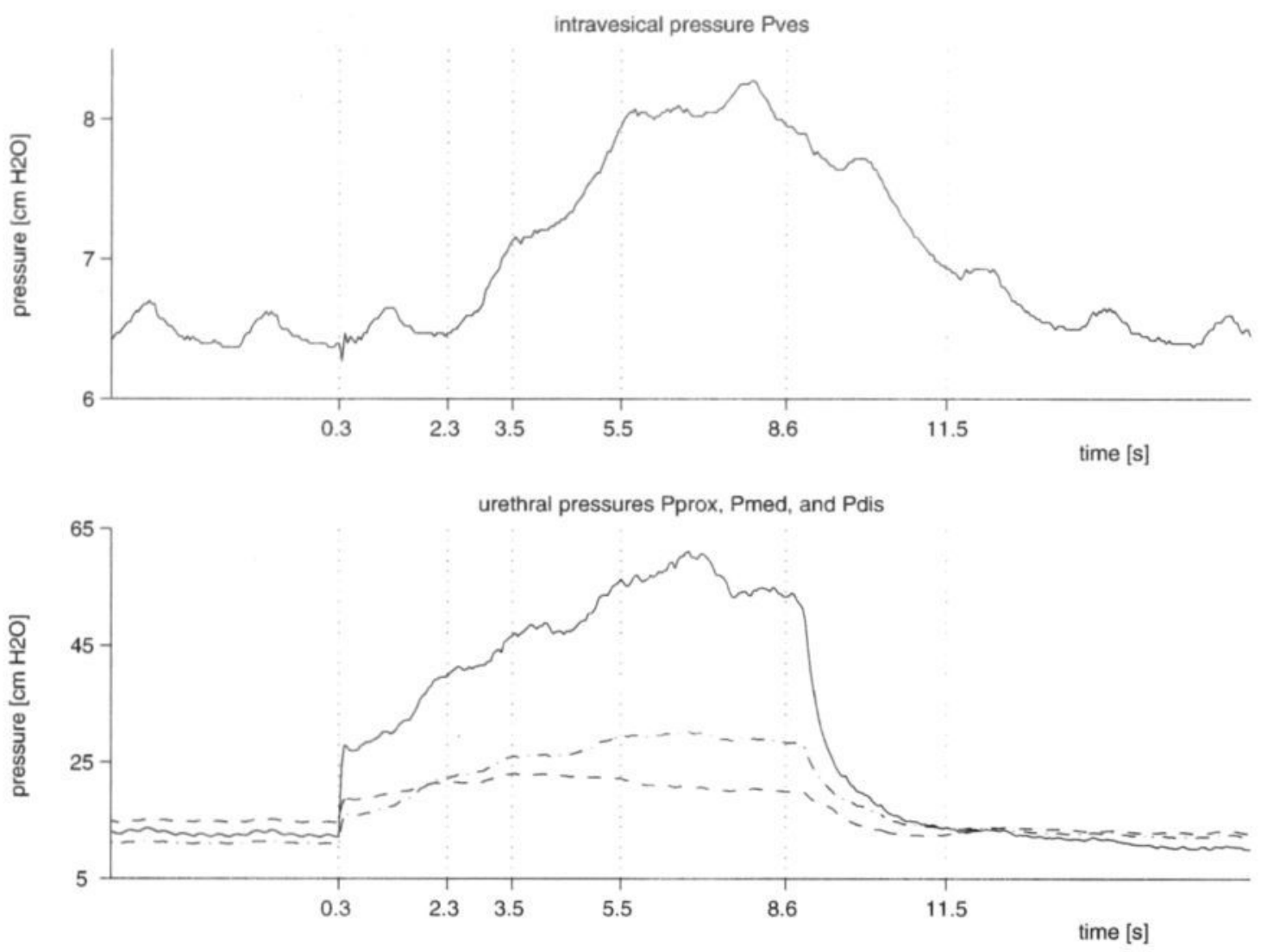

Figure 2: The top panel shows the intravesical pressure (Pves) before, during and after electrical stimulation of sacral nerve root S2. The lower panel shows the three urethral pressures, the proximal (dashed line), medial (dashed-dotted line), and distal urethral pressure (normal line), during the same period in time. Pves can be interpreted as detrusor pressure, since the bladder was exposed by a laparotomy. Electrical stimulation started at $0.3 \mathrm{~s}$ and immediately resulted in contraction of the striated urethral and pelvic floor muscles, which was shown by the fast increase of urethral pressures. The fall of urethral pressures occurred at the end of electrical stimulation. A modest detrusor smooth muscle contraction started several seconds after stimulation was initiated and continued until several seconds after stimulation had ended; a behaviour that is typical for the urinary bladder. These results were obtained after prolonged stimulation earlier in the experiment and the maximum increase of Pves when compared to the first stimulation had decreased about $50 \%$. The times indicated on the X-axis relate directly to the times shown in the strain fields of Fig. 1.

diminished, although still contraction could be noted at the transitional zone of bladder neck to dome upon stimulation (Figs 1-2). Contraction started at the same place as in the previous stimulation. Relaxation of the bladder dome stayed present throughout the stimulation for both principal strains. In general, both principal strains coincided far less when compared to earlier stimulation.

\section{Discussion}

This technique allows to identify local areas of contraction and relaxation on the intact bladder wall in vivo. The measured displacements of the polystyrene spheres surpass the resolution of the applied method by a factor hundred.
The area related to one marker will be covered in the EMG recordings (Kinder et al., 1997) by one electrode on the electrode matrix. In this way the one to one relation between electrical and mechanical activity can be studied in future experiments. In accordance with the EMG set-up we chose to work with an isovolumetric bladder in this study. Other reasons to work with an isovolumetric bladder were that the cameras would more easily stay focused and that most bladder wall deformations would be the result of muscle activity itself. Since a full and relaxed bladder of the rabbit in this set-up is rather flat and oval shaped, an isovolumetric contraction can still lead to shortening of muscle fibers, resulting in a more spherical bladder.

The phenomenon of spontaneous "waxing and waning" of the isovolumetric bladder muscle as 
seen in our recordings of spontaneous activity seems to coincide with results obtained in bladder muscle strips (Van Duyl et al., 1990). The small contractions and relaxations described in these strips are presumably part of the larger wave like motions found in our study.

A relatively unknown article (Kinder \& Van Leeuwen, 1996) described a cellular automaton model of the neuronal activated bladder muscles. According to this model separate waves of activity travell randomly across the bladder surface, leaving a non-active area behind the wave and the active centre. Our experiments, however, show that the whole area between excitation centre and the outermost boundary of the wave stays in a contractive state throughout the electrical stimulation. Moreover, in contradiction to the automaton model, in which the simulated excitable units, representing the smooth muscle cells, return to their initial activation state, these experiments show an active relaxation state.

This technique has proven to be feasible in this bladder wall study and is still flexible, because the diameter and distribution of the spheres can both be enlarged or diminished.

\section{References}

Coolsaet BL, Van Duyl WA, Van Os-Bossagh P, De Bakker HV (1993) New concepts in relation to urge and detrusor activity. Neurourol Urodyn 12:463-471

Delhaas T, Arts T, Prinzen FW, Reneman RS (1993) Relation between regional electrical activation time and subepicardial fiber strain in the canine left ventricle. Pfluegers Arch 423:78-87

Glerum JJ, Van Mastrigt R, Romijn JC, Griffiths DJ (1987) Isolation and individual electrical stimulation of single smooth-muscle cells from the urinary bladder of the pig. J Muscle Res Cell Motil 8:125-134

Glerum JJ, Van Mastrigt R, Van Koeveringe AJ (1990) Mechanical properties of mammalian singel smooth muscle cells III. Passive properties of pig detrusor and human a terme uterus cells $\mathrm{J}$ Muscle Res Cell Motil
11:453-462

Holtzer CAJ, Dahan A, Verschure PCFM, Van Dijk JG, Marani E, Thomeer RTWM (1996) Nerve grafting from spinal cord to spinal nerve: a microsurgical technique in cats. J Neurosci Meth 70:163-169

Kinder MV, Gommer ED, Janknegt RA, Van Waalwijk van Doorn ESC (1997) A method for the electromyographic mapping of the detrusor smooth muscle. Arch Physiol Biochem 105:673-690

Kinder MV, Van Waalwijk van Doorn ESC, Gommer ED Janknegt RA (1998a) A non-invasive method for bladder electromyography in humans. Arch Physiol Biochem 106:2-11.

Kinder MV, Gommer ED, Janknegt RA, Van Waalwijk van Doorn ESC (1998b) Recording the detrusor electromyogram is still a difficult and controversial enterprise. Neurourol Urodyn 17:571-573

Kinder MV, Van Leeuwen JL (1996) Recording and simulation of the electrical activity of the bladder muscle. In: Urodynamica en urine-incontinentie. pp 135-149. Eds. Marani E, Lycklama à Nijeholt AAB, Van Gool JD. Boerhaave Commissie voor Postacademisch Onderwijs in de Geneeskunde, Leiden University, Leiden

Scheepe JR, Wipfler G, Schumacher S, Bross S, Zendler $S$, Jünemann K-P, Alken P (1998) Smooth muscle electromyography of the urinary bladder. Neurourol Urodyn 17:71-83

Van Bavel H, Drost MR, Wielders JDL, Huyghe JM, Huson A, Janssen JD (1996) Strain distribution on rat medial gastrocnemius (MG) during passive stretch. J Biomechanics 29:1069-1074

Van Bavel H, Holtzer CAJ, Van Leeuwen JL, Muijtjens AMM, Willems PJB, Drost MR (1998) Quantification of local surface strains of cat gastrocnemius medialis muscle during contraction. Netherlands J Zoology 48:323-334

Van Donkelaar CC, Willems PJB, Muijtjens AMM, Drost MR (1999) Skeletal muscle transverse strain during isovolumetric contraction at different lengths. J Biomechanics. In press

Van Duyl WA, Van der Hoeven AAM, De Bakker JV (1990) Synchronization of spontaneous contraction activity in smooth muscle of urinary bladder. Neurourol Urodyn 9:547-550

Van Ratingen MR, Petterson R, Drost MR, Oomens CWJ, Janssen JD (1993) A mixed numerical/experimental method to find Langer's lines of skin. Proc. W AM ASME Applied Mechanics, Bioengineering, and Fluids Engineering Conf., New Orleans, Louisiana. 


\section{Demonstration of spontaneous and stretch induced urinary bladder EMG in the living rabbit}


Matti V. Kinder - Ronald Bos

Ruud A. Janknegt · Enrico Marani

\title{
Demonstration of spontaneous and stretch induced
}

\section{urinary bladder EMG in the living rabbit}

\begin{abstract}
Spontaneous bladder EMG was recorded in the living rabbit from an isovolumetric bladder without chemical or electrical stimulation. Mechanical intervention, either by lifting the bladder out of the abdomen or by rapid filling, resulted in stretch induced bladder EMG.

A self made epoxy resin electrode device that embedded 32 EMG recording electrodes in a matrix like pattern, each electrode $\mathrm{Ag} / \mathrm{AgCl}, \mathrm{d}=0.6 \mathrm{~mm}$ with an interdistance of $2.3 \mathrm{~mm}$, was used for registration. The recorder used a common average reference technique and a sample frequency of $400 \mathrm{~Hz}$. A signal bandwidth of $0.05 \mathrm{to} 108 \mathrm{~Hz}$ was available for analysis.

Spontaneous EMG consisted of single spikes and bursts (2-20 spikes), but not of continuous activity. The shape of spikes was triphasic. Single spikes appeared with and without burst activity. Small (2-5 spikes) and large bursts (6-20 spikes) were discerned; small bursts not necessarily propagated across electrodes, large bursts did and were able to organise, suggesting that they were under short neuron system control. Spontaneous EMG was probably related to both contraction and relaxation.

Stretch induced EMG was characterised by continuous activity on all electrodes, spikes that followed each other immediately, slowly fading away. The spikes had an elongated third phase when compared to the shape of spontaneous activity. Highest activity and amplitudes were found after lifting the bladder out of the abdomen and placing it on the electrode device. A concept is put forward in which the continuous activity is not unequivocally related to muscle shortening, but where the current stress and strain situation of the bladder tissue can cause a muscle fibre elongation upon the appearance of electrical activity.
\end{abstract}

Key words: Smooth Muscle . Electromyography - Artefacts - Single Spikes - Bursts - Spontaneous Activity . Continuous Activity

M.V. Kinder - R. Bos - R.A. Janknegt

Department of Urology, Maastricht University Hospital, Maastricht, The Netherlands

\section{E. Marani}

Neuroregulation Group, Department of Neurosurgery, LUMC Leiden and Signals and Systems Group, Faculty of Electrical Engineering, Biomedical Technology Institute, Twente University, Enschede, The Netherlands. 


\section{Introduction}

Urinary bladder EMG studies in human and in living animals were reviewed by Kinder et al. (1997), who showed that the common design of experimental setups induced major artefacts in the recordings. Evoked bladder contraction with subsequent emptying generates movement between recording electrode and bladder muscle, showing major signal disturbances in the recordings. Since bladder emptying is presumed to be accompanied by (increased) bladder EMG, these movement artefacts are often wrongfully interpreted as electrical activity of bladder smooth muscle cells (Brunsting, 1958; Abdel-Rahman et al., 1982; Kinder et al., 1997).

Spontaneous mechanical and electrical activity in bladder smooth muscle cells and strips have been reported (Ursillo, 1961; Creed et al., 1983, 1991; Sibley, 1984; Montgomery \& Fry, 1992; Bramich \& Brading, 1996). Single spikes and bursts of bladder muscle potentials have been unequivocally described (Visser \& Van Mastrigt, 1999). 'Spontaneous electrical activity' should be interpreted here as not induced by chemical or electrical stimuli during the recordings. However, the isolation and fixation of single muscle cells or strips is accompanied by extensive mechanical manipulation.

Assuming that spontaneous electrical activity is present in vivo as well, there seems no initial need to provoke major contractions or bladder emptying for successful bladder electromyography in living animals or humans. In a first attempt to validate this hypothesis, bladder EMG has been studied qualitatively and quantitatively in the mortalised rabbit (Kinder et al., 1997). These experiments were performed under the following standard conditions: after cervical dislocation, the heart was excised and a laparotomy performed; an isovolumetric bladder was created by ligation of the urethra; electromyography commenced as soon as possible after cervical dislocation using a 240 multichannel electrode device that was placed on the outer bladder surface; bladder pressure was recorded continuously and no chemical or electrical stimuli were applied. Since bladder emptying was not provoked, movement between electrodes and bladder wall was reduced to spontaneous bladder muscle contractions only. The recordings were deprived of artefact contributions from heart and respiration that living animal experiments are susceptible to. The basic signal pattern found consisted of a triphasic spike with a repetition frequency of $1.2 \mathrm{~Hz}$, an amplitude of 0.29 $\mathrm{mV}$ and a mean duration of $0.47 \mathrm{~s}$. The present study is a second step to validate that spontaneous electrical bladder smooth muscle activity is present in vivo and similar experimental principles were used for bladder electromyography in the living rabbit.

In the meantime, other EMG studies appeared in which the experimental living animal was the rat (Scheepe et al., 1998). In their signal analysis method, the authors defined an amplitude threshold, above which all activity was interpreted as electrical activity originating from the bladder muscle cells (Scheepe, personal communication). The subsequent rat EMG showed a stochastic occurrence of electrical events in time, of which occurrence and amplitude increased with bladder volume. Unfortunately, no single electrical event has been identified as such by the authors nor has it been isolated in sufficient detail to study its shape and appearance. Their figures indicated a signal amplitude (peak to peak) that ranged between $0.4 \mathrm{mV}$ for an almost empty bladder $(0.1 \mathrm{ml})$ to about $0.7 \mathrm{mV}$ for a full bladder $(0.44 \mathrm{ml})$. Power spectrum analysis showed the basic signal frequency to be below $1 \mathrm{~Hz}$ with a maximum around $0.3 \mathrm{~Hz}$. These results differ significantly of those obtained in the mortalised rabbit. This might partially be explained by species differences, and by the conventional experimental set-up used in the Scheepe study (for discussion, see Kinder et al., 1998a). In their latest study on dogs (Scheepe et al., 1999), the authors identified detrusor EMG above 3 $\mathrm{Hz}$ and now attributed activity below $1 \mathrm{~Hz}$ to (fluid) movement artefacts.

Human EMG studies were reported as well (Kinder et al., 1998b): multiple ECG electrodes ( $\mathrm{Ag} / \mathrm{AgCl}, \mathrm{d}=10$ $\mathrm{mm}$ ) were glued to the suprapubic area of normal healthy individuals to record the EMG activity. Simultaneously, a standard urodynamic investigation (ICS, medium fill) was carried out and a research protocol followed. The promising advantage of this set-up, when compared to previously described ones in literature, was that the recording electrodes did not directly contact the bladder tissue, and subsequently, emptying of the bladder did not generate delusive signal contributions due to movement and friction between electrodes and bladder muscle. Preliminary results showed a monophasic summated EMG signal with a duration of 20 seconds and more, and an amplitude of maximum $0.9 \mathrm{mV}$.

Aim of the present study was to identify the signal components in the living rabbit that represent spontaneous and stretch induced electrical activity of detrusor smooth muscle cells and to discern them from artefact sources like the heart, respiration movement or bowel activity. 
A
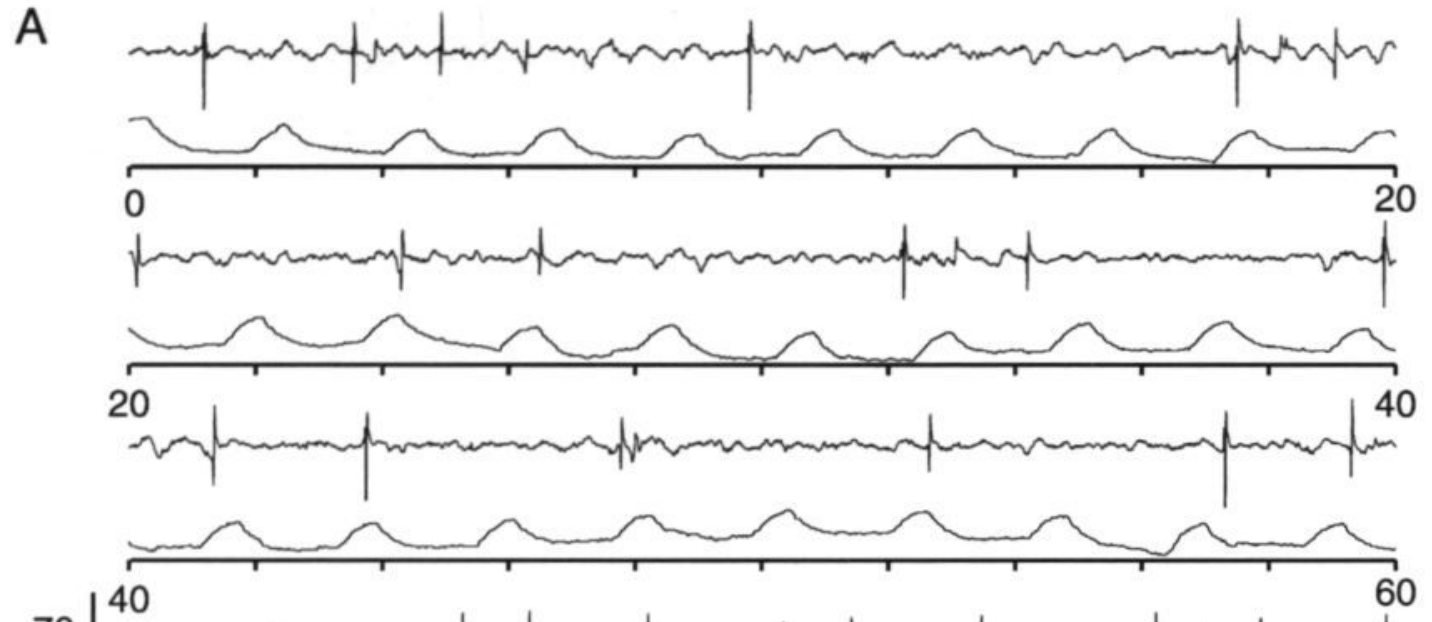

70
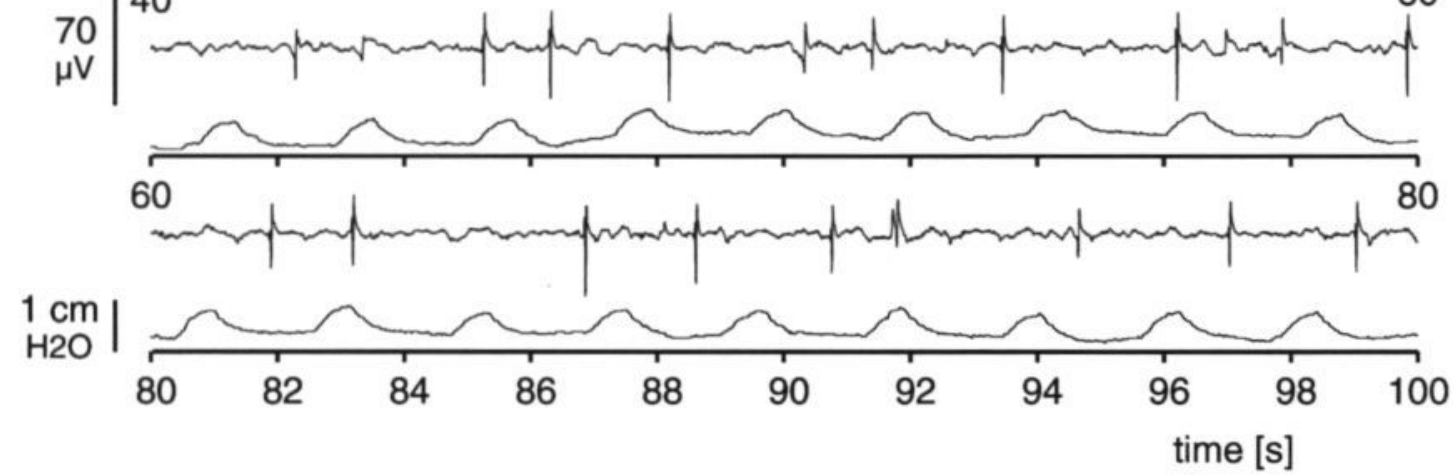

B

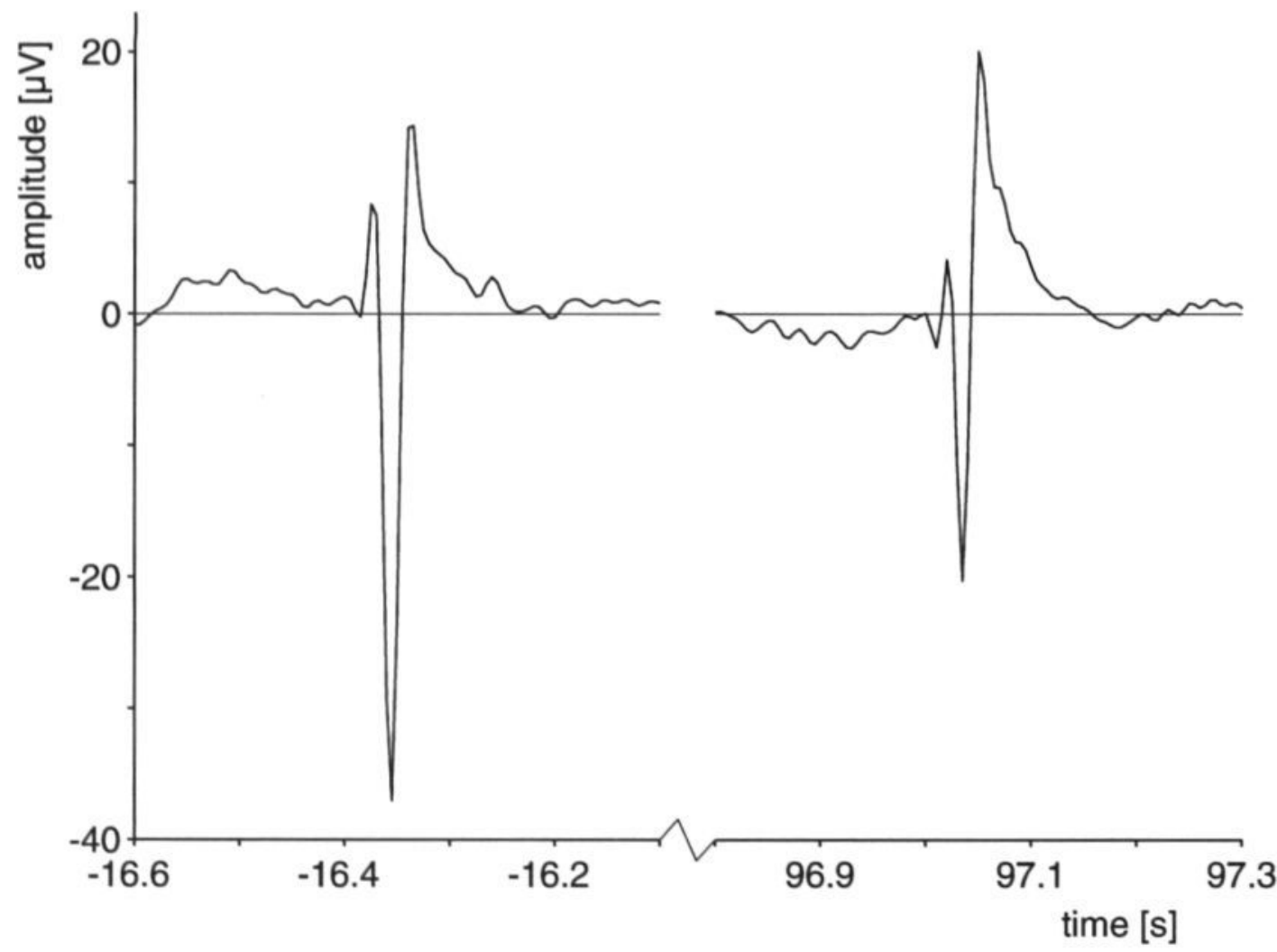

Figure 2: The electrode device was placed on the dorsal bladder wall and the abdominal skin flaps were closed to record spontaneous bladder EMG in animal 3.

A) Single spikes on electrode S28 together with simultaneously recorded vesical pressure during $100 \mathrm{~s}$.

B) Zooming in on two exemplary different spike shapes on electrode S28. Time scaling is related to Fig. 2A. 

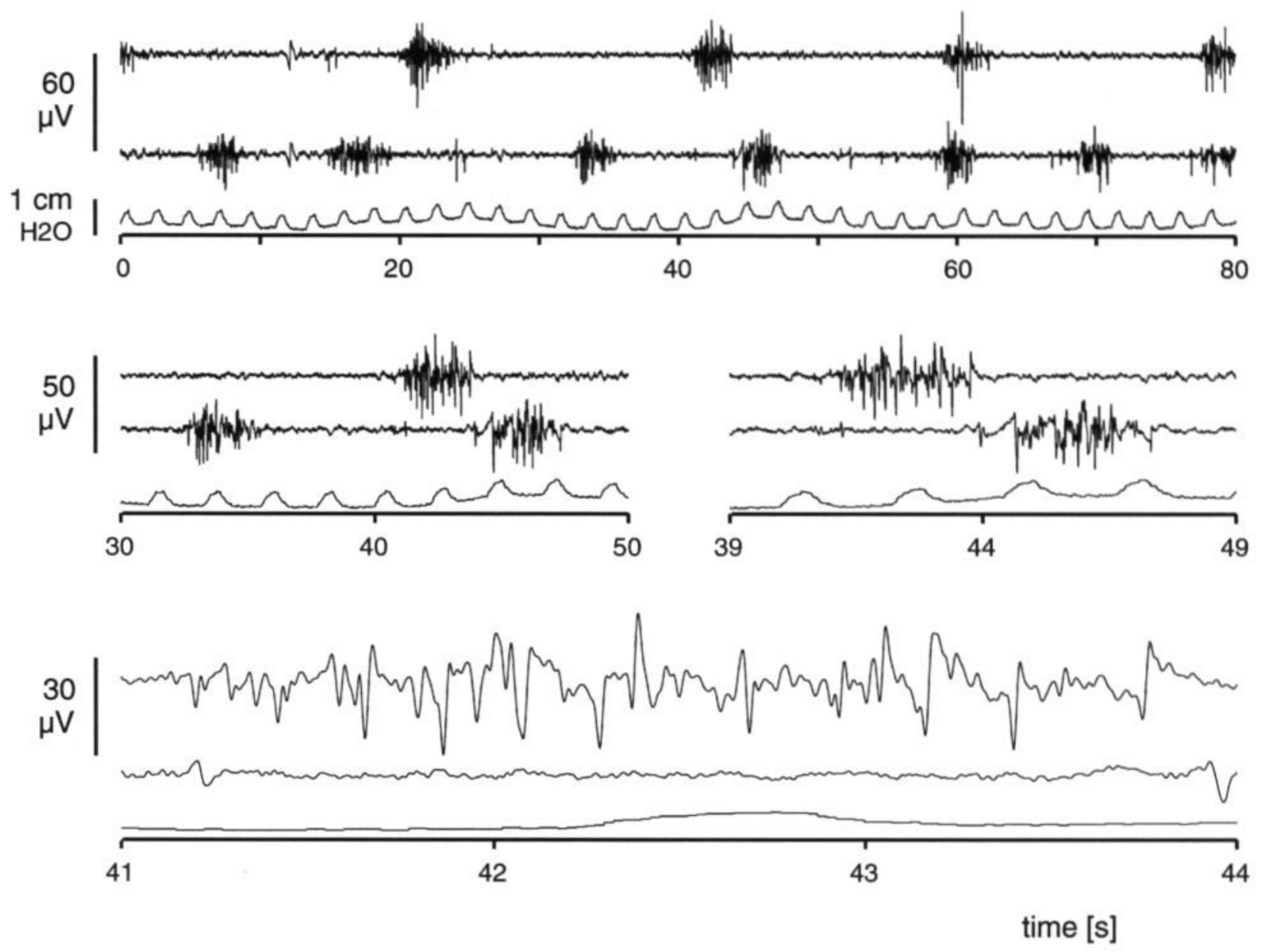

Figure 3: The electrode device was placed on the dorsal bladder wall and the abdominal skin flaps were closed to record spontaneous bladder EMG in animal 6. Four panels show large burst activity and single spikes on two EMG electrodes S1 and S4 accompanied by the simultaneously recorded vesical pressure. The top trace of each panel is EMG signal S1, the middle trace is EMG signal S4 and the bottom trace is vesical pressure, all recorded simultaneously for the time period specified. The top panel has a time scale of $80 \mathrm{~s}$ and serves as a basis for the other three panels that are enlargements, showing $20 \mathrm{~s}, 10 \mathrm{~s}$ and $4 \mathrm{~s}$ respectively as time scale. The two middle panels have identical vertical scales. The single spikes have clearly less amplitude when compared to the spikes contained in bursts.

\begin{tabular}{lcccc}
\hline & $\begin{array}{c}\text { Amplitude } \\
(\mu \mathrm{V}) \pm \mathrm{SD}\end{array}$ & $\begin{array}{c}\text { Spike duration } \\
(\mathrm{ms}) \pm \mathrm{SD}\end{array}$ & $\begin{array}{c}\text { Burst duration } \\
(\mathrm{s}) \pm \mathrm{SD}\end{array}$ & $\begin{array}{c}\text { Number of spikes } \\
\text { Single spikes }\end{array}$ \\
\hline $45.7 \pm 11.9$ & $124.0 \pm 29.9$ & n.a. & 41 \\
Bursts & $70.3 \pm 10.6$ & $101.7 \pm 11.9$ & $3.5 \pm 1.2$ & 12 \\
Continuous activity & $216.2 \pm 19.1$ & $535 \pm 37.7$ & 3.6 n.a. & 12 \\
\hline
\end{tabular}

Table I: Maximum spike amplitudes found for three different types of electrical activity from bladder smooth muscle cells. All values differed significantly at a $\mathrm{p}=0.001$ level using a student's T-test. Abbreviations: not applicable (n.a.), standard deviation (SD). 


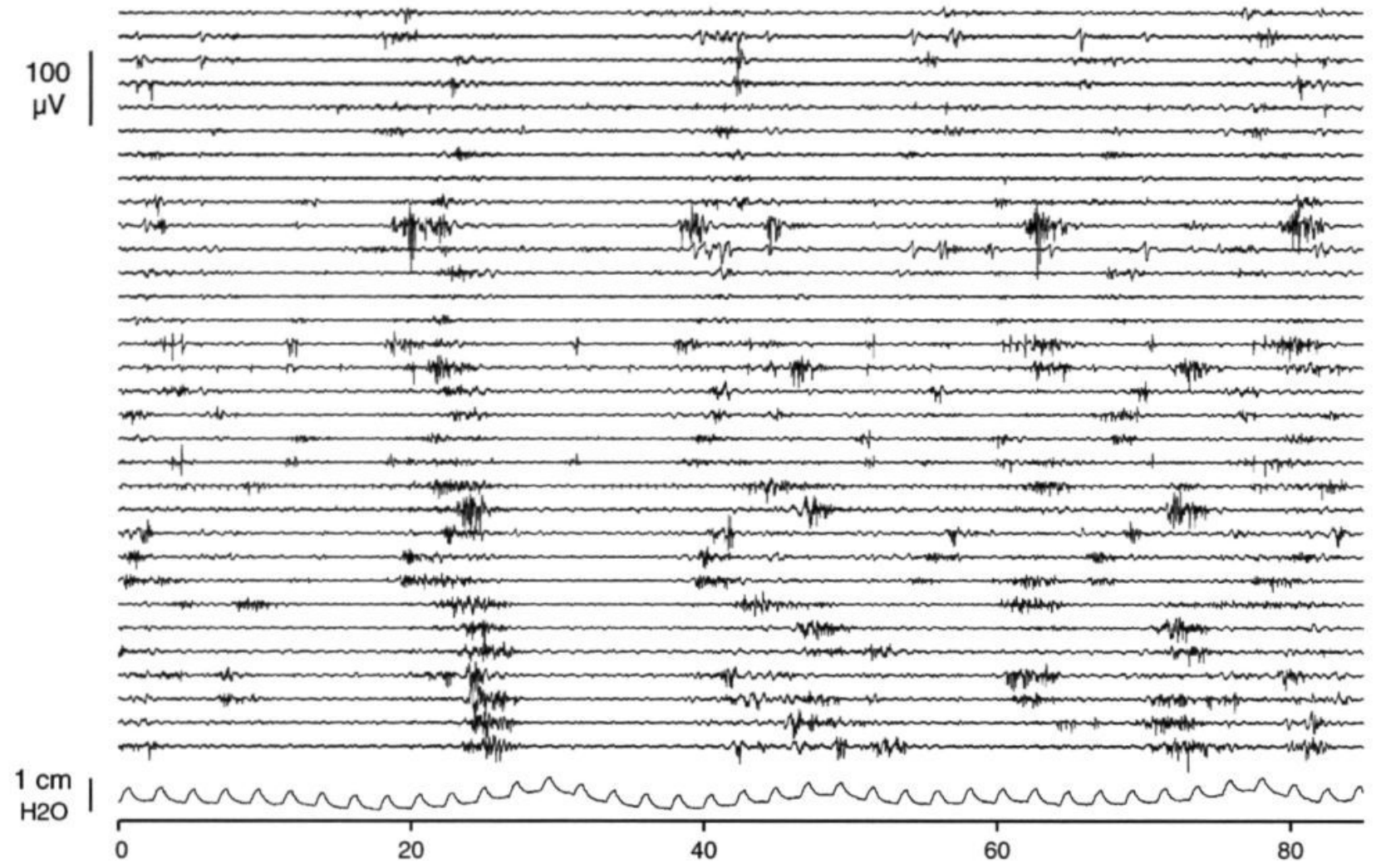

time [s]

Figure 4: The transition between an organised and rythmic burst appearance on the left half and a non-rythmic pattern on the right half was rather abrupt. The rythmic pattern was characterised by a timed burst sequence on several electrodes, followed by a period of relative inactivity, untill the next timed burst sequence occurred. The non-ryhtmic pattern was characterised in that no clearly timed burst episodes could be identified anymore, instead random burst activity was possible at all times. All 32 EMG signals are shown, starting with EMG signal S1 on top to S32 on bottom. For the electrode location, see Fig. 1.

$2 A$ is an excerpt, the repetition frequency of the spikes was $0.4 \mathrm{~Hz}(n=41)$. No relationship was found for the localisation of one spike to the next spike. The spikes did not propagate to adjacent electrodes, indicating their local occurrence, and simultaneous vesical pressure measurements did not show significant changes. They appeared for different bladder volumes and could still be discerned when burst episodes occurred. After chordotomy and cutting the spinal nerves L5-S5 bilaterally, single spikes were still present. The single spikes are called in this paper basic myogenic activity.

\section{Spike bursts}

EMG activity showed spike bursts (Fig. 3), called multiplets in striated muscles (Tarata, 1998). Bursts are defined as grouping of spikes containing 2 to 20 spikes, distributed at random over the burst.

Within a burst, amplitudes of the spikes could differ, but in general were larger than for a single spike. The bursts in Fig. 3 show a mean amplitude of $35.4 \mu \mathrm{V} \pm$ 14.0 SD, and a duration of $64.8 \mathrm{~ms} \pm 14.0 \mathrm{SD}$ for the highest spike in each burst; the total burst duration was $3.0 s \pm 0.60 \mathrm{SD}(n=16)$. The accompanying single spikes have an amplitude of $13.3 \mu \mathrm{V} \pm 5.0 \mathrm{SD}$ and a duration of $73.6 \mathrm{~ms} \pm 25.6 \mathrm{SD}(\mathrm{n}=7)$. The maximum amplitude for spikes in bursts was found in animal 5 (table I).

Bursts containing a large amount of spikes, 6 to 20 , always propagated over several electrodes, while bursts containing small spike amount did not need to propagate. The bursts either had a non-rythmic or an organised, rythmic appearance. A transition between these two patterns was rather abrupt (Fig. 4). The large burst repetition frequency seemed related to the stretch velocity of the muscle fibers rather than to the stretch itself, since slow filling of the bladder did not result in stringing the bursts. Rapid filling or overstretching the rabbits bladder resulted in joining the bursts into a (induced) continuous firing pattern. Burst activity did not induce vesical pressure changes that were directly related to the occurrence of bursts. However, the vesical pressure contained small fluctuations throughout the registration period of bursts. The large burst activity is called short neuron 

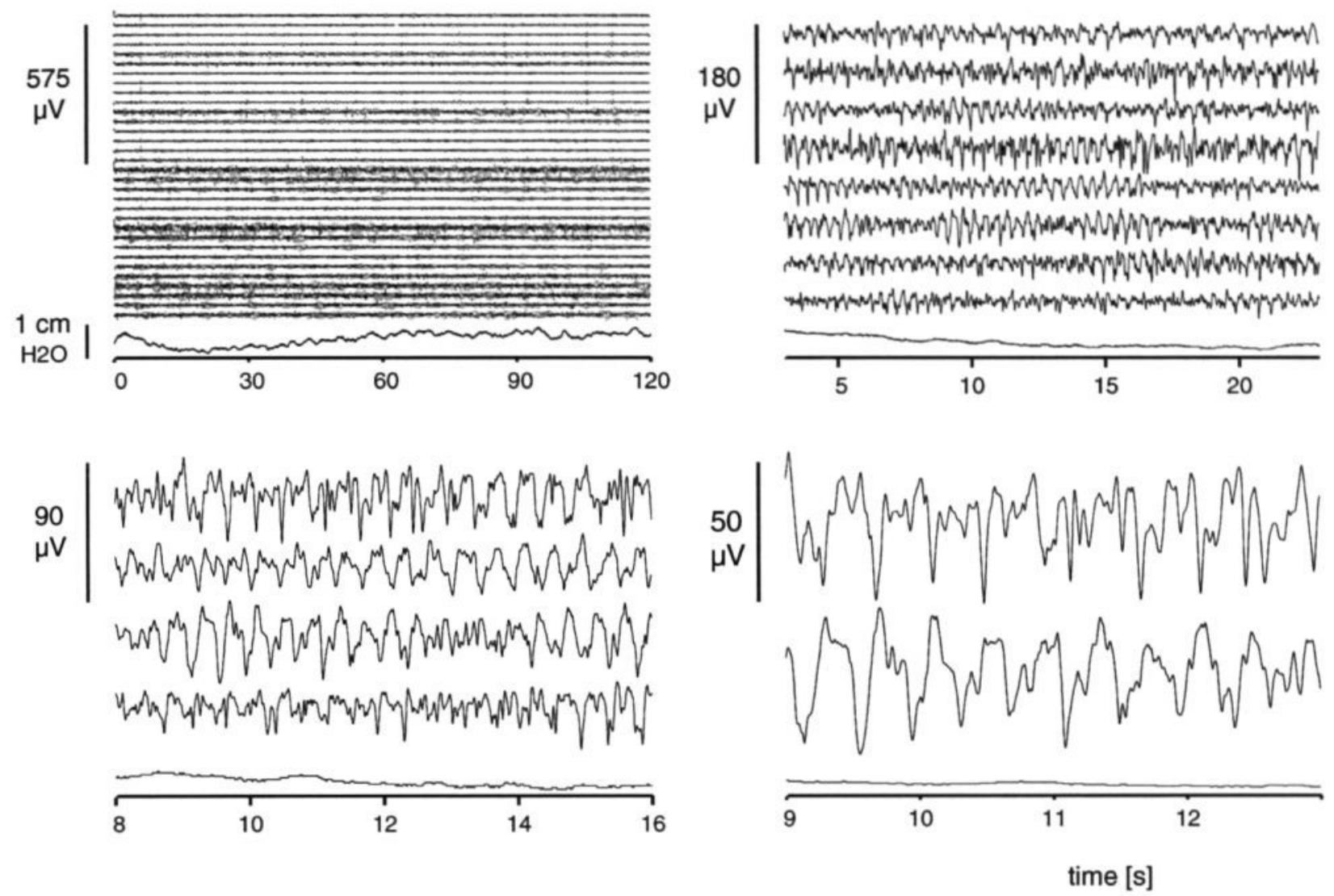

Figure 5: The signals were recorded directly after the bladder had been filled from $40 \mathrm{ml}$ to $80 \mathrm{ml}$ in $45 \mathrm{~s}$, while the ventral side of the bladder was positioned on top of the electrode device in animal 3. Four panels show continuous EMG activity on several electrodes accompanied by vesical pressure for time periods of $120 \mathrm{~s}, 20 \mathrm{~s}, 8 \mathrm{~s}$, and $4 \mathrm{~s}$, respectively.

A) Each single trace represents one of the 32 EMG signals, which are displayed in vertical sequence from electrode S1 on top to S32 on bottom. The vesical pressure is displayed below the EMG signals. The electrode configuration for EMG registration is shown in Fig.1. For example, electrode S4 is not located next to S5 on the electrode device. All signals were recorded simultaneously for the time period of $120 \mathrm{~s}$ shown.

B) Enlargement of A), focusing on S11, S17, S18, S23, S24, S29, S30, and S32 from top to bottom, respectively, for $20 \mathrm{~s}$.

C) Enlargement of B), focusing on S23, S24, S29, and S30, from top to bottom, respectively, for a time period of $8 \mathrm{~s}$.

D) Enlargement of $\mathrm{C}$ ), focusing on in $\mathrm{S} 23$ and $\mathrm{S} 29$ respectively for $4 \mathrm{~s}$.

myogenic activity, mainly because of its ability to switch from non-rythmic to a consistent and repetitive appearance.

\section{Specific distribution pattern}

For the isovolumetric bladder in some cases, main EMG activity was noted on the electrodes at the base of the bladder. Dome activity was then nearly absent, although single spikes were present. Bladder base small burst episodes were composed of confined series of spikes, for which no correlation could be found between neighbouring electrodes. This indicates that each small burst episode had its own appearance in amplitude and shape.

\section{(Induced) Continuous EMG activity in the bladder}

In all six animals, continuous activity could be induced either by rapid filling (Fig. 5) or by handling (Fig. 6), both accompanied by a rise in vesical pressure and independent of the bladder volume. Immediately after intervention the pressure declined and reached a plateau phase, while intense and rythmic electrical activity was present. During continuous activity, spikes repeatedly followed each other, showing large amplitudes. Propagation of spikes could be followed over several electrodes. In time, frequency and amplitude of the spikes deminished, more quickly after rapid filling than after lifting the bladder out of the abdomen and placing it on the electrode device (Figs. 5 and 6). Most intense activity and amplitudes were found for the latter situation. The maximum spike amplitude was observed in animal 4 (table I). The third phase of continuous spikes was considerably elongated in time with respect to the single spikes and spike bursts for both intervention types. The spike repetition frequency directly after 

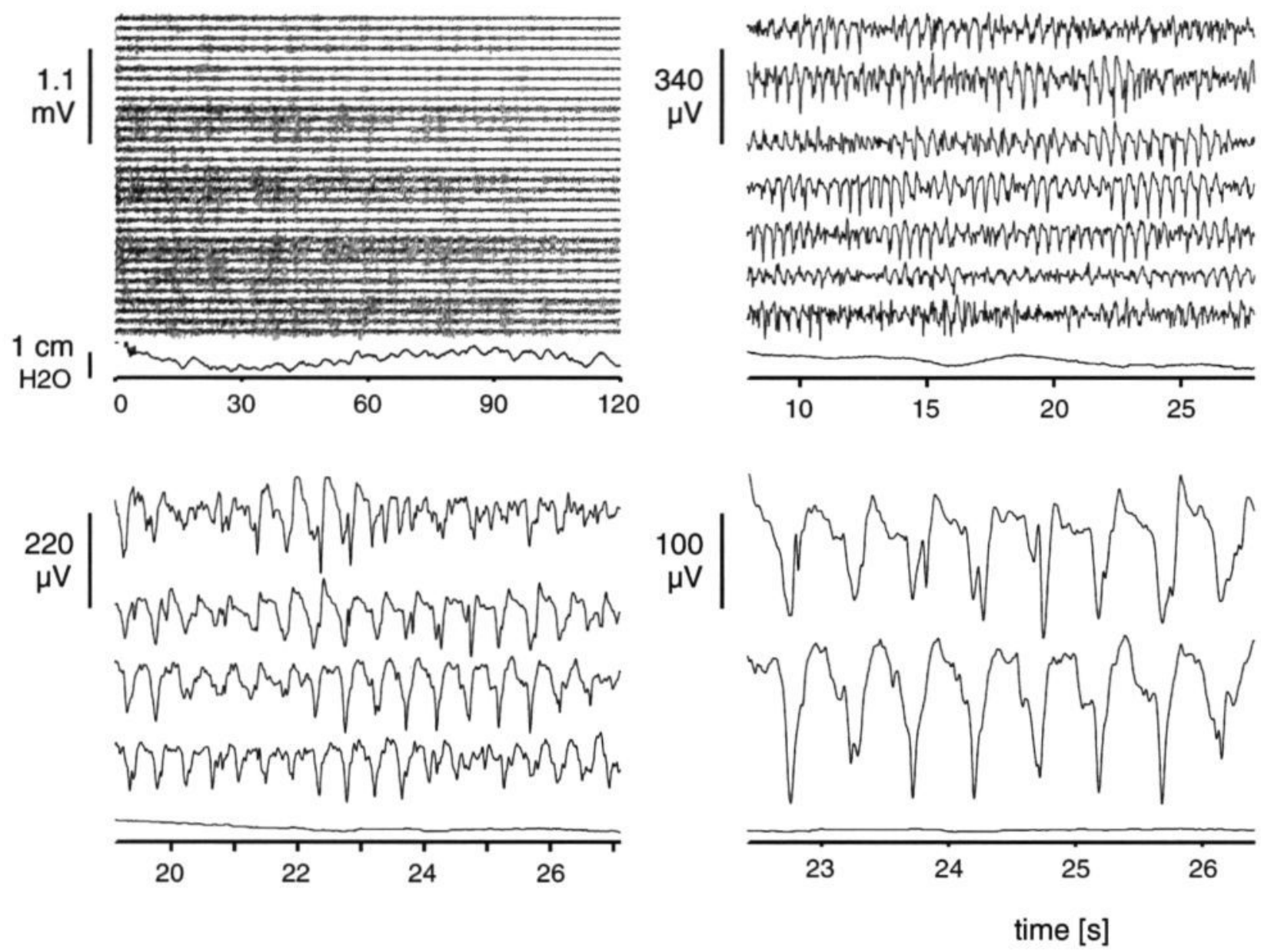

Figure 6: The signals shown were recorded directly after lifting the bladder out of the abdomen and placing its ventral side on top of the electrode device in animal 4. Four panels show continuous EMG activity on several electrodes accompanied by vesical pressure for time periods of $120 \mathrm{~s}, 20 \mathrm{~s}, 8 \mathrm{~s}$, and $4 \mathrm{~s}$, respectively.

A) Each single trace represents one of the 32 EMG signals, which are displayed in vertical sequence from electrode $\mathrm{S} 1$ on top to $\mathrm{S} 32$ on bottom. The vesical pressure is displayed below the EMG signals. All signals were recorded simultaneously for the time period of $120 \mathrm{~s}$ shown.

B) Enlargement of A), focusing on S23 on top to S29 on bottom for $20 \mathrm{~s}$.

C) Enlargement of B), focusing on S24 to S27 from top to bottom respectively for a time period of $8 \mathrm{~s}$.

D) Enlargement of C), focusing on in S25 and S26 respectively for $4 \mathrm{~s}$.

stretching was $1.3 \mathrm{~Hz}$. This activity is called control myogenic activity.

\section{Observations during hardware validation experi- ments in the mortalised rabbit}

New recording equipment and electrodes were tested extensively in the mortalised rabbit to prepare the present study by simulating this research protocol. The stretch induced continuous EMG activity observed was similar to the activity recorded using the old equipment in the previous study (Kinder et al., 1997). Spontaneous EMG in the mortalised rabbit, which was not part of the research protocol in the previous study, showed single spikes and bursts as well, see Fig. 7. These results will not be analysed here in detail, since it was not the aim of study and was used for testing purposes only.

The control experiments that were conducted as described in Kinder et al. (1997) produced qualitative similar results as in the previous study. They did not result in spikes, bursts or continous activity as observed in the present EMG recordings.

\section{General observations}

\section{Shape of spikes}

The shape of spikes was similar for each level of EMG activity, showing a trifasic appearance that consisted of a modest first positive wave, followed by rise to conclude with a slow positive wave, see Fig $2 \mathrm{~B}$ for a close-up of two single spikes. However, the final slow positive wave of spikes found during the induced continuous EMG activity was elongated considerably (Figs 5 and 6 ). 


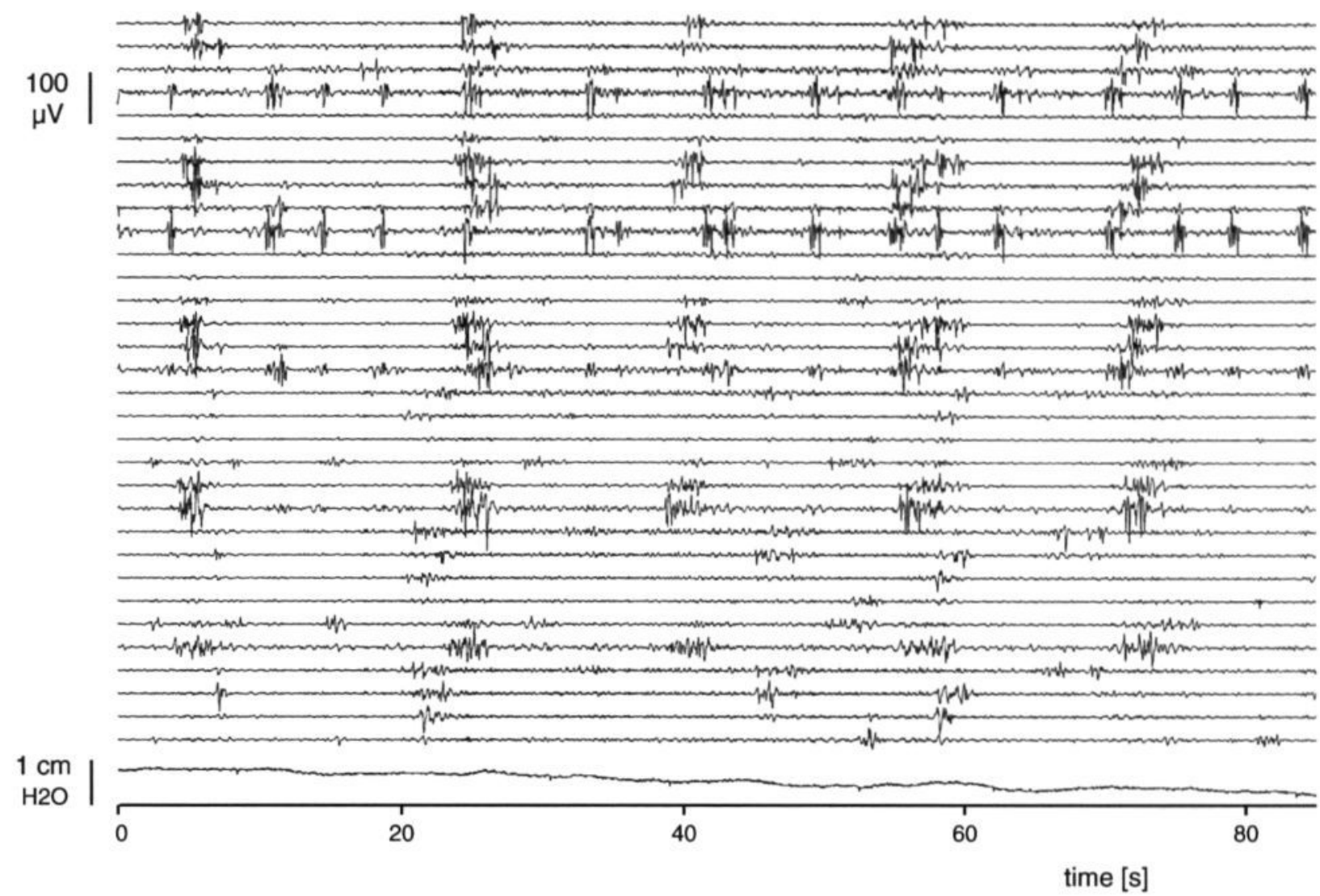

Figure 7: The appearance of bursts in the mortalised rabbit. Comparable to the burst recordings in the living animal, both rythmic and non-rythmic burst activity could occur. Here, non-rythmic burst activity is shown. All 32 EMG signals are shown, starting with EMG signal S1 on top to S32 on bottom. For the electrode location, see Fig. 1.

\section{Bladder shape}

The bladder directly after opening the abdomen had the shape of a flat sack, similar to a balloon on the floor when filled with water. Imposing stretch by filling or by lifting the bladder out of the abdomen resulted in a more globular bladder shape, that became more flat very slowly after the intervention.

\section{ECG, bowel activity and blood pressure}

Interference of electrical heart and bowel activity was not present in the recordings due to the common average reference technique used. Electrodes $\mathrm{S} 1$ and S5, laying near the lateral blood vessel of one rabbit bladder, demonstrated blood pressure changes in their signal. The occurrence of single spikes and of EMG bursts on these electrodes was not related to blood pressure changes.

\section{Respiration}

Respiration frequency was $0.5 \mathrm{~Hz}$ and could easily be identified in the recorded vesical pressure signal. The appearance of single spikes was not related to respiration (Fig. 2A). EMG burst episodes showed a completely different frequency of appearance as low respiration frequency (Fig. 3). The same burst repetition frequency of the EMG was maintained when the respiration frequency was increased. At lower respiration frequencies, EMG bursts could be found on top, flanks and depth of the respiration curve. At higher frequencies, the same appearance of EMG bursts was found, proving that respiration did not induce or correlate to EMG bursts.

\section{Hypnorm ${ }^{\oplus}$ and Isoflurane ${ }^{\oplus}$}

Application of $0.5 \mathrm{ml}$ Hypnorm ${ }^{\circledast}$ reduced the bladder EMG activity considerably. However, this effect disappeared within 5 to 10 minutes after administering. In general, the inhibitive effects of Isoflurane ${ }^{\oplus}$ on electrical muscle activity are well known (Pagel et al., 2000). It reduces the amplitude of the spikes measured.

\section{Discussion}

\section{Artefacts}

Artefact registration has extensively been discussed, including movement between electrode and muscle, 
for a review see Kinder et al. (1997).

Bladder EMG during rapid bladder filling, emptying, and comparable mechanical bladder manipulations was excluded from analysis. Analysis started after these events. The appearance of the accompanying artefacts on all electrodes simultaneously could easily be distinguished from the spikes, spike bursts and continuous activity due to the multiple electrode approach used.

For this experimental set-up, the effect of local bladder muscle contractions on the recordings had been simulated in control experiments (for the control design used see Kinder et al. 1997). The multichannel electrode was moved on a dead bladder surface at frequencies and amplitudes that are comparable to the contraction frequencies and amplitudes of those measured using fluorescent spheres glued on the bladder surface (Kinder et al., 1999b). The control experiments demonstrated not to result in spikes, bursts or continous activity as described in the present EMG recordings. Hence, movement due to local bladder contractions underneath the electrode device is unlikely to produce the signals as recorded in the living animal.

The signal characteristics of the spikes studied are clearly potential related in their appearance (Waring, 1974), both in the immortalised and the living rabbit. Action potential characteristics, like spike duration, shape and course, obtained by in vivo experiments using various recording techniques, are reported in literature (Ursillo, 1961; Creed et al., 1983, 1991, 1994; Montgomery \& Fry, 1992; Bramich \& Brading, 1996, Visser \& Van Mastrigt, 1999). Extrapolation and comparison of these results to the signal characteristics obtained using our extracellular recording technique suggests that they are related.

In the living rabbit, extra disturbing electrical sources are present. Most of these, ECG activity at $4.45 \mathrm{~Hz}$ (present experiments), gastric at $0.08 \mathrm{~Hz}$, and bowel activity at $0.3 \mathrm{~Hz}$, (both in dog, Van der Schee \& Grashuis, 1983), could be excluded in the registration due to the common average reference technique applied. From the mortalized rabbit studies it is known that although bowel activity is present, this activity has no influence on the recordings using the present set-up. However, mechanical disturbances caused by respiration and possibly bowel activity cannot be excluded due to the movement of the bladder to the electrodes, and are refound in the vesical pressure registrered. The occurrence of single spikes and burst showed no relation to the respiration pattern in the vesical pressure. Effects of bowel movement on the vesical pressure were not eminent, suggesting that effects of bowel movement on the EMG recordings must have been neglectable. One type of presumed spontaneous activity, the so called slow wave activity, could not be studied in this experimental set-up, since the respiration frequence nearly overlapped with this slow wave activity. However, in a previous study on the mortalized rabbit bladder, slow wave activity was present in two out of six cases (Kinder et al., 1997).

\section{Single spike activity}

Spontaneous single spike activity has been reported in bladder strips and cells (Ursillo, 1961; Creed et al., 1991; Montgomery \& Fry, 1992; Bramich \& Brading, 1996), but this activity was never so clearly separated from burst like activity in literature as by Visser and Van Mastrigt (1999). The simultaneous appearance of spikes and bursts in their experiments is probably due to stretching the cells during fixation and registration. The sensitivity of urinary bladder strips to stretch has been described early (Ursillo, 1961) and seems to be present in single detrusor cells as well (Wellner \& Isenberg, 1993, 1994, 1995). In our study, however, single spike activity is present with and without bursts, it can be defined as basic myogenic activity. Our recalculation of the results from Visser and Van Mastrigt suggests that the detected single spikes and small bursts are similar to the spontaneous activity we recorded for the intact bladder in living animals.

\section{Burst activity}

Burst activity consisting of few grouped spikes at rythmic irregular intervals or in a non-rythmic appearance in this experimental set-up does not or does propagate, indicating local electrical activity. Small bursts in general do not propagate, large bursts do, having a repetitive appearance.

In a previous study we investigated the feasibility of video monitoring fluorescent spheres placed on top of the outer urinary bladder wall to assess three dimensional strain fields in the living rabbit (Kinder et al., 1999b). Figure 8 shows a period of spontaneous mechanical bladder activity in the same set-up as used for spontaneous bladder EMG (Marani, 2000). The results showed that local bladder muscle areas could contain shortening, but also elongation in both directions of principal strain (Fig 8 and Kinder et al., 1999b). Shortening during spontaneous activity can start in a point and spreads in a circle wave like manner, comparable to a mountain rising up out of the sea. The center point showing maximum shortening can propagate. We assume that such a pattern is related to contraction. Similar patterns can be observed for areas of elongation, that we assume corresponds to relaxation. The electrical burst activity might thus be associated with both, relaxation and contraction. Unfortunately, simultaneous bladder EMG and registration of muscle contractility or relaxation using fluorescent spheres on the same bladder area is impossible using these techniques, since sphere 

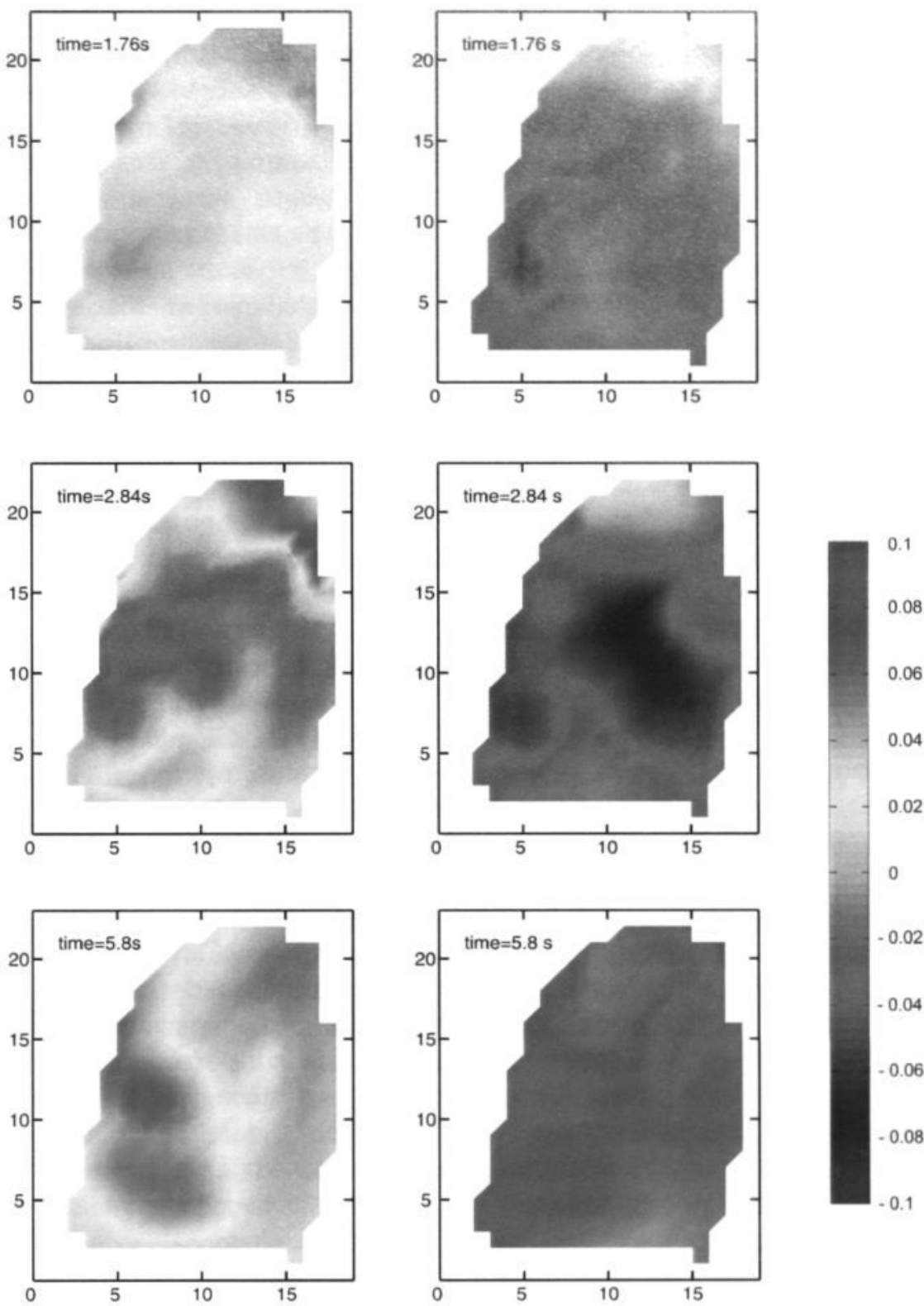

0
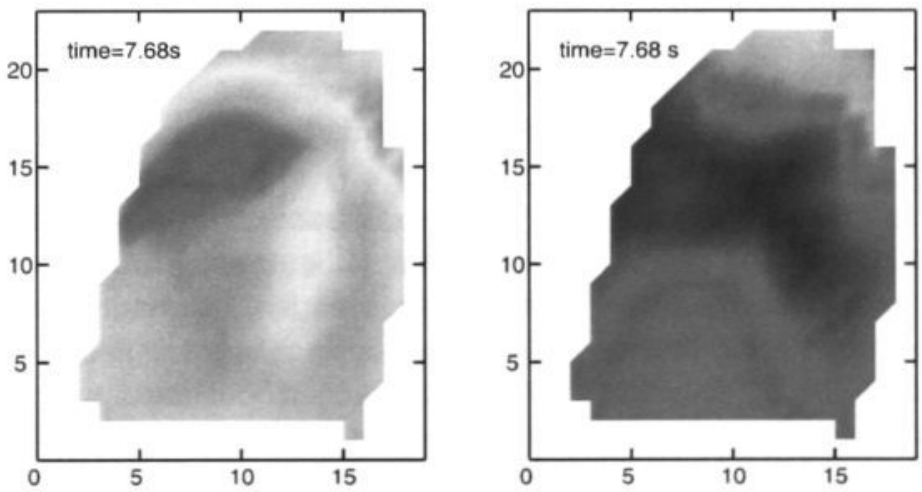

Figure 8: The strain field of spontaneous bladder activity is visualised using a matrix of 32 fluorescent markers attached to the dorsal bladder wall. The marker displacements are filmed using two video cameras, enabling to calculate the three dimensional strain field. Two principal strain directions $\left(\varepsilon_{1}\right.$ and $\left.\varepsilon_{2}\right)$ are shown in the left $\left(\varepsilon_{1}\right)$ and right $\left(\varepsilon_{2}\right)$ column as colorplot. Each row of two panels represents the same moment in time. All strain was defined being zero $\%$ at $t=0 \mathrm{~s}$. In the vertical color bar on the left, 0.1 represents a stretch of $10 \%$, and -0.1 represents $-10 \%$. The top of each panel is oriented towards the bladder dome, whilst the bottom is located a few millimeters above the bladder neck. 
displacement cannot be filmed when an electrode device is positioned on top of them. The possibility of an active relaxation mechanism related to electrical activity should not be ruled out and awaits further investigation. The traditional concept for relaxation of contracted smooth muscles is that this relaxation is associated with dephosphorylation of the $20-\mathrm{kDa}$ myosin light chain (LC20), for a review see Barany (1995). However, the relation between relaxation and LC20 dephosphorylation and vice versa is not established. Stretch induces phosporylation of LC20, probably with $\mathrm{Ca}^{2+}$ involved from intracellular stores (Csabina et al., 1986), but the phosphorylation decreases as a function of time regardless of whether stress was maintained (Barany et al., 1985). On the other hand, various smooth muscles can relax without a significant LC20 dephosphorylation, for example, porcine uterus (Barany \& Barany, 1993) and porcine bladder (Barany et al., 1994), indicating that mechanisms other than LC20 dephosphorylation must exist for relaxation. Glerum et al. (1991) observed relaxation upon electrical stimulation of pig urinary bladder and human a terme uterus single smooth muscle cells.

Whatsoever, it seems reasonable that for local contractions and relaxations local electrical activity propagating over a few electrodes is sufficient. The rythmic large bursts in the present study are able to organise and propagate and are, therefore, considered to be short neuron system related. Since the electrode distance used in this experimental setup and the distance of the fluorescent spheres are nearly equal (Kinder et al., 1999b), the propagation of EMG activity could be compared to the contractile or relaxated area, and indeed, they had the same magnitude.

The importance of the short neuron system in the organisation of the lower urinary tract is not completely clear yet (Kinder et al., 1995, 1999a). The short neuron system consists of juxta- and intramural ganglia, which lie in or on the outer surface of the bladder wall, together with the ganglia of the pelvic plexus (Elbadawi, 1984, 1987a, b, 1991). The ganglia of the short neuron system are innervated by either sympathetic nerve fibres, parasympathetic nerve fibres or both (Bradley \& Teague, 1968). Besides synapses of efferent axons from one autonomic nervous system on dendrites and cell bodies inside ganglia of the other autonomic nervous system, and direct axoaxonal contacts between both parts of the autonomic nervous systems have been discerned on the bladder base and proximal urethra (Elbadawi, 1984). The actual autonomic innervation of the lower urinary tract is derived predominantly from the peripheral ganglia adjacent to or within the bladder and urethra. Extraspinal loops may well be used for local regulation (Bradley \& Teague, 1968; Elbadawi, 1987b; Morrison, 1987). It is speculated that changes in neural control, e.g., changed afferent urethral nerve traffic due to outlet obstruction, can even alter morphologic and physiologic properties of the bladder and that the short neuron system might take a considerable role in that plasticity. In unstable bladders, after outlet obstruction, partial denervation is known to occur. However, partial denervation does not develop in the rat (Brading \& Turner, 1994), which has no intramural ganglia (Gabella \& Uvelius, 1990). In normal behaviour, bladder musculature has to adapt, during the physiological filling phase, to loca tension caused by movement, respiration, bowel activity, etcetera. We suppose that this local adaptation is organised by the short neuron system itself, but under tonic overall input from higher centers (Kinder et al., 1999a). The central influence during the filling phase is limited to exception handling only, and is coordinated by the 'UROCONTROL' structure (Kinder et al., 1999a).

Besides these active centers of contraction and relaxation, the inactive bladder areas act based on their passive material properties. In the isovolumetric bladder, centers of active contraction or relaxation will result in both bladder shape changes and passive elongation and shortening areas elsewhere or on the same place in the bladder. In vivo, the resulting three dimensional strain field is dependent on the active contraction and relaxation behaviour we proposed, possibly heterogenic material properties, and the direction and magnitude of the external load.

\section{Induced continuous activity}

Continuous activity can be induced in our study by over-stretching the bladder, seemingly independent of the initial bladder filling situation. Over-stretching is defined in this context as a forced elongation in a very short time period, the combination of both going beyond any physiological situation. Bladder musculature shows non-linear, visco-elastic material behaviour (Glerum et al., 1990), meaning that the bladder responds differently for fast changes in load than for slow changes. Consequently, the bladder filling situation in our tests was of less importance than the time period in which the load change was imposed when related to the appearance of continuous electrical activity. Stringing the bursts to continuous activity was not evoked by slow bladder filling $(40 \mathrm{ml}$ per three minutes and $80 \mathrm{ml}$ per 10 minutes), but only by rapid filling $(40 \mathrm{ml}$ per 45 seconds) and by lifting the bladder out of the abdomen and placing it on top of the electrode device. Detrusor pressure in both situations, filling 
and mechanical manipulation, rose fast during the intervention, decreased afterwards and reached a plateau phase, underlining the visco-elastic material behaviour of bladder smooth muscle cells. Apparently, the bladder musculature seeks for an adaptation of the bladder surface to reduce the unphysiological stress and the force of gravity imposed on the muscle fibers. Filling or mechanical manipulation have different mechanical effects. Filling imposes a volume increase that results in both an increased globular bladder shape and in forced fibre elongation. Lifting the bladder out of the abdomen is an isovolumetric procedure that elongates the trigonal area, but invites the ventral bladder side to shorten: the transition to an increased globular bladder shape always was clearly visible in the experiments, indicating that at least an initial overall contraction must have occurred.

The plateau phase in detrusor pressure coincided with strong electrical activity. The electrical activity was clearly most intense for lifting the bladder out of the abdomen: the highest spike amplitudes were found and the activity faded away more slowly than for bladder filling.

On bladder strip preparations and myocytes, stretch is known to induce electrical activity (Ursillo, 1961; Levin et al., 1986) by activation of stretch sensitive nonselective cation channels (Wellner \& Isenberg, $1993,1994,1995)$. However, there seem to be significant differences in the occurrence of spontaneous activity related to stretch in vitro versus in vivo rabbit preparations as reported by Levin et al. (1986). Spontaneous activity in bladder strips was triggered by stretch and could not be blocked by various neurogenic inhibitory compounds, indicating a myogenic origin. In vivo spontaneous activity disappeared completely by intravenous ganglionic blockade using hexamethonium, indicating that this activity is mediated through neuronal reflexes. Due to the multiple intertwined and complex regulatory mechanism involved in smooth muscle contraction and relaxation, Barany \& Barany (1995) and Rembold (1995) stress the importance of an in vivo approach and warn for the risks of scientific reductionism to which in vitro approaches are suspectible. Wellner \& Isenberg (1994) reported that action potentials triggered by stretch of single bladder myocytes were separated by longer silence periods. To our knowledge, no in vitro study reports the existence of continuous action potentials with a repetition frequency as high as we found in our experiments which are also present simultaneously on a considerable bladder area. Based on the present data, the continuous in vivo electrical activity we found is most likely controlled by the central nervous system and is not myogenic.

\section{Concept}

A concept is formulated in which the origin of the continuous electrical smooth muscle activity is related to neuronal activation of contraction, but where the net result, muscle shortening or elongation, is also dependent on the environmental stress situation.

In our stretch induced bladder EMG experiments, a force is applied on the bladder tissue that is beyond physiological means. The force imposed on an individual cell is more than it can counteract in its present state, with imminent tissue damage. The neuronal control, activated by intense sensory traffic, initiates muscle cells to contract in order to create a sufficient counterforce, which is apparently accompanied by intense electrical activity. Activation of a muscle cell under stress initially results in weak connection phase or decoupling of the actine/myosine mechanism (Eisenberg \& Greene, 1980; Eisenberg \& Hill, 1985). The cell aims to produce a higher counterforce by inducing muscle shortening. However, the external load imposed on the cell exceeds its force generating capabilities by far, and it will be forced to elongate even further, thereby reducing the external load imposed. This way, the socalled latch mechanism proposed for smooth musculature to handle exerted stress passively is dodged actively. So to speak, the non-liniar visco elastic material properties are changed, the visceus properties becoming less dominant.

That both shortening and elongation occurs during the plateau phase after filling is very likely and is based on the following observations. When in rest, the rabbit bladder is oval shaped as a flat sack, with the caudocranial axis from urethra to bladder dome being longest. During and after filling we observed by visual inspection that the bladder increases its globular shape, thereby combining a minimum surface with a maximum volume. First recordings with fluorescent markers during and after bladder filling showed that the bladder shortens over the caudo-cranial axis and elongates over the perpendicular lateral axis (unpublished data). The selective contraction over the caudo-cranial axis is remarkable, since no selective muscle fiber orientation or nerve fiber activation is reported in literature for rabbit bladder. Moreover, one should have expected an overall elongation after bladder filling instead of contraction in one direction and elongation in the perpendicular direction, but that is probably dependent on multiple factors like the initial bladder situation and history, filling volume and speed. The marker feasibility study was limited in its investigation aim and more study of in vivo strain fields in various situations will be required to further elicit the active mechanisms.

The continuous activity slowly fades away in both the mortalised and the living rabbit. Two reasonable 
explanations for the fading activity are that the stress strain situation of the tissue has changed to an extent where the intense electrical activity has become obsolete and sensory input to the central nervous system no longer triggers muscle cell activation, or that the continuous electrical activity is related to extensive neurotransmitter release and the neurotransmitter stores become exhausted. No continuous electrical activity is found in muscle strips, regardless of the stress strain situation. In vitro strips are not degenerated, lack central control, but still can have parts of the short neuron system intact. During long preparation periods and extensive mechanical manipulations performed on the sample before it is clamped in the experimental set-up, neurotransmitter stores might have been depleted already. Another explanation for lack of continuous activity in strips could be that complete short neuron and central control are required to trigger the depletion.

\section{Bladder EMG in mortalised rabbits}

In our previous study on bladder EMG in the mortalised rabbit (Kinder et al., 1997) we reported the presence of continuous spike activity after lifting the bladder out of the abdomen and placing it on the recording electrode. The continuous activity slowly faded away in both the mortalised and the living rabbit. This suggests that the degeneration of the dead preparation seems to happen more slowly than the electrical effects studied.

In two out of six mortalised animals, slow waves were observed. Single spike and burst activity was not being identified as such, since spontaneous EMG was not part of the research protocol (Kinder et al., 1997). In the preparation of this study, spontaneous EMG was recorded on mortalised rabbits as well, showing single spikes and bursts. This brings the observations for both experimental set-ups in balance and underlines the easy to use, yet very suitable set-up of mortalised rabbits to study bladder EMG: i) The nature and origin of slow wave activity can be investigated better in the mortalised rabbit, since no respiration artefacts will disturb the recordings; ii) The amplitude of continuous (and other) electrical activity in the living animal has shown to be lower when compared to that observed in the mortalised rabbit (Kinder et al., 1997). The reduction of the amplitude is likely to be caused by the administration of the aneasthetics isoflurane (see Pagel et al., 2000). Other volatile aneasthetics like halothane have a similar or even more depressive effect on the muscular activity (Pagel et al., 2000); iii) The mortalised preparation can be combined with other experiments, like Langendorff perfusion of the rabbit heart, to reduce the number of acute animal experiments.

\section{Conclusions}

Single spikes, burst and continuous activity recorded in this study represent electrical activity originating from rabbit urinary bladder smooth muscle cells. Single spikes and burst are the bladder response to physiological stretch during the filling phase and are related to both contraction and relaxation. The possible existence of an active relaxation mechanism that is related to electrical activity has to be taken into account. Since large burst activity is able to organise its pattern of appearance, it is thought to be under neuronal control of the short neuron system. Continuous electrical activity is the bladder response to unphysiological fast applied stretch, appears simultaneous on all electrodes, fades away in time and is most likely induced by the central nervous system. The appearance of continuous electrical activity is not unequivocally related to muscle shortening. The current stress and strain situation of the bladder tissue can cause a fibre elongation upon the appearance of electrical activity. The model using mortalised rabbits to study bladder EMG is valid and valuable as reference for the further investigation of bladder EMG in living mammals.

\section{Acknowledgements}

Paul Willems and Maarten Drost, Biomechanical Department of Maastricht University, are greatfully acknowledged for bladder strainfield calculations based on their fluorescent sphere technique. Inspector Research Systems BV and Twente Medical Systems International are greatfully acknowledged for their full support.

\section{References}

Abdel-Rahman M, Coulombe A, Abdel-Hakim A, Galeano C, Elhilali M (1982) Vesicourethral electromyography: facts or artefacts. Br J Urol 54:381-386

Barany M, Barany K (1995) Protein phosphoylation during contraction and relaxation. In: Barany $M$, editor. Biochemistry of smooth muscle contraction. San Diego: Academic Press. pp 321-339

Barany M, Barany K (1993) Dissociation of relaxation and myosin light chain dephosphorylation in porcine uterine muscle. Arch Biochem Biophys 305:202-204

Barany M, Hegedus L, Barany K (1994) Dissociation of relaxation and myosin light chain dephosphorylation in smooth muscle. Biophys J 66:A139

Barany K, Ledvora RF, Mougios V, Barany M (1985) Stretch-induced myosin light chain phosphorylation and stretch-release-induced tension development in arterial smooth muscle. J Biol Chem 11:7126-7130

Brading AF, Turner WH (1994) The unstable bladder: 
towards a common mechanism. Br J Urol 73:3-8

Bradley WE, Teague CT (1968) The pelvic ganglia. J Urol 100:649-652

Bramich NJ, Brading AF (1996) Electrical properties of smooth muscle in the guinea-pig urinary bladder. J Physiol 492:185-198

Brunsting CD (1958) An interpretation of the urinary bladder "electrocystogram" as artefact. J Urol 79:165-170

Creed KE, Callahan SM, Ito $Y$ (1994) Excitatory neurotransmission in the mammalian bladder and the effects of suramin. $\mathrm{Br} \mathrm{J}$ Urol 74:736-743

Creed KE, Ishikawa S, Ito $Y$ (1983) Electrical and mechanical activity recorded from rabbit urinary bladder in response to nerve stimulation. J Physiol 338:149-164

Creed KE, Ito $Y$, Katsuyama $\mathrm{H}$ (1991) Neurotransmission in the urinary bladder of rabbits and guinea pigs. Am J Physiol 261:C271-C277

Csabina S, Barany M, Barany K (1986) Stretch-induced myosin light chain phosphorylation in rat uterus Arch Biochem Biophys 249:374-381

Elbadawi A (1984) Ultrastructure of vesicourethral innervation. II. Postganglionic axoaxonal synapses in intrinsic innervation of the vesicourethral lissosphincter: a new structural and functional concept in micturition. J Urol 131:781-790

Elbadawi A (1987a) Comparative neuromorphology in animals. In: Torrens MJ, Morrison JFB, editors. The Physiology of the Lower Urinary Tract. London: Springer Verlag, pp 23-52

Elbadawi A (1987b) Neuromuscular Mechanisms of Micturition. In: Yalla SV, McGuire EJ, Elbadawi A, Blaivas JG, editors. The Principles and Practice of Neurourology and Urodynamics. New York: Macmillan, pp 3-35

Elbadawi A (1991) Anatomy and innervation of the vesicourethral muscular unit of micturition. In: Krane RJ, Siroky MB, editors. Clinical Neuro-Urology. 2nd Ed. Boston: Little, Brown \& Company, pp 5-23

Eisenberg E, Greene LE (1980) The relation of muscle biochemistry to muscle physiology. Ann Rev Physiol 42:293-309

Eisenberg E, Hill TL (1985) Muscle contraction and free energy transduction in biological systems. Science 227:999-1006

Gabella G, Uvelius B (1990) Urinary bladder of rat: fine structure of normal and hypertonic musculature. Cell Tissue Res 262:67-69

Glerum JJ, Van Mastrigt R, Van Koeveringe AJ (1991) Mechanical properties of mammalian single smooth muscle cells. IV. Active properties of pig detrusor and human a terme uterus cells. In: Glerum JJ, PhD. Mechanical properties of mammalian single smooth muscle cells. Rotterdam University, ISBN 90-9004485-X. pp 63-78

Glerum JJ, Van Mastrigt R, Van Koeveringe AJ (1990) Mechanical properties of mammalian single smooth muscle cells III. Passive properties of pig detrusor and human a terme uterus cells. J Muscle Res Cell Motil 11:453-462

Hellstrand $P$ (1990) Mechanical processes in the smooth muscle cell. Neurourol Urodyn 9:297-298

Kinder MV, Bastiaanssen EHC, Janknegt RA, Marani E (1995) Neuronal circuitry of the lower urinary tract; central and peripheral neuronal control of the micturition cycle. Anat Embryol 192:195-209

Kinder MV, Bastiaanssen EH, Janknegt RA, Marani E (1999a) The neuronal control of the lower urinary tract: A model of architecture and control mechanisms. Arch Physiol Biochem 107:203-22

Kinder MV, Bos R, Willems PJB, Drost MR, Holtzer CAJ, Janknegt R, Marani E (1999b) Three dimensional registration of mechanical bladder activity using polystyrene fluorescent spheres: a technical note. Arch Physiol Biochem 107:236-241

Kinder MV, Gommer ED, Janknegt RA, Van Waalwijk van Doorn ESC (1997) A method for the electromyographic mapping of the detrusor smooth muscle. Arch Physiol Biochem 105:673-690

Kinder MV, Gommer ED, Janknegt RA, Van Waalwijk van Doorn ESC (1998a) Recording the detrusor electromyogram is still a difficult and controversial enterprise. Neurourol Urodyn 17:571-573

Kinder MV, Van Waalwijk van Doorn ESC, Gommer ED Janknegt RA (1998b) A non-invasive method for bladder electromyography in humans. Arch Physiol Biochem 106:2-11

Levin RM, Ruggieri MR, Velagapudi S, Gordon D, Altman B, Wein AJ (1986) Relevance of spontaneous activity to urinary bladder function: an in vitro and in vivo study. $\mathrm{J}$ Urol 136:517-521

Marani E (2000) The bladder EMG. Proceedings of 26th congress of the Turkish Physiological Society.

Montgomery BSI, Fry CH (1992) The action potential and net membrane currents in isolated human detrusor smooth muscle cells. J Urology 147:176-184

Morrison JFB (1987) Neural connections between the lower urinary tract and the spinal cord. In: Torrens MJ, Morrison JFB, editors. The Physiology of the Lower Urinary Tract. London: Springer Verlag, pp 53-85

Pagel PS, Farber NE, Warltier DC (2000) Cardiovascular pharmacology in anesthesia. In: Miller RD, editor. Philidelphia: Churchill Livingstone, pp 97-124

Rembold CM (1995) Electromechanical and pharmacomechanical coupling. In: Barany $M$, editor. Biochemistry of smooth muscle contraction. San Diego: Academic Press. pp 321-339

Scheepe, personal communication at the 'Achte Arbeitstreffen des Forum Urodynamikum e.V.', February 13-15, 1997, Murnau, Germany

Scheepe JR, Bross S, Schumacher S, Braun P, Weiss J, Alken P, Juenemann K (1999) Recording the evoked canine detrusor electromyogram. Neurourol Urodynam 18:687-695

Scheepe JR, Wipfler G, Schumacher S, Bross S, Zendler S, Jünemann K.P. Alken P (1998) Smooth muscle electromyography of the urinary bladder. Neurourol Urodynam 17:71-83

Sibley GNA (1984) A comparison of spontaneous and nervemediated activity in bladder muscle from man, pig and rabbit. J Physiol 354:431-443

Tarata MT (1998) Specific processing of the spontaneous EMG. Eng Med Biol Magazine 17-2, pp 102-109

Ursillo RC (1961) Electrical activity of the isolated nerveurinary bladder strip preparation of the rabbit. Am $\mathrm{J}$ Physiol 201:408-412

Van der Schee EJ, Grashuis JL (1983) Contraction-related, low frequency components in canine electrogastrographic 
signals. Am J Physiol 245:G470-G475

Visser AJ, Van Mastrigt R (1999) Intracellular recording of spontaneous electrical activity in human urinary bladder smooth muscle strips. Arch Physiol Biochem 107:257-270 Waring W (1974) Observing signals from nerve and muscle. In: Biomedical electrode technology - theory and practice. Miller HA, Harrison DC, editors. New York: Academic Press, Inc., pp 215-262

Wellner MC, Isenberg G (1993) Properties of stretch activated channels in myocytes from the guinea-pig urinary bladder. J Physiol (Lond) 466:213-227

Wellner MC, Isenberg G (1994) Stretch effects on whole-cell currents of guinea-pig urinary bladder myocytes. J Physiol 480:439-448

Wellner MC, Isenberg G (1995) cAMP accelerates the decay of stretch-activated inward currents in guinea-pig urinary bladder myocytes. J Physiol 482:141-156 


\section{Recording the detrusor electromyogram is still a difficult and controversial enterprise}

Addendum to CHAPTER 5

The addendum to Chapter 5 has been accepted as letter to the editor in:

Neurourology and Urodynamics (1998) 17:571-573 
Matti V. Kinder - Erik D. Gommer .

Ruud A. Janknegt - Ernst S.C. van Waalwijk van Doorn

\section{Recording the detrusor electromyogram is still a difficult and controversial enterprise}

The technique for bladder smooth muscle EMG as presented by Scheepe et al. (Neurourol Urodyn $17: 71-83)$ and the editorial comment gave rise to the following discussion in our group.

The applied methodology does not differ on essential points from the methods on bladder-EMG described in the literature over the past 45 years (Kinder et al., 1997): signals are recorded in living mammals with electrodes that contact the bladder directly, while bladder contractions and emptying are evoked. Reliable bladder EMG has not been achieved with these methods. One of the problems is, as also Dr. Craggs points out, '... the large electromechanical artefact caused by electrode movement as the tissue contracts'. In the present study no control experiments determine to what extent movement of the bladder to the electrode is responsible for the signals recorded. We agree with Dr. Craggs and the authors' reply that the unequivocal identification of electrical detrusor activity is impossible without relevant control experiments. The discrimination between electrical detrusor activity and signal components from other sources will remain difficult, in spite of appropriate recording equipment and dataanalysis, because Amplitude, Frequency and Shape (AF\&S) of electrical detrusor activity recorded by these methods are unknown.

The authors emphasize features such as 'highly sophisticated equipment' and 'computer-aided waveform recognition', but they omit basic information on filter types and settings. Since AF\&S are unclear, a 'signal pattern recognition program' (p. 77) will not be of great value. Change of methodology might be far more effective than, e.g., 'three-dimensional power spectra' (p. 79). It is also not clear how a bladder volume of $0.45 \mathrm{ml}$ can be reached in an empty bladder when both ureters are ligated and filling steps of $0.1 \mathrm{ml}$ are used. We wonder whether the pressure measurement with a buret has been tested for capillary effects? Time windows for power spectrum calculations are not given. This is especially of interest in the carbachol experiments, where dislocation of the electrode due to bladder contraction crudely limits the time window available. In the results section the authors mention 'recurring electrical events', but do not characterize AF\&S.
It is not clear how many electrical events are displayed in Fig. 1; they have failed to mark where the biological background noise ends and an electrical event starts. The authors claim that 'an increase in EMG activity was seen several seconds before the onset of drug action' (p.75). As the onset of drug action has been determined arbitrarily, it remains indefinite whether this EMG activity precedes muscle contraction. To our knowledge, both time and frequency domain hold the same amount of signal information, provided that signal analysis is performed properly. Correlations found in the time domain are present in the frequency domain as well and vice versa. Changing domain simply means looking at the signals from another perspective. To our surpise, the authors mention qualitative correlations in the time domain they could not extract from the frequency domain. We wonder what kind of '....analysis of this low-frequency continuum...' (p.74) has been conducted. Did they try to calculate signal energy? Power spectra are often used to determine the signal energy within a specific frequency band. This energy is given by the surface underneath the spectrum. By calculating the signal energy, a quantitative measure is available to determine whether signal activity has changed. We do not understand why the authors judge increased signal activity (empty bladder vs. full bladder; no carbachol vs. carbachol) only qualitatively by looking at the signal in the time domain (e.g., Fig.1 vs. 2 ; Fig. 4 vs. 5) instead of making quantitative statements as well, using the calculation of signal energy from their power spectra. The drawback of qualitative statements is shown when the authors claim that similar electrical activity is shown in Fig. 1 and Fig. 4. Our group would not agree with this conclusion. We start to feel uncomfortable with their other subjective statements that are deprived of signal display or quantitative backup.

In our opinion, new ways of thinking are needed to make major improvements on bladder EMG.

M.V. Kinder - E.D. Gommer - R.A. Janknegt - E.S.C. van Waalwijk van Doorn

Department of Urology, Maastricht University Hospital, Maastricht, The Netherlands 
Therefore, our group recently suggested new strategies (Kinder et al., 1996, 1997, 1998). In an animal set-up with rabbits several unwanted signal sources are excluded beforehand by a cervical dislocation and excision of the heart just prior to the recordings, while bladder contractility remains intact. No contractions of the isovolumetric bladder are evoked by any stimulus. A large area (circa $37 \mathrm{~mm} \times$ $37 \mathrm{~mm}$ ) of the detrusor muscle is mapped with 240 electrodes that are placed against the serosal bladder surface in six rabbits. This set-up produces clear and reproducible potentials that propagate across the mapped detrusor surface. Control experiments support that the potentials reflect electrical detrusor activity and that movement due to detrusor contractions has minor effects on the recordings. Although the set-up is not so ambitious as to record in living mammals, it does produce new information on AF\&S of the electrical detrusor activity post mortem. A more precarious set-up concerns non-invasive bladder EMG using surface electrodes on the abdominal skin of healthy volunteers with simultaneous urodynamic investigation. First results look promising, as a clear correlation between the abdominal electrode signals and vesical pressure and flow is found. This technique excludes '.... the large electromechanical artefact caused by electrode movement as the tissue contracts' and allows to study electrical detrusor activity during bladder emptying.
Finally, the authors report that the frequency content of their signals is below $1 \mathrm{~Hz}$. We were surprised by the presentation of co-author K.-P. Jünemann at the International Congress of the Dutch Urological Association in Maastricht, November 1997. He concluded that '.. the basic relevant frequency band [for bladder EMG] is above $5 \mathrm{~Hz}$... low frequency compounds, however, they seem to be tissue movement or maybe fluid movements under the electrode .... We suppose his conclusion did not take the present study into account, therefore we are interested to hear more about newer studies of this group and their arguments why the results presented here are no artefact.

\section{References}

Kinder MV, Van Waalwijk van Doorn ESC, Gommer ED, Janknegt RA (1996) Surface detrusor EMG in healthy volunteers. Neurourol Urodyn 15:288-290

Kinder MV, Gommer ED, Janknegt RA, Van Waalwijk van Doorn ESC (1997) A method for the electromyographic mapping of the detrusor smooth muscle. Arch Physiol Biochem 105:673-690

Kinder MV, Van Waalwijk van Doorn ESC, Gommer ED, Janknegt RA (1998) A non-invasive method for bladder electromyography in humans. Arch Physiol Biochem 106:2-11 



\section{A non-invasive method for bladder electromyography in humans}

CHAPTER 6 
Matti V. Kinder - Ernst S.C. van Waalwijk van Doorn

Erik D. Gommer · Ruud A. Janknegt

\title{
A non-invasive method for
}

\section{bladder electromyography in humans}

\begin{abstract}
No convincing correlation of human bladder EMG to simultaneously measured intravesical pressure has been reported in the literature. In most studies on bladder EMG the electrodes contact the bladder wall itself. This causes problems in the discrimination between very small extracellular signals, reflecting actual membrane potential changes of bladder muscle cells, and large electro-mechanical artifact caused by electrode movement as the tissue contracts.

Aim of this study is to investigate whether bladder EMG can be performed non-invasively with $\mathrm{Ag}-\mathrm{AgCl}$ surface electrodes that are placed on the abdominal skin of healthy volunteers. Bipolar electrode signals are obtained in a diagonal, vertical and horizontal direction of the abdominal electrodes. A conventional urodynamic investigation is performed according to International Continence Society standards simultaneously with bladder EMG.

This new method shows that voiding is accompanied by a slow voltage change in bipolar electrode signals. The contribution of abdominal and other striated muscle activity to the bipolar electrode signals can clearly be distinguished from the slow voltage changes related to voiding. Free flowmetry shows that the electrical activity picked up by the abdominal electrodes is related to bladder emptying. In pressure/flow studies a relation between the electrical activity and the detrusor pressure is found.

The present results suggest that the slow voltage changes found during bladder contraction might be summed membrane potential changes of bladder muscle cells, but this concept needs further testing. Also, validation for clinical use remains to be established.
\end{abstract}

Key words Bladder. EMG - Lower Urinary Tract - Methods - Non-invasive . Smooth Muscle - Urodynamics

M.V. Kinder - E.S.C. van Waalwijk van Doorn - E.D. Gommer - R.A. Janknegt

Department of Urology, Maastricht University Hospital, Maastricht, The Netherlands

E.D.Gommer

Stan Ackermans Institute, Eindhoven University of Technology, Eindhoven, The Netherlands. 


\section{Introduction}

Human bladder electromyography (EMG) has once been introduced as a potential clinical tool to investigate the physiological state of the bladder with greater accuracy than before (Corey et al., 1951). Ever since, bladder EMG has been controversial. The information about the signal properties amplitude and frequency is contradictory (Kinder et al., 1997). Most studies concern living mammals, in which fibre or wire-hook electrodes are inserted in or positioned against the bladder wall (Corey et al., 1951; Doyle et al., 1975; Jones et al., 1974; Takaiwa \& Shiraiwa, 1984 and others). Electrical signals with frequencies ranging from 0.1 to $15 \mathrm{~Hz}$ and amplitudes varying from 0.1 to $2 \mathrm{mV}$ have been reported. Differences in the bladder electromyogram of patients have been discussed and related to the pathology of the patient (Doyle et al., 1975; Jones et al., 1974; Takaiwa \& Shiraiwa, 1984).

Nevertheless, no convincing correlation of bladder EMG to simultaneously measured intravesical pressure has been reported to date. The problem is the discrimination between very small extracellular signals, reflecting actual bladder muscle membrane potential changes, and large electro-mechanical artifact caused by electrode movement as the tissue contracts (Abdel-Rahman et al., 1982; Brunsting, 1958; Kinder et al., 1997).

Aim of this study is to investigate whether bladder EMG can be performed non-invasively with surface electrodes that are placed on the abdominal skin of healthy volunteers. To have a notice of bladder function, bladder EMG is performed simultaneously with a conventional urodynamic investigation. The electrical activity of the bladder muscle recorded with surface electrodes on the abdominal skin is expected to be very slow, even when compared to other slow electrical muscle activities like those present in the gastrointestinal tract (Weisbrodt, 1991). Bladder emptying itself is a slow process, which sometimes can last for over sixty seconds. This has to be considered when choices are made on the electrodes, signal amplifiers and noise reduction techniques to be used.

\section{Materials and Methods}

In the process of developing and testing the method, recordings of electrical activity were obtained from the abdominal skin of two male and three female volunteers. The volunteers were recruited from a student population and without urological problems.

The surface electrodes we used were eight standard
$\mathrm{Ag}-\mathrm{AgCl}$ disc electrodes ( $\mathrm{d}=10 \mathrm{~mm}$; ATE, Brunssum, The Netherlands). $\mathrm{Ag}-\mathrm{AgCl}$ as electrode material has a very stable electrode contact voltage, which is important when measuring low frequent signals. Six electrodes were placed on the abdominal skin of a volunteer. Electrode positioning was based on the perpendicular projection of a full bladder on the abdominal wall (Fig. 1). A grounding electrode was fixed on the left iliac crest. The upper left arm served as a recording site for ECG to identify its contribution to the signals obtained from the abdominal area.

All electrodes were connected to a portable 16 channel recorder, of which eight channels were suitable for electromyography (Porti-16; TMS, Enschede, The Netherlands). Unipolar electrode signals on seven channels were recorded DC; no analog highpass filter was implemented in the recorder. The sample frequency of $250 \mathrm{~Hz}$ and the dataprocessing applied resulted in a bandwidth of 0.005 to $65.6 \mathrm{~Hz}$. Bipolar electrode signals Right TopRight Bottom (RT-RB), Middle Top-Middle Bottom (MT-MB), Left Top-Left Bottom (LT-LB), Right TopLeft Top (RT-LT), Right Bottom-Left Bottom (RB-LB), Right Top-Middle Bottom (RT-MB) and Left TopMiddle Bottom (LT-MB) were calculated on-line from the unipolar signals (Fig. 1). The different directions of the bipolar derivations were chosen to get information about the course of a bladder contraction.

A simultaneous conventional urodynamic investigation performed according to International Continence Soc-

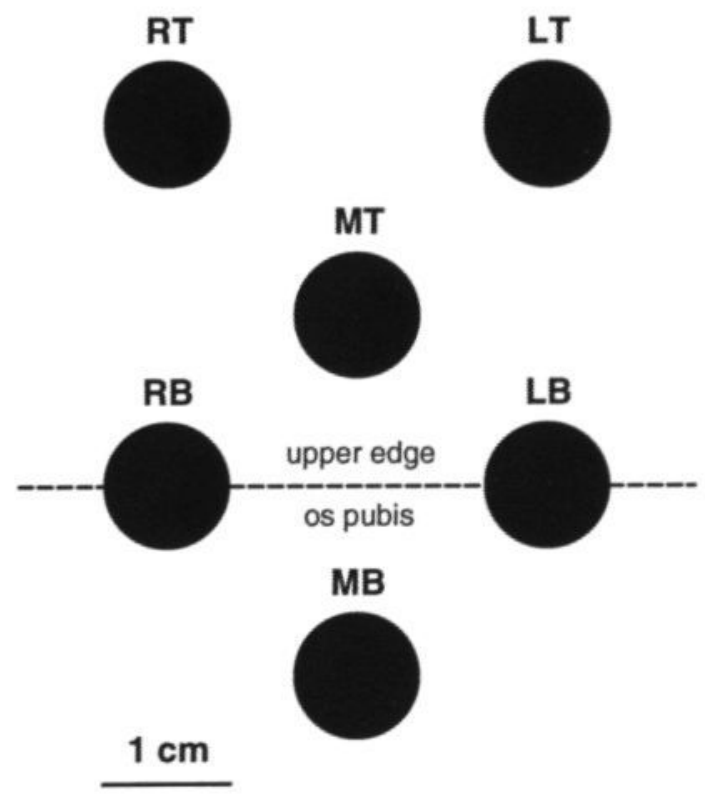

Figure 1: Schematic configuration of the surface electrodes on the abdominal skin. RT = Right Top, RB = Right Bottom, $\mathrm{LT}=$ Left Top, $\mathrm{LB}=$ Left Bottom, MT $=$ Mid Top, MB = Mid Bottom. 
iety standards was part of the protocol (Rowan et al., 1987; Abrams et al., 1988). The intravesical and urethral pressure were measured transurethrally by one catheter with two micro pressure transducers ( $d=2 \mathrm{~mm}$, Gaeltec Ltd., Dunvegan, Scotland). A second catheter $(\mathrm{d}=2 \mathrm{~mm})$ was introduced transurethrally to fill the bladder. To measure the abdominal pressure, a catheter with one micro pressure transducer ( $d=2 \mathrm{~mm}$, Gaeltec Ltd., Dunvegan, Scotland) was placed in the rectum. A computer based urodynamic system digitized the acquired data at $20 \mathrm{~Hz}$ (MMS, Enschede, The Netherlands).

\section{Measurement protocol}

Each volunteer was investigated according to a standardised measurement protocol (Fig. 2). The volunteer was asked to attend with a full bladder. After placement of the electrodes the electrode cables were taped to the skin with a loop to prevent that any mechanical stress on the cables could affect the electrode fixation. The volunteer was instructed to take a sitting position on the urodynamic table and to refrain from further movement. The unipolar electrode signals were checked for any unexpected signal contributions or excessive noise levels, indicating for example bad electrode-skin contact. When necessary, an electrode was removed and fixed again until the unipolar signals were optimal.

In the first part of the measurement protocol (phase 1), recording of electrical activity picked up by the electrodes on the abdominal skin was combined with free flowmetry. The volunteer was asked to find a sitting position, in which voiding was comfortable, and was explicitly told to prevent final repositioning just prior to voiding. Silence was maintained during the recordings.

In the second part of the measurement protocol (phases 2 and 3), recording of electrical activity was combined with simultaneous urodynamic investigation. The catheters with the micro pressure transducers and the filling catheter were inserted. On several occasions listed in Fig. 2 both the correct position of the catheters was checked by inspecting the urodynamic signals when the volunteer coughed and the electrode contacts were checked by evaluating the unipolar electrode signals. The bladder was filled with saline solution $\left(T=35^{\circ} \mathrm{C}\right)$ at a rate of $60 \mathrm{ml} / \mathrm{min}$ (medium fill) until the volunteer indicated normal desire to void. A compact set of control exercises involving striated muscle activity was executed with a full bladder to study its effect on the electrode signals: coughing, straining the abdominal muscles, contracting the pelvic floor musculature and subsequently lifting the left and right leg. Each exercise was followed by thirty seconds of recording with the volunteer as relaxed as possible. For a period of five minutes, signals were recorded from a relaxed volunteer with a full bladder. The volunteer was then permitted to void without changing position. After micturition, five minutes of calmness and relaxation of the volunteer with an empty bladder was recorded.

Phase 3 of the measurement protocol consisted of a second cystometry with simultaneous recording of electrical activity. No exercises were carried out after the cystometry. Five minutes recording before voiding were followed by the micturition phase and five minutes recording after voiding to finish the protocol.

PHASE 1

A

B

C

D

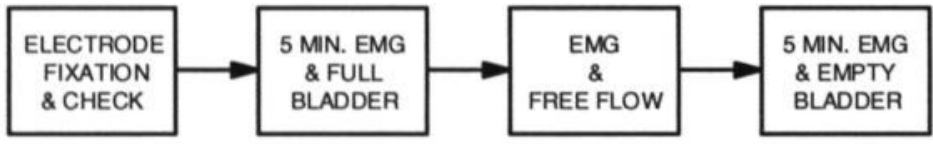

PHASE 2 A

B $\quad$ C

C D

$E$

F

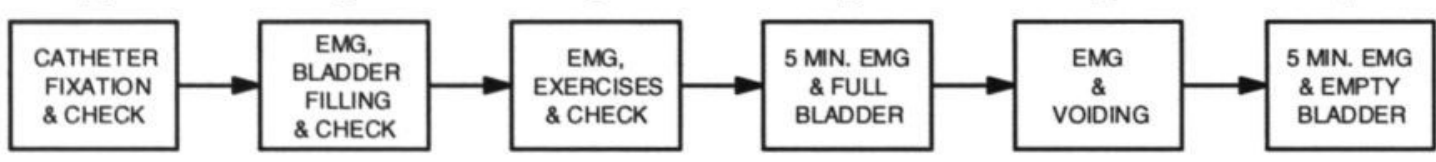

PHASE 3

A

B

C

D

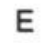

F

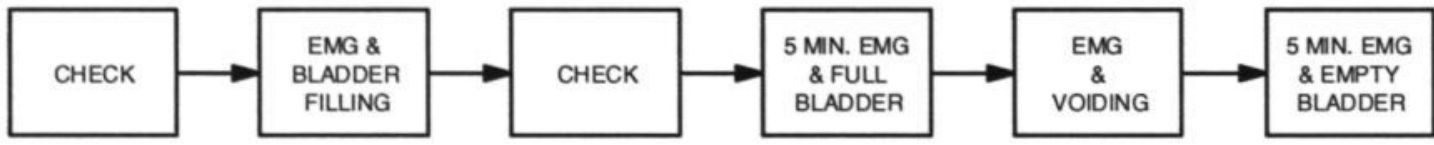

Figure 2: Schematic view of the standardised measurment protocol. For description of the protocol, see text. 
The time settings of the urodynamic and EMG recording system were synchronised before the investigations started. Off-line processing and dataanalysis was used to combine, interpret and display the urodynamic and the electrode signals. The flow signals were corrected for the time the urineflow needed to hit the flowmeter. This delay was estimated to be $0.8 \mathrm{~s}$.

\section{Recorder technique}

Technological innovations during the last decade have supplied new powerful measuring and dataacquisition tools that were used in this study to explore bladder EMG.

All electrode wires were individually screened to reduce unwanted signal contributions picked up by the electrode cables in a noisy environment. A signal guarding technique was applied to reduce capacitive effects between the screening and the electrode wire: the screening of each electrode cable was driven with a low impedant version of the electrode signal itself. The electrode signals of seven channels were recorded DC; no analog highpass filter was implemented in the recorder. The electrode signals were amplified with a multi-channel reference amplifier. The benefit of this multi-channel reference amplifier is a high common mode rejection rate (>90 dB). From all seven electrode signals one average signal was constructed. This is called the common average reference. It was put on the inverting input of the differential amplifier for each signal channel. The input impedance of the amplifier was in the range of $10 \mathrm{~T} \Omega$, which makes the impedance of the electrodeskin contact less critical. The amplification for the signal on each channel was 20 times with regard to the common average reference. Each electrode signal was analog lowpass filtered at $20 \mathrm{kHz}$ to prevent aliasing. Analog to digital conversion of the filtered signal was realized with a 22 bits $A D$-convertor at a sample frequency of $3.7 \mathrm{MHz}$ for each channel. At this stage, the end user could perform further dataprocessing on-line to suit the current experimental conditions. Lowpass filtering was carried out digitally at $66 \mathrm{~Hz}$ to prevent aliasing before the signals were resampled at the user's selected sample frequency of $250 \mathrm{~Hz}$. Reduction of the sample frequency improves the signal to noise ratio of the recorded signals. Highpass filtering was performed digitally at $0.005 \mathrm{~Hz}$ to exclude the very slow variations in the electrode contact voltages.
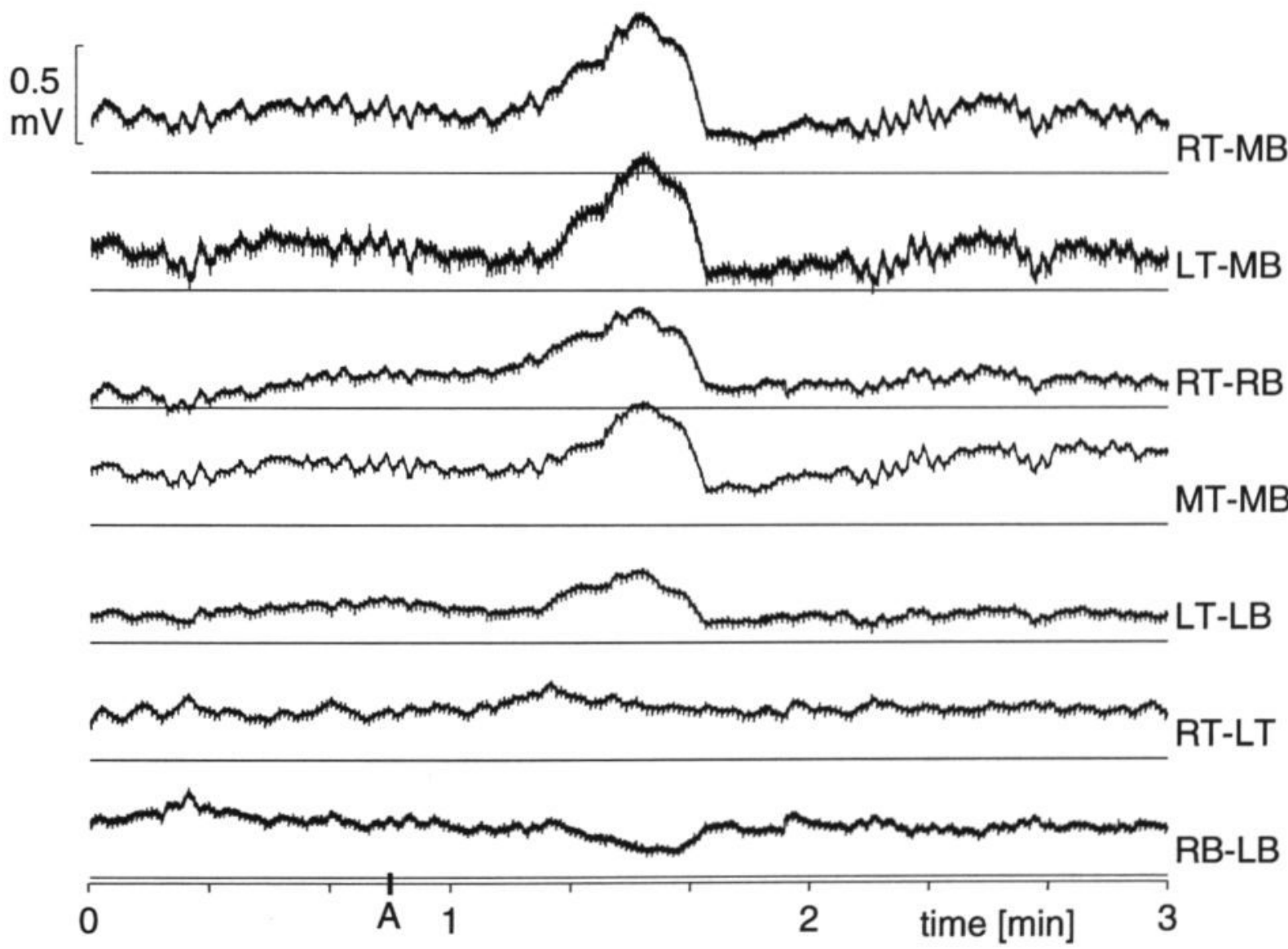

Figure 3: All seven bipolar electrode signals are shown during free flow of (male) volunteer 2. Mark $A$ on the $X$ axis indicates the permission to start voiding. For discussion, see text. 


\section{Results}

An example of the seven bipolar electrode signals derived from the abdominal skin during voiding is shown in Fig. 3 for (male) volunteer 2.

In general, the bipolar electrode signals measured on the abdominal skin show symmetry between left and right from the abdominal midline (RT-RB versus $L T$ LB and RT-MB versus LT-MB). The vertical bipolar electrode signal MT-MB is similar to the other two vertical bipolar electrode signals RT-RB and LT-LB. The signal MT-MB is thought to be more reliable since it lies on the midline of the recording area. The two horizontal bipolar electrode signals RT-LT and RB-LB show similar curves as well. Therefore, only the three bipolar electrode signals RT-MB, MT-MB and RB-LB are shown in Figs. 5-7.

During voiding the diagonal bipolar electrode signals (RT-MB and LT-MB) show voltage changes with highest amplitudes, followed by the vertical derivations (RT-RB, MT-MB and LT-LB). No considerable rise in electrical activity of both horizontal bipolar electrode signals (RB-LB and RTLT) can be found, although the electrode distances of the vertical and horizontal bipolar derivations are equal.

The influence of control exercises (coughing, abdominal straining, pelvic floor contraction and lifting of each leg) on the bipolar electrode signals is expressed by higher frequencies up to $66 \mathrm{~Hz}$, which is indicative for electrical activity of striated muscles. Possible signal components with frequencies exceeding $66 \mathrm{~Hz}$ are attenuated by the applied lowpass filter. The signal components up to $66 \mathrm{~Hz}$ are absent when the person is not performing the exercises and is sitting relaxed with a full or empty bladder at rest. The effect of exercises in volunteer 1 is shown in Fig. 4 for the electrode signal RT-MB. Coughing and straining of the abdominal muscles generates the highest amplitudes of signals up to 66 $\mathrm{Hz}$, but they all remain below $0.2 \mathrm{mV}$. Contraction of the pelvic floor shows minor effects. Recordings of a full and empty bladder at rest, just before and after micturition, is shown for (female) volunteer 4 in Fig. $5 A-B$ respectively. The electrode signals look rather stable in both situations and show minor variations only. This is in agreement with the stable vesical and abdominal pressure, which show respiration artefact only.
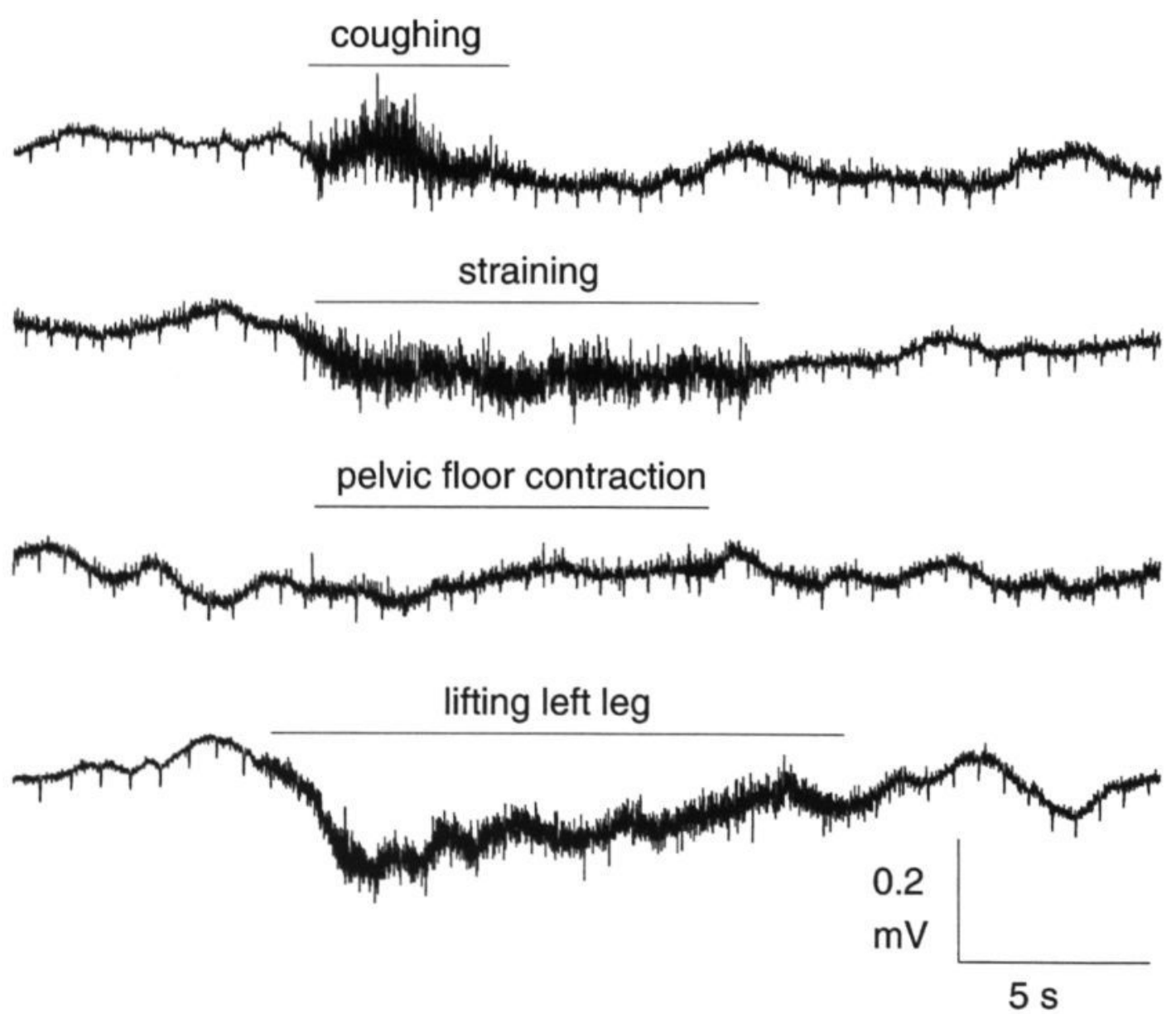

Figure 4: The bipolar electrode signal RT-MB during coughing, straining, pelvic floor contraction and lifting of the left leg. 
A

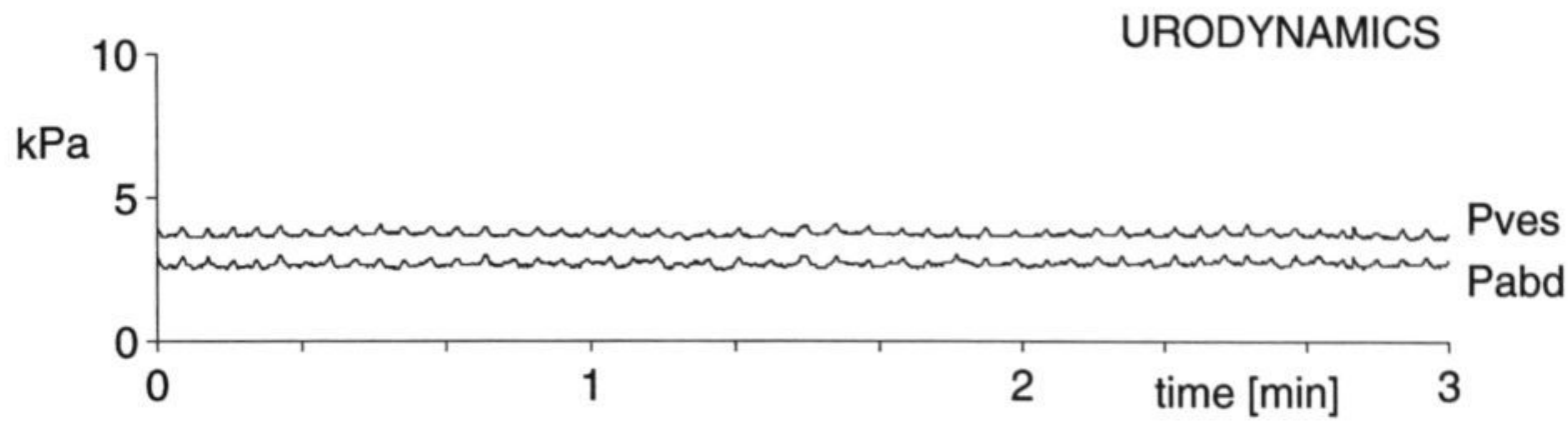

ELECTRODE SIGNALS

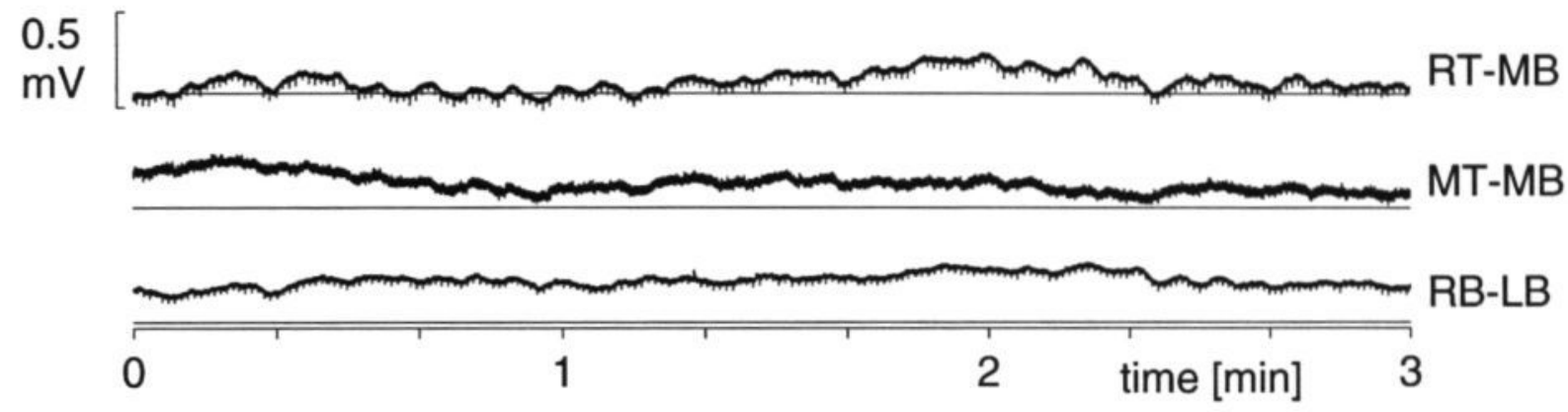

Figure 5A: The signals before micturition are shown when (female) volunteer 4 has a full bladder in phase 2D. The upper part shows the intravesical and abdominal pressures, in which respiration is clearly visible. The lower part shows the bipolar electrode signlas RT-MB, MT-MB and RB-LB.

B

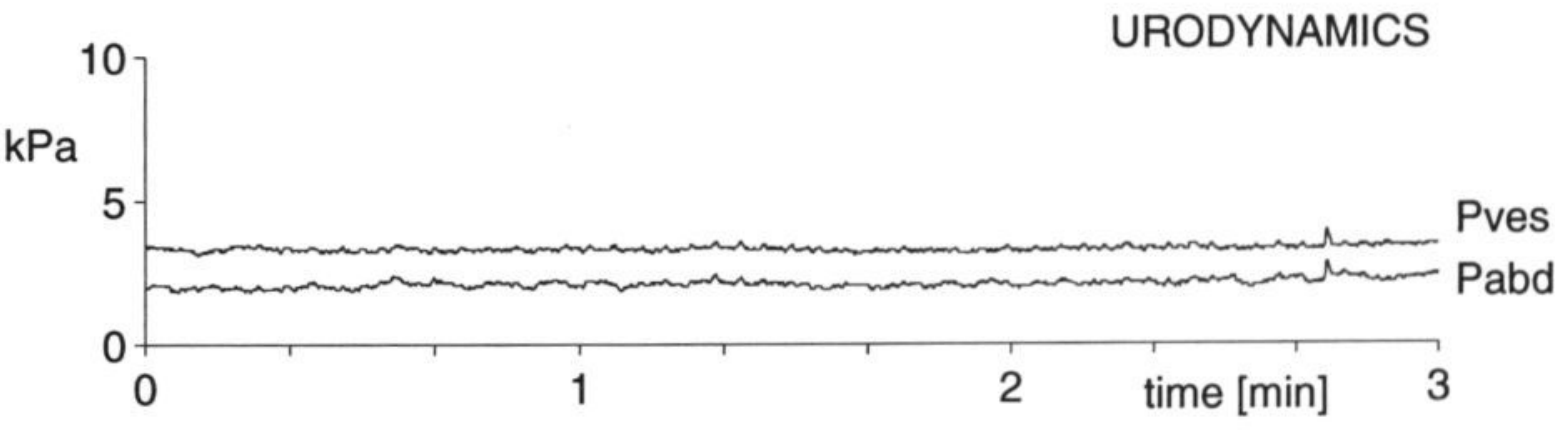

\section{ELECTRODE SIGNALS}

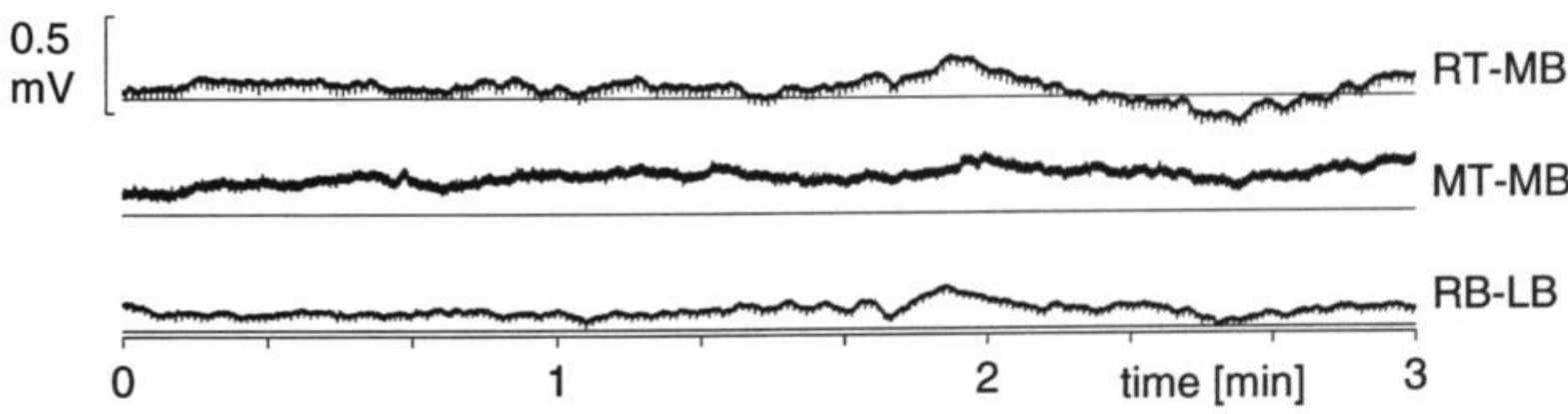

Figure 5B: The signals after micturition are shown with (female) volunteer 4 having an empty bladder in phase $2 \mathrm{~F}$. The upper part shows the intravesical and abdominal pressures. Respiration is much less dominant when compared to the full bladder. The lower part shows the bipolar electrode signals RT-MB, M-MB and RB-LB. 


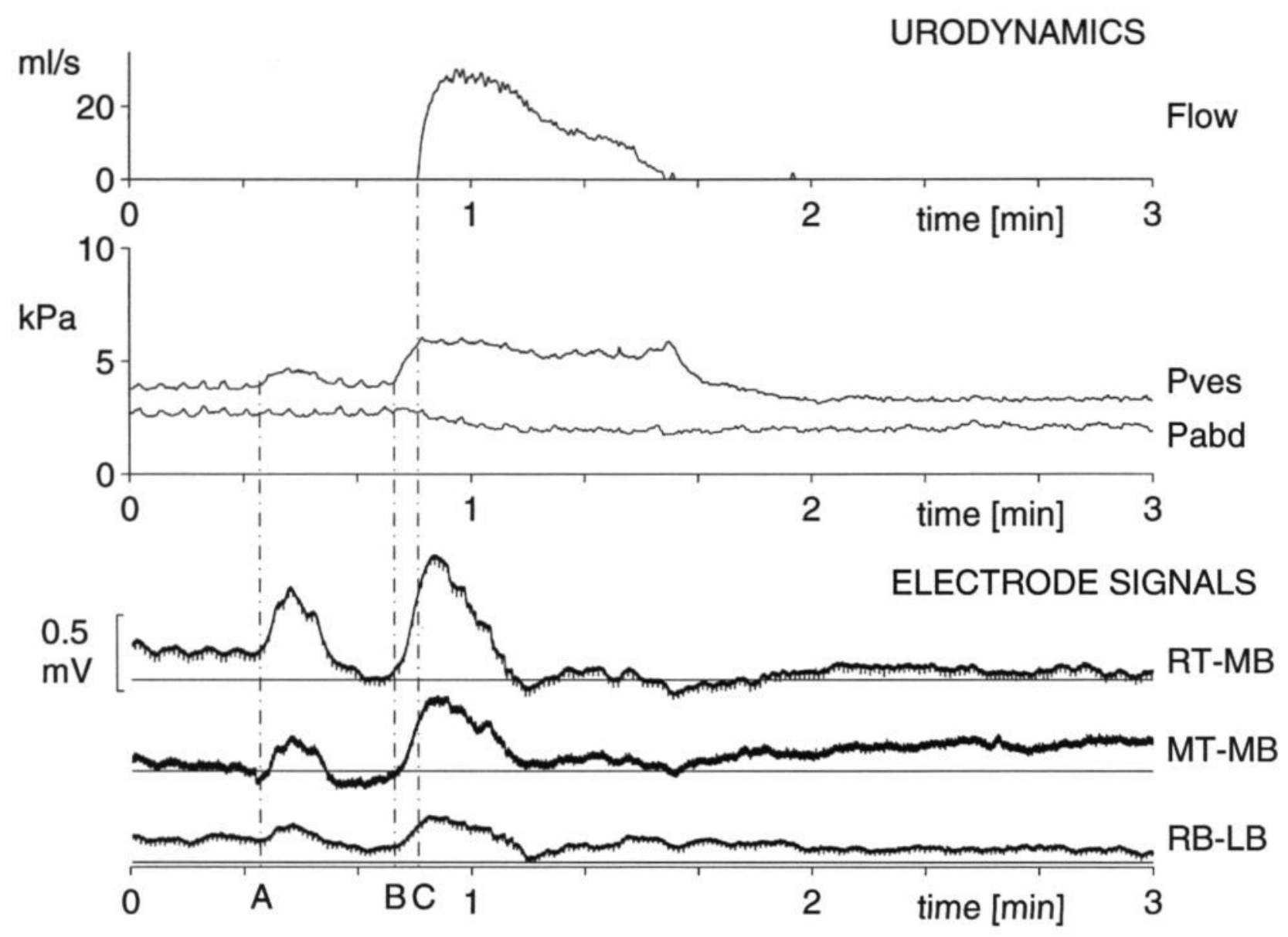

Figure 6: The micturition phase of (female) volunteer 4 in phase 3E. The upper three tracings show the urodynamic signals flow, intravesical and abdominal pressure, respectively. The lower three tracings show the bipolar electrode signals RT-MB, MT-MB, and RB-LB, respectively, obtained from the abdominal skin. All signals shown are synchronised in time. At mark A on the $\mathrm{X}$ axis, she has a pre-voiding contraction, not yet resulting in a flow and therefore isovolumetric. The rise in intravesical pressure comes along with a change in electrical activity, which is present in all bipolar electrode signals. The slow voltage change lasts at least until the pressure returns to its baseline. At mark B, both the intravesical pressure and the recorded electrical activity rise, introducing the voiding contraction. When the flow begins at mark $\mathrm{C}$, the intravesical pressure decreases, but the slow voltage wave has not yet reached its maximum value. Once it has, the electrical activity declines to about its initial prevoiding value before the intravesical pressure signal does or the flow has stopped. The large slow voltage change seen on RT-MB and MT-MB at the beginning of voiding seems to be followed by a relative small change, which ends when the flow has ceased.

The micturition phase of (female) volunteer 4 is shown in Fig. 6. At mark A, when the bladder muscle contracts isovolumetrically, the diagonal and vertical electrode signals contain a slow voltage change that correlates well with detrusor pressure changes. On these occasions, the horizontal electrode signals show no or only minor signal increase. When a contraction of the bladder muscle occurs with a flow, a voltage change in all diagonal and vertical electrode signals coincides with detrusor pressure change in the first half of the voiding phase. In contrast with the prevoiding bladder contraction, during voiding the electrode signals decline before the pressure wave does.

The micturition phase of (male) volunteer 2 is shown in Fig. 7. The volunteer is very calm and relaxed when voiding is about to occur. The diagonal and vertical electrode signals start to rise simultaneously with the vesical pressure. The course of both the vesical pressure and the electrode signals is rather smooth during voiding. The diagonal and vertical electrode signals reach their maximum when the flow is about to cease and the vesical pressure shows an after contraction. The electrode signals decline more gradually than the vesical pressure does. A specific signal pattern is present in the diagonal and vertical electrode signals just prior to and after voiding (Fig. 7, mark C). This pattern seems not related to the urodynamic signals. 


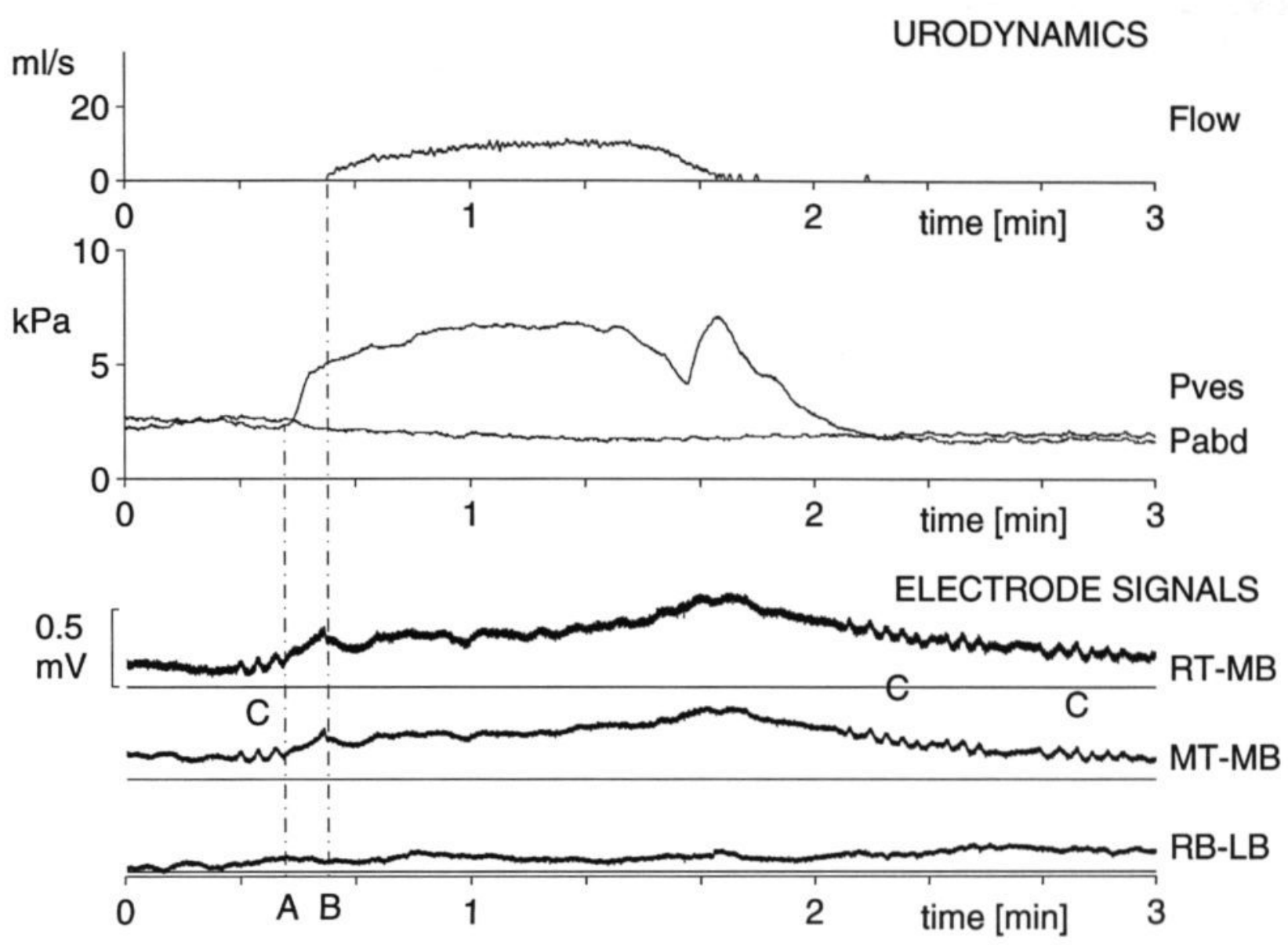

Figure 7: The micturition phase of (male) volunteer 2 in phase 2E. The upper three tracings show the urodynamic signals flow, intravesical and abdominal pressure, respectively. The lower three tracings show the bipolar electrode signals RT-MB, MT-MB, and RB-LB, respectively, obtained from the abdominal skin. All signals shown are synchronised in time. The voiding phase starts at mark $A$ on the $X$ axis. A slow rise in intravesical pressure is accompanied by a slow rise in the two bipolar electrode signals RT-MB and MT-MB. As soon as the flow starts at mark B, the slow signals RT-MB and MT-MB decrease slightly. During flow, the course of the intravesical pressure is smooth, slowly rising at first and decreasing again, to end with a clear after contraction. The signals RT-MB and MT-MB rise to reach a maximum at the point where both the intravesical pressure shows the after contraction and the flow ceases. They return to their initial level rather slowly and after the intravesical pressure has declined. The origin of the signal changes indicated by mark $C$ in the signals RT-MB and MT-MB is not clear.

\section{Reproducibility}

Slow voltage changes during at least one bladder contraction were found more or less pronounced in all five volunteers. Consecutive micturitions in the same volunteer did not always result in similar unequivocal electrode signals.

\section{Discussion}

This study shows for the first time electrical signals from abdominal surface electrodes, which undoubtfully relate to simultaneously recorded urodynamic signals. The course of the electrode signals during voiding differs for the two pressure/flow examples shown. In (female) volunteer 4 , the diagonal electrode signals reach their maximum amplitude in about 10 seconds after they have started to rise and return to baseline abruptly within 30 seconds when about $70 \%$ of the bladder volume has been voided. The diagonal electrode signals of (male) volunteer 2 contain a more gradual slow voltage change during voiding that reaches its maximum not before voiding is about to cease. Nevertheless, in both cases the diagonal and vertical electrode signals relate to the urodynamic signals flow and vesical pressure. Although more measurements are needed to perform a statistical analysis of the electrode signals and to determine possible relations with variables such as gender, voided volume, maximum flow rate, maximum vesical pressure, etc., some general remarks on the 
appearance of the electrode signals can be made.

The electrode signals recorded in combination with free flowmetry show a voltage change during voiding in both the diagonal and vertical bipolar electrode signals as well.

The electrode signals before and after voiding look rather stable in absence of a bladder contraction with acceptable noise levels and a small ECG contribution. No slow voltage changes as seen during voiding for pressure/flow and free flow, nor any activity resembling the recordings during the exercises are present. These observations suggest a relation between bladder contractions and the slow voltage changes recorded by the abdominal surface electrodes. Assuming that membrane potential changes of contracting bladder muscle cells are the source of the recorded bipolar signals, several explanations for the differences in signal amplitude of the diagonal, vertical and horizontal bipolar electrode signals during bladder contractions can be given. Some factors that influence the appearance of the electrode signals are the direction of bipolar electrode derivation, the interelectrode distance and the physiological course of bladder muscle activation.

The interelectrode distance of the diagonal derivations is larger than the distance of both the vertical and horizontal derivations. In the former situation, more muscle cells might contribute to the recorded electrical activity, thereby increasing the signal amplitude. The diagonal bipolar electrode signals are expected to be similar to the vertical electrode signals, because of the small angle $\left( \pm 18^{\circ}\right)$ between MT-MB and LT-MB, MT-MB and RT-MB, respectively. Indeed, the signals we have obtained by these two derivations look similar, while the amplitudes of the diagonal bipolar electrode signals seem slightly higher when compared to those of the vertical ones.

The bipolar horizontal electrode signals show no or minor signal change during bladder contractions. This gives rise to some speculations on the yet unknown (electro-)physiological course of the bladder contraction. Either there is no strong signal source in the recording area, or uniform activity is synchronous for the two electrodes of an horizontal derivation. As the diagonal and vertical electrode signals clearly show activity during bladder contractions, it is very unlikely that there is no signal source present in the recording area. This suggests the physiological course of a bladder contraction to be symmetrical left and right to the abdominal midline, for this would not result in a considerable rise of electrical activity in horizontal electrode signals. The activity seen in the diagonal or vertical electrode signals implies a topdown or bottom-up activation of the bladder muscle instead.
Other factors that might influence the appearance of the electrode signals are based on anatomical considerations. The bladder becomes smaller when it empties and sinks behind the pubic bone, which might hamper the conductance of electrical activity from the bladder muscle to the abdominal skin. The contribution of the electrically active bladder muscle to the voltage difference over the bipolar electrodes on the abdominal skin is expected to be lowered, since the mean distance between the source of the electrical activity and the recording electrodes is enlarged.

The major advantage of this method is that the electrodes do not directly contact the bladder wall. Artifacts originating from movement between the electrodes and the bladder as described in the literature (Abdel-Rahman et al., 1982; Brunsting, 1958; Kinder et al., 1997) are excluded completely. Nevertheless, other disturbing signal sources will be present. Therefore, a critical examination of possible artefact sources and physiological interpretations of the electrode signals will be discussed.

Local striated muscle activity clearly influences the electrode signals. The control exercises showed that the electrical activity recorded from striated musculature contains much higher frequencies than the voltage changes measured during bladder contractions. The amplitude of the signals generated by the exercises is considerably smaller than the amplitudes of the same bipolar electrode signal RTMB during bladder contraction. For these reasons the local striated muscle electrical activity can easily be identified in the recordings.

With the volunteer relaxed and the bladder at rest, minor variations of the electrode signals are present before and after voiding. These variations have a lower amplitude and higher frequency when compared to the voltage change during bladder contractions. The origin of this activity is not clear to us. It is probably not related to respiration, since the variations in the vesical pressure due to respiration show a higher frequency. It might possibly be related to neighbouring bowel activity, which is expected to be slow (Weisbrodt, 1991) and might be picked up by the recording electrodes. Variations in the $\mathrm{Ag}-\mathrm{AgCl}$ electrode contact potential are known to cause slow electrical voltage changes as well. Nevertheless, both effects seem to be very modest here as the electrode signals with a full and empty bladder at rest are stable and show minor variations in electrical activity only. Abdominal straining and coughing introduce modest movement of the abdominal skin and the electrodes. The slow voltage changes seen in the electrode signals during (isovolumetric) bladder contraction can not be caused by such movement, because they are 
not present during abdominal straining and coughing. Another possible signal source for the slow voltage changes during bladder contractions is sympathetic skin response (SSR), a phenomenon which is triggered by activation of the sympathetic nervous system and results in sweat production (Arunodaya \& Taly, 1994; Ravits, 1997). It seems curious for a bladder contraction to trigger a SSR since a bladder contraction is a parasympathetic driven event, during which the sympathetic nervous system is most likely to be inhibited (Kinder et al., 1995). It seems however possible that other stimuli that accompany a bladder contraction might trigger SSR. To our knowledge, the occurrence of SSR on the abdominal skin during bladder contraction has never been described in the literature. Of course this does not mean that it might not occur. Usually, SSR is recorded from hand and foot. In these cases the complete SSR occurs within five seconds after the stimulus (Arunodaya \& Taly, 1994; Ravits, 1997). This suggest that the slow potential changes with a duration of twenty seconds and more, as we recorded during voiding, are no SSR.

\section{Conclusion}

We were interested whether it was possible to obtain a bladder-electromyogram using this non-invasive approach. In this we succeeded in all volunteers at least once. Consecutive micturitions in the same volunteer did not always result in unequivocal electrode signals, a phenomenon for which we have no explanation yet. At this stage we showed that it is possible to record electrical signals from the abdominal area, which are related to bladder contractions. Whether these signals reflect actual membrane potential changes of bladder muscle cells is not clear yet. More research is necessary to further develop and test the method. Reproducibility and clinical applicability of the method remain to be established. Extensive control experiments have to be designed and conducted to further validate the physiological interpretation of the recorded signals. The advantages of this non-invasive method for recording bladder EMG above the methods described in literature and its potential are promising.

\section{Acknowledgements}

The generous hardware support of Twente Medical Systems is greatfully acknowledged. Ronald de Vreeze is acknowledged for his kind electrode support.

\section{References}

Abdel-Rahman M, Coulombe A, Abdel-Hakim A, Galeano C, Elhilali M (1982) Vesicourethral Electromyography: Facts or Artifacts. Br J Urol 54:381-386

Abrams P, Blaivas JG, Stanton SL, Andersen JT (1988) Standardization of terminology of lower urinary tract function. The international continence society committee on standardization of terminology. Neurourol Urodyn 7 , 403-427 / Scand J Urol Nephrol 114 (suppl):5-19

Arunodaya GR, Taly AB (1995) Sympathetic skin response: a decade later. J Neurol Sci 129:81-89

Brunsting CD (1958) An interpretation of the urinary bladder "electrocystogram" as artefact. J Urol 79:165-170

Corey EL, Boyce WH, Vest A, French CR (1951) Electropotential changes in human urinary bladder: a method of measurement. J Appl Physiol 3:631-636

Doyle PT, Hill DW, Stanton SL (1975) Electromyography of the detrusor muscle. J Urol 114:208-212

Jones WG, La Joie WJ, Cosgrove MD (1974) Electromyography in pathologic bladder. Urology 2:186189

Kinder MV, Gommer ED, Van Waalwijk van Doorn ESC, Janknegt RA (1997) A method for the electromyographic mapping of the detrusor muscle with multiple electrodes on the serosal bladder surface. Arch Physiol Biochem, in press

Ravits JM (1997) AAEM Minimonograph \#48: Autonomic nervous system testing. Muscle Nerve 20:919-937

Rowan D, James ED, Kramer AEJL, Sterling AM, Suhel PF (1987) Urodynamic equipment: technical aspects. J Med Eng Techn 11:57-64

Takaiwa M, Shiraiwa $Y$ (1984) A new technique of vesical electromyogram with cystometrogram and urethral electromyogram. Urol Int 39:217-221

Weisbrodt NW (1991) Motility of the small intestine. In: Gastrointestinal physiology Johnson Eds Mosby-Year Book, Inc, London pp $42-49$ 


\section{Discussion}




\section{Sense and nonsense about urinary bladder EMG}

Bladder EMG evoked by electrical sacral nerve root stimulation has the reputation to deliver real bladder electromyograms (Craggs \& Stephenson, 1976; Scheepe et al., 1999). Arguments are presented that question this reputation and the consequences are discussed.

The EMG signals found by both groups have a duration of $150-200 \mathrm{~ms}$. Scheepe and coworkers unequivocally mention 'spike duration'. Craggs and Stephenson report 'response duration' and, unfortunately, do not show spike shape in detail. However, the latter state that their findings are consistent with intracellular recordings by Ursillo (1961), who showed spikes with a duration of about 150-200 ms.

Spike duration of $150-200 \mathrm{~ms}$ indicates that major frequency components must be present at about 5-7 $\mathrm{Hz}$. Scheepe and coworkers assert that the true EMG signal in the dog lies above $3 \mathrm{~Hz}$, below that only artefacts are expected. The latter remark is surprising, since it was only in their previous article that they presented EMG activity in the rat with a main signal frequency below $1 \mathrm{~Hz}$ (Scheepe et al., 1998). Craggs \& Stephenson report that only the frequency band of 10 to $40 \mathrm{~Hz}$ is reasonably free of artefacts and therefore represents the true bladder EMG signal. All these apparently conflicting statements about the same spikes with a duration of $150-200 \mathrm{~ms}$ make a discussion necessary to elicit possible pro and cons of the authors statements.

Craggs and Stephenson state that the real bladder EMG is most clear from $10-40 \mathrm{~Hz}$. One should not conclude from this statement that the major bladder EMG components are located in this range, which is apparently not the case taking their signal duration of 150-200 ms into account. Many signals in the time domain can be represented by a broad range of frequencies, being most intense at those frequencies where the time signal is strongest, but still showing small components at other frequencies. Since the major signal components of bladder EMG are expected at 5-7 Hz, the signal remaining in the 10-40 $\mathrm{Hz}$ frequency band must have very low amplitudes left, which is, indeed, what Craggs and Stephenson report and their amplitudes found are about $25-50 \mu \mathrm{V}$. The question remains what this high frequency low amplitude signal represents.

The main flaw of the Craggs approach is the assumption that movement artefact and signals that represent electrical smooth muscle activity can be separated at frequencies above $10 \mathrm{~Hz}$, while both phenomena have their main signal components in the same frequency range clearly below $10 \mathrm{~Hz}$. This assumption does not hold, since not only the true EMG signals are likely to be represented at higher frequencies with small amplitudes, but the artefact components as well. A control experiment, conducted on an in vivo rabbit bladder 24 hours post mortem, shows that electrode movement with a frequency of $1.5 \mathrm{~Hz}$ can produce signal components in the $10-40$ $\mathrm{Hz}$ frequency band with a small amplitude of around 25-40 $\mu \mathrm{V}$. The electrode device was moved by hand in a sinusoidal way across the outer bladder surface with an amplitude of $1 \mathrm{~cm}$ and is shown as top trace in each of the three panels of Fig.1. This movement signal was compared to a recording period in which the electrode device was not moved but at rest on top of the bladder 24 hours p.m., shown as bottom trace in each panel. For a detailed description of the control set-up see Kinder et al. (1997). The unfiltered signals have a frequency range of $0.005-108 \mathrm{~Hz}$ (top panel). The main signal component showing highest amplitudes in the upper trace of panel 1 is located around $1.5 \mathrm{~Hz}$, since this was the source frequency of movement. Filtering the signals in the top panel in the frequency domain, i.e., applying Fast Fourier Transform (FFT), eliminating the unwanted frequencies and conducting inverse FFT, produced the middle and bottom panel, showing a frequency band of $1-10 \mathrm{~Hz}$ and $10-40 \mathrm{~Hz}$ respectively. It becomes clear that the low frequent, high amplitude movement in the top panel has high frequent, low amplitude signal components in the signal range of 10-40 Hz. This effect also occurs for other types of low frequent signals. It seems very similar to what happens during evoked bladder contraction: high amplitude, low frequent movement results in movement artefact in the recordings, which is expected to have low amplitude, high frequency components as well. It must, therefore, be taken into account that the real bladder EMG as presented by Craggs \& Stephenson (1976) in the $10-40 \mathrm{~Hz}$ range is once more movement artefact.

We might have misinterpreted the findings of Craggs and Stephenson and they might argue for a major bladder EMG signal component existent in the 10-40 $\mathrm{Hz}$ range only. However, such components would not be consistent with spike durations found in intracellular recordings from bladder smooth muscle cells (Ursillo, 1961; Bramich \& Brading, 1996; Visser 


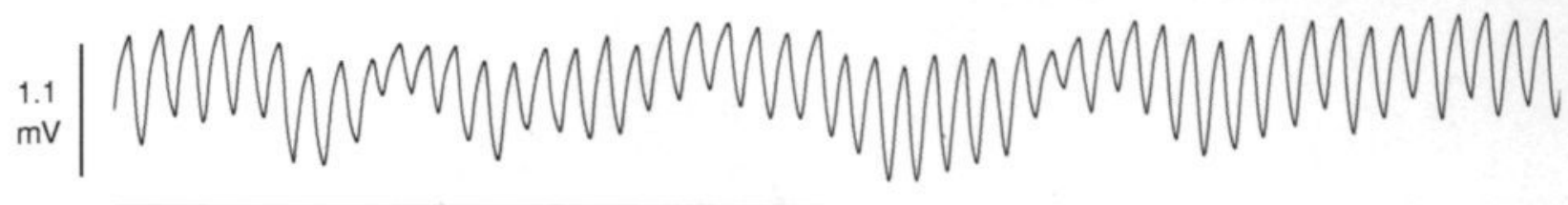

\section{$1 \cdot 10 \mathrm{~Hz}$}

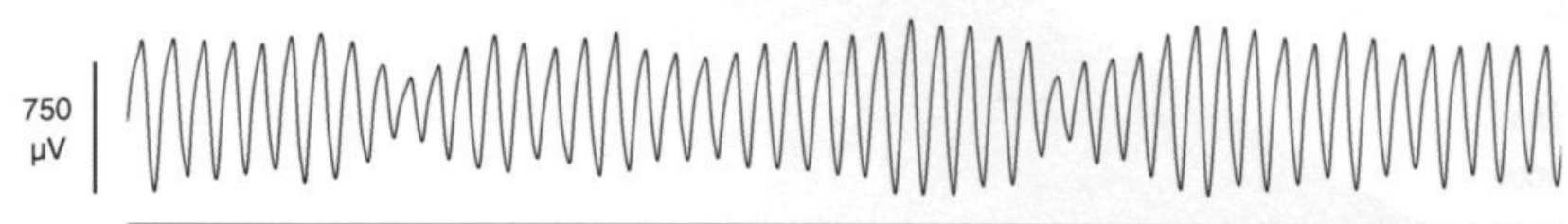

$10-40 \mathrm{~Hz}$

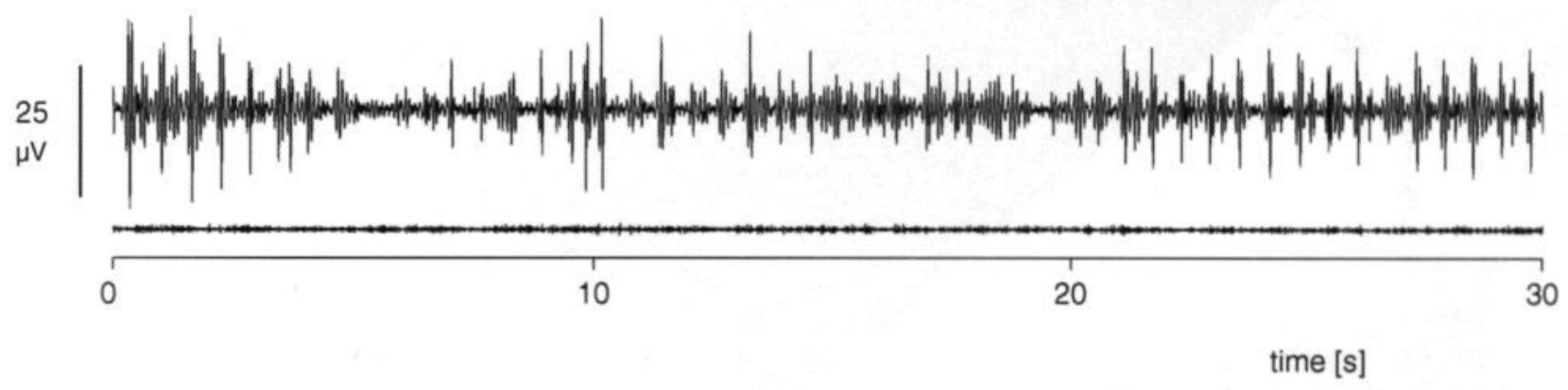

Figure 1: All traces were obtained from the outer surface of a rabbit bladder, 24 hours post mortem at $4{ }^{\circ} \mathrm{C}$. Each panel holds two traces: the upper trace shows the signal while moving the electrode device by hand; the lower trace shows when the electrode device is at rest. The top panel shows the signals in a frequency band of $0.005-108 \mathrm{~Hz}$. This band is limited in the middle panel to $1-10 \mathrm{~Hz}$, and in the bottom panel to $10-40 \mathrm{~Hz}$ using filtering in the frequency domain. The low frequent movement in the upper panel is clearly represented in the $10-40 \mathrm{~Hz}$ panel with amplitudes of up to $40 \mu \mathrm{V}$. These signals look similar to the signals presented by Craggs \& Stephenson (1976) as the real bladder electromyogram. For further discussion, see text.

\& Van Mastrigt, 1999). Extracellular recording of summated electrical events from multiple cells is likely to show increased spike duration instead of shorter duration when compared to intracellular spike duration found in a single cell. Moreover, the present control experiments suggest that major EMG components existent in a $10-40 \mathrm{~Hz}$ band would have to exceed amplitudes of $25 \mu \mathrm{V}$ in order to be discernible from low frequent movement artefacts evoked during bladder contraction and likely to be present in that frequency band as well (Fig.1).

Craggs and Stephenson mention another possible origin for the $10-40 \mathrm{~Hz}$ activity. Carry over from the 1 $10 \mathrm{~Hz}$ band might have occurred due to the analog filters used at the time. Carry over means that when a frequency band of $10-40 \mathrm{~Hz}$ is displayed, components from below $10 \mathrm{~Hz}$ are still present in the signal. It is likely that this actually contributed to the $10-40 \mathrm{~Hz}$ range of Craggs. The signals shown in Fig. 1 were filtered in the frequency domain, a technique that results in a filtered time signal where no carry over occurs.

Bladder EMG in combination with electrostimulation of sacral nerves emerged from the concept of electromechanical coupling of smooth bladder muscle cells: increased mechanical activity always appears in tandem with increased electrical activity. For striated muscle EMG, the concept of electromechanical coupling is satisfactory (Rembold, 1995). In smooth mucle, however, this concept has proven not to be complete, since contraction can also be achieved using mechanisms that do not affect the membrane potential, representing pharmacomechanical coupling (Brading, 1990; Rembold, 1995). Sacral nerve root stimulation and subsequent bladder contraction might just induce less electrical bladder activity than hoped for, while movement is considerable. Fry \& Wu (1998) 


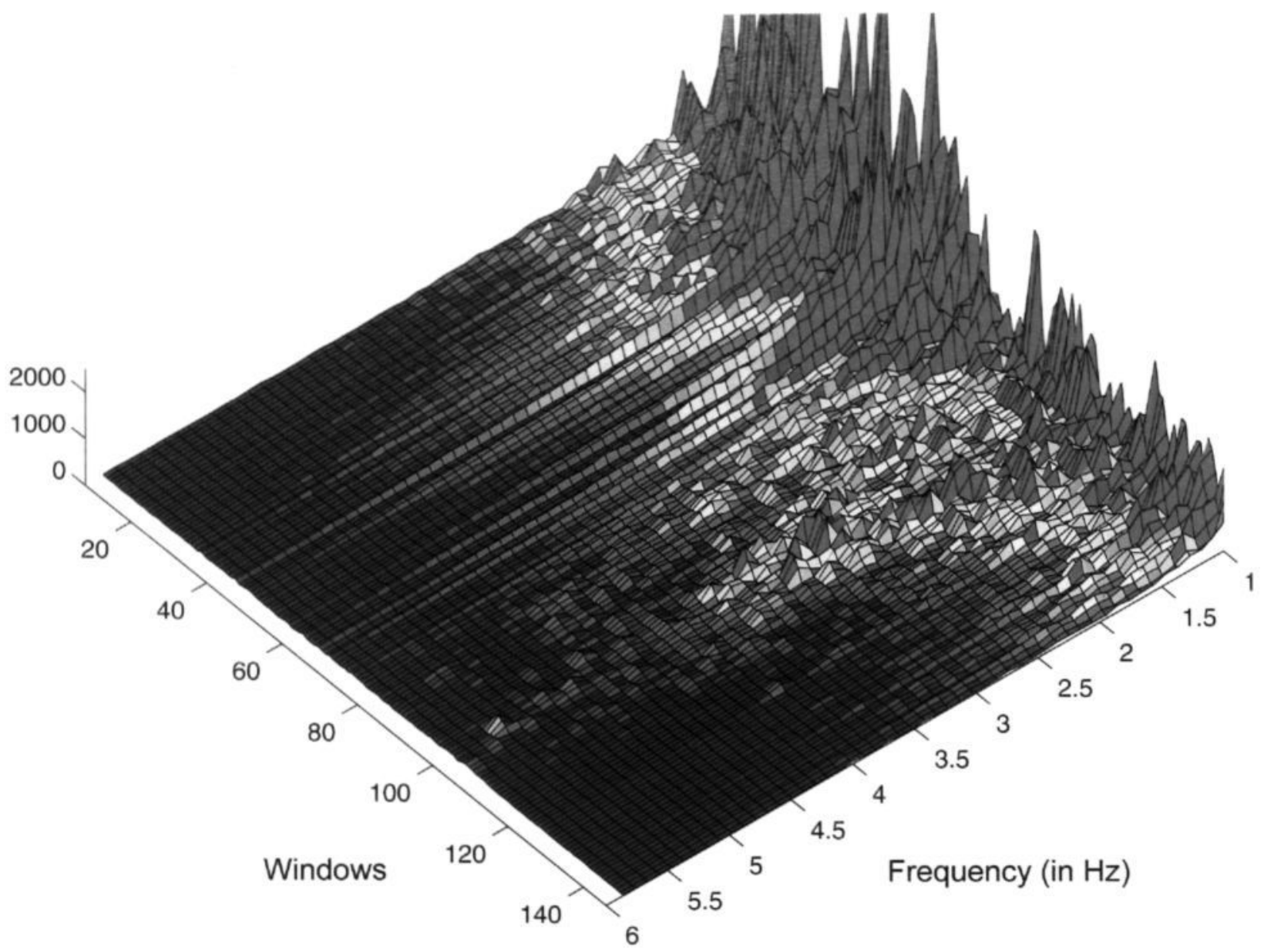

Figure 2A: The power spectral densities of all 32 EMG channels are summed and displayed for windows of 2048 samples. Each window overlaps for $75 \%$ with its previous. A frequency range from 1-6 $\mathrm{Hz}$ is displayed. On the left side, the movement artefacts during filling are clearly discernable as straight lines throughout the frequencies. This is caused by Fast Fourier Transform (FFT) of clipping signals. The low frequent signal components around $1 \mathrm{~Hz}$ are rather high. Immediately after filling. movement artefacts dissappear, the low frequent activity around $1 \mathrm{~Hz}$ clearly diminishes and EMG activity emerges in the 1-6 $\mathrm{Hz}$ band.

imply that the generation of tension is not accompanied by electrical activity in normal human detrusor muscle. First results from non-invasive bladder EMG in human (Kinder et al., 1998) suggested that electrical activity is present during voiding, but merely at the beginning of the voiding period and not necessarily throughout. Several explanations have been proposed, like the bladder sliding away from the recording electrode behind the os pubis, but it could also be that the electromechanical part decreases at the end of voiding and intracellular calcium takes over. Whatsoever, one of the criteria to identify real bladder EMG postulated by Craggs (1998) that 'electrical activity must always precede mechanical activity' remains to be confirmed and is possibly not valid.

The contribution of various mechanisms in electroand pharamacomechanical coupling might differ among species. The importance to study electro- and pharmacomechanical coupling mechanism in vivo because of their seemingly crucial interrelations has been stressed, and the hazard of scientific reductionism focusing on a single mechanism has been pointed out best by Rembold (1995).

The most fruitful approach from a signal analysis point of view is to study signals at frequencies where they are strongest, giving the opportunity for an optimal signal to noise ratio. Assuming that the real bladder EMG lies below $10 \mathrm{~Hz}$, this means that frequencies below $10 \mathrm{~Hz}$ should not simply be excluded from further analysis as proposed by Craggs. An alternative approach, instead, is to reduce the noise source in this region. Several techniques were proposed for human (Kinder et al., 1998b) and animal experimental set-ups (Kinder et al., 1997, 1998a, 2001). In the animal set-up, spontaneous and stretch 


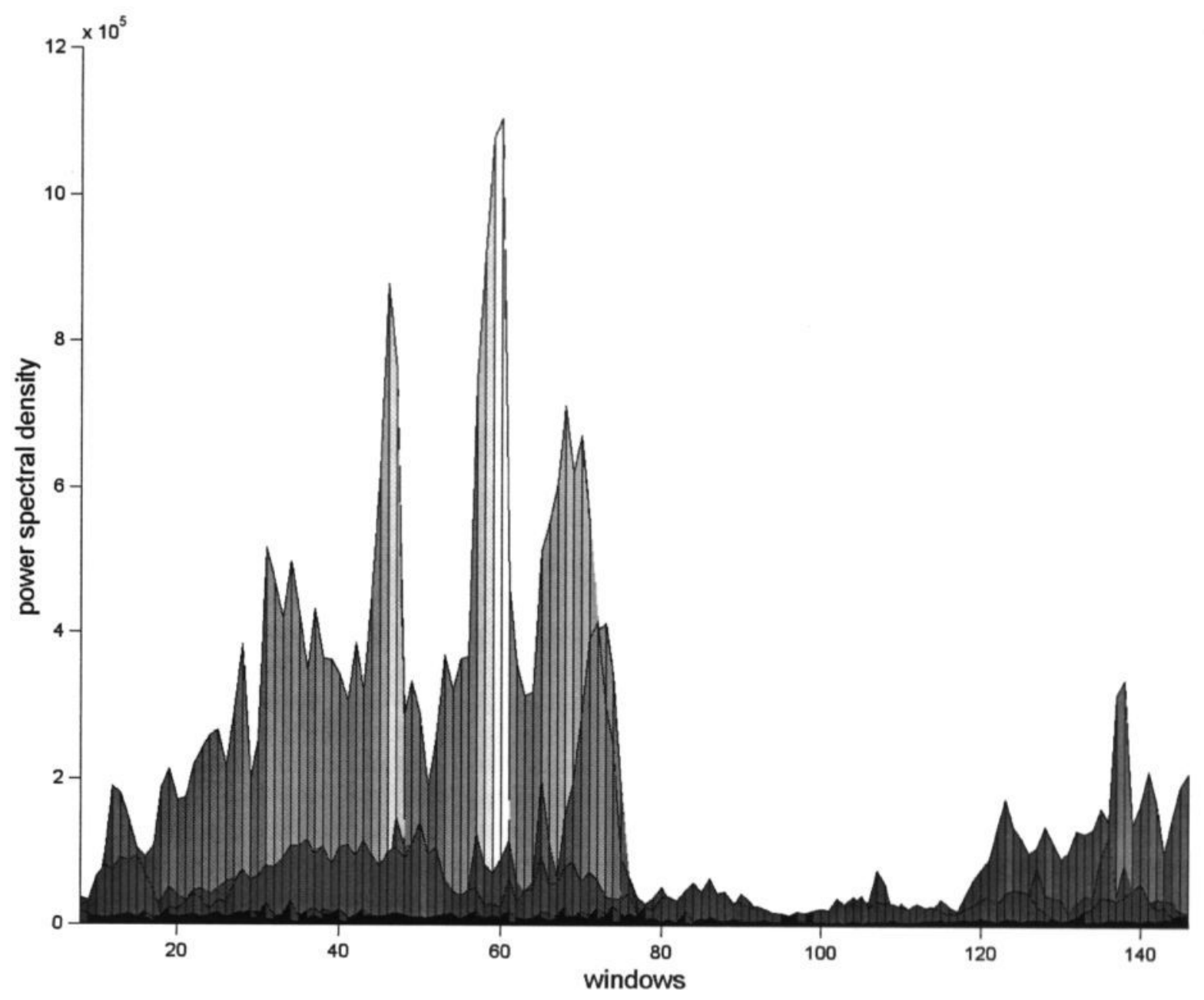

Figure 2B: The power spectral density for a frequency range from $0-10 \mathrm{~Hz}$ is displayed, to the decrease in low frequent activity after filling has ended. The calculation method from Fig 2A has been applied. Note that the frequency axis is not visible, which is caused by the viewers perspective on the 3-D plot.

evoked electrical bladder smooth muscle activity was recorded. This activity was similar in appearance both in mortalised and living rabbits. In the mortalised rabbit, movement was reduced to local mechanical bladder smooth muscle activity underneath the recording electrodes only. In practice, no significant movement artefacts were present during recording of spontaneous activity and after stretch induced activity. In the living rabbit, respiration movement was in addition visible in the bladder EMG. In this context, the multiple electrode approach to record EMG on a confined bladder surface area has proven to be indispensable for artefact recognition. When the signal is not present on all electrodes at exactly the same moment in time and spike shape, amplitude and duration are conform the characteristics of bladder EMG spikes, two main criteria for positive bladder EMG identification are met. Further criteria, for example pharmacological ones, are likely to become available soon.
Bladder electromyography in the living rabbit showed single spikes, spike bursts and continuous spike activity, which all differed significantly in spike amplitude and duration. The single spikes and small bursts ( $2-5$ spikes) are considered myogenic in origin, because they were present underneath one electrode only and did not propagate across electrodes. More certainty about their supposed myoginic origin will be obtained in case the single spikes and small bursts are preserved after application of TTX. Large burst (520 spikes) are considered to originate from short neuron system activity, since they are present on multiple electrodes, are able to organise themselves in specific patterns and propagate across electrodes. Urinary bladder smooth muscle cells are considered to have poor electrotonic coupling and do not act as a single syncytium. Organisation and sychronisation of electrical smooth muscle activity is expected to be orchestrated by the nervous system. Since large bursts are present during normal bladder filling, our 
concept is that of short neuron system control. Findings presented in literature on short neuron system morphology and physiology show that it is utilised to fulfil local control actions (Bradley \& Teague, 1968; Elbadawi, 1984, 1987a, b, 1991; Morrison, 1987). Despite its expected importance it is surprising how little is known about short neuron system behaviour.

The central nervous system is thought to organise the continuous activity, since it is present on all electrodes simultaneously, propagates and is triggered by unphysiological stimuli.

Power spectra can be calculated from the recorded signals and give more information about the frequency content of the bladder EMG. Power spectral density from continuous, stretch induced activity in the mortalised rabbit, which is devoid of movement artefact, clearly showed frequency components from 1 to $10 \mathrm{~Hz}$ (Kinder et al., 1997). This is confirmed in the living rabbit, e.g., after bladder filling, in Fig. 2. The movement artefacts during filling are clearly visible in the spectrum. This movement attanuates significantly after filling while the EMG signal emerges in the 1 to $6 \mathrm{~Hz}$ band.

Scheepe et al. (1999) stated that the true EMG signal in the dog lies above $3 \mathrm{~Hz}$, below that only artefacts are expected. This clearly is not the case in the rabbit and we do not agree with Scheepe and coworkers that below $3 \mathrm{~Hz}$ only artefacts occur, although their experimental set-up and protocol seems very susceptible to movement in this range. It seem likely that movement artefact prevales below $3 \mathrm{~Hz}$ and masks EMG activity in their recordings. It is tempting to define a frequency threshold for EMG activity, however, physiological phenomena cannot always be categorised. Our recordings show that both, artefact and EMG, can occur in the same frequency band. Depending on the experimental set-up and protocol, one of them or both are emphasized. We have discussed several methods to emphasize the EMG activity and attanuate the movement artefacts.

Craggs and Stephenson state that frequency components below $10 \mathrm{~Hz}$ are contaminated with mainly movement artefacts and do not correlate well with intravesical pressure. The question here is why movement artefacts do not correlate with vesical pressure. One obvious explanation is that this movement is not originating from the bladder but from other sources. Another possibility is that the bladder can be active and generate movement and electrical activity without significant changes in vesical pressure. Urodynamics is restricted to the monitoring of a set of micturition process parameters and useful to demonstrate the overall behaviour of the bladder and the urethral closure mechanisms, but it neither reveals the underlying causes for dysfunction nor does it give information about local bladder muscle behaviour, like the onset and possible spread of contractions (Kinder, 1999). This indicates that intravesical pressure is not selective enough in combination with the study of (local) electrical bladder smooth muscle activity. A more refined technique to asses local mechanical bladder activity is needed. Video monitoring fluorescent spheres placed on top of the outer urinary bladder wall to assess three dimensional strain fields in the living rabbit has proven to be feasible (Kinder et al., 1999b). The onset and spread of contractions can be studied in vivo using this technique, information that is not available in the literature to the best of our knowledge. However, it cannot be used simultaneously with urinary bladder EMG of the same area.

The results of the feasibility study with the fluorescent markers have been discussed rather briefly and focused on the qualitative results, not on the quantitative. In depth analysis of the quantitative results this limited feasibility study has provided is not useful, but a first glance at it looks interesting. It is unexpected that the spontaneous actvity of the isovolumetric bladder as shown in Fig. 8 of Chapter five reaches an amount of stretch that approaches $10 \%$. During this registration, bladder pressure remains within a one $\mathrm{cm} \mathrm{H}_{2} \mathrm{O}$ band (unpublished). The stretch found seems to be comparable or even more than seen during bladder contraction when the sacral nerve S2 is stimulated electrically, shown in Fig. 1 in Chapter 4. However, there the bladder had been stimulated several times already and the amount of stretch during the first stimulations was clearly higher than shown in Fig. 1 of Chapter 4. A more detailed study using this marker technique that enables a quantitative discussion would probably enhance the present knowledge on in vivo bladder function considerably.

To investigate the relations between neural innervation and electro- and pharmacomechanical coupling mechanisms of the urinary bladder smooth muscle in vivo, an approach is optimal in which assessment of local mechanical bladder activity can be combined simultaneously with urinary bladder EMG of the same area. Application of various pharmaca can further elicit the origin of the single spikes, bursts and stretch induced activity and their relation to the neuronal control pathways and mechanisms.

One final point of attention is the effect aneasthetics have on bladder EMG. Hypnorm ${ }^{\circledR}$, Halothane ${ }^{\circledR}$, Isoflurane $^{(2)}$ and other aneasthetics are known to reduce the activity of muscle (Pagel, 2000). On 


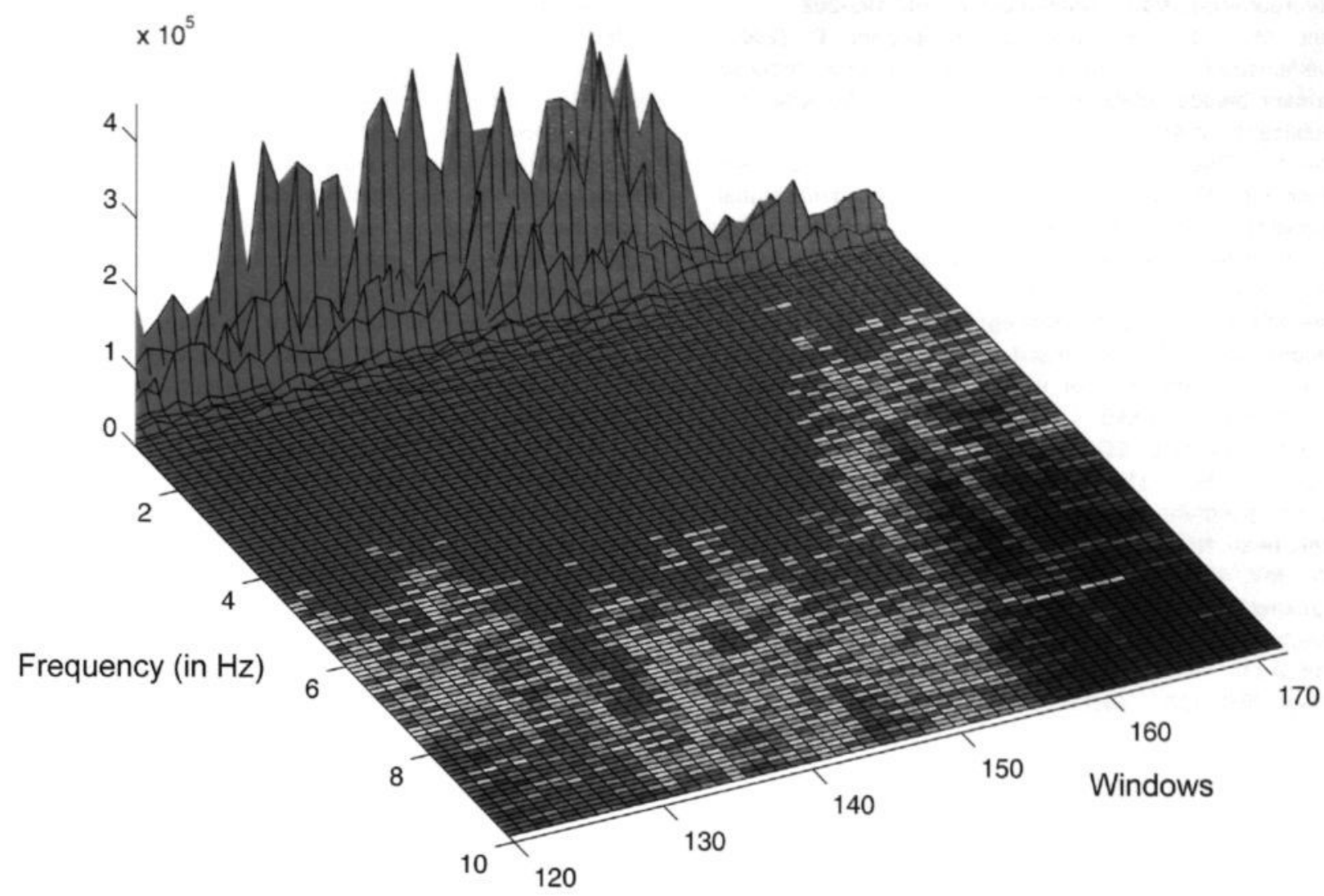

Figure 3: The power spectral densities of all 32 EMG channels are summed and displayed for windows of 2048 samples. The effects of $0.5 \mathrm{ml} \mathrm{Hypnorm} \mathrm{i.v.} \mathrm{on} \mathrm{the} \mathrm{EMG} \mathrm{signals} \mathrm{are} \mathrm{shown} \mathrm{in} \mathrm{the} \mathrm{frequency} \mathrm{domain} \mathrm{from} \mathrm{1-10} \mathrm{Hz}$. Soon after application, the activity clearly deminishes.

several occasions, Hypnorm® was applied in vivo, and a marked decerease of bladder activity was noted as is shown in Fig. 3. This might as well have contributed to the difficulty of recording bladder EMG in the past (Corey et al., 1951; Boyce, 1952; Franksson \& Petersen, 1953; Brunsting, 1958; Fredericks et al., 1969; Stanton et al., 1973, 1974; Cosgrove et al., 1974, 1977; Jones et al., 1974; Doyle et al., 1975; La Joie et al., 1975; Craggs \& Stephenson, 1976, 1982, 1985; Kaplan et al., 1976; Kaplan \& Nanninga, 1978; Nanninga \& Kaplan, 1978; Abdel-Rahman et al., 1982; Takaiwa et al., 1983a, b, 1992; Takaiwa \& Shiraiwa, 1984; Jünemann et al., 1994; Shafik, 1994). We changed from halothane to isoflurane in our experiments, the latter of which is known for its less supressive effects.

\section{References}

Barany M, Barany K (1995) Protein hosphoylation during contraction and relaxation. In: Barany $\mathrm{M}$, editor. Biochemistry of smooth muscle contraction. San Diego: Academic Press. p 321-339

Brading AF (1990) Pathways of smooth muscle stimulation.
Neurourol \& Urodyn 9:299-301

Bradley WE, Teague CT (1968) The pelvic ganglia. J Urol 100:649-652

Bramich NJ, Brading AF (1996) Electrical properties of smooth muscle in the guinea-pig urinary bladder. $J$ Physiol 492:185-198

Craggs MD, Stephenson JD (1976) The real bladder electromyogram. Br J Urol 48:443-451.

Elbadawi A (1984) Ultrastructure of vesicourethral innervation. II. Postganglionic axoaxonal synapses in intrinsic innervation of the vesicourethral lissosphincter: a new structural and functional concept in micturition. $J$ Urol 131:781-790

Elbadawi A (1987a) Comparative neuromorphology in animals. In: Torrens MJ, Morrison JFB, editors. The Physiology of the Lower Urinary Tract. London: Springer Verlag, pp 23-52

Elbadawi A (1987b) Neuromuscular Mechanisms of Micturition. In: Yalla SV, McGuire EJ, Elbadawi A, Blaivas JG, editors. The Principles and Practice of Neurourology and Urodynamics. New York: Macmillan, pp 3-35

Elbadawi A (1991) Anatomy and innervation of the vesicourethral muscular unit of micturition. In: Krane RJ, Siroky MB, editors. Clinical Neuro-Urology. 2nd Ed. Boston: Little, Brown \& Company, pp 5-23

Fry CH, Wu C (1998) Review: The cellular basis of bladder instbility. Br J Urol 81:1-8

Kinder MV (1999) Introduction to this special issue on 
Neurourology. Arch Physiol Biochem 107:195-202

Kinder MV, Bos R, Janknegt R, Marani E (2001) Demonstration of spontaneous and stretch induced urinary bladder EMG in the living rabbit. Accepted for publication in Arch Physiol Biochem

Kinder MV, Bos R, Willems PJB, Drost MR, Holtzer CAJ, Janknegt R, Marani E (1999) Three dimensional registration of mechanical bladder activity using polystyrene fluorescent spheres: a technical note. Arch Physiol Biochem 107:236-241

Kinder MV, Gommer ED, Janknegt RA, Van Waalwijk van Doorn ESC (1997) A method for the electromyographic mapping of the detrusor smooth muscle. Arch Physiol Biochem 105:673-690

Kinder MV, Gommer ED, Janknegt RA, Van Waalwijk van Doorn ESC (1998a) Recording the detrusor electromyogram is still a difficult and controversial enterprise. Neurourol Urodyn 17:571-573

Kinder MV, Van Waalwijk van Doorn ESC, Gommer ED Janknegt RA (1998b) A non-invasive method for bladder electromyography in humans. Arch Physiol Biochem 106:2-11

Morrison JFB (1987) Neural connections between the lower urinary tract and the spinal cord. In: Torrens MJ, Morrison JFB, editors. The Physiology of the Lower Urinary Tract. London: Springer Verlag, p 53-85

Pagel PS, Farber NE, Warltier DC (2000) Cardiovascular pharmacology in anesthesia. In: Miller RD, editor. Philidelphia: Churchill Livingstone, pp 97-124

Rembold CM (1995) Electromechanical and pharmacomechanical coupling. In: Barany M, editor. Biochemistry of smooth muscle contraction. San Diego: Academic Press. pp 321-339

Scheepe JR, Bross S, Schumacher S, Braun P, Weiss J, Alken P, Juenemann K (1999) Recording the evoked canine detrusor electromyogram. Neurourol Urodynam 18:687-695

Scheepe JR, Wipfler G, Schumacher S, Bross S, Zendler S, Jûnemann $\mathrm{KP}$, Alken $\mathrm{P}$ (1998) Smooth muscle electromyography of the urinary bladder. Neurourol Urodynam 17:71-83

Visser AJ, Van Mastrigt R (1999) Intracellular recording of spontaneous electrical activity in human urinary bladder smooth muscle strips. Arch Physiol Biochem 107:257270. 
Summary 


\section{Summary}

The introduction of this thesis showed that the voiding process (micturition) is a complicated process not yet completely understood. The complex biological situation as described in the literature showed differences in anatomical perception, for example, peripheral connections in humans are not well understood, while the possibilities for neuroanatomical and neurophysiological research are limited. Clinically, the current diagnostic techniques are unable to indicate selectively the origins of urinary tract dysfunction. Moreover, possibilities for electrical stimulation to test the integrity of neuronal pathways involved in micturition control are limited.

There is a variety of approaches in the study of the micturition process. Seemingly, a solution is to describe the complex organisation by system theory, providing a foundation for the design of mathemathical models. The basic principles of mathematical modelling are easy to explain but difficult to carry out. Considering the bladder and its neuronal control as a black box, input/output relations can be studied. Unfortunately, only limited techniques are available to obtain quantitative data in human to model input/output relations. One promising tool to obtain new data on the functioning of the bladder muscle and its neuronal control in vivo is urinary bladder smooth muscle electromyography (bladder EMG).

The literature review in Chapter one, on the neuronal innervation of the lower urinary tract and mechanisms that control the micturition cycle, focused on the concepts of four research groups. Their concepts were chosen for closer study because they seemed to be most complete. One uniform representation technique using flow charts was introduced to visualize each concept. The flow charts integrated neuro-anatomical architecture and control mechanisms in three different stages of the micturition cycle: storage, voiding and end of micturition. Using flow charts, neuro-anatomical architecture and elementary control mechanisms were compared.

The results of this literature review were rather disappointing: no complete or generally accepted model was available to describe the principles of micturition control. The central and peripheral nervous structures and connections said to be involved in micturition control were different and sometimes contradictory. This also held for the control mechanisms which were thought responsible for a coordinated and succesful micturition cycle. On some occasions the control mechanisms proposed were in conflict with either neuroanatomical knowledge, the principles of control theory or both.

An explanation for the differences in the concepts of the four research groups, which are named here by their most prominent worker, might be found in different scientific approaches used. De Groat (De Groat, 1975; De Groat et al., 1979b; De Groat \& Steers, 1990) included data from animal experiments to support parts of his description of pathways and their function in human; Bradley (Bradley, 1974; Bradley et al., 1974) employed a functional approach with his "loop-concept"; Blaivas' main article (Blaivas, 1982) was based on a clinical study and Holstege (Holstege, 1989; Holstege \& Griffiths, 1990; Griffiths et al., 1990) focused on supraspinal nervous structures and connections.

In Chapter two again the neuronal innervation of the lower urinary tract and mechanisms that control the micturition cycle were discussed. At this point, a complete and detailed review of the central and peripheral nervous structures and connections involved in the control of the lower urinary tract seemed difficult to provide due to the complex biological situation, the limitations of the research tools available and equivoque anatomical nomenclature used in literature. An integrative approach using (neuro-)anatomy, (neuro-)physiology and control theory was chosen to model a state-of-the-art qualitative controller of the lower urinary tract, clearly showing possible gaps in present knowledge.

A neuro-anatomical basis of peripheral pathways, central connections and interconnecting celgroups was described. It was found that not all the nervous structures and connections, involved in the control of the uropoetic system, had been identified as such yet. The linking up between several nervous structures (e.g., the presence of central and peripheral relay stations) was not completely clear. The function of the neuroanatomical organization in micturition control was described, using neurophysiological data and principles of control theory. Some control mechanisms active during the micturition cycle could still not be revealed in detail. Crucial questions on the neuronal innervation of the human uropoetic system and the control 
mechanisms active during the micturition cycle remained. Applications of this qualitative control model for mathematical modelling, e.g., neural network simulations, were described. Future research should focus on the white spots in present knowledge.

In Chapter three bladder smooth muscle electromyography as described in the literature over the past 50 years was evaluated. The methods described in literature did not differ on essential points: signals were recorded in living mammals with extracellular electrodes that contacted the bladder directly, while bladder contractions and emptying were evoked. One of the problems with these methods was the separation of very small extracellular signals, reflecting actual membrane potential changes of detrusor smooth muscle cells, from the large electromechanical artefact caused by electrode movement as the tissue contracts. No adequate control experiments were described in these studies to determine to what extent movement of the bladder to the electrode(s) were responsible for the signals recorded. It was concluded that, in future studies with similar set-ups, the discrimination between electrical detrusor activity and signal components from other sources would remain difficult, in spite of appropriate recording equipment and data-analysis, because amplitude, frequency and shape of electrical detrusor activity recorded by these methods were still unknown. Reliable bladder EMG had not been achieved yet.

Based on the problems found, a new strategy on detrusor electromyography was formulated in Chapter three. In an animal set-up with rabbits several unwanted signal sources were excluded beforehand by a cervical dislocation and excision of the heart just prior to the recordings, while bladder contractility remained intact. No contractions of the isovolumetric bladder were evoked by any stimulus. A large area $( \pm 37 \mathrm{~mm} \times 37 \mathrm{~mm})$ of the detrusor muscle was mapped with 240 electrodes (flat circular silver electrodes, $d=0.3 \mathrm{~mm}$ each) that were placed against the serosal bladder surface in six rabbits.

Consistent results in all six animals showed a repetitive spike pattern on multiple electrodes with a repetition frequency of $1.2 \mathrm{~Hz}$. Spikes were triphasic and had a mean duration of $0.47 \mathrm{~s}$ (STD $=0.15 \mathrm{~s}$, $\mathrm{n}=40$ ) and a mean amplitude of $0.29 \mathrm{mV}$ (STD $=0.07$ $m V, n=40$ ). On adjacent electrodes a time shift between the spikes was found, suggesting the propagation of electrical activity across the detrusor surface. The maximum conduction velocity of an arbitrary spike front in the direction of propagation was approximately $30 \mathrm{~mm} / \mathrm{s}$. In two animals, slow waves were found on the edge of the highpass filter setting of $0.7 \mathrm{~Hz}$.

Extensive control experiments were executed to validate the set-up and to interpret the data obtained from the animal experiments. The bladder was still able to contract thirthy minutes post mortem. The heart, as a distant signal source, generated a signal that was present on all electrodes and showed no detectable time shift from one electrode to any other. Motion imposed on the electrodes relative to the bladder wall did not reproduce the slow waves and spikes found in the animal experiments. The control experiments supported that the results of the animal experiments showed electrical activity from the detrusor muscle itself. With the experimental set-up described, nearly artefact free detrusor EMG could be recorded. An electromyographic map of a considerable detrusor smooth muscle area could be obtained.

The three dimensional registration of mechanical bladder activity using polystyrene fluorescent spheres in chapter four showed that during spontaneous activity random shortening and elongation occurred simultaneously and seperately across the bladder wall for the two principal strains that were distinghuished. After extradural stimulation of sacral nerve S2 the principal strains synchronised in time in such a way that both strains represented shortening or both represented elongation. The study indicated that one and the same bladder wall area passed through phases of shortening followed by elongation and vise versa. The applied technique allowed to identify local areas of shortening and elongation in the intact bladder wall in vivo.

Recording of the spontaneous bladder EMG in the living rabbit in Chapter five was performed using an isovolumetric bladder without chemical or electric stimulation. Mechanical intervention was the only parameter that was changed, either by lifting the bladder out of the abdomen, or by rapid filling. This induced stretch in the urinary bladder and was reflected in the bladder electromyograms. The spontaneous electromyograms consisted of single spikes and bursts (2-20 spikes) but not of continuous activity. A trifasic spike shape was noted. Small (2-5) spike bursts and large bursts (520) were discerned; small bursts did not propagate across electrodes, large bursts did and were able to organise. Spontaneous EMG was both related to contraction and relaxation. Stretch induced electromyograms were characterised by continuous activity on all electrodes. These spikes had an 
elongated third phase when compared to the spikes of spontaneous activity. This chapter contained a concept in which the continuous activity was not unequivocally related to muscle shortening. In this concept, the current stress and strain situation of the bladder tissue could explain muscle fiber elongation upon the appearance of electrical activity.

In the addendum to chapter 5, topics were discussed that are related to the unchanged experimental approach several research groups nowadays choose for urinary bladder EMG despite of the problems known for over the past 50 years.

In Chapter six a new method for human bladder electromyography was proposed, keeping in mind the biological and technical limitations as described in Chapter three. No convincing correlation of human bladder EMG to simultaneously measured intravesical pressure had been reported in the literature sofar. Aim of Chapter six was to investigate whether bladder EMG could be performed non-invasively with $\mathrm{Ag}-\mathrm{AgCl}$ surface electrodes that were placed on the abdominal skin of volunteers. Two male and three female healthy volunteers had been recruited. Bipolar electrode signals were obtained in a diagonal, vertical and horizontal direction of the abdominal electrodes. Electromyography was performed simultaneously with urodynamic free flow and pressure flow studies. Recordings were made with both a full and empty bladder at rest and during micturition itself. Control experiments were conducted with a full bladder at rest and comprised coughing, abdominal straining, contraction of the pelvic floor and the subsequent lifting of each leg.

This new method showed that voiding was accompanied by a slow voltage change in bipolar electrode signals. Slow voltage changes during at least one bladder contraction were found more or less pronounced in all five volunteers. The contribution of abdominal and other striated muscle activity to the bipolar electrode signals could clearly be distinguished from the slow voltage changes that seemed related to voiding. Free flowmetry showed that the electrical activity picked up by the abdominal electrodes was related to bladder emptying. In pressure/flow studies a relation between the electrical activity and the detrusor pressure was found. However, consecutive micturitions in the same volunteer did not always result in similar unequivocal electrode signals.

The present results suggested that the slow voltage changes found during bladder contraction might be summed membrane potential changes of bladder muscle cells, but this concept needs further testing. Validation of the method remains to be established.

In the Discussion, sense and nonsense about urinary bladder EMG was discussed. The idea put forward in 1976 that the real bladder EMG is most clear in a frequency range of $10-40 \mathrm{~Hz}$ comes up in most contemporary discussions on bladder EMG. An analysis was conducted that questions this idea in its fundament and it was shown that EMG signals at frequencies below $10 \mathrm{~Hz}$ can be identified as such clearly in the rabbit. Finally, effects of Hypnorm ${ }^{\circledast}$ on bladder EMG were demonstrated. 


\section{Samenvatting}

De inleiding van dit proefschrift geeft aan dat we nog niet helemaal begrijpen hoe de plascyclus (de mictiecyclus) precies werkt. In de literatuur wordt een moeilijke biologische situatie geschetst, die duidelijke verschillen in de anatomische perceptie van de werkelijkheid laat zien (zo is er bijvoorbeeld onduidelijkheid over de perifere verbindingen). Daarbij zijn de mogelijkheden tot neuroanatomisch en neurofysiologisch onderzoek bij de mens erg beperkt.

Er kan een groot aantal benaderingen gekozen worden om de mictiecyclus beter te bestuderen. Een mogelijkheid is om de complexe organisatie te beschrijven met behulp van systeem theorie, waarmee een basis gelegd kan worden voor het ontwerp van wiskundige modellen. De basisprincipes van wiskundig modelleren zijn eenvoudig uit te leggen, maar vaak moeilijk uitvoerbaar. Wanneer we de blaas en zijn zenuwbesturing benaderen als een zwarte doos kunnen relaties tussen ingangs- en uitgangssignalen gelegd worden. Helaas beschikt men slechts over een beperkt aantal technieken om zulke ingangs/uitgangsrelaties bij de mens te kwantificeren. Een veelbelovende methode om nieuwe, qualitatieve en kwantitatieve gegevens over het in vivo functioneren van de blaasspier en zijn zenuwbesturing te verkrijgen is blaas elektromyografie (blaas EMG).

In het literatuuroverzicht van Hoofdstuk een, over de innervatie van de lagere urinewegen en de mechanismen die de mictiecyclus regelen, lag de nadruk op de concepten van vier onderzoeksgroepen. Hun concepten werden uitgekozen voor nadere analyse, omdat ze het meest compleet leken te zijn. In Hoofdstuk een werd een uniforme representatietechniek op basis van stroomdiagrammen geintroduceerd, waarmee elk concept gevisualiseerd kon worden. In de stroomdiagrammen werd de neuroanatomisch architectuur geintegreerd met regelmechanismen tijdens drie verschillende fasen in de mictiecyclus, te weten de urine opslag, de mictie en het einde van de mictie. De neuroanatomische architectuur en de elementaire regelmechanismen werden vervolgens met behulp van de stroomdiagrammen met elkaar vergeleken.

De resultaten van dit literatuuroverzicht waren teleurstellend: er bestond geen compleet of algemeen geaccepteerd model dat de sturing van de mictie beschreef. De centrale en perifere zenuw- structuren en verbindingen, die betrokken zouden zijn bij de sturing van de mictie, bleken verschillend en soms zelfs tegenstrijdig. Dit gold ook voor de regelmechanismen, die volgens de vier concepten voor een gecoördineerd en succesvol verloop van de mictiecyclus verantwoordelijk worden geacht. In een aantal gevallen waren de voorgestelde regelmechanismen in strijd met neuroanatomische kennis, met de basisprincipes van de regeltheorie, of met beiden.

Een verklaring voor de verschillen in de concepten van de vier onderzoeksgroepen, die hier verder genoemd worden naar hun meest bekende deelnemer, ligt mogelijk bij het verschil in wetenschappelijke aanpak en perspectief. De Groat maakte gebruik van dierexperimenten om delen van zijn beschrijving over het verloop van zenuwverbindingen en hun functie bij de mens te onderbouwen; Bradley ging uit van een functionele benadering met zijn 'loop-concept; het belangrijkste artikel van Blaivas op dit gebied was gebaseerd op een klinische studie en Holstege legde zich met name toe op supraspinale zenuwstructuren en verbindingen.

In Hoofdstuk twee werd opnieuw gekeken naar de innervatie van de lagere urinewegen en de mechanismen die het mictieprocess besturen. Het geven van een compleet en gedetailleerd overzicht van de centrale en perifere zenuwstructuren en verbindingen die betrokken zijn bij de besturing van de lagere urinewegen werd met name bemoeilijkt door de lastige biologische situatie, de beperkingen van de beschikbare onderzoekstechnieken en de niet eenduidige nomenclatuur in de literatuur. $\mathrm{Er}$ werd gekozen voor een geintegreerde aanpak, gebruik makende van de (neuro-)anatomie, de (neuro-)fysiologie en de regeltechniek, om te komen tot een state-of-the-art kwalitatieve regelaar voor de lagere urinewegen, waarbij de hiaten in de huidige kennis duidelijk naar voren zouden komen.

Als resultaat werd er een neuroanatomische basis van perifere zenuwverbindingen, centrale verbindingen en aan elkaar gerelateerde celgroepen gegeven. Naar voren kwam dat niet alle zenuwstructuren en verbindingen die betrokken zijn bij de besturing van het uropoëtisch systeem als zodanig konden worden geidentificeerd. De verbindingen tussen diverse zenuwstructuren, bijvoorbeeld waar het gaat om de aanwezigheid van centrale en perifere tussenstations, bleken niet helemaal 
duidelijk. De functie van de neuroanatomische organisatie in de mictiebesturing werd beschreven, gebruik makend van neurofysiologische gevens en van principes uit de regeltechniek. Enkele regelmechanismen die geactiveerd worden tijdens de mictiecyclus konden nog steeds niet tot in detail worden ontrafeld. Belangrijke vragen over de zenuwinnervatie van het menselijke uropoëtische systeem en de regelmechanismen die actief zijn tijdens de mictiecyclus bleven onbeantwoord. Mogelijke toepassingen van dit qualitatieve model voor wiskundige modellering, bijvoorbeeld voor neurale netwerk simulaties, werden beschreven. Toekomstig onderzoek zou zich moeten richten op de hiaten in onze kennis.

In Hoofdstuk drie werd de gladde blaasspier elektromyografie zoals deze in de laatste vijftig jaar in de literatuur is beschreven, nader geevalueerd. De meetmethoden die in de literatuur werden beschreven verschilden op een aantal belangrijke punten nauwelijks van elkaar: signalen werden gemeten in levende zoogdieren met behulp van extracellulaire elektroden die direct kontakt maakten met de blaaswand, terwijl blaascontracties en lediging werden opgewekt. Een van de problemen daarbij bleek het onderscheid tussen de erg kleine extracellulaire signalen, die veroorzaakt worden door verandering in de membraanpotentiaal van de gladde detrusor spiercellen, en de grote electromechanische artefacten die veroorzaakt worden door bewegingen van de elektrode langs de blaaswand tijdens spiercontractie. In deze studies werden geen afdoende controle experimenten beschreven waarmee de bijdrage van blaasbewegingen ten opzichte van de elektrode aan de gemeten signalen bepaald zou kunnen worden. Geconcludeerd werd, dat bij toekomstige studies met een vergelijkbare proefopzet het onderscheid tussen elektrische detrusor activiteit en signaal componenten van andere origine moelijk te maken zou zijn, omdat de amplitude, frequentie en de vorm van de elektrische activiteit zoals gemeten met deze methoden nog steeds onbekend waren. Betrouwbaar blaas EMG was nog niet gerealiseerd.

Gebaseerd op deze problemen werd er in Hoofdstuk drie een nieuwe strategie voor detrusor elektromyografie geformuleerd. In een dierexperimentele opzet met konijnen werden verscheidene ongewenste signaalbronnen bij voorbaat uitgeschakeld door een cervicale dislocatie en excisie van het hart kort voor de metingen uit te voeren, terwijl de contractiliteit van de blaas behouden bleef. Er werden geen contracties van de isovolumetrische blaas opgewekt door welke stimulus dan ook. De elektrische activiteit over een aanzienlijk gebied van de blaasspier (ongeveer 37 $\mathrm{mm}$ bij $37 \mathrm{~mm}$ ) werd in kaart gebracht door 240 meetelektroden (platte, cirkelvormige elektroden, $\mathrm{d}=0.3 \mathrm{~mm}$ elk) tegen de serosale blaaswand te plaatsen.

Consistente resultaten in alle zes dieren lieten een repeterend potentiaal patroon zien op meerdere elektroden met een repeteer frequentie van $1.2 \mathrm{~Hz}$. De potentialen waren trifasisch in hun verschijning en hadden een gemiddelde duur van $0.47 \mathrm{~s}$ (STD=01.5 s, $n=40$ ) en een gemiddelde amplitude van $0.29 \mathrm{mV} \quad(\mathrm{STD}=0.07 \mathrm{mV}, \mathrm{n}=40)$. Op aangrenzende elektroden werd een tijdsverschuiving tussen de potentialen geconstateerd, hetgeen een propagatie van elektrische activiteit over het blaasoppervlak suggereerde. De maximale geleidingssnelheid van een willekeurig potentiaalfront in de richting van propagatie bedroeg ongeveer $30 \mathrm{~mm} / \mathrm{s}$. In twee beesten werden trage golfpotentialen gevonden op de rand van het hoogdoorlaatfilter, dat zijn -3 dB punt bij $0.7 \mathrm{~Hz}$ had. Uitvoerige controle experimenten werden uitgevoerd om de proefopzet te valideren en de meetgegevens van de dierexperimenten te interpreteren. De blaas was ook na dertig minuten post mortem nog tot contracties in staat. Het hart, als afgelegen signaalbron, genereerde een signaal dat zich op alle electroden tegelijkertijd manifesteerde en waarbij geen tijdsverschuiving over de electroden te constanteren viel. Opgelegde beweging van de elektroden ten opzichte van de blaaswand resulteerde niet in de potentialen die tijdens de dierexperimenten gevonden werden. De controle experimenten bevestigden dat de resultaten van de dierexperimenten daadwerkelijk elektrische activiteit van de blaasspier zelf lieten zien. Met de beschreven proefopzet konden vrijwel artefact vrije detrusor elektromyogrammen verkregen worden. Een elektromyografische afbeelding van een aanzienlijk detrusor areaal kon worden verkregen.

De drie dimensionale registratie van mechanische blaas activiteit in Hoofdstuk vier met behulp van polystyreen fluoriseerende bolletjes liet zien dat tijdens spontane activiteit willekeurige verkortingen en verlengingen samen en afzonderlijk verspreid over de blaaswand voorkwamen voor de twee onderscheiden hoofdrekken. Bij extradurale elektrische stimulatie van de sacrale zenuw S2 trad er synchronisatie op tussen de twee hoofdrekken, zodanig dat beide hoofdrekken tegelijkertijd of verkorting, danwel verlenging lieten zien. Deze studie gaf aan dat een en hetzelfde gebied op de blaaswand een fase van verkorting gevolgd door een fase van verlenging en vice versa kon ondergaan. De toegepaste methode maakte het 
mogelijk locale gebieden van verkorting en verlenging op de intacte blaaswand in vivo te herkennen.

De registratie van spontane blaas elektromyogrammen in het levende konijn in Hoofdstuk vijf werd uitgevoerd met een isovolumetrische urineblaas zonder enige chemische of elektrische stimulatie toe te passen. Mechanische manipulatie was de enige parameter die met opzet gevarieerd werd, hetzij door de blaas uit het abdomen op de meetelektrode te tillen, dan wel door de blaas snel te vullen. Dit induceerde rek van de urineblaas, hetgeen zichtbaar was in het blaas EMG. De spontane blaas elektromyogrammen waren opgebouwd uit enkele potentialen en potentiaalsalvo's (2-20 potentialen), maar niet uit continue activiteit. Een trifasische potentiaal vorm werd geconstateerd. Korte (2-5) potentiaalsalvo's en lange salvo's (5-20) konden worden onderscheiden; korte slavo's propageerden niet over de elektroden, lange salvo's propageerden wel en konden zich organiseren in specifieke patronen. Spontaan blaas EMG was gerelateerd aan zowel contractie als relaxatie. Rek geinduceerde elektromyogrammen werden gekarakteriseerd door continue potentiaal activiteit op alle elektroden. Deze potentialen hadden een verlengde derde fase in vergelijking tot de potentialen van de spontane activiteit. Dit hoofdstuk bevatte een concept waarmee de continue activiteit niet enkel aan spier verkorting gerelateerd werd. In dit concept waren de momentele spannings- en reksituatie van het blaasweefsel bepalend voor de uiteindelijke spiervezelverlenging bij het opkomen van elektrische activiteit.

In het addendum bij Hoofdstuk vijf werden onderwerpen bediscussieerd die betrekking hebben op de onveranderde, traditionele proefopzet waarmee verschillende onderzoeksgroepen tot op heden elektromyografie van de urineblaas bedrijven, ondanks de gemelde problemen uit de literatuur met betrekking tot deze traditionele opzet.

In Hoofdstuk zes werd een nieuwe meetmethode geintroduceerd voor humane blaaselektromyografie, rekening houdende tijdens het ontwerpen met de biologische en technische beperkingen zoals die in Hoofdstuk drie beschreven zijn. Tot op dat moment was in de literatuur geen overtuigend verband aangetoond tussen het humane blaas EMG en de simultaan gemeten intravesicale druk. Het doel van Hoofdstuk zes was om te onderzoeken of blaas
EMG niet-invasief kon worden uitgevoerd met Ag$\mathrm{AgCl}$ oppervlakte elektroden, vastgelijmd op de abdominale huid van vrijwilligers. Twee mannelijke en drie vrouwelijke gezonde vrijwilligers werden gerekruteerd. Bipolaire elektrodesigalen werden verkregen in diagonale, verticale en horizontale richting van de abdominaal aangebrachte elektroden. Electromyografie werd simultaan uitgevoerd met een vrije urinestroom en druk/urinestroom metingen. Registraties werden uitgevoerd bij een volle en lege blaas in rust en tijdens de mictie zelf. Controle metingen met een volle blaas in rust omvatten: hoesten, aanspanning van abdominale spieren en van de bekkenbodem en het achtereenvolgens afzonderlijk optillen van elk been.

Deze methode liet zien dat mictie samenging met een langzame potentiaal verandering in bipolaire signaalafleidingen. Zulk een langzame potentiaal verandering was in alle vijf vrijwilligers bij tenminste een mictiecontractie meer of minder uitgesproken aanwezig. De bijdrage van abdominale en andere dwarsgestreepte musculatuur aan de bipolaire elektrode afleidingen kon makkelijk worden onderscheiden van de langzame potentiaal veranderingen die klaarblijkelijk aan de mictie gerelateerd waren. Vrije urinestroom metingen lieten zien dat de elektrische activiteit gemeten door de abdominale elektroden gerelateerd waren aan blaaslediging. In druk/urinestroom metingen kon een verband worden herkend tussen elektrische activiteit en de blaasdruk. Echter, achtereenvolgende micties van eenzelfde vrijwilliger resulteerden niet elke keer in dezelfde eenduidige elektrode signalen.

De gepresenteerde resultaten suggeerden dat de langzame potentiaalveranderingen die tijdens blaascontractie optreden een sommatie van membraan potentiaal veranderingen van gladde blaasspiercellen zouden kunnen zijn, maar dit concept behoeft verdere bewijsvoering. Validatie van deze meetmethode dient nog te worden gerealiseerd.

In de Discussie werd vooral ingegaan op een idee uit 1976, dat in de meeste hedendaagse discussies over blaas EMG wel weer naar voren wordt gebracht, namelijk dat het 'echte' blaas EMG het meest duidelijk tot uiting komt in een frequentie bereik van 10 tot $40 \mathrm{~Hz}$. In een grondige analyse werd deze misvatting weerlegd en aangegeven dat het zwaartepunt van het EMG signaal in het konijn onder de $10 \mathrm{~Hz}$ ligt en als zodanig duidelijk herkenbaar is. Tot slot werden effecten van Hypnorm ${ }^{\oplus}$ op het blaas EMG gedemonstreerd. 
Miscellaneous 
Prof.dr. Enrico Marani, my promotor, without your challenging ideas, consequent loyalty, personal and professional interest and support, this thesis would never have been written. You are an example in science, one of the few people I feel that are true scientist, and, moreover, embed this quality in a humanistic view of life in an admiring way. Your ability to communicate througout the scientific disciplines is unmatched. Thank you, Brain and Heart friend.

Prof.dr. Rudi A. Janknegt, my promotor, your vision, enthousiasm and commitment to high risk research made this all begin. You're a maker, not a technocrat. Knowing what research needs, giving opportunities and stimulation, going beyond disciplinary boundaries, creating questions and ideas. Thinking of it, we still don't know how neuromodulation works, do we? Maybe we should just discuss that this evening.

I would like to thank the members of the thesis committee, Prof.dr. C. Baeten, Prof.dr. R. Reneman, Prof.dr. J. Drukker, Dr.ir. R. van Mastrigt, and Drs. G. Kramer for their participation and their valuable comments.

Prof.dr.ir. Jan Janssen, I should blame you for all this. Over the years, I have formed the idea that you made your lectures on Dynamic Mechanical Systems so difficult on purpose to save some masochist souls for Biomedical Engineering, which proved to be even more dificult. It is with you that I have learned how to think without any borders of scientific disciplines, titles and other bla bla. You have served as an example of integrity in the more difficult phases of my professional work. I have thanked you more often than you know. But now I have the chance to thank you more in public for the opportunities you were willing to create for me and I hope you will not be too disappointed of what has become of me.

Jantine, Gaspare, Carlina and Giulietta, thank you for the nice hours with you all in Leiden, Maastricht or Marcillac and all of your support. I hope I have not claimed Enrico too much, finally we can stop the thesis work and spend some more personal time together.

Of course, Jan Hollen, you are a professional with an enormous knowledge that I have always truly admired and was jealous about. Moreover, you are a Brain and Heart friend. Thank you for all your support.

Erik Gommer, we shared good and less good times and both have left research. Thank you for your cooperation and I am sure that you will be a great help as paranifm.

Ronald Bos, maybe you should not be a doctor, because your capabilities go beyond. But you are damn good at being a doctor and I am gratefull that you were willing to help me. Thanks a lot! We had a lot of fun together and you showed that David can still win from Goliath.

Peter Kelderman, May Bost and Ton van den Boogaard, your professional attitude and knowledge in your work with research animals is impressive. Your indispesible help and enthousiasm made the new results on bladder EMG possible in combination with an ethic balance that seems truly exceptional to me. Thank you for your help and trust and I wished we could have conducted more good research together.

The Department of Urology is acknowledged for their support and interest concerning this research. Special thanks to all the people on the shopfloor, Theo Vanspauwen, Sabine, Petra, Ellen, Truus and all the others, also Petie, Elvira, Harrie, you all were a great help during the measurements in human volunteers.

Thanks to the Department of Psychiatry and Neuropsychology, especially to Prof.dr. Harry Steinbush, wo offered the opportunity to do part of the experiments on his premises when need was high and contributed in several fruitful discussions.

Carlo 'magic hands' Holtzer, your exceptional talent for neurosurgery is a lust for the eye. Paul, the same holds for your aneasthetical experience. Thanks you both for your help.

The whole Neuroregulation group in Leiden always cheered me up, Egbert, Marga, Sylvia, Herman, Simon, Hans, Erica, Johan, Dick, and all the others, it was always a pleasure after a long journey to feel in place at my second home.

Roel Straetemans, I think I should thank you too, for being a friend and sharing all my troubles next to the stove with a glass of Macallan. You showed me that also different forms of life besides research exist.

Mam, dad, some things do not need to be said here. I could not have wished for better parents. A save harbor that is always there for me. I hope we still have a lot of time left.

Mirjam, now the work is done. Let's enjoy the times to come.

Many others have contributed to this thesis and I really want to thank you all! 


\section{International publications}

Kinder MV, Bos R, Janknegt R, Marani E (2001) Demonstration of spontaneous and stretch induced urinary bladder EMG in the living rabbit. Accepted for publication in Arch Physiol Biochem

Kinder MV, Bastiaanssen EH, Janknegt RA, Marani E (1999) The neuronal control of the lower urinary tract: A model of architecture and control mechanisms. Arch Physiol Biochem 107:203-222

Kinder MV, Bos R, Willems PJB, Drost MR, Holtzer CAJ, Janknegt R, Marani E (1999) Three dimensional registration of mechanical bladder activity using polystyrene fluorescent spheres: a technical note. Arch Physiol Biochem 107:236-241.

Kinder MV (1999) Introduction to this special issue on Neurourology. Arch Physiol Biochem 107:195-202.

Gommer ED, Vanspauwen TJ, Miklosi M, Wen JG, Kinder MV, Janknegt RA, Van Waalwijk van Doorn ES (1999) Validity of a non-invasive determination of the

\section{National publications}

Marani E, Kinder MV (2001) Neuroregulatie en biomedische techniek: de neuronenlus. Accepted for publication in Klinische Fysica

Kinder MV, Gommer ED, Van Waalwijk van Doorn ESC, Janknegt RA (1997) Elektromyografie van de blaasspier: 'de lange mars'. Profundum 3:19-26.

Kinder MV, Van Leeuwen JL (1996) Recording and simulation of the electrical activity of the bladder muscle. In: Urodynamica en urine-incontinentie: specialistische cursus voor paramedici. E Marani, AAB Lycklama a Nyeholt, JD van Gool, eds.: pp 135-149 Boerhaave Commissie voor Postacademisch onderwijs in de Geneeskunde, Royal University of Leiden. ISBN 90-6767- isovolumetric bladder pressure during voiding in men with LUTS. Neurourol Urodyn 18:477-486.

Kinder MV, Gommer ED, Janknegt RA, Van Waalwijk van Doorn ESC (1998) Recording the detrusor electromyogram is still a difficult and controversial enterprise. Neurourol Urodyn 17:571-573.

Kinder MV, Van Waalwijk van Doorn ESC, Gommer ED Janknegt RA (1998) A non-invasive method for bladder electromyography in humans. Arch Physiol Biochem 106:2-11.

Kinder MV, Gommer ED, Janknegt RA, Van Waalwijk van Doorn ESC (1997) A method for the electromyographic mapping of the detrusor smooth muscle. Arch Physiol Biochem 105:673-690.

Kinder MV, Bastiaanssen EHC, Janknegt RA, Marani E (1995) Neuronal circuitry of the lower urinary tract; central and peripheral neuronal control of the micturition cycle. Anat \& Embryol 192:195-209.

324

Kinder MV, Marani E (1995) Zin en onzin over de periphere innervatie van het urinewegstelsel: Bradley's "loop concept". Profundum 1:23-26.

Kinder MV, Bastiaanssen EHC, Janknegt RA, Marani E (1995) Spieghel Uropoetica: denkbeelden betreffende de sturing van de lagere urinewegen bij de mens. In: Urologische gezichtspunten, LM Groenveld, ed.: pp 1-26. Byk BV, Zwanenburg.

Kinder MV, Bastiaanssen EHC, Marani E, Van Waalwijk van Doorn ESC, Janknegt RA (1994) Stroomdiagram van de neuronale besturing van de lagere urinewegen bij de mens. Klinische Fysica 4:386-398 ISSN 0168-7026.

\section{Abstracts and posters}

Kinder MV, Bastiaanssen EHC, Janknegt RA, Marani E (1997) Central and peripheral control of the micturition cycle. Abstractbook 4th International Congress of the Dutch Urological Association, November 5-7th, 1997. Maastricht.

Kinder MV, Bastiaanssen EHC, Janknegt RA, Marani E (1997) Central and peripheral control of the micturition cycle. Poster on annual meeting of the Nederlandse Anatomenvereniging, January 3th, 1997, Lunteren.

Kinder MV, Van Waalwijk van Doorn ESC, Gommer, ED, Janknegt, RA (1996) Surface detrusor EMG in healthy volunteers. Neurourol Urodyn 15:288-290.

Kinder MV, Gommer ED, Van Waalwijk van Doorn ESC Janknegt, RA (1996) Multi-electrode recording of a 'clean' detrusor electromyogram. Neurourol Urodyn 15:287-288.

Kinder MV, Van Waalwijk van Doorn ESC, Gommer, ED, Janknegt, RA (1996) Surface detrusor EMG in healthy volunteers. Proceedings Behavioral and Cognitive Neuro- sciences Summerschool (BCN), University of Groningen.

Kinder MV, Gommer ED, Van Waalwijk van Doorn, ESC, Janknegt, RA (1996) Multi-electrode recording of a 'clean' detrusor electromyogram. Proceedings Behavioral and Cognitive Neurosciences Summerschool (BCN), University of Groningen.

Kinder MV, Van Waalwijk van Doorn ESC, Gommer ED, Janknegt RA (1995) Neuromodulation of sacral nerves for treatment of voiding disorders and incontinence: neuronal pathways involved. Proceedings BES Symposium on Electrical Stimulation-Clinical Systems: 59-60, Glasgow, University of Strathclyde. 


\section{Curriculum vitae}

The author was born on January seventeenth, 1970 . In 1988 he finished Gymnasium at the Scholengemeenschap St. Ursula in Horn. In 1989 he obtained a propaedeutic degree in Mechanical Engineering at the Eindhoven University of Technology. Here he subsequently followed the postpropaedeutic curriculum in Biomechanical Engineering (Werktuigkundige Medische Technologie). During his study he spent a practical period of six months on research of active car suspensions (head: Dr. Dipl-Ing. Hennecke) at the Bayerische Motoren Werke AG in Munich, Germany. Once returned to Eindhoven, he was admitted to a masterclass on "lean enterprise" given by Prof. Daniel T. Jones. He conducted his graduation project on the neuronal innervation of the lower urinary tract under supervision of Prof.dr.ir. Jan D. Janssen and in close cooperation with the Depart- ment of Urology, Maastricht University Hospital (head: Prof.dr. Rudi A. Janknegt) and the Neuroregulation Group, Leiden University (head: Prof.dr. Enrico Marani). After he received his masters degree in April 1994, Prof.dr. Janknegt invited him to work as research engineer at the Department of Urology in the Maastricht University Hospital. In 1998, he started to work for Pyramid Applied Solutions V.o.F., a small SAP business consultancy firm. He attended the SAP Partner Academy for Sales and Distribution and certified as SAP Business Consultant. Later that year he also certified as SAP Business Information Warehouse Consultant. He was assigned to an Order-to-Cash redesign project at DSM in Sittard. In 2001, he attended a position as business consultant at Philips Semiconductors B.V. 
